\author{
UNIVERSIDADE DE SÃO PAULO \\ INSTITUTO DE FÍSICA
}

\title{
ESTUDO E APLICAÇÃO DO ALGORITMO FDK PARA A RECONSTRUÇÃO DE IMAGENS TOMOGRÁFICAS MULTI- CORTES
}

\author{
Ericky Caldas de A. Araújo
}

Dissertação apresentada ao Instituto de Física da Universidade de São Paulo como parte dos requisitos para a obtenção do grau de Mestre em Ciências.

Orientador:

Dr. Paulo Roberto Costa

Banca Examinadora:

Dra. Cecil Chow Robilotta - IF-USP

Dr. Paulo Roberto Costa - IEE-USP

Dr. Ricardo Tadeu Lopes - IEN-UFRJ

São Paulo

2008 


\section{Dedicatória}

Dedico este trabalho ao futuro tecnológico desta nação, na tentativa de difundir esta área do conhecimento. 


\section{Agradecimentos}

Agradeço, acima de tudo, a Deus, por me proporcionar esta maravilhosa oportunidade.

A realização deste projeto só foi possível graças às contribuições de diversas pessoas às quais presto minha homenagem:

Aos meus pais e meus irmãos, pelo amor e apoio incondicionais em todos os momentos da minha vida.

À minha namorada, Karina, pelo amor e carinho dedicados durante toda esta jornada.

Ao meu orientador, que iluminou com sabedoria os caminhos a serem seguidos.

Ao Engenheiro e amigo, Dr. Marco Aurélio, pela ajuda prestada em todas as etapas deste trabalho.

Aos amigos, Leonardo Severo e Edson Barbosa, por me ajudarem na realização dos procedimentos experimentais.

A todos os colegas e professores, que contribuíram de maneira direta ou indireta na conclusão deste trabalho.

Por fim, agradeço à sociedade brasileira que, através da CAPES e da FAPESP, financiou parte deste trabalho. 


\title{
ESTUDO E APLICAÇÃO DO ALGORITMO FDK PARA A RECONSTRUÇÃO DE IMAGENS TOMOGRÁFICAS MULTI-CORTES
}

\author{
Ericky Caldas de A. Araújo
}

\section{RESUMO}

O presente projeto consistiu no estudo e aplicação do algoritmo FDK (Feldkamp-DavisKress) para a reconstrução de imagens tomográficas utilizando a geometria de feixe cônico, resultando na implementação de um sistema adaptado de tomografia computadorizada multicortes (TCMC).

Para a aquisição das projeções, utilizou-se uma plataforma giratória com goniômetro acoplado, um equipamento de raios $\mathrm{X}$ e um detector digital, tipo CCD. Para processar a reconstrução das imagens, foi utilizado um PC, no qual foi implementado o algoritmo FDK.

Inicialmente foi aplicado o algoritmo FDK original, no qual se assume o caso físico ideal no processo de medições. Em seguida, foram incorporadas ao algoritmo, algumas correções de artefatos relacionados ao processo de medição das projeções. Para testar o funcionamento do algoritmo implementado, foram feitas reconstruções a partir de projeções simuladas computacionalmente.

Foram montados e testados três sistemas de aquisição de projeções, nos quais foram usados diferentes equipamentos de raios $\mathrm{X}$, detectores, metodologias e técnicas radiográficas, a fim de garantir que fossem coletados os melhores conjuntos possíveis de projeções.

Realizou-se a calibração do sistema de TCMC implementado. Para isso, utilizou-se um objeto com uma distribuição de coeficientes de atenuação linear conhecida, que foi projetado e fabricado especificamente para isto.

Por fim, o sistema de TCMC implementado foi utilizado na reconstrução tomográfica de um objeto não homogêneo, cuja distribuição volumétrica do coeficiente de atenuação linear é desconhecida.

As imagens reconstruídas foram analisadas a fim de avaliar o desempenho do sistema de TCMC implementado. 


\title{
STUDY AND APPLICATION OF THE FDK ALGORITHM FOR MULTI-SLICE TOMOGRAPHIC IMAGES RECONSTRUCTION
}

\author{
Ericky Caldas de A. Araújo
}

\begin{abstract}
This work consisted on the study and application of the FDK (Feldkamp-Davis-Kress) algorithm for tomographic image reconstruction using cone-beam geometry, resulting on the implementation of an adapted multi-slice computed tomography (MSCT) system.

For the acquisition of the projections, a rotating platform coupled to a goniometer, an x-ray equipment and a CCD type digital detector were used. The FDK algorithm was implemented on a PC which was used for the reconstruction process.

Initially, the original FDK algorithm was applied considering only the ideal physical conditions in the measurement process. Then some artifacts corrections related to the projections measurement process were incorporated. Computational simulations were performed to test the functioning of the implemented algorithm.

Three projections acquisition systems, which used different x-ray equipments, detectors, methodologies and radiographic techniques, were assembled and tested in order to ensure that the best possible set of data was collected.

The implemented MSCT system was calibrated. A specially designed and manufactured object with a known linear attenuation coefficient distribution was used for this purpose.

Finally, the implemented MSCT system was used for multi-slice tomographic reconstruction of an inhomogeneous object, whose attenuation coefficient distribution was unknown.

The reconstructed images were analyzed to assess the performance of the TCMC system that was implemented.
\end{abstract}




\section{SUMÁRIO}

CAPÍTULO 1 - INTRODUCÃ̃

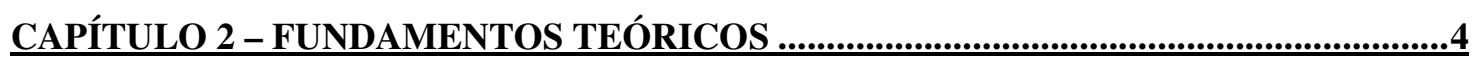

2.1. CONTEXTO HISTÓRICO.........................................................................................................

2.2. PRINCÍPIOS FÍSICOS DA TOMOGRAFIA COMPUTADORIZADA...................................11

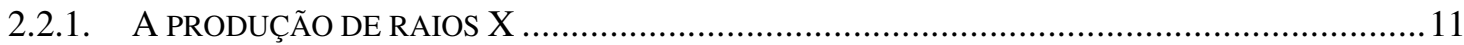

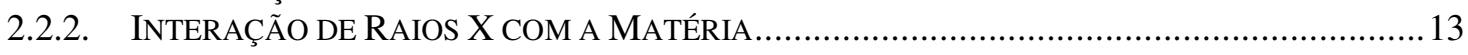

2.3. DETERMINAÇÃO DO COEFICIENTE DE ATENUAÇÃ̃o LINEAR .......................................14

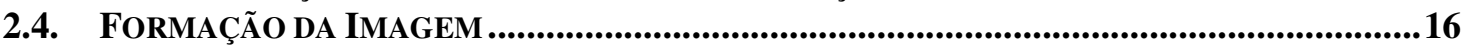

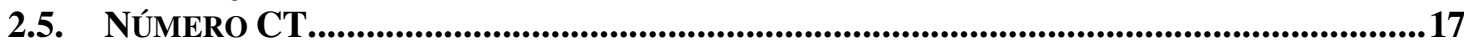

CAPÍTULO 3 - ASPECTOS MATEMÁTICOS DA RECONSTRUCÃO TOMOGRÁFICA

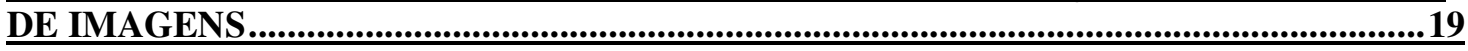

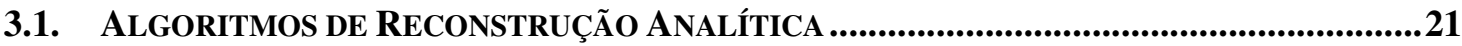

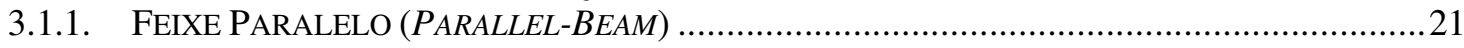

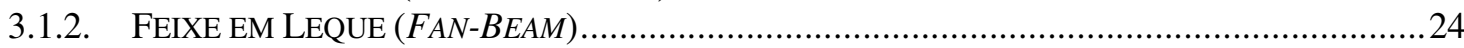

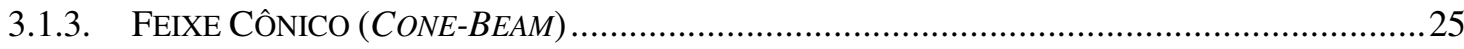

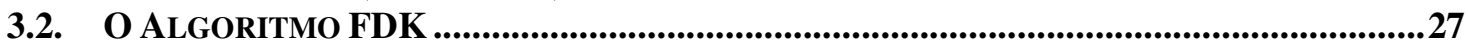

CAPÍTULO 4 - OS PRINCIPAIS COMPONENTES DE UM EQUIPAMENTO DE TC....31

4.1. O TUBo de RAIOS X E O GERAdOR de ALTA TENSÃo ...............................................31

4.2. DETECTOR DE RAIOS $X$ E SiSTEMA DE AQUiSiÇÃo de DADOS.......................................35

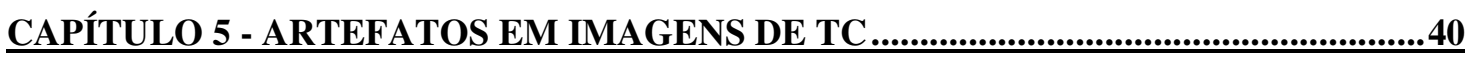

5.1. ARTEFATOS INDUZIDOS PELO PACIENTE ..................................................................42

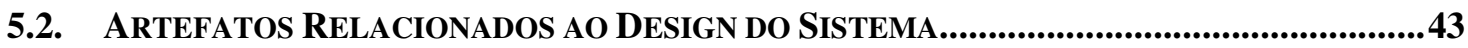

5.3. Artefatos Relacionados a Problemas com o Tubo de Raios X e com o

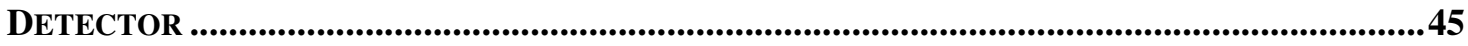

5.4. Reconstrução de Imagens Tomográficas a PaRTir de Projeções COM Rúído 45

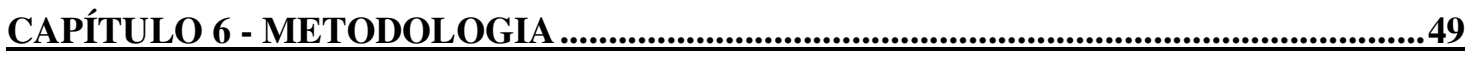

6.1. IMPLEMENTAÇÃO DO ALGORITMO FDK..............................................................................49

6.2. IMPLEMENTAÇÃO EXPERIMENTAL: MONTAGEM DOS SISTEMAS DE AQUISIÇÃO DE

DADOS ........................................................................................................................................63

6.2.1. SisteMA DE AQUISIÇÃO DE DADOS $\mathrm{N}^{\circ}$ 1: EQUIPAMENTO DE RAIOS X INDUSTRIAL MCN

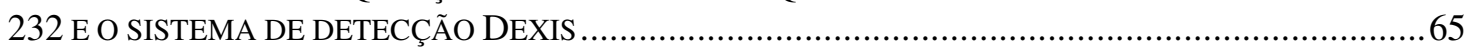


6.2.2. Sistema de Aquisição de IMAGENS $\mathrm{N}^{\mathrm{O}}$ 2: EQUiPAMENTO de RAIOS X ClíNICO

HELIOPHOS 4B E O SISTEMA DE DETECÇÃO SENS-A-RAY

6.2.3. SISTEMA DE AQUISIÇÃo DE IMAGENS N ${ }^{\mathrm{O}}$ 3: EQUIPAMENTO DE RAIOS X ODONTOLÓGICO,

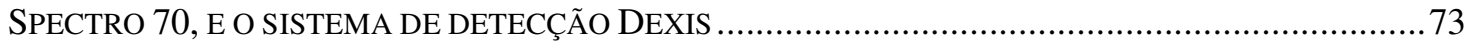

6.3. IMPLEMENTAÇÃO DAS CORREÇÕES MATEMÁTICAS DOS ARTEFATOS ...........................77

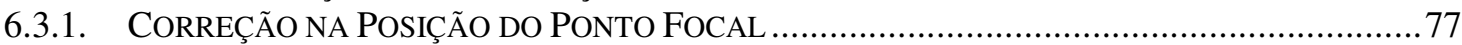

6.3.2. CORREÇÃO DE ARTEFATOS DEVIDOS AO RUÍDO PRESENTE NAS PROJEÇÕES:

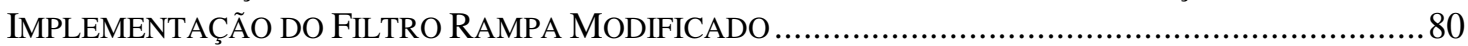

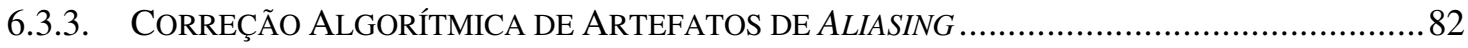

6.4. ANÁLISE DAS IMAGENS RECONSTRUÍDAS.........................................................................83

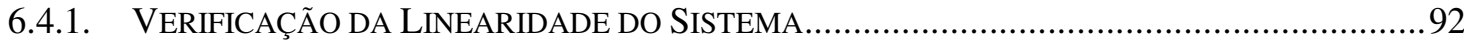

6.4.2. RECONSTRUÇÃO TOMOGRÁFICA MULTI-CORTES DE UM OBJETO NÃO HOMOGÊNEO E

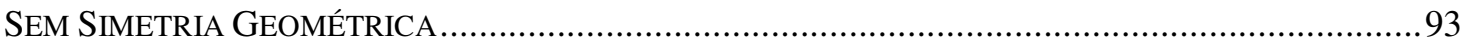

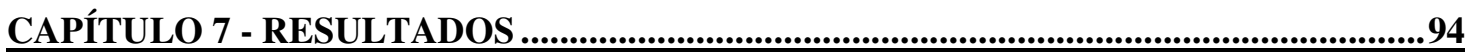

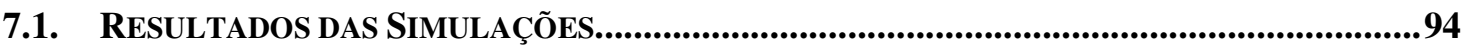

7.2. RESULTADOS DAS RECONSTRUÇÕES REAIS ......................................................................97

7.2.1. IMAGENS RECONSTRUÍDAS A PARTIR DAS PROJEÇÕES COLETADAS COM O SISTEMA DE

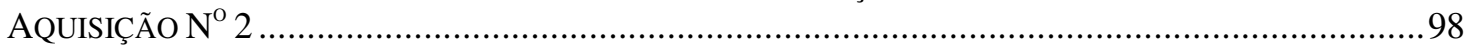

7.2.2. IMAGENS RECONSTRUÍDAS A PARTIR DAS PROJEÇÕES COLETADAS COM O SiSTEMA DE

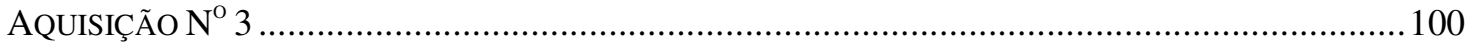

7.2.2.1. CALIBRAÇÃO DO SISTEMA: VERIFICAÇÃO DA LINEARIDADE E CORREÇÃO DOS

VALORES DE NÚMERO CT ……………........................................................................ 100

7.2.2.2. RECONSTRUÇÃO MULTI-CORTES DE UM OBJETO NÃO HOMOGÊNEO E

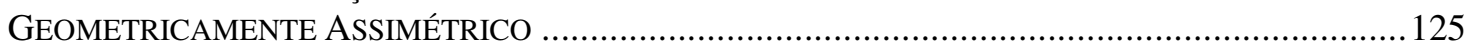

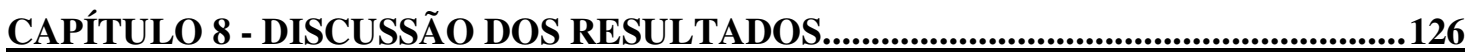

8.1. RESUltados das SIMULAÇÕES COMPUTACIONAIS..................................................126

8.2. RESULTADOS DAS RECONSTRUÇÕES REAIS .......................................................127

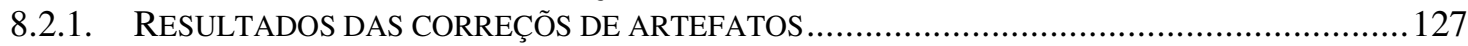

8.2.2. RESULTADOS DA CALIBRAÇÃO DO SISTEMA …......................................................... 128

8.2.3. Resultados da RECONSTRUÇÃo Multi-CORTES de um OBJETO NÃo HOMOGÊNEO E

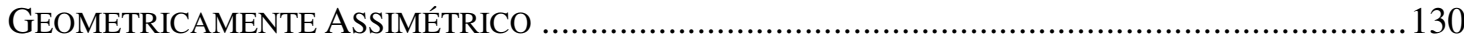

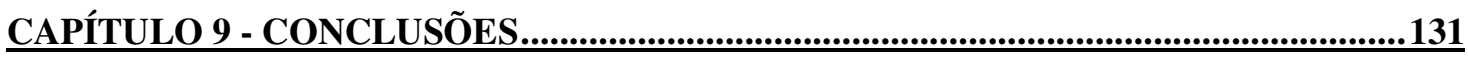

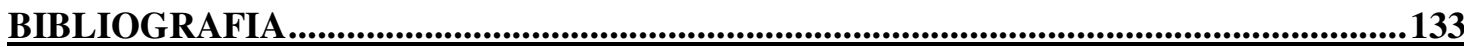




\section{LISTA DE FIGURAS}

Figura 1 - (a) Geometria utilizada nos equipamentos tomográficos da primeira geração. (b) Geometria utilizada nos equipamentos tomográficos da segunda geração.

Figura 2 - Geometria utilizada nos equipamentos tomográficos da terceira geração. Estes equipamentos utilizam um feixe de raios $\mathrm{X}$ em forma de leque (fan beam) e o sistema tubodetector efetua somente um movimento de rotação em torno do paciente.

Figura 3 - Geometria utilizada nos equipamentos tomográficos da quarta geração. Estes equipamentos utilizam um feixe de raios $\mathrm{X}$ em forma de leque (fan beam) e somente o tubo de raios $\mathrm{X}$ executa um movimento de rotação em torno do paciente.

Figura 4 - Elemento detector bidimensional típico utilizado em equipamentos de tomografia multi-cortes.

Figura 5 - Imagens volumétricas obtidas com equipamentos de tomografia computadorizada multi-cortes com varredura helicoidal.

Figura 6 - Diferenças na forma do feixe de radiação e composição de detectores em sistemas convencionais (a) e multi-cortes (b).

Figura 7 - Método de determinação da integral de linha do coeficiente de atenuação linear, $\mu$, para: (a) um objeto com distribuição homogênea do coeficiente de atenuação, utilizando radiação monocromática; (b) um objeto com distribuição não homogênea, utilizando radiação monocromática; (c) um objeto com distribuição não homogênea, utilizando radiação policromática.

Figura 8 - Ilustração do processo de retro-projeção filtrada. (a) Aquisição da projeção; (b) Retro-projeção da projeção filtrada.

Figura 9 - Geometrias do feixe de raios X em TC

Figura 10 - Esquema da projeção de um objeto na geometria de feixe paralelo (Parallel-

Beam).

Figura 11 - Parâmetros da geometria de feixe em leque (fan-beam).

Figura 12- Parâmetros da geometria de feixe cônico (cone-beam)......

Figura 13 - Sistema de coordenadas para projeções acima do plano central (xy).

Figura 14 - Fotografia de um tubo metálico cortado para que se possa ver o anodo e o catodo.

Figura 15 - Ilustração do anodo de tubos de raios X utilizados em equipamentos de TC....33 
Figura 16 - Ionização do gás xenônio com fótons de raios X. Quando um fóton incide em uma célula do detector, suas colisões ionizam o gás. Os núcleos pesados de xenônio são coletados pelas placas de $0 \mathrm{~V}$, e os elétrons livres formados são coletados pelas placas de alta tensão, produzindo sinais de corrente

Figura 17 - Diagrama esquemático do funcionamento de um detector de estado sólido. Os fótons de radiação $\mathrm{X}$ incidentes sofrem interação fotoelétrica com o material cintilante. $\mathrm{O}$ fotoelétron arrancado do átomo viaja pelo material excitando outros átomos. Ao retornarem ao estado fundamental, os átomos emitem radiação característica no espectro visível ou UV, que é detectada pelos fotodiodos.

Figura 18 - Exemplos típicos de artefatos em imagens de TC que podem resultar de falhas no detector (a), movimento do paciente (b), endurecimento de feixe (c), efeitos de volume parcial (d), implantes metálicos (e) ou pacientes que excedem o campo de medição (f).....41

Figura 19 - Ilustração do quarter-quarter offset. Técnica utilizada para a redução de artefatos de aliasing, na qual desloca-se o detector em 1/4 da largura dos canais do detector.

Figura 20 - Conceito de oscilação do ponto focal. Técnica utilizada para reduzir o fenômeno de aliasing presente nos processos de reconstrução de imagens nos tomógrafos atuais (terceira geração), na qual o feixe de elétrons do tubo é constantemente desviado por um campo eletromagnético de modo a atingir, alternadamente, dois pontos focais do tubo e, dessa maneira, dobrar a amostragem reduzindo o problema de aliasing.

Figura 21 - Gráfico ilustrativo do filtro rampa (a) e do filtro rampa modificado (b), ambos em coordenadas espaciais

Figura 22 - Esquema geométrico da simulação das projeções com geometria de feixe paralelo.

Figura 23 - Esquema da simulação computacional da projeção dos cilindros coaxiais centrados na origem, ambos com coeficiente de atenuação linear constante igual a $\mu$. O objeto possui simetria cilíndrica e o eixo principal coincidente com o eixo z.

Figura 24 - Esquema da simulação computacional da projeção de dois cilindros com eixos principais paralelos ao eixo $\mathrm{z}$ e deslocado da origem.

Figura 25 - Esquema geométrico da simulação das projeções com geometria de feixe em leque.

Figura 26 - Modelo físico idealizado para a simulação das projeções com feixe em leque do segundo objeto.

Figura 27 - Equipamento emissor de raios X MCN 323 (Philips, Hamburgo, Alemanha). (a) Cúpula do tubo de raios X; (b) Unidade de controle MGC 40 (Philips, Hamburgo,

Alemanha). 
Figura 28 - Sistema de detecção Dexis: (a) sensor CCD; (b) drive (ISA Bus card); (c) software de aquisição das imagens.

Figura 29 - Cilindro de acrílico utilizado nas primeiras imagens radiográficas realizadas no trabalho (a); Artefato produzido nas imagens radiográficas coletadas com o Dexis (b).......67

Figura 30 - Equipamento de raios X modelo Heliophos 4b (Siemens,). (a) Unidade de Controle; (b) Cúpula do tubo de raios X.

Figura 31 - Unidade de controle do suporte suspenso para o deslocamento tridimensional do Heliophos $4 \mathrm{~b}$.

Figura 32 - Sistema de detecção Sens-a-ray: (a) sensor CCD; (b) fonte de alimentação; (c) software de aquisição das imagens.

Figura 33 - Janelas de chumbo colimadoras do Heliophos 4b. (a) Reguladores de abertura das janelas de chumbo; (b) Janelas de chumbo colimadoras.

Figura 34- (a) Plataforma giratória com goniômetro acoplado. (b) Ajuste angular com precisão de 2 centésimos de grau.

Figura 35 - (a) Cilindro de acrílico que compõe o objeto a ser reconstruído; (b) Cilindros plásticos inseridos no cilindro de acrílico para formar o objeto; (c) Objeto montado, que será reconstruído pelo sistema de TC simplificado implementado.

Figura 36 - (a) Suporte de acrílico fabricado para fixar o objeto a ser reconstruído à plataforma mecânica giratória. (b) Objeto fixo à plataforma giratória pelo suporte de acrílico

Figura 37 - Sistema de aquisição de imagens para a reconstrução tomográfica montado....72

Figura 38 - Equipamento de raios X odontológico Spectro 70X (Dabi Atlante, Ribeirão Preto, Brasil). (a) Unidade de controle; (b) Cúpula do tubo de raios X.

Figura 39 - Curvas de perfil de projeções coletadas com o Sens-a-ray (a) e com o Dexis (b).

Figura 40 - (a) Peça fabricada para a fixação e centralização do detector no colimador; (b) colimador do equipamento odontológico; (c) suporte próprio do detector Dexis.

Figura 41 - Sistema de aquisição de imagens montado com o equipamento de raios X odontológico e o sistema de detecção Dexis.

Figura 42 - Medição da inclinação do detector (a), inclinação do plano de rotação do objeto (b), inclinação da cúpula do equipamento de raios X (c)

Figura 43 - Objeto não homogêneo e sem simetria cilíndrica que foi reconstruído a partir de 720 projeções coletadas com o sistema No 3 . O objeto é constituído por um material plástico com bolhas de ar distribuídas em seu interior. 
Figura 44 - Esquema da reconstrução do corte central de um cilindro sólido, a partir de 4 projeções, utilizando um algoritmo do tipo FBP.

Figura 45 - Esquema da retro-projeção de um ponto $\mathrm{Y}$ do detector no caso de feixe central deslocado (a). Esquema da retro-projeção de um ponto Y do detector no caso de feixe central corretamente posicionado.

Figura 46 - Esquema da reconstrução do corte central de um cilindro sólido, a partir de 4 projeções com feixe central deslocado, utilizando um algoritmo do tipo FBP.

Figura 47 - Esquema de re-amostragem das projeções, assumindo pixels com duas vezes a largura dos elementos originais do detector. P(i) e P'(i) correspondem ao i-ésimo elemento de cada linha das projeções, originais e re-amostradas, respectivamente.

Figura 48 - Medição das dimensões relativas e número CT encontrados nas imagens reconstruídas, utilizando ferramentas do software ImageJ. (a) Medição das dimensões relativas de cada estrutura identificada na curva de nível; Medição dos valores médios de número CT de cada estrutura que compõe os objetos reconstruídos (b).

Figura 49 - Gráfico de $\ln \left(\frac{\mu}{\rho}\right) \times E$ para o polietileno, com a regressão exponencial de segunda ordem dos valores de $\ln \left(\frac{\mu}{\rho}\right)$ sobre os valores de E.

Figura 50 - Gráfico de $\ln \left(\frac{\mu}{\rho}\right) \times E$ para o Nylon, com a regressão exponencial de segunda ordem dos valores de $\ln \left(\frac{\mu}{\rho}\right)$ sobre os valores de E.

Figura 51 - Gráfico de $\ln \left(\frac{\mu}{\rho}\right) \times E$ para o Acrílico, com a regressão exponencial de segunda ordem dos valores de $\ln \left(\frac{\mu}{\rho}\right)$ sobre os valores de E. .88

Figura 52 - Gráfico de $\ln \left(\frac{\mu}{\rho}\right) \times E$ para o PVC, com a regressão exponencial de segunda ordem dos valores de $\ln \left(\frac{\mu}{\rho}\right)$ sobre os valores de E.

Figura 53 - Curva de $\ln ^{\ln \left(\mu_{A l}\right) \times E}$, para o alumínio 90 
Figura 54 - Imagens reconstruídas do corte central do primeiro objeto, a partir de projeções simuladas com feixe paralelo, para 3 configurações diferentes. (a) 180 projeções de 200 pixels, com um intervalo angular de $1^{\circ}$ entre cada uma; (b) 360 projeções de 200 pixels, com um intervalo angular de $0,5^{\circ}$ entre cada uma; (c) 360 projeções de 800 pixels, com intervalo angular de $0,5^{\circ}$ entre cada uma. Todas as imagens reconstruídas possuem resolução de $512 \times 512$ pixels.

Figura 55- Imagens reconstruídas do corte central do segundo objeto, a partir de projeções simuladas com feixe paralelo, para 3 configurações diferentes. (a) 180 projeções de 200 pixels, com um intervalo angular de $1^{\circ}$ entre cada uma; (b) 360 projeções de 200 pixels, com um intervalo angular de $0,5^{\circ}$ entre cada uma; (c) 360 projeções de 800 pixels, com intervalo angular de $0,5^{\circ}$ entre cada uma. Todas as imagens reconstruídas possuem resolução de $512 \times 512$ pixels.

Figura 56 - Imagens reconstruídas do corte central do segundo objeto, a partir de projeções simuladas com geometria de feixe em leque, para 3 configurações diferentes. (a) 180 projeções de 200 pixels, com um intervalo angular de $1^{\circ}$ entre cada uma; (b) 360 projeções de 200 pixels, com um intervalo angular de $0,5^{\circ}$ entre cada uma; (c) 360 projeções de 800 pixels, com intervalo angular de $0,5^{\circ}$ entre cada uma. Todas as imagens reconstruídas possuem resolução de $512 \times 512$ pixels.

Figura 57 - Imagens reconstruídas a partir das projeções medidas com o sistema de aquisição de imagens No 2. (a) 180 projeções e (b) 360 projeções, com um intervalo angular de $1^{\circ}$ entre cada projeção

Figura 58 - Imagens reconstruídas com correção de posicionamento do feixe central, a partir de 180 (a) e 360 (b) projeções simuladas.

Figura 59 - Imagens reconstruídas do corte central do objeto com o algoritmo FDK modificado, a partir de 180 (a) e 360 projeções simuladas (b), ambas com intervalos angulares de $1^{\circ}$......

Figura 60 - Imagem reconstruída, sem correção de aliasing, a partir de 180 projeções coletadas com o sistema de aquisição No 3 , com $2^{\circ}$ de intervalo angular entre cada. Espessura do corte: $1 \mathrm{~mm}$. (a) imagem normal; (b) imagem com ajuste de janela, J, e nível, N. $(J=922$ e $N=-579)$.

Figura 61 - Imagem reconstruída, sem correção de aliasing, a partir de 360 projeções coletadas com o sistema de aquisição No 3, com $1^{\circ}$ de intervalo angular entre cada. Espessura do corte: $1 \mathrm{~mm}$. (a) imagem normal; (b) imagem com ajuste de janela e nível. ( $\mathrm{J}=2034$ e $\mathrm{N}=-124)$.

Figura 62 - Imagem reconstruída, sem correção de aliasing, a partir de 720 projeções coletadas com o sistema de aquisição No 3, com $0,5^{\circ}$ de intervalo angular entre cada. Espessura do corte: $1 \mathrm{~mm}$. (a) imagem normal; (b) imagem com ajuste de janela e nível. $(\mathrm{J}=3974$ e $\mathrm{N}=835)$. 
Figura 63 - Imagem reconstruída, sem correção de aliasing, a partir de 720 projeções coletadas com o sistema de aquisição No $3, \operatorname{com} 0,5^{\circ}$ de intervalo angular entre cada. Espessura do corte: $0,5 \mathrm{~mm}$. (a) imagem normal; (b) imagem com ajuste de janela e nível. $(\mathrm{J}=4062$ e $\mathrm{N}=823)$.

Figura 64 - Imagem reconstruída, sem correção de aliasing, a partir de 720 projeções coletadas com o sistema de aquisição No $3, \operatorname{com} 0,5^{\circ}$ de intervalo angular entre cada. Espessura do corte: $0,25 \mathrm{~mm}$. (a) imagem normal; (b) imagem com ajuste de janela e nível. $(\mathrm{J}=4109$ e $\mathrm{N}=807)$.

Figura 65 - Imagem reconstruída, com correção de aliasing (re-amostragem para duas vezes o tamanho original dos elementos do detector), a partir de 720 projeções coletadas com o sistema de aquisição No 3 , com $0,5^{\circ}$ de intervalo angular entre cada. Espessura do corte: 1 mm. (a) imagem normal; (b) imagem com ajuste de janela e nível. ( $\mathrm{J}=2026$ e $\mathrm{N}=218$ )..... 107

Figura 66 - Imagem reconstruída, com correção de aliasing (re-amostragem para duas vezes o tamanho original dos elementos do detector), a partir de 720 projeções coletadas com o sistema de aquisição No 3 , com $0,5^{\circ}$ de intervalo angular entre cada. Espessura do corte: 3 mm. (a) imagem normal; (b) imagem com ajuste de janela e nível. ( $\mathrm{J}=2499$ e N=405)..... 108

Figura 67 - Legenda com a denominação de cada estrutura identificada nas imagens reconstruídas e com a indicação das linhas sobre as quais foram plotadas as curvas de perfil.

Figura 68 - Curvas de perfil de tons de cinza das estruturas identificadas na reconstrução No 1, obtidas com o software ImageJ. As curvas são plotadas sobre duas linhas perpendiculares que se interceptam no centro do objeto reconstruído.

Figura 69 - Curvas de perfil de tons de cinza das estruturas identificadas na reconstrução No 2, obtidas com o software ImageJ. As curvas são plotadas sobre duas linhas perpendiculares que se interceptam no centro do objeto reconstruído. .111

Figura 70 - Curvas de perfil de tons de cinza das estruturas identificadas na reconstrução No 3 , obtidas com o software ImageJ. As curvas são plotadas sobre duas linhas perpendiculares que se interceptam no centro do objeto reconstruído.

Figura 71 - Curvas de perfil de tons de cinza das estruturas identificadas na reconstrução No 4, obtidas com o software ImageJ. As curvas são plotadas sobre duas linhas perpendiculares que se interceptam no centro do objeto reconstruído.

Figura 72 - Curvas de perfil de tons de cinza das estruturas identificadas na reconstrução No 5 , obtidas com o software ImageJ. As curvas são plotadas sobre duas linhas perpendiculares que se interceptam no centro do objeto reconstruído. 114

Figura 73 - Curvas de perfil de tons de cinza das estruturas identificadas na reconstrução No 6 , obtidas com o software ImageJ. As curvas são plotadas sobre duas linhas perpendiculares que se interceptam no centro do objeto reconstruído. 115

Figura 74 - Curvas de perfil de tons de cinza das estruturas identificadas na reconstrução No 7, obtidas com o software ImageJ. As curvas são plotadas sobre duas linhas perpendiculares que se interceptam no centro do objeto reconstruído. 
Figura 75 - Curva de atenuação do feixe de raios $\mathrm{X}$ do equipamento odontológico.

Intensidade relativa por espessura de alumínio, I/I0 x mmAl.

Figura 76 - Gráfico com a regressão linear dos valores de número CT esperados sobre os valores medidos na reconstrução 1

Figura 77 - Gráfico com a regressão linear dos valores de número CT esperados sobre os valores medidos na reconstrução 2 .

Figura 78 - Gráfico com a regressão linear dos valores de número CT esperados sobre os valores medidos na reconstrução 3 .

Figura 79 - Gráfico com a regressão linear dos valores de número CT esperados sobre os valores medidos na reconstrução 4.

Figura 80 - Gráfico com a regressão linear dos valores de número CT esperados sobre os valores medidos na reconstrução 5 .

Figura 81 - Gráfico com a regressão linear dos valores de número CT esperados sobre os valores medidos na reconstrução 6 .

Figura 82 - Gráfico com a regressão linear dos valores de número CT esperados sobre os valores medidos na reconstrução 7 .

Figura 83 - Imagens reconstruídas a partir de 720 projeções de um objeto não homogêneo e assimétrico. Cada imagem representa um corte de $1 \mathrm{~mm}$ de espessura. Foram reconstruídos 16 cortes com uma única varredura. 


\section{LISTA DE TABELAS}

Tabela 1 - Valores de número CT de alguns tecidos e órgãos do corpo humano para um feixe com energia efetiva de $80 \mathrm{kV}$

Tabela 2- Os diferentes processos de filtração no algoritmo FDK; no primeiro, realiza-se a convolução da projeção com a transformada inversa de Fourier do filtro rampa, no segundo, multiplica-se a transformada de Fourier da projeção pelo filtro rampa e realiza-se a transformada inversa do produto.

Tabela 3 - Componentes utilizados em cada um dos sistemas de aquisição de projeções montados.

Tabela 4 - Materiais que compõem o objeto fabricado e suas respectivas fórmulas químicas.

Tabela 5 - Medidas das dimensões das estruturas que compõem os objetos reconstruídos, a partir das projeções simuladas com geometria de feixe paralelo.

Tabela 6 - Comparação entre os valores de número CT esperados e medidos, para os dois objetos idealizados.

Tabela 7 - Medidas das dimensões das estruturas que compõem o objeto reconstruído a partir das projeções simuladas com geometria de feixe em leque.

Tabela 8 - Valores de número CT esperados e medidos, para cada estrutura cilíndrica que compõe o segundo objeto.

Tabela 9 - Comparação entre o ruído presente nas imagens reconstruídas a partir das projeções coletadas com o sistema de aquisição No 2, com e sem a aplicação do filtro rampa modificado.

Tabela 10 - Parâmetros usados em cada reconstrução realizada, a partir das projeções coletadas com o sistema de aquisição No 3

Tabela 11 - Valores de intensidade relativa obtidos na medição da CSR de alumínio para o feixe do equipamento de raios $\mathrm{X}$ odontológico.

Tabela 12 - Materiais que compõem o objeto, e suas respectivas fórmulas químicas e coeficientes de atenuação linear na energia efetiva, $\mu$ (EEf).

Tabela 13 - Valores de número CT esperados para cada material que compõe o objeto, juntamente com seus respectivos valores medidos nas imagens reconstruídas.

Tabela 14 - Coeficientes angular e linear das retas, $y=A+B x$, obtidas pela regressão linear dos valores de número $\mathrm{CT}$ medidos sobre os valores de número $\mathrm{CT}$ esperados nas imagens reconstruídas. 
Tabela 15 - Valores de número CT esperados para cada material que compõe o objeto, juntamente com seus respectivos valores medidos nas imagens reconstruídas com o algoritmo corrigido. 



\section{CAPÍTULO 1 - Introdução}

A introdução da tomografia computadorizada na medicina revolucionou o diagnóstico por imagens, primeiramente, por ter sido o primeiro sistema a produzir imagens tomográficas digitalizadas com boa resolução espacial (em comparação com aquelas produzidas por técnicas de medicina nuclear). Além disso, as imagens produzidas na tomografia computadorizada apresentam maior contraste entre diferentes tecidos, quando comparadas às imagens produzidas na radiografia convencional ${ }^{1}$.

Um dos avanços mais recentes na tecnologia tomográfica foi a introdução dos equipamentos multi-cortes (multi-slice computed tomography - MSCT). Estes equipamentos possuem um diferencial fundamental com relação aos sistemas convencionais de corte único: possuem uma matriz de detectores que permitem a aquisição de imagens volumétricas do corpo do paciente.

O Brasil encontra-se, atualmente, no grupo de países produtores e exportadores de equipamentos de diagnóstico por imagens, juntamente com Alemanha, Holanda, Estados Unidos, Israel e Japão, além de outros. Dados da $\mathrm{ABIMO}^{2}$ têm mostrado um grande destaque desta produção quando empresas brasileiras participam de feiras no exterior. As empresas brasileiras agregaram tecnologias para a produção de equipamentos radiológicos convencionais, mamógrafos e sistemas para radiologia intervencionista, todos com boa aceitação clínica no Brasil e nos países para os quais estes equipamentos são exportados. Contudo, equipamentos de tomografia computadorizada não fazem parte do parque produtivo nacional atualmente.

O domínio da tecnologia para o desenvolvimento de sistemas de TC passa pela reunião de informações para a elaboração de algoritmos para reconstrução de imagens. Como a tecnologia atual vem sendo pautada pela tomografia multi-slice, o conhecimento e a aplicação de algoritmos desta natureza tornaram-se importantes marcos a serem atingidos pelos pesquisadores das áreas de Física Médica, Engenharia Biomédica e Informática em Saúde. Além disso, a melhoria dos padrões de utilização deste tipo de equipamento pode receber importantes aportes conceituais com o domínio da tecnologia de reconstrução destas imagens, com possíveis conseqüências na melhoria da qualidade das informações clínicas resultantes. 
Esta abordagem está bastante clara no destaque que vem sendo dado aos trabalhos científicos encontrados na literatura. Dentre os diversos trabalhos encontrados, ressaltamos a importância daqueles identificados nas referências ${ }^{3-24}$. Outras referências importantes estão apresentadas nos itens seguintes. Assim, o presente trabalho tem como objetivo reunir informações, estudar, aplicar e desenvolver algoritmos de reconstrução de imagens, ainda que simplificados, que contribuam pra evolução científica e tecnológica na área da tomografia computadorizada e para o futuro domínio dessa tecnologia no Brasil.

No capítulo 2, resume-se brevemente a evolução dos equipamentos de TC desde a sua invenção. Ainda neste capítulo, são discutidos os princípios físicos envolvidos na técnica, desde a produção dos raios $\mathrm{X}$ até sua interação com a matéria, além de ser apresentada a definição de número CT e se descrever de maneira resumida e simplificada o processo de retro-projeção filtrada, utilizado na maioria dos algoritmos de reconstrução de imagens tomográficas ${ }^{1}$.

No capítulo 3, são apresentadas as diferentes geometrias de aquisição de dados que foram utilizadas nas várias gerações de tomógrafos. Para cada geometria, é derivada uma fórmula matemática que descreve um algoritmo para a reconstrução de imagens. Por último é discutido o algoritmo FDK (Feldkamp - Davis - Kress), que trata de projeções com geometria de feixe cônico (cone-beam $)^{25}$.

No capítulo 4, é apresentado, de maneira geral, o funcionamento de um equipamento de TC, destacando-se os principais componentes e suas funções. Realiza-se uma discussão mais detalhada a respeito dos tubos de raios $\mathrm{X}$ e detectores, apontando os principais avanços tecnológicos exigidos pela necessidade de um desempenho cada vez melhor dos equipamentos de TC.

No quinto capítulo, são apresentados e descritos diferentes tipos de artefatos encontrados em imagens de TC. Para cada caso, são discutidas suas causas e, quando possível, suas correções. Devido à natureza sigilosa e proprietária deste tópico, grande parte das discussões encontradas na literatura, a respeito da correção de artefatos, é superficial. Ainda neste capítulo, discute-se mais detalhadamente a amenização dos artefatos devidos ao ruído presente nas projeções. 
No sexto capítulo, é apresentada a metodologia utilizada na etapa de implementação do algoritmo, na simulação computacional usada para testar o seu funcionamento, nas montagens dos diferentes sistemas de aquisição de dados que foram utilizados no trabalho, o método utilizado na análise das imagens reconstruídas e implementação de cada correção de artefatos implementada. Discute-se ainda o método utilizado para calibrar o sistema e, por fim, a aplicação do sistema na reconstrução multicortes de um objeto real.

No capítulo 7, são apresentados os resultados obtidos nas simulações computacionais e nas reconstruções reais que foram realizadas. São apresentados os resultados da aplicação das correções de artefatos nas imagens, é verificada a linearidade do sistema.

No capítulo 8, discutem-se os resultados obtidos, incluindo os efeitos das correções de artefatos implementadas. Ainda neste capítulo, discutem-se os resultados da calibração do sistema de TCMC implementado e sua utilização na reconstrução multicortes de um objeto real.

No nono e último capítulo, são apresentadas as conclusões a respeito do trabalho e apresentadas as sugestões para trabalhos futuros. 


\section{CAPÍTULO 2 - Fundamentos Teóricos}

A primeira grande diferença da tomografia computadorizada para a radiografia, é que, ao invés de gerar a projeção do corpo do paciente num filme fotográfico, ela possibilita obter imagens de cortes transversais do corpo, apresentando detalhes anatômicos ao longo da trajetória dos raios $\mathrm{X}$ até atingir o detector digital.

Imaginando o corpo humano composto por um número finito de cortes transversais com uma determinada espessura, que, por sua vez, podem ser imaginados sendo compostos por um número finito de elementos cúbicos de volume (Voxel), pode-se dizer que o processo de reconstrução tomográfica tem por objetivo determinar o coeficiente de atenuação linear de cada voxel, que corresponde ao tom de cinza de cada elemento da matriz de imagem digital formada, ou seja, da imagem reconstruída do corte em questão.

\subsection{Contexto Histórico}

As bases matemáticas para a solução dos problemas de reconstrução de imagens encontrados na tomografia computadorizada são muito anteriores a sua idealização. Em 1917 J. H. Radon ${ }^{26}$ desenvolveu as bases matemáticas da TC. Em seu trabalho ele mostra que é possível reconstruir imagens de cortes transversais de objetos a partir das suas

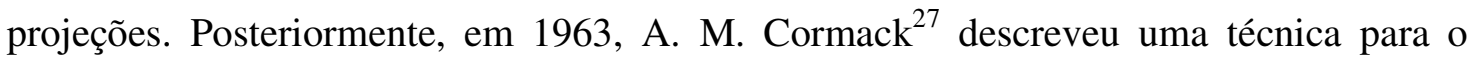
cálculo da distribuição da absorção de raios $\mathrm{X}$ no corpo humano e iniciou os primeiros experimentos com TC em aplicações médicas, o que lhe rendeu um Prêmio Nobel em Fisiologia e Medicina, em 1979. Esse prêmio foi dividido com o engenheiro G. N. Hounsfield, que obteve sucesso, em 1972, no desenvolvimento do primeiro equipamento médico de tomografia computadorizada a ser usado em hospitais em diagnóstico por imagens. Hounsfield é conhecido como o inventor da tomografia computadorizada. Um fato curioso é que os trabalhos de Hounsfield, Cormack e Radon foram todos independentes. Cormack, em sua pesquisa, descobriu ${ }^{28}$ que o próprio Radon desconhecia 
o trabalho do físico H. A. Lorentz, de 1905, onde já era proposta uma solução para o problema matemático no caso 3D.

Desde o primeiro exame clínico de TC, realizado em 1972, a técnica foi muito bem aceita na comunidade médica graças ao grande sucesso no diagnóstico de doenças. Até 1980 já havia mais de 10.000 equipamentos de TC em uso nos hospitais de todo o mundo ${ }^{1}$.

A evolução dos sistemas de tomografia computadorizada passou por etapas bem definidas, cada uma delas caracterizada por uma geometria particular de aquisição dos $\operatorname{dados}^{29}$, que tinham como objetivo reduzir o tempo de varredura. Estas etapas foram rotuladas como gerações dos equipamentos de tomografia. Até hoje estão definidas cinco gerações desses sistemas, apesar de alguns autores apresentarem definições diferentes ${ }^{30}$.

A primeira geração foi inaugurada pelo EMI Mark 1, desenvolvido por Hounsfield, na década de setenta. A geometria de varredura deste sistema consistia em uma translação seguida por uma rotação do sistema tubo-detector. $\mathrm{O}$ campo de radiação era colimado de modo a produzir um pequeno feixe cilíndrico (pencil beam) que, após atravessar a cabeça do paciente, atingia um único detector (Figura 1 (a)). O sistema de detecção consistia de um cristal de NaI e uma fotomultiplicadora. Após transladar linearmente o feixe, cobrindo toda a extensão do objeto, o sistema efetuava uma rotação de 1 grau. A seqüência repetia-se por 180 vezes, gastando, para isso, cerca de 4 minutos e meio. Este longo tempo de aquisição inviabilizava a aquisição de imagens de partes do corpo que não pudessem ser totalmente imobilizadas, como tórax ou coração. Além disso, o sistema gastava 7 minutos para reconstruir uma imagem de $80 \times 80$ pixels, referente a uma região do corpo de $24 \mathrm{~cm}$. A espessura da secção era de $13 \mathrm{~mm}$. 


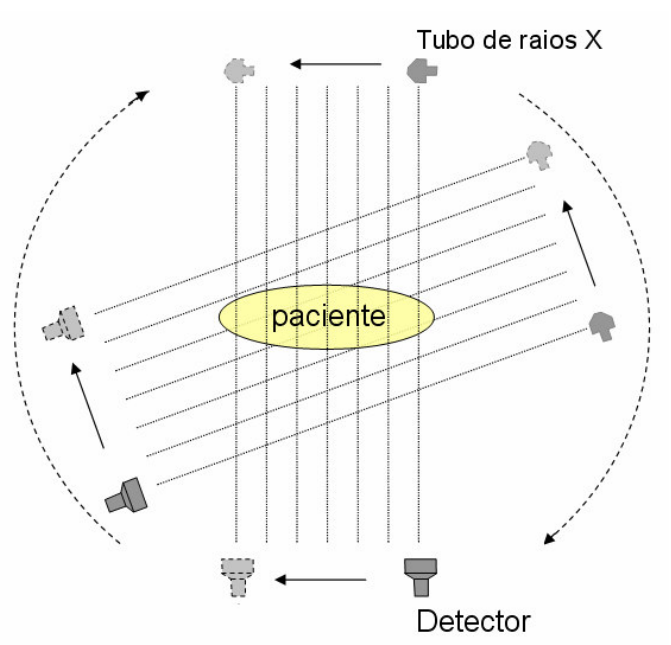

(a)

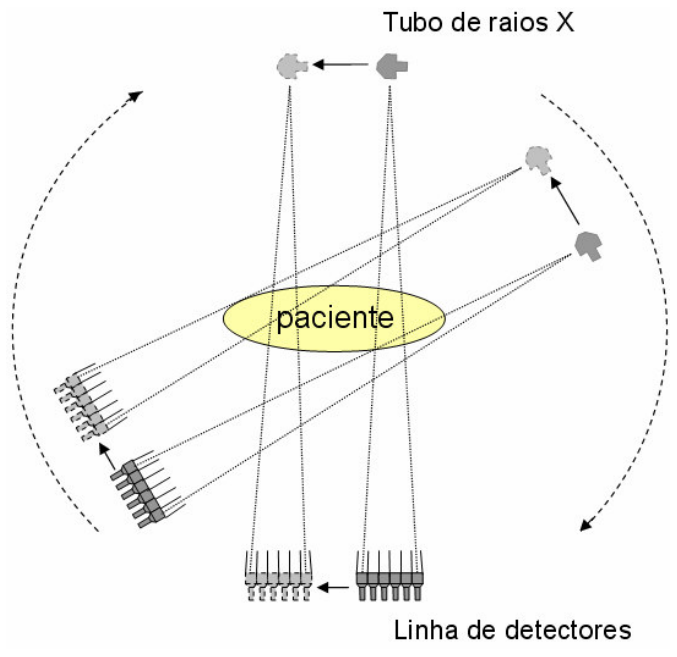

(b)

Figura 1 - (a) Geometria utilizada nos equipamentos tomográficos da primeira geração. (b) Geometria utilizada nos equipamentos tomográficos da segunda geração. ${ }^{2}$

Seguindo este sistema, a segunda geração (Figura 1 (b)) introduziu uma modificação significativa com respeito à geometria do feixe de raios X. O feixe cilíndrico foi substituído por um feixe em leque (fan beam), mas o movimento básico de translação seguido por rotação manteve-se idêntico aos sistemas de primeira geração. Para detectar corretamente este fan beam, o detector único foi substituído por um conjunto linear de detectores. Com isso, para um feixe com abertura de, por exemplo, $10^{\circ}$, somente 18 movimentos de translação e rotação eram necessários para reconstruir adequadamente uma imagem. Por esta razão, os tempos de varredura passaram a ser da ordem de 10 a 20 segundos. Neste tipo de sistema já era possível efetuar imagens de outras partes do corpo além da cabeça. Contudo, artefatos devido a movimentos involuntários dos pacientes eram ainda comuns com os tempos de aquisição destas máquinas.

A terceira geração de tomógrafos caracteriza-se por uma geometria intitulada "rotação-rotação" (em contraste com a "translação-rotação" das gerações anteriores), na qual movimentos translacionais do sistema fonte-detector foram suprimidos (Figura 2). Um leque de radiação bastante amplo atravessa o paciente e atinge uma bateria semicircular de detectores. O número de elementos detectores na matriz pode ir de $300 \mathrm{a}$ 1200. Ambos, tubo e detectores, descrevem um movimento circular em torno do objeto de interesse. Devido às grandes dimensões do feixe que atinge o paciente nestes sistemas, 
um número maior de fótons espalhados pode atingir os detectores, degradando a qualidade das imagens produzidas. Para evitar este efeito, um colimador pós-paciente precisa ser utilizado.

Com as características geométricas dos sistemas de terceira geração, foi possível um grande decréscimo dos tempos de varredura. Existem sistemas comerciais que efetuam a varredura em menos de meio segundo. Outra diferença com relação às gerações anteriores é a trajetória de rotação dos sistemas, que passou a ser de $360^{\circ}$.

A geração seguinte (quarta) difere da anterior por não possuir movimento da matriz de detectores. Neste caso, o conjunto de detecção circunda completamente o objeto e o movimento é executado somente pelo tubo de raios X (Figura 3). Este anel de detectores deve ser bastante grande, de modo a permitir tanto o posicionamento do paciente quanto para garantir espaço para a rotação do tubo. Existem algumas vantagens desta geração sobre a terceira, como por exemplo, a maior estabilidade dos detectores, a possibilidade de utilizar uma grande abertura do leque de radiação, a facilidade em eliminar os artefatos de aliasing $^{31}$, etc. Contudo, como conseqüência do posicionamento da fonte e dos detectores, os raios emergentes não atingem o sistema de detecção em uma faixa angular constante, como acontece nos sistemas de terceira geração. Com isso, grades ou colimadores pós-paciente não podem ser utilizados, resultando em uma fração maior de radiação espalhada que atinge os detectores. Além disso, pela necessidade de se utilizar um anel de detectores de maior diâmetro, os fabricantes são obrigados a preencher a matriz com um grande número de elementos de detecção, o que aumenta o custo desses sistemas. Outras opções são a utilização de um menor número de detectores de tamanho maior, acarretando uma redução na resolução espacial, ou, em outro caso, inserir um maior espaçamento entre detectores de pequeno tamanho, que produz uma amostragem incompleta dos dados, além de sub-utilizar a fonte de raios X. 


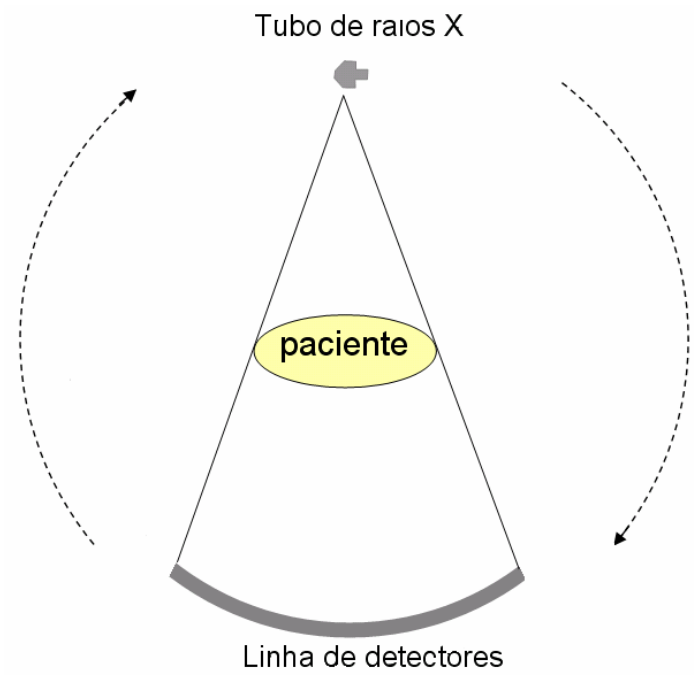

Figura 2 - Geometria utilizada nos equipamentos tomográficos da terceira geração. Estes equipamentos utilizam um feixe de raios $\mathrm{X}$ em forma de leque (fan beam) e o sistema tubo-detector efetua somente um movimento de rotação em torno do paciente. ${ }^{29}$

A quinta geração de equipamentos tomográficos elimina a necessidade de movimentos relativos entre fonte de raios $\mathrm{X}$ e a matriz de detectores. A evolução dessas gerações vem sempre visando reduzir os tempos de varredura. Como a limitação principal dos sistemas diz respeito ao tempo necessário para efetuar os movimentos mecânicos para a aquisição dos dados, nada mais natural que desenvolver sistemas que eliminem movimentos desta natureza. Com esta finalidade foram desenvolvidos dois sistemas experimentais. O primeiro deles foi o DSR (dynamical spatial reconstructor), desenvolvido na Mayo Clinic (EUA), que era formado por um conjunto de 14 tubos de raios $\mathrm{X}$ e uma matriz de detectores fixos. Os tubos eram acionados em seqüência, sem movimentação, o que permitia a aquisição de imagens com grande velocidade. O sistema ainda movimenta-se em torno do paciente para otimizar a resolução espacial ou a sensibilidade de contraste. 


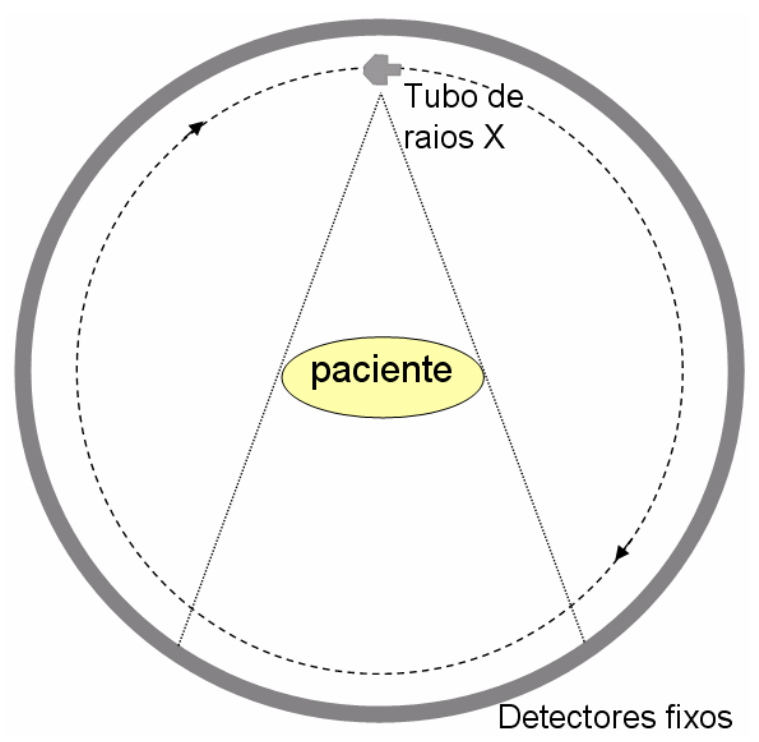

$\square$ Figura 3 - Geometria utilizada nos equipamentos tomográficos da quarta geração. Estes equipamentos utilizam um feixe de raios $\mathrm{X}$ em forma de leque (fan beam) e somente 0 tubo de raios $X$ executa um movimento de rotação em torno do paciente. ${ }^{29}$

A década de oitenta foi muito pobre com relação ao progresso tecnológico dos equipamentos de TC. Somente em 1989, com a introdução dos tomógrafos de varredura helicoidal $^{32-33}$ (spiral or helical $C T$ ) e os desenvolvimentos na tecnologia dos tubos de raios $\mathrm{X}$ e dos detectores, foi retomado o avanço tecnológico nas aplicações clínicas.

A TC helicoidal expandiu a capacidade da TC tradicional, permitindo a varredura de um órgão inteiro num intervalo de tempo curto o suficiente para que o paciente consiga prender a respiração durante toda a varredura. Pode-se dizer que a TC helicoidal é um dos principais fatores que possibilitam a reconstrução tridimensional de órgãos inteiros dos pacientes.

Um dos avanços mais recentes na tecnologia tomográfica foi a introdução dos chamados equipamentos multi-cortes (multi-slice computed tomography - MSCT). Equipamentos de quatro cortes foram lançados em 1998, 16 cortes em 2001 e 64 em 2004. Em 2007, foi lançado o primeiro equipamento de TC 4D, com 320 cortes, capaz de varrer até $16 \mathrm{~cm}$ do paciente com uma única rotação, que leva cerca de $0,35 \mathrm{~s}$.

Estes equipamentos possuem um diferencial fundamental com relação aos sistemas convencionais de corte único: possuem uma matriz de detectores (Figura 4) que permite a aquisição de imagens volumétricas do corpo do paciente (Figura 5). 


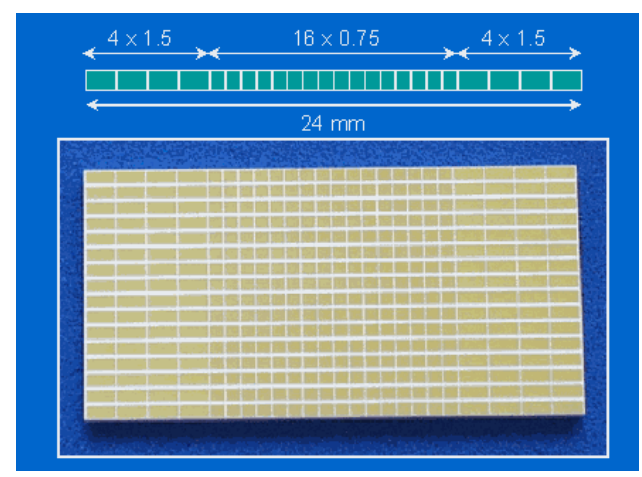

Figura 4 - Elemento detector bidimensional típico utilizado em equipamentos de tomografia multicortes $^{34}$.
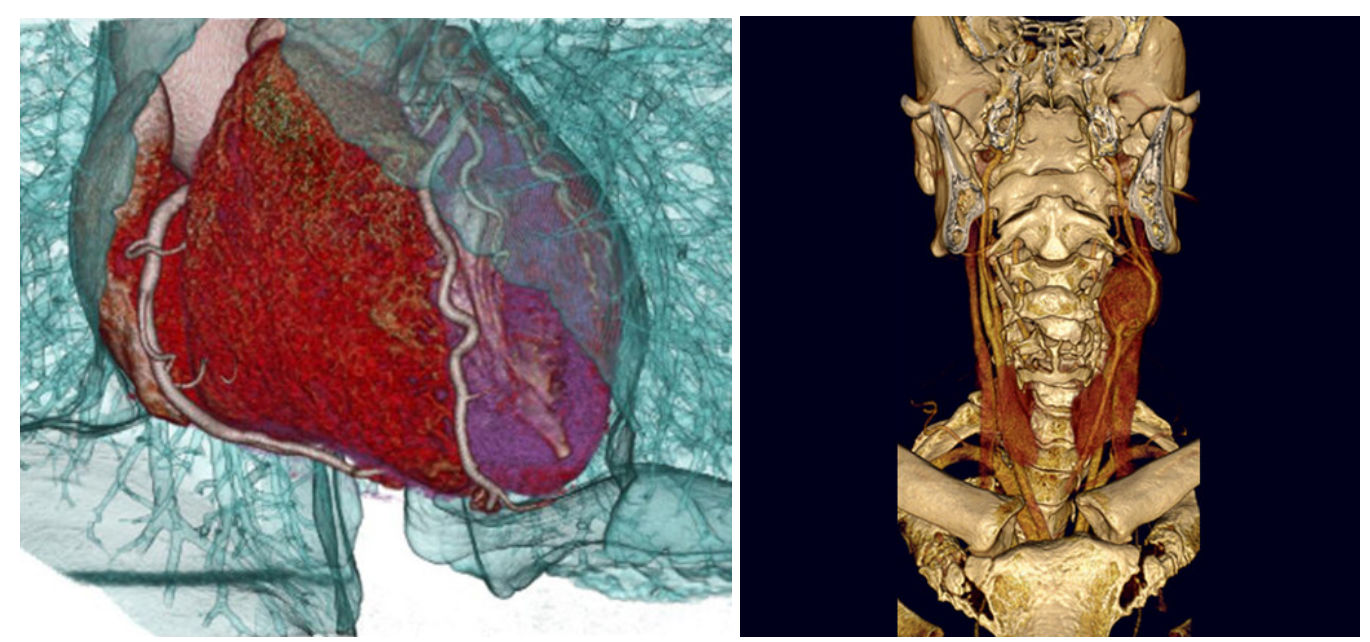

Figura 5 - Imagens volumétricas obtidas com equipamentos de tomografia computadorizada multicortes com varredura helicoidal ${ }^{35}$.

Esta composição entre um feixe em forma de cone (cone beam) (Figura 6) e uma matriz bidimensional de detectores, associada a um sistema de movimentação da mesa do paciente e de processamento dos dados coletados similar aos da tomografia helicoidal, permite um aumento considerável na velocidade de aquisição de dados para as imagens. Utilizando-se este tipo de sistema é possível obter imagens clínicas de partes do corpo em movimento rápido, tais como o coração. 


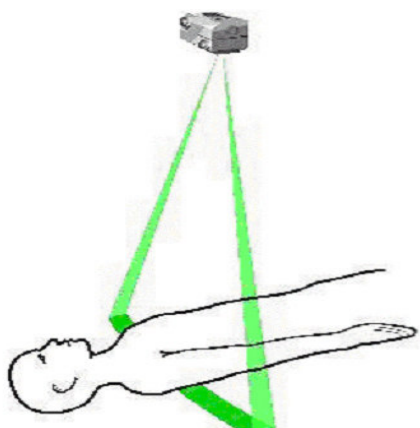

(a)

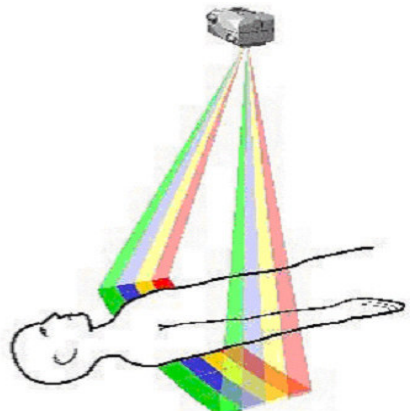

(b)

Figura 6 - Diferenças na forma do feixe de radiação e composição de detectores em sistemas convencionais (a) e multi-cortes (b).

Há atualmente mais de 40.000 tomógrafos de corpo inteiro sendo utilizados em clínicas e hospitais em todo o mundo ${ }^{1}$, e a tomografia computadorizada ocupa uma posição consagrada na área de diagnóstico por imagens, independentemente do desenvolvimento de outras técnicas radiológicas.

\subsection{Princípios Físicos da Tomografia Computadorizada}

Em 8 de novembro de 1895, Wilhelm Röntgen, no Instituto de Física da Universidade de Wurzburg, Alemanha, observou pela primeira vez a radiação eletromagnética que ele mesmo veio a chamar de raios $\mathrm{X}$. Convencionalmente, a região do espectro eletromagnético onde se encontram os raios $\mathrm{X}$ corresponde ao intervalo de comprimentos de onda que variam de $\lambda \approx 0,01-10 \mathrm{~nm}$, isto é, fótons com energias entre $\mathrm{E} \approx 120 \mathrm{eV}-120 \mathrm{keV}^{36}$.

\subsubsection{A produção de raios $X$}

Nos tubos de raios $\mathrm{X}$ convencionais, utilizados em equipamentos médicos de radiodiagnóstico, a radiação $\mathrm{X}$ é produzida como parte da energia liberada no processo de colisão de elétrons de alta energia cinética contra uma placa de metal, que é o alvo do tubo. Esse feixe de elétrons, acelerados por uma diferença de potencial da ordem de dezenas de milhares de volts, colide com o alvo, perdendo a maior parte de sua energia 
em fenômenos de dissipação térmica, e o restante na produção de raios $X$, que ocorre através de dois fenômenos distintos: radiação característica e radiação de freamento (Bremsstrahlung) $)^{37}$.

A radiação característica ocorre quando o elétron incidente choca-se com um elétron da camada interna do átomo do alvo e o arranca do átomo. Com isso a camada de energia que este elétron ocupava no átomo fica vaga. Este átomo, agora ionizado, precisa se estabilizar. Para isto, um elétron de uma camada de energia mais externa migra para a vaga deixada na camada interna liberando, neste processo, uma determinada e bem definida quantidade de energia (fóton) na forma de raios X. Esta energia corresponde à diferença entre as energias de ligação das duas camadas (a externa, que o elétron ocupava, e a mais interna que ele passou a ocupar). Essa radiação emitida denomina-se radiação característica, já que a diferença de energia entre as camadas é particular de cada elemento (pode-se descobrir qual é o elemento do alvo a partir da análise das energias dos fótons de raios $\mathrm{X}$ da radiação característica).

A radiação de freamento, ou Bremsstrahlung, ocorre quando o elétron incidente tem sua trajetória modificada por uma colisão com o núcleo. Este desvio de trajetória é acompanhado por uma desaceleração, o que faz com que parte da energia cinética do elétron seja emitida como um fóton de raios X. A energia do fóton depende da variação do momento linear do elétron em sua colisão com o núcleo, e é tão maior quanto maior for o ângulo de espalhamento. Portanto, não há mais uma faixa de energia característica na qual os fótons são emitidos, mas sim um espectro contínuo, que depende do ângulo do desvio.

Para cada diferença de potencial (ddp) aplicada entre os eletrodos do tubo, existe um espectro diferente, que sempre possui um comprimento de onda mínimo bem definido, o qual depende somente da ddp aplicada. Esse fóton de máxima energia é produzido quando o elétron é completamente freado numa única colisão com um núcleo, transformando toda sua energia cinética em um fóton. O fenômeno de Bremsstrahlung é o mais comum na produção de raios $X$ na faixa de energias usadas nas técnicas de radiodiagnóstico (20 a $150 \mathrm{keV}$ ), apesar de a radiação característica ter maior importância no caso de técnicas de mamografia. 


\subsubsection{Interação de Raios $X$ com a Matéria}

As maneiras com que os raios $\mathrm{X}$ interagem com a matéria determinam o design de suas fontes, a natureza da sua óptica, a operação de seus detectores e as suas aplicações. Os raios X interagem por colisões elásticas e inelásticas, e por absorção fotoelétrica.

Dois tipos de processos contribuem para o espalhamento elástico: espalhamento Thomson, que ocorre basicamente com elétrons livres, e o espalhamento Rayleigh, que ocorre com elétrons fortemente ligados.

Nas técnicas radiológicas utilizadas em TC, as interações mais comuns e importantes são: a absorção fotoelétrica e o espalhamento Compton (inelástico).

Absorção fotoelétrica é uma interação na qual o fóton incidente desaparece. Tal fóton, de energia $h v$, interage com o átomo como um todo. Sua energia é transferida a um elétron, normalmente pertencente à camada mais interna do átomo. Esse elétron é emitido com uma energia cinética $E_{e}$, dada por:

$$
E_{e}=h v-E_{b}
$$

onde $E_{b}$ é a energia de ligação do elétron orbital (da ordem de 1-10 eV). A conservação de momento requer que o átomo recue neste processo, mas essa energia de recuo é muito pequena e normalmente é desprezada.

A vacância que é criada na camada eletrônica, como resultado da emissão do fotoelétron, é rapidamente preenchida através de um rearranjo eletrônico ${ }^{38}$. Neste processo, a energia de ligação é liberada na forma de raios $\mathrm{X}$ característicos ou de elétrons de Auger. Entretanto, os elétrons de Auger são de baixa energia e seu alcance é extremamente pequeno.

Já os raios X característicos viajam certa distância (aproximadamente $1 \mathrm{~mm}$ ) antes de serem absorvidos através de interações fotoelétricas com camadas eletrônicas mais externas dos átomos absorvedores.

No espalhamento Compton, o fóton incidente pode interagir com qualquer um dos elétrons orbitais. Os elétrons são considerados livres pelo fato da energia do fóton incidente ser extremamente elevada se comparada com a energia de ligação dos elétrons. $\mathrm{O}$ resultado do espalhamento Compton é um elétron recuado e um fóton $\mathrm{X}$ espalhado (com uma freqüência menor que a do fóton incidente). A energia $\mathrm{E}$ do fóton incidente é 
dividida entre o elétron recuado e o fóton espalhado. Essa divisão da energia depende do ângulo de espalhamento $\theta$. Impondo a conservação do momento e da energia-massa relativística, obtém-se a seguinte relação entre a energia $\mathrm{E}$ do fóton antes da colisão e a energia E' do fóton depois da colisão,

$$
\square \frac{1}{E^{\prime}}-\frac{1}{E}=\frac{(1-\cos \theta)}{m_{e} c^{2}}
$$

onde $m_{e} c^{2}$ é a energia de repouso do elétron $(511 \mathrm{keV})$.

\subsection{Determinação do Coeficiente de Atenuação Linear}

Em TC, o objetivo é determinar o coeficiente de atenuação linear, $\mu$, em cada ponto do objeto (ou corpo) cujas imagens foram reconstruídas. A partir de medidas da transmissão dos raios $\mathrm{X}$ através de um objeto, é possível obter a distribuição espacial do coeficiente de atenuação em todo o volume atravessado pelos raios X. Embora quase todos os tecidos moles do corpo humano sejam compostos basicamente de água, há variação suficiente para resultar em diferenças entre os coeficientes de atenuação linear da maioria dos tecidos que compõem o corpo humano. Na técnica da tomografia computadorizada é possível detectar e exibir essas diferenças. Então, em um exame de TC, o radiologista obtém uma imagem que, além de mostrar um corte transversal da anatomia do paciente, contém informação quantitativa que pode ser usada para vários propósitos.

Para tanto, é necessário conhecer a intensidade $I$ do feixe de raios $\mathrm{X}$ que atravessa o corpo, e a intensidade $I_{0}$, que não é atenuada pelo corpo. À direita da Figura 7 estão as equações que descrevem a atenuação dos raios $\mathrm{X}$ em diferentes tipos de materiais. 


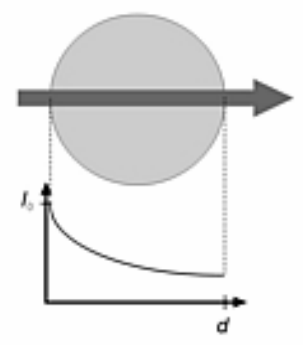

a - Objeto homogêneo, radiação monocromática.

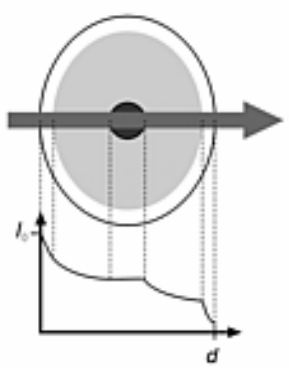

$$
\begin{aligned}
& I=I_{0} \cdot e^{-\mu \cdot d} \\
& P=\ln \frac{I_{0}}{I}=\mu \cdot d \\
& \mu=\frac{1}{d} \cdot \ln \frac{I_{0}}{I}
\end{aligned}
$$

b - Objeto não homogêneo, radiação monocromática.

$$
\begin{aligned}
& I=I_{0} \cdot e^{-\int_{0}^{d} \mu(s) d s} \\
& P=\ln \frac{I_{0}}{I}=\int_{0}^{d} \mu(s) d s
\end{aligned}
$$

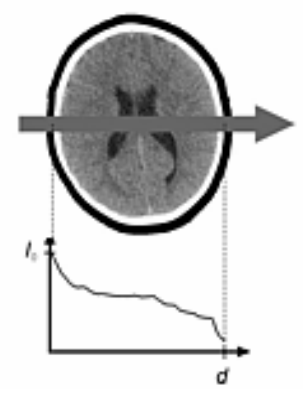

c - Objeto não homogêneo, radiação policromática.

$$
\begin{aligned}
& I=\int_{0}^{E_{\max }} I_{0}(E) \cdot e^{-\int_{0}^{d} \mu(E, s) d s} d E \\
& P=\ln \frac{I_{0}}{I}
\end{aligned}
$$

Figura 7 - Método de determinação da integral de linha do coeficiente de atenuação linear, $\mu$, para:

(a) um objeto com distribuição homogênea do coeficiente de atenuação, utilizando radiação monocromática; (b) um objeto com distribuição não homogênea, utilizando radiação monocromática; (c) um objeto com distribuição não homogênea, utilizando radiação policromática. ${ }^{1}$

O caso mais simples possível ocorre na medição de um objeto homogêneo utilizando radiação monocromática (Figura 7 (a)). Nesse caso a intensidade do feixe decresce exponencialmente com sua distância de penetração no material absorvedor. A projeção, $P$, definida como o logaritmo natural da razão entre as intensidades $I_{0}$ e $I$, é dada, nesse caso, simplesmente como o produto do coeficiente de atenuação linear $\mu$ do objeto com a sua espessura $d$. Se a espessura é conhecida, $\mu$ é determinado de maneira direta.

O segundo caso trata um objeto não homogêneo simples (Figura 7 (b)). Nesse caso a atenuação total de cada raio que atravessa o objeto depende do valor de $\mu$ em cada ponto da trajetória dos fótons, e pode ser calculada como a integral de $\mu$ (s) ao longo da trajetória. A técnica da TC consiste em medir o maior número possível de tais integrais. 
Radon mostrou em seu trabalho ${ }^{26}$ que a distribuição bidimensional de uma característica de um objeto pode ser determinada exatamente se um conjunto denso de integrais de linha em todas as direções sobre todo o corte de reconstrução for conhecido. Em outras palavras, é possível determinar com a precisão desejada a distribuição de tal característica no corte desde que seja dado um número suficientemente grande de integrais de linha dessa distribuição sobre todo o corte.

É importante frisar que o coeficiente de atenuação linear dos materiais depende da energia dos fótons incidentes. Portanto, medindo-se as intensidades dos feixes, está sendo feita a integral sobre todos os intervalos de energia também, como ilustrado na Figura 7 (c). A dependência na energia pode acarretar alguns problemas, como o de endurecimento do feixe, que tem como conseqüência o surgimento de artefatos na imagem reconstruída. Isso se deve, basicamente, ao fato de que o espectro policromático de radiação $\mathrm{X}$ é atenuado diferentemente, dependendo da energia e direção do feixe, assim como do tipo de objeto irradiado. Conseqüentemente há variações na energia efetiva, $E_{E f}$, dos feixes. Isto significa que a quantidade $\mu\left(E_{E f}\right)$ varia de uma direção de projeção para outra, dando origem a conjuntos inconsistentes de medidas.

Para reconstruir uma imagem tomográfica de qualidade, é necessário um número muito grande de integrais do coeficiente de atenuação em todas as direções. A Figura 1 (a) retrata o funcionamento do primeiro equipamento de TC clínico. Com 180 projeções com intervalo angular de $1^{\circ}$ entre cada e 160 pontos por projeção. Os equipamentos de TC atuais utilizam uma geometria cônica, e medem cerca de oitocentas a mil e quinhentas projeções, com seiscentos a mil e duzentos pontos cada ${ }^{1}$.

\subsection{Formação da Imagem}

Atualmente o tipo de algoritmo mais utilizado em TC é o de retro-projeção filtrada (FBP - Filtered Back-Projection) que, como o próprio nome diz, é dividido em duas etapas; filtração e retro-projeção. A primeira se encarrega de filtrar as projeções, enquanto a segunda realiza a retro-projeção da projeção filtrada sobre toda a imagem (Figura 8). A superposição dessas retro-projeções forma a imagem da secção transversal do objeto. 
Uma grande vantagem no uso de algoritmos do tipo FBP é a economia de tempo, pois é possível realizar a aquisição das projeções paralelamente aos processos de filtração e retro-projeção.

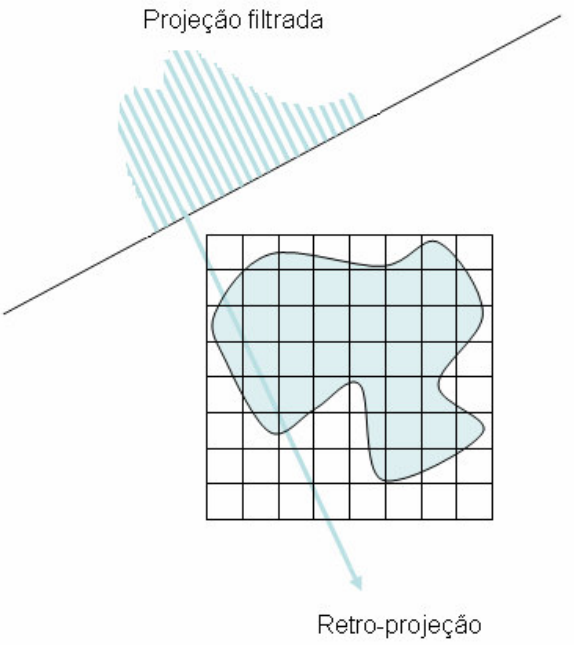

(a)

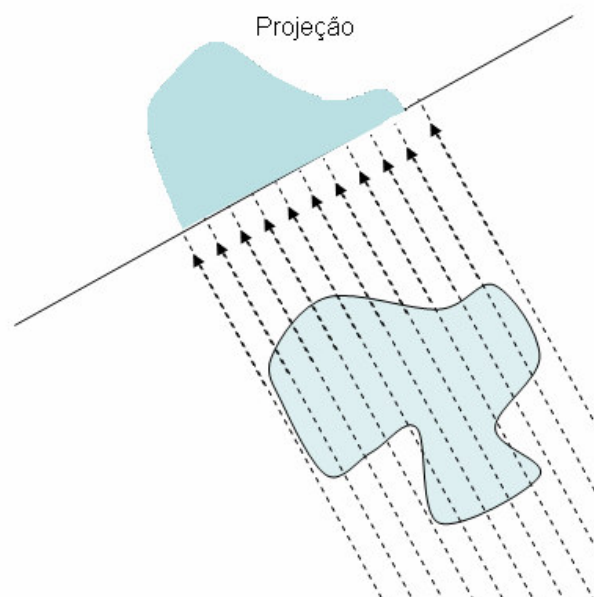

(b)

Figura 8 - llustração do processo de retro-projeção filtrada. (a) Aquisição da projeção; (b) Retroprojeção da projeção filtrada.

\subsection{Número CT}

No processo de reconstrução de imagens em TC calcula-se a distribuição espacial do coeficiente de atenuação linear, $\mu(x, y, z)$. No entanto, a quantidade física $\mu$ depende muito da energia do feixe e, por isso, não seria possível comparar duas imagens obtidas com equipamentos que utilizam diferentes tensões aplicadas ao tubo de raios $\mathrm{X}$. É definida, portanto, uma quantidade chamada número $\mathrm{CT}$, relativo à atenuação da água. Em homenagem ao inventor da tomografia computadorizada, os números CT são especificados em unidades Hounsfield (HU). Para um tecido T, com coeficiente de atenuação linear $\mu_{T}$, o seu número CT é, por definição, dado por 


$$
\neg \text { Número } C T=\frac{\left(\mu_{T}\left(E_{E f}\right)-\mu_{\text {agua }}\left(E_{E f}\right)\right)}{\mu_{\text {agua }}\left(E_{E f}\right)} \cdot 1000 \quad[\mathrm{HU}]
$$

Onde, $E_{E f}$ é a energia efetiva do feixe que, por definição, é a energia que teria um feixe monocromático com mesma camada semi-redutora (CSR) do feixe policromático.

Na escala de número CT, a água e o ar $\left(\mu_{a r} \cong 0\right)$ possuem, por definição, valores fixos, respectivamente iguais a 0 e -1000 , independente do espectro de energias do feixe utilizado. Porém, para qualquer outro material, o número CT correspondente continua dependente do espectro. Este fato implica na importância de se determinar a técnica radiográfica mais adequada para cada exame, que depende dos tecidos que compõem o órgão ou região do corpo a ser examinada. A Tabela 1 apresenta o número CT de alguns tecidos e órgãos do corpo humano para um feixe com energia efetiva de $80 \mathrm{keV}$.

\section{Tabela 1 - Valores de número CT de alguns tecidos e órgãos do corpo humano para um feixe com energia efetiva de $80 \mathrm{keV}$.}

\begin{tabular}{cc}
\hline \hline Tecido & Número CT \\
\hline \hline Ar & -1000 \\
\hline Pulmão & -900 a -400 \\
\hline Gordura & -110 a -65 \\
\hline Rim & 30 \\
\hline Sangue normal & 35 a 55 \\
\hline Sangue coagulado & 80 \\
\hline Músculo & 40 a 60 \\
\hline Fígado & 50 a 85 \\
\hline \hline Ossos & 130 a 250 \\
\hline \hline
\end{tabular}




\section{CAPÍTULO 3 - Aspectos Matemáticos da Reconstrução Tomográfica de Imagens}

Os métodos de reconstrução de imagens podem ser divididos basicamente em duas classes: métodos analíticos e métodos iterativos.

No processo de reconstrução analítica trata-se o objeto a ser reconstruído $f(\vec{r})$, que se caracteriza pela distribuição espacial do coeficiente de atenuação linear, e o conjunto de medidas $p_{\Phi}(Y, Z)$, que caracteriza a projeção para cada posição angular $\Phi$ da fonte, como funções integráveis. Deste modo o problema de reconstrução é tratado em termos de equações integrais. A solução exata ou aproximada destas equações define dois grupos de algoritmos analíticos; algoritmos exatos ou algoritmos aproximados. Por último, é realizada a discretização inerente ao processo de medições e fundamental para a implementação computacional.

Os métodos iterativos iniciam-se com uma estimativa sobre como é o objeto. Depois se compara esta estimativa com as medidas obtidas, e ela é, então, modificada. Este processo é repetido várias vezes até que a suposta imagem esteja de acordo com os dados obtidos, dentro de uma incerteza definida inicialmente.

Em geral os algoritmos analíticos são mais compactos e exigem menos processamento de dados que os iterativos, o que os torna mais rápidos. Dado o fato de que algoritmos analíticos são, atualmente, os métodos mais utilizados em tomografia computadorizada, a discussão que segue se limitará aos mesmos ${ }^{31}$.

Existem tipos comuns de geometria que são tratados em reconstrução de imagens tomográficas. Os algoritmos de reconstrução estão baseados nas diversas geometrias dos feixes de raios X (Figura 9). 

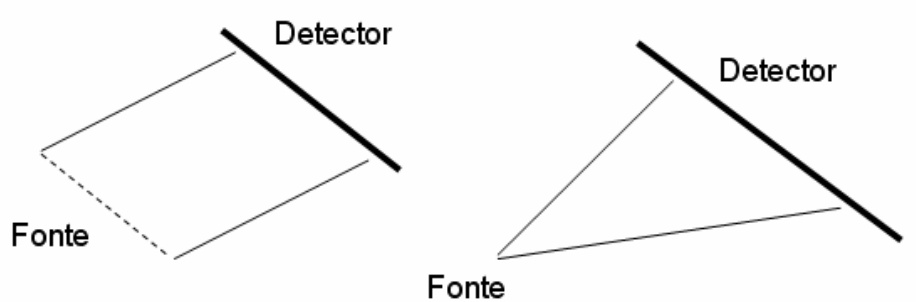

feixe paralelo

(parallel beam)

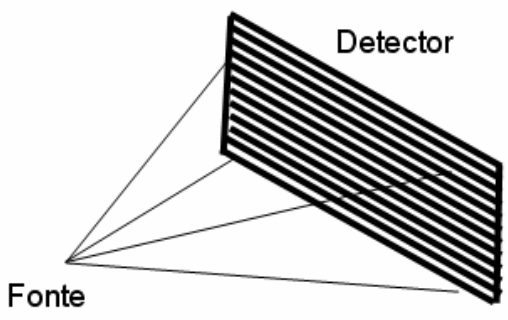

feixe cônico

(cone beam)

Figura 9 - Geometrias do feixe de raios X em TC.

$\mathrm{Na}$ geometria de feixe paralelo (parallel-beam), usada nos primeiros tomógrafos comerciais, a fonte realiza dois movimentos, um de rotação e um de translação. Para cada posição angular da fonte, ela se move perpendicularmente à direção do feixe emitido, até varrer todo o objeto, e desse modo obter uma projeção.

As gerações seguintes de tomógrafos passaram a utilizar um feixe em leque ( $f a n$ beam), com o intuito de eliminar o movimento translacional da fonte e, desse modo, economizar tempo de varredura, sem contar que é possível magnificar as projeções, possibilitando aumentar a resolução espacial das imagens reconstruídas e facilitar a identificação de estruturas menores. Seguindo o mesmo objetivo, passou-se a utilizar uma matriz de detectores e um feixe cônico (cone beam) e, desse modo, reconstruir imagens volumétricas, isto é, reconstruir vários cortes com uma só varredura.

Existem muitas formas com os quais as projeções coletadas podem ser apresentadas. O mais popular deles é o chamado sinograma. No espaço do sinograma, o eixo horizontal representa os canais do detector, e o vertical as posições angulares de cada projeção. Essa representação é particularmente eficaz para examinar o funcionamento de cada canal do detector, pois cada um é representado por uma coluna na matriz do sinograma. Então, um canal do detector que não esteja funcionando corretamente, aparecerá como uma linha vertical diferenciada na imagem do sinograma. 


\subsection{Algoritmos de Reconstrução Analítica}

Cada uma das geometrias citadas no item anterior define um tipo específico de algoritmo. As descrições dos algoritmos apresentados nos itens 3.1.1, 3.1.2 e 3.1.3, não possuem um caráter matemático formal, que pode ser encontrado nas referências 26 e 39.

\subsubsection{Feixe Paralelo (Parallel-Beam)}

Define-se a projeção $P_{\Phi}(Y)$ como a integral de linha de $f(\vec{\rho})$ sobre a trajetória do feixe que parte da fonte, na posição angular $\Phi$, e passa por $Y$, como pode ser visto na Figura 10. Onde $\vec{\rho}=(x, y)$.

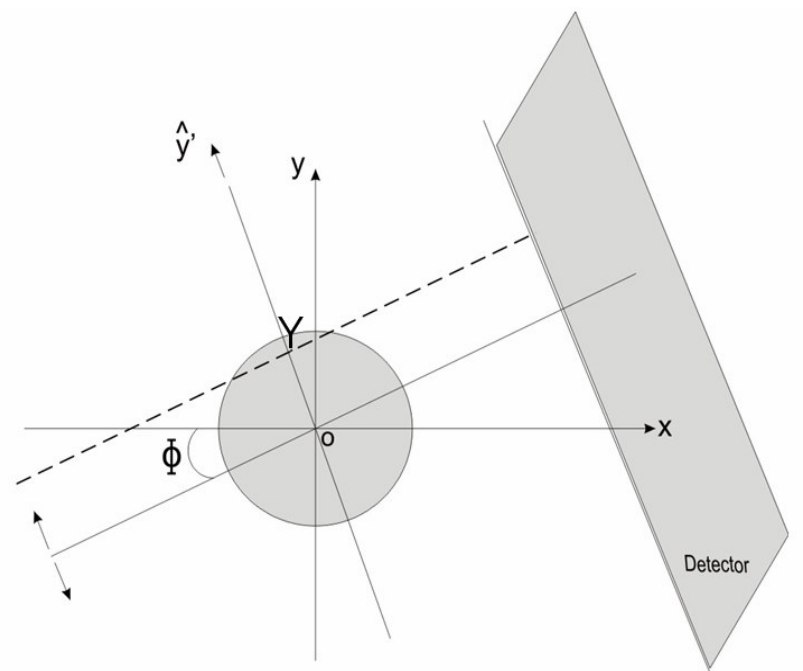

Figura 10 - Esquema da projeção de um objeto na geometria de feixe paralelo (Parallel-Beam).

Neste caso, $P_{\Phi}(Y)$ é definida por:

$\square P_{\Phi}(Y)=\iint d^{2} \vec{\rho} f(\vec{\rho}) \cdot \delta\left(\vec{\rho} \cdot \hat{y}^{\prime}-Y\right)$

Considere a transformada de Fourier de $P_{\Phi}(Y)$

$$
Q_{\Phi}(w)=\int_{-\infty}^{\infty} P_{\Phi}(Y) e^{-i 2 \pi w Y} d Y
$$

Substituindo (4) em (5) resulta 


$$
\begin{gathered}
Q_{\Phi}(w)=\int_{-\infty}^{\infty}\left\{\iint d^{2} \vec{\rho} f(\vec{\rho}) \delta\left(\vec{\rho} \cdot \hat{y}^{\prime}-Y\right) e^{-i 2 \pi w Y}\right\} d Y=\iint d^{2} \vec{\rho} f(\vec{\rho}) e^{-i 2 \pi w(\vec{\rho} \cdot \hat{y})} \\
=\int_{-\infty}^{\infty} d x \int_{-\infty}^{\infty} d y f(x, y) e^{-i 2 \pi(-x w s e n \Phi+y w \cos \Phi)}=F\left(w_{x}, w_{y}\right)
\end{gathered}
$$

onde, $w_{x}=-w \operatorname{sen} \Phi$ e $w_{y}=w \cos \Phi$. Portanto, pode-se obter $f(\vec{\rho}) \equiv f(x, y)$ a partir da transformação inversa da $F(\vec{w})=F\left(w_{x}, w_{y}\right)$. Desse modo

$$
\square f(\vec{\rho})=\operatorname{Re} \int_{-\infty-\infty}^{\infty} \int^{\infty} d^{2} \vec{w} F(\vec{w}) e^{i 2 \pi w(\vec{\rho} \cdot \hat{y})}=\operatorname{Re} \oint d \Phi \int_{0}^{\infty} d w w Q_{\Phi}(w) e^{i 2 \pi w(\vec{\rho} \cdot \hat{y})}
$$

Mas nota-se que $Q_{\Phi}(-w)=F(-w, \Phi)=F(w, \Phi+\pi)$. Portanto, pode-se reescrever a equação (7), de forma que

$$
\begin{aligned}
& f(\vec{\rho})=\operatorname{Re}\left\{\int_{0}^{\pi} d \Phi \int_{0}^{\infty} d w w F(w, \Phi) e^{i 2 \pi w(\vec{\rho} \cdot \hat{y})}+\int_{\pi}^{2 \pi} d \Phi \int_{0}^{\infty} d w w F(w, \Phi) e^{i 2 \pi w(\vec{\rho} \cdot \hat{y})}\right\} \\
& \text { * }=\operatorname{Re}\left\{\int_{0}^{\pi} d \Phi \int_{0}^{\infty} d w w F(w, \Phi) e^{i 2 \pi w(\vec{\rho} \cdot \hat{y})}+\int_{0}^{\pi} d \Phi \int_{0}^{\infty} d w w F(w, \Phi+\pi) e^{-i 2 \pi w(\bar{\rho} \cdot \hat{y})}\right\}= \\
& =\operatorname{Re}\left\{\int_{0}^{\pi} d \Phi \int_{0}^{\infty} d w w F(w, \Phi) e^{i 2 \pi w(\vec{\rho} \cdot \hat{y})}+\int_{0}^{\pi} d \Phi \int_{0}^{\infty} d w w F(-w, \Phi) e^{-i 2 \pi w(\vec{\rho} \cdot \hat{y})}\right\} \Rightarrow \\
& \square \Rightarrow f(\vec{\rho})=\operatorname{Re}\left[\int_{0}^{\pi} d \Phi \int_{-\infty}^{\infty} d w|w| F(w, \Phi) e^{i 2 \pi(\vec{w} \cdot \vec{\rho})}\right] \\
& \text { * } \hat{y}(\Phi)=-\operatorname{sen} \Phi \hat{x}+\cos \Phi \hat{y} \Rightarrow \hat{y}(\Phi+\pi)=\operatorname{sen} \Phi \hat{x}-\cos \Phi \hat{y}=-\hat{y}(\Phi)
\end{aligned}
$$

Sabendo-se que a transformada de Fourier obedece à propriedade $T^{-1}[f . g]=T^{-1}[f] * T^{-1}[g]$, pode-se ainda escrever a equação (8) na forma

$$
f(\vec{\rho})=\left.\int_{0}^{\pi} d \Phi K(Y) * P_{\Phi}(Y)\right|_{Y=\vec{\rho} \cdot \hat{y}}
$$

onde 


$$
\square K(Y)=\operatorname{Re}\left\{\int_{-\infty}^{\infty}|w| e^{i 2 \pi w Y}\right\}
$$

Ou, simplesmente, substituindo a equação (5) na equação (7), obtém-se

$$
\square f(\vec{\rho})=\operatorname{Re}\left\{\oint d \Phi \int_{-\infty}^{\infty} P_{\Phi}(Y) \int_{0}^{\infty} w e^{i 2 \pi w(\vec{\rho} \cdot \hat{y}-Y)} d w d Y\right\} \Rightarrow f(\vec{\rho})=\operatorname{Re}\left\{\oint \bar{K}(Y) * P_{\Phi}(Y) d \Phi\right\}
$$

onde

$$
\square \bar{K}(Y)=\operatorname{Re}\left\{\int_{0}^{\infty} w e^{i 2 \pi w Y}\right\}
$$

Nota-se que, por simetria

$$
\left.\square \int_{0}^{\pi} d \Phi \bar{K}(Y) * P_{\Phi}(Y)\right|_{Y=\hat{\rho} \cdot \hat{y}}=\left.\int_{\pi}^{2 \pi} d \Phi \bar{K}(Y) * P_{\Phi}(Y)\right|_{Y=\bar{\rho} \cdot \hat{y}}
$$

e pode-se ver também que

$$
\operatorname{Re}\left\{\int_{-\infty}^{\infty}|w| e^{i 2 \pi w Y} d w\right\}=\int_{-\infty}^{\infty}|w| \cos (2 \pi w Y) d w
$$

Uma vez que o integrando do lado direito da equação (14) é par, pode-se relacionar trivialmente as quantidades $K(Y)$ e $\bar{K}(Y)$, onde

$$
\square K(Y)=2 \int_{0}^{\infty} w \cos (2 \pi w Y) d w=2 \operatorname{Re}\left\{\int_{0}^{\infty} w e^{i 2 \pi w Y} d w\right\}=2 \bar{K}(Y)
$$

Substituindo as equações (13) e (15) nas equações (11) e (9), respectivamente, obtém-se

$$
\square f(\vec{\rho})=\oint \bar{K}(Y) * P_{\Phi}(Y) d \Phi=2 \int_{0}^{\pi} \bar{K}(Y) * P_{\Phi}(Y) d \Phi=\int_{0}^{\pi} K(Y) * P_{\Phi}(Y) d \Phi=\frac{1}{2} \oint K(Y) * P_{\Phi}(Y) d \Phi
$$

A equação (16) determina uma fórmula para se obter a distribuição $f(\vec{\rho})$ a partir das suas projeções. Além disso, devido à simetria da geometria de feixe paralelo, fica evidente que a integração em $\Phi$ pode ser realizada no intervalo $(0, \pi)$. Sendo assim, 
teoricamente, o sistema fonte-detector de um equipamento de TC com geometria de feixe paralelo só precisa coletar projeções num intervalo angular de $180^{\circ}$.

\subsubsection{Feixe em Leque (Fan-Beam)}

Há duas configurações distintas na geometria de feixe em leque. Numa delas, que é utilizada em praticamente todos os tomógrafos comerciais de corte único, o detector tem o formato de um arco de circunferência e é chamada de geometria em leque equiangular. Na outra configuração, o detector é reto, ou seja, seus elementos estão dispostos em uma linha reta, eqüidistantes entre si e, neste caso, tem-se a chamada geometria de feixe em leque equilinear. Os detectores disponíveis para a realização da etapa experimental do presente trabalho são planos (flat-panel) e, portanto, exigem o uso da geometria equilinear. Sendo assim, a discussão que segue se limita a esse caso.

Sem perda de generalidade, o detector plano pode ser representado por sua projeção no plano paralelo ao seu que contém o eixo de rotação do sistema fontedetector. De agora em diante, referir-se-á ao plano do detector, como se fosse o plano contendo o eixo de rotação.

De maneira análoga à definição dada pela equação (4), pode-se definir (Figura 11)

$\square p(l, \theta)=\iint d^{2} \vec{\rho} f(\vec{\rho}) \delta(\vec{\rho} \cdot \hat{l}-l)=\int_{0}^{\infty} d \rho \rho \oint d \phi f(\rho, \phi) \delta(\rho \cos (\theta-\phi)-l)$

e seja $q(w, \theta)$ a transformada de Fourier de $p(l, \theta)$. Então

$$
\begin{aligned}
& q(w, \theta)=\int_{-\infty}^{\infty} d l p(l, \theta) e^{-i 2 \pi v l}=\int_{0}^{\infty} d \rho \rho \oint d \phi f(\rho, \phi) \int_{-\infty}^{\infty} d l \delta(\rho \cos (\theta-\phi)-l) e^{-i 2 \pi w l}= \\
& \square=\int_{0}^{\infty} d \rho \rho \oint d \phi f(\rho, \phi) e^{-i 2 \pi v \rho \cos (\theta-\phi)}=\int_{-\infty}^{\infty} d x \int_{-\infty}^{\infty} d y f(x, y) e^{-i 2 \pi\left(x w_{x}+y w_{y}\right)}=F\left(w_{x}, w_{y}\right)
\end{aligned}
$$

onde, $w_{x}=w \cos (\theta), w_{y}=w \operatorname{sen}(\theta), x=\rho \cos (\phi)$ e $y=\rho \operatorname{sen}(\phi)$ 


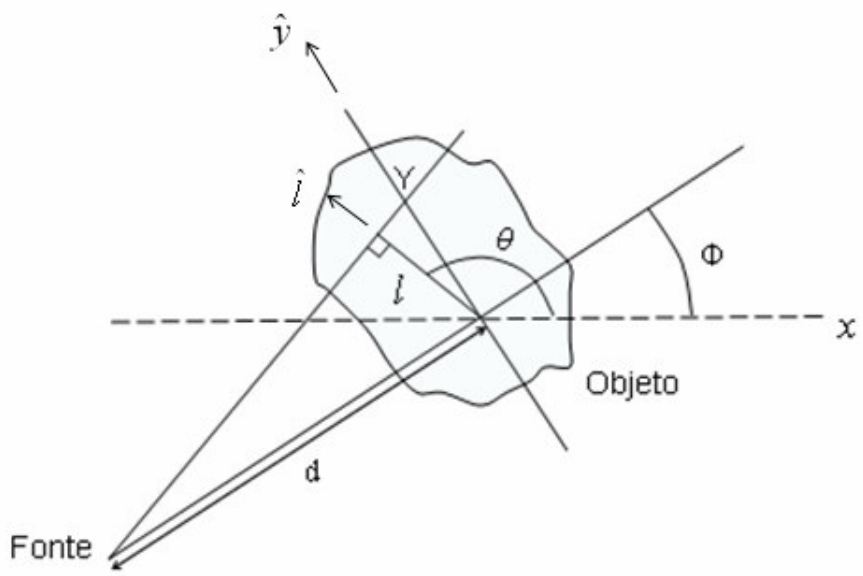

Figura 11 - Parâmetros da geometria de feixe em leque (fan-beam).

Portanto, pode-se escrever

$$
\square f(\vec{\rho})=\operatorname{Re}\left\{\left.\oint d \theta \int_{0}^{\infty} w d w q(w, \theta) e^{i 2 \pi w l}\right|_{l=\vec{\rho} \cdot \hat{l}}\right\}
$$

Substituindo (18) em (19), fica

$$
\square f(\vec{\rho})=\oint d \theta \operatorname{Re}\left\{\int_{0}^{\infty} d w w \int_{-\infty}^{\infty} d l p(l, \theta) e^{i 2 \pi w[\cdot \hat{\rho} \cdot \hat{l}-l]}\right\}
$$

Na equação (20) é definida uma fórmula para se obter a função $f(\vec{\rho})$ a partir de suas projeções $p(l, \theta)$. Porém, nota-se que os parâmetros $l$ e $\theta$ são dependentes do ângulo $\Phi$ e do ângulo de abertura de cada trajetória dos fótons que compõem o feixe, o que torna mais complicada a implementação prática desse algoritmo. Porém, como será apresentado no item 3.2, é possível, a partir de uma transformação de coordenadas, reescrever a equação (20) em função dos parâmetros $\Phi$ e $Y$.

\subsubsection{Feixe Cônico (Cone-Beam)}

Utilizando uma matriz de detectores, é possível reconstruir vários cortes de um objeto em uma única varredura. Nesta configuração passa-se a considerar a geometria cônica do feixe de raios $\mathrm{X}$, de modo que a radiação atenuada pelo objeto a ser 
reconstruído atinja todo o detector. A dedução da fórmula de reconstrução para a geometria de feixe cônico é bem semelhante àquela para a geometria de feixe em leque. Pode-se mostrar que para algumas trajetórias da fonte, que respeitem as condições de Tuy $^{39}$, é possível realizar a reconstrução analítica exata das imagens.

Como pode ser visto na Figura 12, escrevendo o vetor unitário $\hat{l}$, em coordenadas esféricas, e o vetor posição $\vec{r}$, em coordenadas cilíndricas, ambos na base $\{\hat{x}, \hat{y}, \hat{z}\}$, obtêm-se $\quad \hat{l}=(\operatorname{sen} \eta \cos \theta, \operatorname{sen} \eta \operatorname{sen} \theta, \cos \eta) \quad$ e $\quad \vec{r}=(\rho \cos \phi, \rho \operatorname{sen} \phi, z)$. De maneira totalmente análoga ao que foi feito para a geometria fan-beam, pode-se deduzir uma fórmula de reconstrução para a geometria cônica do feixe.

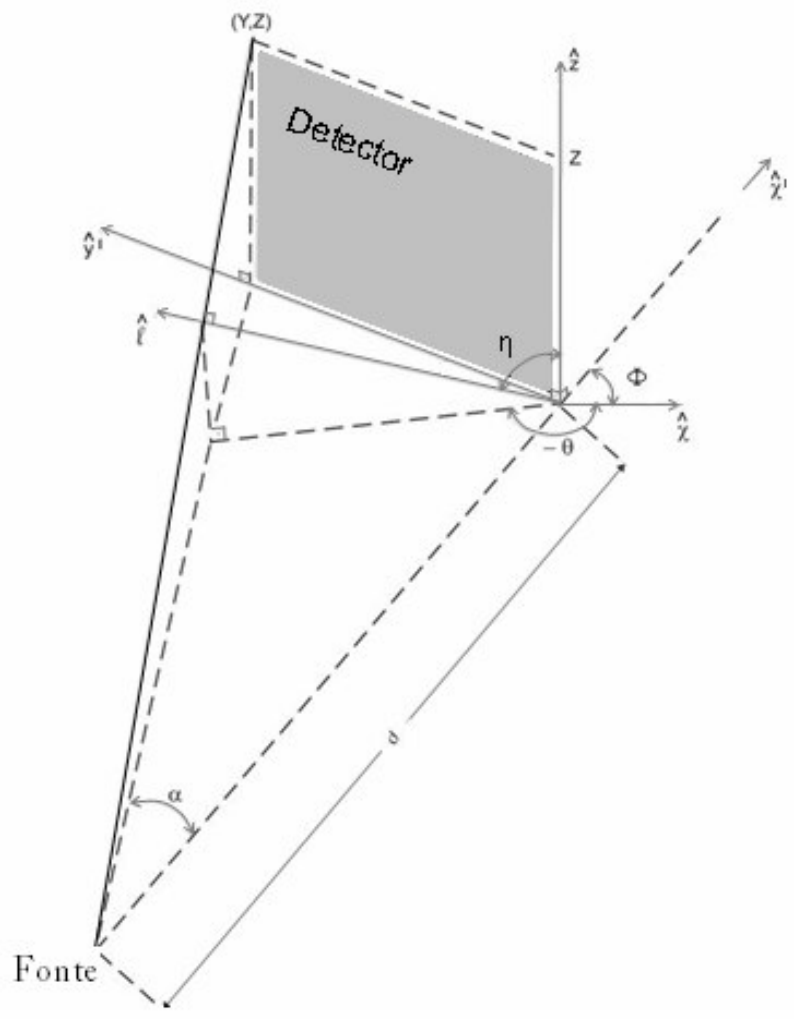

Figura 12- Parâmetros da geometria de feixe cônico (cone-beam).

Define-se

$\square p(l, \theta, \eta)=\iiint d^{3} \vec{r} f(\vec{r}) \delta(\vec{r} \cdot \hat{l}-l)$

e seja 
$\square(w, \theta, \eta)=\int_{-\infty}^{\infty} d l p(l, \theta, \eta) e^{-i 2 \pi w l}=\iiint d^{3} \vec{r} f(\vec{r}) e^{-i 2 \pi w[\rho \operatorname{sen} \eta(\cos \theta \cos \phi+\operatorname{sen} \theta \operatorname{sen} \phi)+z \cos \eta]}=F(\vec{w})$

onde $\vec{w}=(w \operatorname{sen} \eta \cos \theta, w \operatorname{sen} \eta \operatorname{sen} \theta, w \cos \eta)$. Logo, o valor do coeficiente de atenuação linear em qualquer objeto pode ser representado por:

$\square f(\vec{r})=\operatorname{Re}\left\{\iiint d^{3} w F(\vec{w}) e^{i 2 \pi(\vec{w} \cdot \vec{r})}\right\}=\operatorname{Re}\left\{\int_{0}^{\infty} w^{2} d w \int_{0}^{\pi} \operatorname{sen} \eta d \eta \oint d \theta \int_{-\infty}^{\infty} d l p(l, \theta, \eta) e^{i 2 \pi(\vec{w} \cdot \vec{r}-w l)}\right\}$

O algoritmo definido pela equação (23) apresenta diferenças significativas com relação àqueles definidos anteriormente pelas equações (16) e (20). A integração na variável $\eta$ definida na Figura 12, impõe exigências sobre a trajetória do sistema fontedetector, que não são satisfeitas, em particular, pela trajetória circular ${ }^{39}$. Há, porém, algoritmos aproximados para a reconstrução volumétrica, onde se considera uma trajetória circular para o sistema fonte-detector, como por exemplo, o algoritmo $\mathrm{FDK}^{25}$, que apresenta bons resultados para pequenas aberturas de feixe.

\subsection{O Algoritmo FDK}

O algoritmo FDK $^{25}$ (Feldkamp-Davis-Kress) é um algoritmo analítico aproximado de reconstrução para feixe cônico, que se consagra como a base dos algoritmos mais utilizados atualmente ${ }^{1}$. A formulação que se segue é válida apenas para uma trajetória circular da fonte de raios X. Existem, porém, generalizações desse algoritmo para trajetórias não planares, como as utilizadas na tomografia helicoidal.

Para descrever adequadamente o algoritmo FDK, é interessante reescrever a equação (20) nas coordenadas $\{\Phi, Y\}$, definidas na Figura 11. Pode-se ver que

$$
\square l=\frac{d . Y}{\left(Y^{2}+d^{2}\right)^{\frac{1}{2}}}, \theta=\Phi+\alpha+\frac{\pi}{2} \Rightarrow d l d \theta=\left|\begin{array}{ll}
\frac{\partial l}{\partial y} & \frac{\partial l}{\partial \Phi} \\
\frac{\partial \theta}{\partial y} & \frac{\partial \theta}{\partial \Phi}
\end{array}\right| d Y d \Phi=\frac{d^{3}}{\left(d^{2}+Y^{2}\right)^{\frac{3}{2}}} d Y d \Phi
$$

Portanto, 
$\square f(\vec{r})=\oint d \Phi \operatorname{Re}\left\{\int_{0}^{\infty} d w w \int_{-\infty}^{\infty} d Y P_{\Phi}(Y) \frac{d^{3}}{\left(d^{2}+Y^{2}\right)^{\frac{3}{2}}} e^{i 2 \pi w\left[r \cos \left(\Phi+\alpha+\frac{\pi}{2}-\phi\right)-\frac{Y d}{\left(d^{2}+Y^{2}\right)^{\frac{1}{2}}}\right]}\right\}$

Fazendo a mudança de variáveis $W=\frac{[d+r \cos (\phi-\Phi)]}{1} w$, que no fundo é um $\left(d^{2}+Y^{2}\right)^{\frac{1}{2}}$

reescalonamento da freqüência espacial $w$, obtêm-se

$\square f(\vec{r})=\oint d \Phi \frac{d^{2}}{[d+r \cos (\phi-\Phi)]^{2}} \operatorname{Re}\left\{\int_{0}^{\infty} W d W \int_{-\infty}^{\infty} d Y \frac{d}{\left(d^{2}+Y^{2}\right)^{\frac{1}{2}}} P_{\Phi}(Y) e^{i 2 \pi W\left[\frac{d \cdot r \operatorname{sen}(\phi-\Phi)}{d+r \cos (\phi-\Phi)}-Y\right]}\right\}$

Note que $Y(\vec{r})=\frac{d . r \operatorname{sen}(\phi-\Phi)}{d+r \cos (\phi-\Phi)}$ é a posição onde o feixe que passa por $\vec{r}$ corta o eixo Y. Finalmente se obtém,

$\square f(\vec{r})=\oint d \Phi \frac{d^{2}}{\left[d+\vec{r} \cdot \hat{x}^{\prime}\right]^{2}} \operatorname{Re}\left\{\int_{0}^{\infty} W d W \int_{-\infty}^{\infty} d Y \frac{d}{\left(d^{2}+Y^{2}\right)^{\frac{1}{2}}} P_{\Phi}(Y) e^{i 2 \pi W[Y(\vec{r})-Y]}\right\}$

A idéia básica do algoritmo FDK é aproximar a contribuição de um incremento de rotação, $\delta \Phi^{\prime}$, da fonte no plano que contém os vetores unitários $\hat{m}$ e $\hat{n}$ por um incremento associado de rotação, $\delta \Phi$, da fonte no plano xy (Figura 13).

A partir da equação (27), é possível determinar a contribuição incremental $\delta f$ devido a uma rotação, $\delta \Phi^{\prime}$, no plano inclinado, que vem dada por

$$
\square \delta f\left(\vec{\rho}^{\prime}+Z \hat{z}\right)=\delta \Phi^{\prime} \frac{d^{\prime 2}}{\left(d^{\prime}+\vec{p}^{\prime} \cdot \hat{m}\right)^{2}} \operatorname{Re}\left\{\int_{0}^{\infty} W d W \int_{-\infty}^{\infty} d Y \frac{d^{\prime}}{\left(d^{\prime 2}+Y^{2}\right)^{\frac{1}{2}}} P_{\Phi}(Y, Z) e^{i 2 \pi W\left(\frac{d^{\prime} \hat{\rho}^{\prime} \cdot \hat{n}}{d^{\prime}+\vec{\rho}^{\prime} \cdot \hat{m}}-Y\right)}\right\}
$$

Mas note que $\quad \vec{\rho}^{\prime} \cdot \hat{m}=\vec{r} \cdot \hat{x}^{\prime} \frac{d^{\prime}}{d}, \quad \vec{\rho}^{\prime} \cdot \hat{n}=\vec{r} \cdot \hat{n}, \quad d^{\prime}=\left(d^{2}+Z^{2}\right)^{\frac{1}{2}}, \quad Z(\vec{r})=\frac{z \cdot d}{d+\vec{r} \cdot \hat{x}^{\prime}}$, $Y(\vec{r}) \equiv Y_{r}=\frac{d \vec{r} \cdot \hat{n}}{d+\vec{r} \cdot \hat{x}^{\prime}}$ e que, em primeira ordem

$$
\delta \hat{m}=\hat{k} \times \hat{m} \delta \Phi^{\prime}=\hat{z} \times \hat{m} \delta \Phi \Rightarrow \delta \Phi^{\prime}=\frac{d}{\left(d^{2}+Z^{2}\right)^{\frac{1}{2}}} \delta \Phi
$$




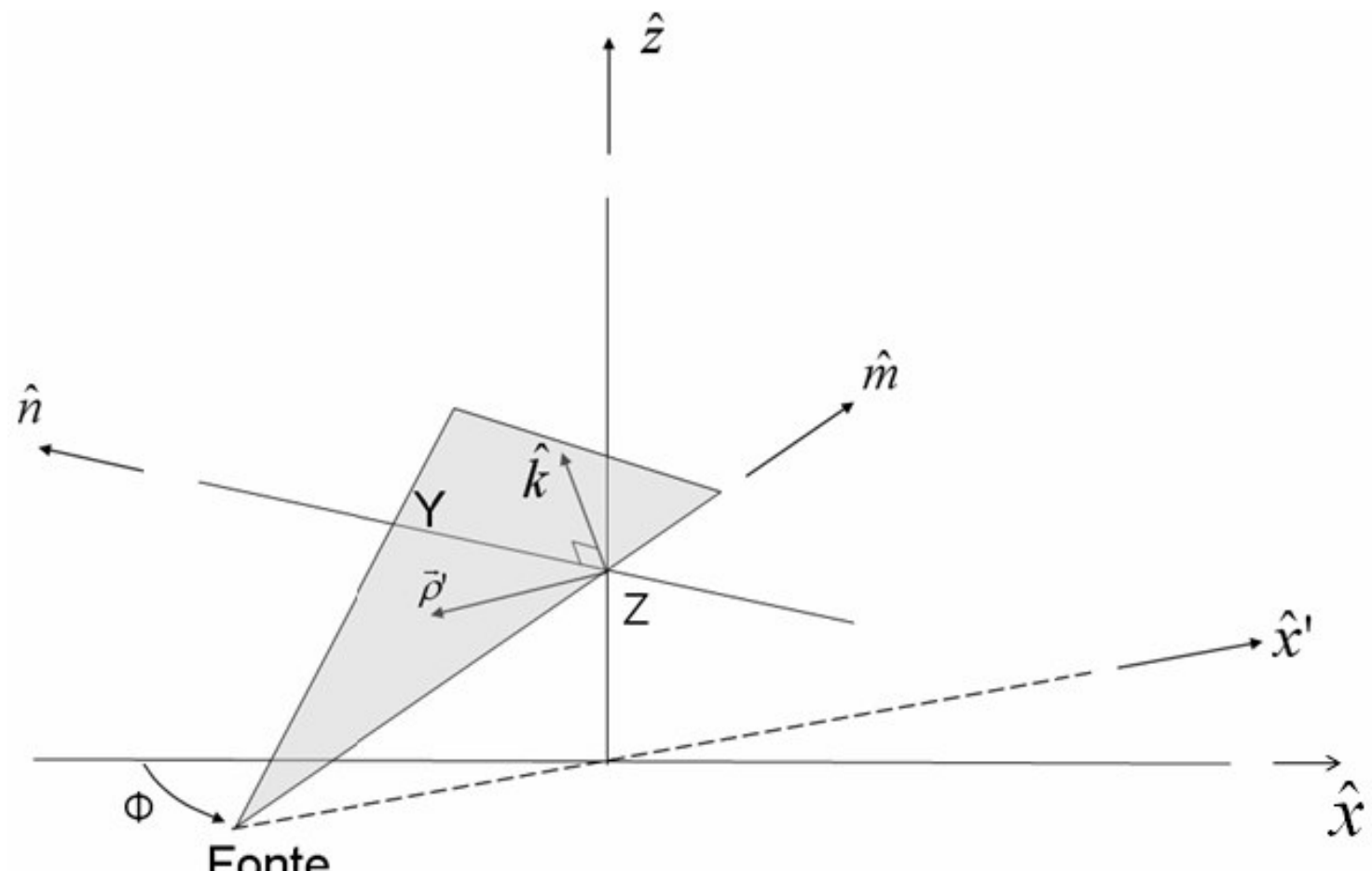

Fonte

Figura 13 - Sistema de coordenadas para projeções acima do plano central $(x y)$.

$\hat{k}=\hat{m} \times \hat{n}, \vec{\rho}^{\prime}$ é linearmente dependente de $\hat{m}$ e $\hat{n}$, e $\hat{n}$ está contido no plano $x y$.

Substituindo esses dados na equação (28), é obtida a seguinte equação para $\delta f$ :

$$
\delta f(\vec{r})=\delta \Phi \frac{d^{2}}{\left(d+\vec{r} \cdot \hat{x}^{\prime}\right)^{2}} \int_{0}^{\infty} W d W \int_{-\infty}^{\infty} d Y \frac{d}{\left(d^{2}+Y^{2}+Z^{2}\right)^{\frac{1}{2}}} P_{\Phi}(Y, Z) e^{i 2 \pi W(Y(\vec{r})-Y)}
$$

Agora, para encontrar $f(\vec{r})$, simplesmente somam-se os incrementos $\delta f(\vec{r})$ sobre todas as projeções. Portanto,

$$
\square f(\vec{r})=\oint d \Phi \frac{d^{2}}{\left(d+\vec{r} \cdot \hat{x}^{\prime}\right)^{2}} \int_{0}^{\infty} W d W \int_{-\infty}^{\infty} d Y \frac{d}{\left(d^{2}+Y^{2}+Z^{2}\right)^{\frac{1}{2}}} P_{\Phi}(Y, Z) e^{i 2 \pi W\left(Y_{r}-Y\right)}
$$

A equação (31) pode ser escrita na forma simplificada

$$
\square f(\vec{r})=\oint d \Phi \frac{d^{2}}{\left(d+\vec{r} \cdot \hat{x}^{\prime}\right)^{2}} \widetilde{P}_{\Phi}(Y(r), Z(r))
$$

onde, 


$$
\begin{aligned}
& \square \widetilde{P}_{\Phi}(Y, Z)=\int_{-\frac{N}{2} \Delta Y}^{\frac{N}{2} \Delta Y} g_{y}\left(Y-Y^{\prime}\right) P_{\Phi}\left(Y^{\prime}, Z^{\prime}\right) \frac{d}{\left(d^{2}+Y^{\prime 2}+Z^{\prime 2}\right)^{\frac{1}{2}}} d Y^{\prime} \\
& \square g_{y}(Y)=\operatorname{Re} \int_{0}^{w_{y 0}} d W W e^{i 2 \pi W Y} \\
& \square W_{y 0}=\frac{\pi}{\Delta Y}
\end{aligned}
$$

Note que o tamanho finito do detector limita os valores da freqüência em $W=\frac{\pi}{\Delta Y}$, onde $\Delta Y=Y_{i}-Y_{i-1}$ é a dimensão de cada elemento do detector, e $N$ é o número de elementos do detector.

Analisando-se as equações (32) e (33), fica claro que o algoritmo FDK é do tipo FBP, onde $\tilde{P}_{\Phi}(Y(\vec{r}), Z(\vec{r}))$ é a projeção $P_{\Phi}(Y(\vec{r}), Z(\vec{r}))$ filtrada (equação (33)), e a integral em $\Phi$ (equação (32)) representa a retro-projeção de todas projeções filtradas.

Na prática, $P_{\Phi}(Y, Z)$ é amostrado para um conjunto finito de valores discretos de $\Phi, Y$ e $Z$. Para efetuar a discretização da equação (31), considera-se que $P_{\Phi}(Y, Z)$ varia bem mais lentamente que $g_{y}(Y)$, de modo que possa ser considerado constante em cada intervalo $\Delta Y$. Sendo assim,

$$
\square \widetilde{P}_{\Phi_{i}}\left(Y_{j}, Z_{k}\right)=\sum_{j^{\prime}} P_{\Phi_{i}}\left(Y_{j^{\prime}}, Z_{k}\right) \cos \varphi_{j^{\prime}, k} \int_{Y_{j^{\prime}}-\frac{\Delta Y}{2}}^{Y_{j^{\prime}}+\frac{\Delta Y}{2}} d Y g_{y}\left(Y_{j}-Y\right)
$$

onde $\cos \varphi_{j^{\prime}, k}=\frac{d}{\left(d^{2}+Y_{j^{\prime}}{ }^{2}+Z_{k}^{2}\right)^{\frac{1}{2}}}$.

A fórmula final de reconstrução é dada por

$$
f(\vec{r})=\sum_{i} \Delta \Phi \frac{d^{2}}{\left(d+\vec{r} \cdot \hat{x}^{\prime}\right)^{2}} \widetilde{P}_{\Phi_{i}}\left(Y_{r}, Z_{k}\right)
$$

Os valores de $\widetilde{P}_{\Phi_{i}}\left(Y_{r}, Z_{k}\right)$ são calculados por interpolação linear entre os elementos da matriz $\widetilde{P}_{\Phi_{i}}\left(Y_{j}, Z_{k}\right)$. 


\section{CAPÍTULO 4 - Os Principais Componentes de um Equipamento de TC}

Os componentes básicos de um tomógrafo são: um computador de controle operacional, um conjunto emissor de raios $X$, um detector de raios $X$, um sistema de aquisição de dados, um hardware específico para o pré-processamento (condicionamento dos dados e calibração), pela reconstrução das imagens e pelo pós-processamento (correção de artefatos, aplicação de filtros de imagem, etc.), um dispositivo de armazenamento de dados e um dispositivo para a visualização das imagens. O funcionamento do equipamento começa no computador de controle operacional, que envia os comandos a serem executados pelo conjunto emissor de raios $\mathrm{X}$, pelo sistema de detecção e pelo sistema gerador de imagens, controlando toda a mecânica do sistema. Uma vez iniciado o processo, o tubo de raios $X$ produz um fluxo de radiação $X$, cujos fótons são detectados pelo detector de raios X, o qual produz sinais elétricos. Ao mesmo tempo, o sistema de aquisição de dados organiza a amostragem desses sinais elétricos e os transforma em sinais digitais. Esse conjunto de dados amostrados, ou raw data, são enviados ao sistema gerador de imagens para serem processados. Geralmente, o sistema possui computadores de alto desempenho e chips de processamento de sinais digitais (PSD). As imagens produzidas são então enviadas para os dispositivos de visualização e armazenamento.

Todos os comandos do operador são importantes para garantir a qualidade dos exames. É necessário que o operador selecione sempre os parâmetros técnicos mais convenientes a cada tipo de exame. Nos equipamentos comerciais, estes parâmetros vêm pré-programados na forma de protocolos operacionais.

\subsection{O Tubo de Raios X e o Gerador de Alta Tensão}

O tubo de raios $\mathrm{X}$ é um dos componentes mais importantes em um sistema de TC. No início da TC, eram usados tubos de raios $\mathrm{X}$ pulsados. Nestes tubos, os raios $\mathrm{X}$ eram produzidos em pulsos de curta duração, que variavam de 1 a 4 ms. O intervalo entre cada 
pulso variava de 12 a 15 ms. Isso se devia, principalmente, à incapacidade dos detectores de fazerem medições enquanto os sinais que produziam eram amostrados ${ }^{31}$.

Com os avanços na eletrônica, na tecnologia dos tubos de raios $\mathrm{X}$ e dos detectores, os equipamentos de TC passaram a fazer varreduras cada vez mais rápidas, diminuindo o tempo dos exames. Nos tomógrafos atuais de alta velocidade, é necessário que os tubos estejam continuamente produzindo raios $\mathrm{X}$ para que haja fluência suficiente de fótons.

Os componentes básicos de um tubo de raios $\mathrm{X}$ consistem em um catodo e um anodo. $\mathrm{O}$ catodo fornece elétrons, enquanto o anodo se comporta como alvo para esses elétrons que são acelerados por uma diferença de potencial. Como discutido no capítulo 2, fótons de raios $\mathrm{X}$ são produzidos pelo bombardeamento de elétrons de alta velocidade em um alvo. A intensidade dos raios $\mathrm{X}$ produzidos é proporcional ao número atômico do material bombardeado e ao número de elétrons que bombardeiam o alvo. Por outro lado, a energia dos fótons de radiação X gerados depende da diferença de potencial (ddp) entre o catodo e o anodo.

O catodo e o anodo são acomodados no interior de um tubo de vidro vedado que sustenta um vácuo da ordem de $10^{-7}$ torr. Nos tubos de raios $\mathrm{X}$ mais avançados, o vidro é substituído por metal (Figura 14), que apresenta algumas vantagens, como por exemplo, coletar os elétrons retro-espalhados do alvo, entre outras.

$\mathrm{O}$ processo de produção de raios $\mathrm{X}$ por bombardeamento de elétrons tem baixa eficiência. Somente menos de $1 \%$ da energia usada para acelerar os elétrons é convertida em fótons de radiação X. Os $99 \%$ restantes se transformam em calor, e os pontos de impacto do anodo podem atingir temperaturas de até $2700^{\circ} \mathrm{C}$. Essa é uma das razões pelas quais, geralmente, utiliza-se o tungstênio como material do alvo, que possui ponto de fusão de aproximadamente $3300^{\circ} \mathrm{C}$. Para evitar o derretimento do alvo, o anodo é girado a mais de $8000 \mathrm{rpm}$, de modo que o calor dissipado se distribua sobre uma área bem maior do que seria se ele estivesse fixo (Figura 15). 


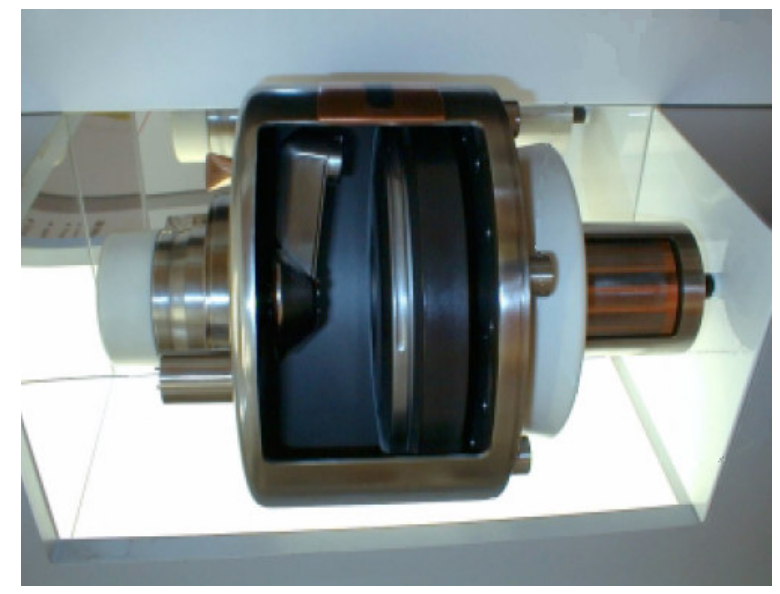

Figura 14 - Fotografia de um tubo metálico cortado para que se possa ver o anodo e o catodo ${ }^{40}$.

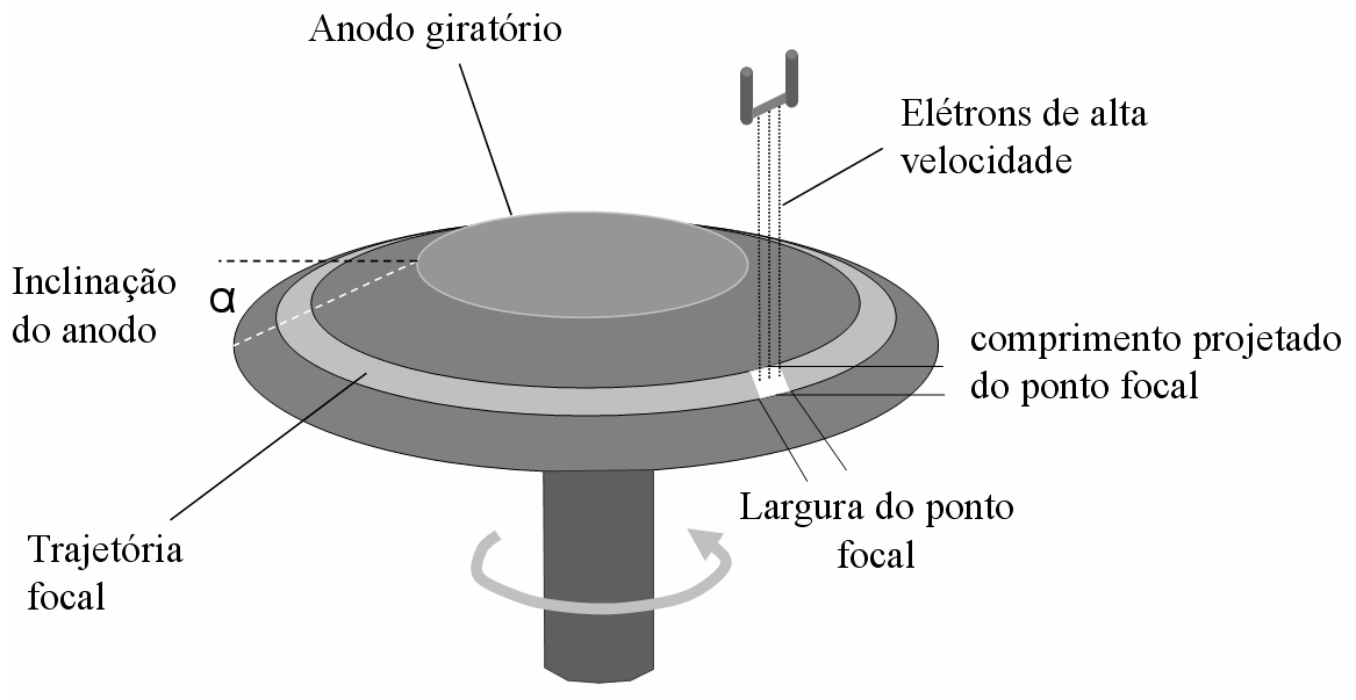

Figura 15 - Ilustração do anodo de tubos de raios $\mathrm{X}$ utilizados em equipamentos de $\mathrm{TC}^{31}$.

A inclinação do plano de impacto do anodo permite aumentar a área física do alvo, mantendo-se a pequena área projetada do ponto focal, ajudando a distribuir mais o calor sobre a superfície de impacto. A área projetada do ponto focal, A', relaciona-se à sua área física, A, pela seguinte equação:

$$
A^{\prime}=A \operatorname{sen} \alpha
$$

Apesar de aumentar a área de exposição, esta inclinação no plano de impacto do anodo traz alguns problemas menores. Um deles é o fato de que o tamanho e a forma do 
ponto focal projetado se tornam dependentes da posição a partir da qual ele é observado. Esse fato contribui para a variação da resolução espacial em TC. Outro problema é o efeito anódico, que descreve o fenômeno de que a intensidade dos raios X não é constante na direção do eixo de rotação do anodo. Ele pode ser explicado pelo fato dos fótons de radiação X serem emitidos a uma certa profundidade da superfície do alvo. Devido à inclinação dessa superfície, o comprimento do trajeto que os fótons têm que atravessar no alvo varia muito. $\mathrm{O}$ material do alvo age como um filtro para o feixe produzido, causando a redução da intensidade dos fótons.

Com a introdução da TC espiral e varreduras mais rápidas, a capacidade térmica dos tubos passou a ser, em muitos casos, insuficiente. Para resolver esse problema, novos tubos, com alvos que combinam tungstênio com grafite de alta pureza, passaram a ser produzidos.

Há outros parâmetros importantes no desempenho dos tubos de raios X. Um bom exemplo é a dimensão do ponto focal, que tem grande impacto na resolução espacial das imagens reconstruídas, assim como na espessura dos cortes. Outro parâmetro importante é a corrente máxima permitida do tubo para um dado valor de tensão. Este fator determina o fluxo de raios $\mathrm{X}$ durante um exame. Para exames que utilizam varreduras muito rápidas, este é, muitas vezes, um fator limitante na qualidade das imagens.

Outro componente importante nos sistemas de produção de raios $\mathrm{X}$ é o gerador de alta tensão. Para produzir e manter um fluxo constante e desejável de raios X, a tensão e a corrente do tubo precisam ser mantidas constantes. Variações significativas nesses parâmetros causam dificuldades para calibrar os sistemas de TC, e correções de artefatos, como os de endurecimento de feixe se tornam inviáveis. Nota-se que o espectro de energia do feixe está intimamente ligado com a ddp aplicada entre o anodo e o catodo. Somando este fato à dependência do coeficiente de atenuação linear dos materiais com a energia do feixe, qualquer variação do espectro durante uma varredura gera um conjunto inconsistente de dados, produzindo artefatos nas imagens reconstruídas. 


\subsection{Detector de Raios X e Sistema de Aquisição de Dados}

Assim como os tubos de raios $\mathrm{X}$, os detectores sofreram um grande avanço tecnológico nos últimos 30 anos.

Detectores utilizados nos primeiros equipamentos da terceira geração usavam gás pressurizado (geralmente Xenônio). O princípio de funcionamento de um detector de xenônio é ilustrado na Figura 16.

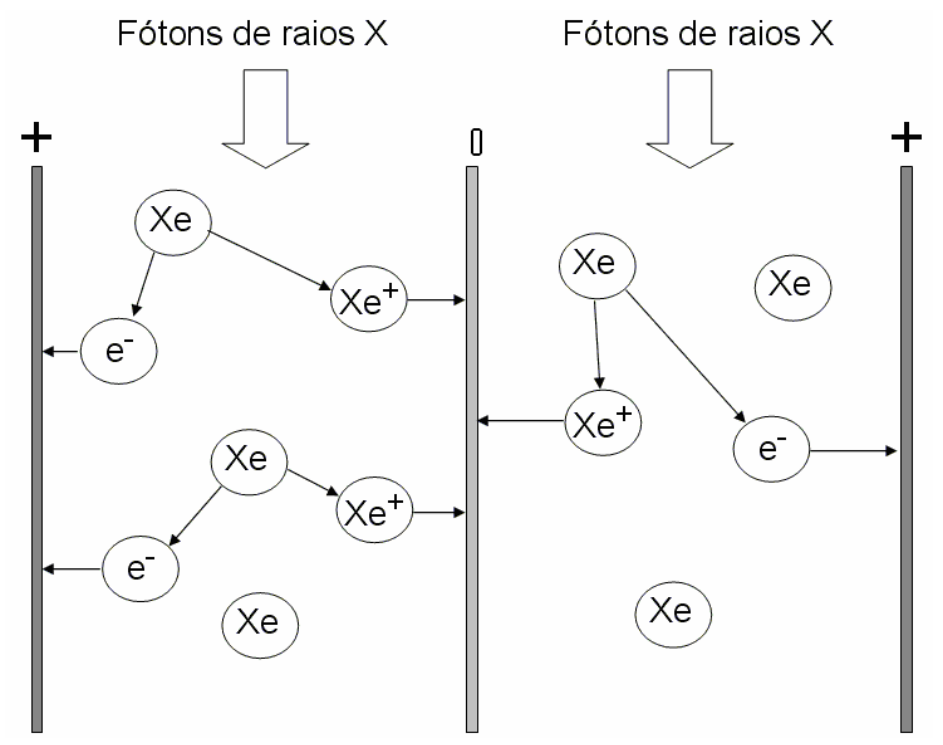

Figura 16 - lonização do gás xenônio com fótons de raios X. Quando um fóton incide em uma célula do detector, suas colisões ionizam o gás. Os núcleos pesados de xenônio são coletados pelas placas de $0 \mathrm{~V}$, e os elétrons livres formados são coletados pelas placas de alta tensão, produzindo sinais de corrente.

Os detectores a gás são construídos com muitas placas finas de tungstênio dentro de uma câmara de xenônio de alta pressão. São aplicadas altas tensões em algumas placas, enquanto as demais flutuam eletricamente ao redor de $0 \mathrm{~V}$. Cada célula do detector é formada por um par de placas, uma de alta e outra de baixa tensão. Quando um fóton incide em uma célula do detector, suas colisões ionizam o gás. Os núcleos pesados de xenônio são coletados pelas placas de $0 \mathrm{~V}$, e os elétrons livres formados são coletados pelas placas de alta tensão, produzindo sinais de corrente. Na configuração correta de tensão, essa corrente produzida é linearmente proporcional à energia dos fótons de raios $\mathrm{X}$ absorvidos em cada célula do detector. 
Com a introdução dos detectores de estado sólido, que nada mais são do que cintiladores acoplados a fotodiodos, os detectores a gás tornaram-se obsoletos e não são mais utilizados em equipamentos de TC. Os detectores de estado sólido superam facilmente alguns dos limites dos detectores de xenônio, como o de se construir detectores bidimensionais. A Figura 17 ilustra, esquematicamente, o seu funcionamento.

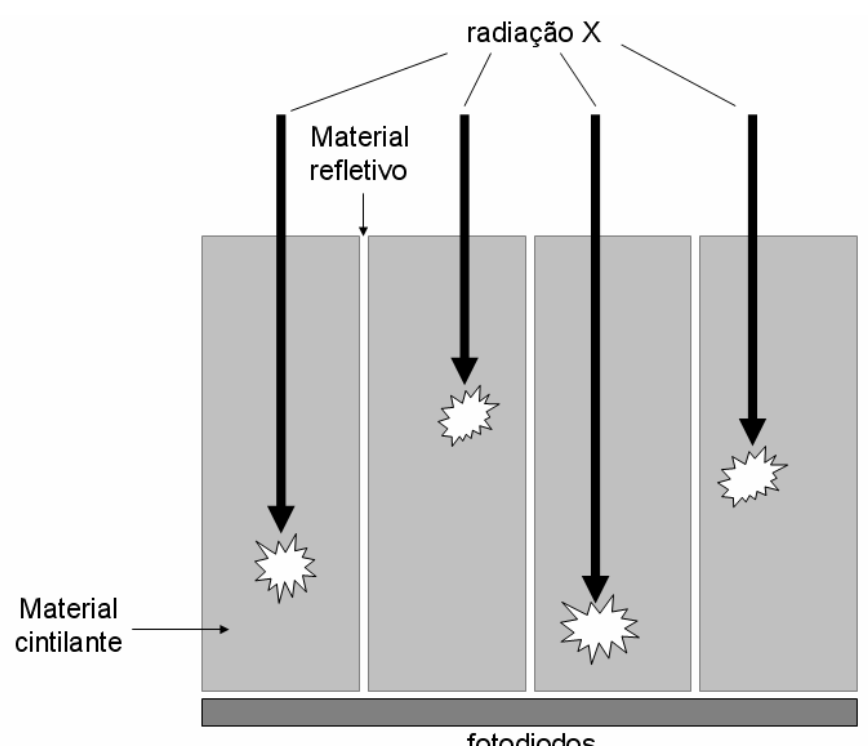

Figura 17 - Diagrama esquemático do funcionamento de um detector de estado sólido. Os fótons de radiação $X$ incidentes sofrem interação fotoelétrica com o material cintilante. $O$ fotoelétron arrancado do átomo viaja pelo material excitando outros átomos. Ao retornarem ao estado fundamental, os átomos emitem radiação característica no espectro visível ou UV, que é detectada pelos fotodiodos.

Um fóton de radiação $\mathrm{X}$ incidente sofre uma interação fotoelétrica com o material cintilante. $\mathrm{O}$ fotoelétron arrancado do átomo viaja pelo material excitando outros átomos. Ao retornarem ao estado fundamental, os átomos emitem radiação característica no espectro visível ou UV. O decaimento da intensidade de radiação característica é exponencial, com uma constante de tempo característica do material cintilante. Devido à presença de impurezas, uma pequena porcentagem dos elétrons permanece em seus estados excitados por um período de tempo maior, o que produz constantes de decaimento maiores, conhecidas como afterglow.

Os fótons de luz visível ou UV são produzidos em todas as direções. Portanto, na tentativa de forçá-los a atingir os fotodiodos, os cintiladores são blindados com materiais altamente reflexíveis. Devido à reflexão e à absorção no material cintilante, apenas uma 
porção dos fótons atinge os fotodiodos. Ainda assim, na prática, detectores de estado sólido são muito mais eficientes que detectores de xenônio.

Há muitos parâmetros que são utilizados para avaliar o desempenho de um detector. A eficiência quântica de detecção (EQD) de um detector é definida pela porcentagem dos fótons de radiação $\mathrm{X}$ incidentes que contribuem para o sinal de saída do detector. A EQD é definida matematicamente pela seguinte expressão:

$$
E Q D=\frac{\int_{0}^{E_{\max }} \Phi(E)\left[1-e^{-\mu(E) \Delta}\right] d E}{\int_{0}^{E_{\max }} \Phi(E) d E}
$$

onde, $\Phi(\mathrm{E})$ é o espectro de raios $\mathrm{X}, \mu(\mathrm{E})$ é o coeficiente de atenuação linear do material do detector e $\Delta$ é a sua espessura. Para detectores típicos de xenônio, a EQD está entre $60 \%$ a 70\%. Há, porém, detectores de estado sólido com EQD da ordem de 99,5\%.

Embora a EQD proporcione uma boa descrição da eficiência do detector em absorver os fótons incidentes, ela não indica a porcentagem dos fótons que viajam na direção do detector e não entram nas suas células. Em tomógrafos da terceira geração, chapas colimadoras são colocadas na frente dos detectores para evitar que a radiação espalhada atinja o detector. Essas chapas têm aproximadamente 0,2 $\mathrm{mm}$, o que corresponde a cerca de $20 \%$ da largura de uma célula do detector. Portanto, para o exemplo dado acima, a eficiência geométrica de detecção (EGD) do detector vale $80 \%$. A multiplicação dos dois fatores, (EQD)x(EGD), descreve a eficiência do detector em converter os raios $\mathrm{X}$ incidentes em sinais de saída.

Existem outros parâmetros importantes usados para descrever o desempenho de um detector. As constantes de decaimento de tempo, por exemplo, são importantes para determinar a influência, a partir de um sinal anterior, em um sinal que está sendo medido. Isso afeta o desempenho do sistema na produção de imagens rápidas de partes do corpo em movimento.

Outro parâmetro importante é o dano causado no detector pela radiação. O ganho de um detector diminui com o seu uso. Se diferentes quantidades de radiação atingem, sistematicamente, diferentes canais do detector, seus ganhos mudarão, produzindo 
artefatos nas imagens reconstruídas. Calibrações e correções algorítmicas são freqüentemente realizadas, visando diminuir esses efeitos.

Outro parâmetro que pode afetar a qualidade das imagens é a estabilidade térmica do detector. Nos detectores de estado sólido, o ganho varia com a temperatura ambiente. Durante um exame, a temperatura no ambiente que envolve o detector geralmente varia. Para combater esse problema, a maioria dos equipamentos de TC possui dispositivos de controle térmico, que mantém a temperatura ambiente praticamente constante.

Há exigências de desempenho similares para o sistema de aquisição de dados (SAD). Note que o sinal medido é a combinação do sinal analógico do detector e do sinal digital obtido do SAD. A saída do SAD deve reproduzir fielmente o sinal analógico produzido pelo detector.

A saída do SAD possui dois componentes que contribuem significativamente para o ruído: o número limitado de fótons de radiação $\mathrm{X}$ coletados durante o intervalo de amostragem e os seus componentes eletrônicos.

\section{Câmaras CCD}

O sensor digital utilizado no presente trabalho é um dispositivo de carga acoplada, conhecido na linguagem eletrônica como CCD. A operação de um sensor CCD ocorre em três etapas ${ }^{41}$ :

a) $\mathrm{O}$ sensor possui um arranjo bidimensional de poços de potencial que são chamados de registros paralelos. Com a interação da luz ou dos raios X com o silício, cargas elétricas são criadas e coletadas em cada poço de potencial. A disposição do sensor CCD pode integrar ou acumular cargas num período de tempo pré-determinado de modo que toda a carga acumulada em um poço de potencial individual é proporcional à radiação incidente.

b) Transferem-se as cargas acumuladas seqüencialmente ao longo dos capacitores para a etapa de leitura de saída. Em um arranjo bidimensional o pacote de cargas é transferido, linha por linha, para registro em série em um arranjo unidimensional 
ao lado do registro paralelo. Depois da chegada de cada linha de cargas o registro em série é lido, produzindo um sinal que é transmitido a um amplificador.

c) Na etapa de leitura, cada pacote de cargas é convertido em um sinal de tensão proporcional. O amplificador produz um sinal eletrônico que representa a sequiência de cargas lidas. Este sinal analógico é convertido para um sinal de vídeo que é subseqüentemente digitalizado. A imagem digital resultante é um arranjo bidimensional de valores de níveis de cinza variando de 0 a 255.

No início do processo é realizada a coleta dos fótons seguindo-se a transmissão das cargas por todos os poços de potencial até que acabem as cargas contidas no interior destes capacitores. 


\section{CAPÍTULO 5 - Artefatos em Imagens de TC}

Independentemente dos parâmetros de qualidade de imagem, como resolução espacial e contraste, que podem ser determinados quantitativamente, deve-se, acima de tudo, avaliar o quanto a imagem reconstruída é fiel ao corte real do objeto reconstruído ${ }^{31}$. O processo de reconstrução de imagens pode produzir estruturas artificiais que não existem no objeto real. A essas estruturas dá-se o nome de artefatos.

Comparado à radiografia convencional, o processo de TC é mais propício a gerar artefatos. Uma imagem de TC é formada a partir de centenas de projeções, cada uma delas com centenas de medidas independentes. Esse fato, somado à natureza do processo de retro-projeção, no qual um único ponto na projeção é mapeado sobre toda uma linha na imagem, faz com que a probabilidade de se produzir artefatos em imagens de TC seja muito maior.

Métodos usados para diminuir artefatos em imagens de TC são desenvolvidos em instituições acadêmicas ou na indústria, e muitos artigos, relatórios de pesquisa e patentes podem ser encontrados. No entanto, uma porção significativa dos métodos para redução de artefatos, é considerada segredo comercial, e não está disponível ao público em geral.

Nem sempre é simples distinguir o que é real e o que foi produzido artificialmente em uma imagem de TC. Há artefatos comuns de caráter técnico, como por exemplo, artefatos de anel (ring artifacts) (Figura 18 (a)), que se devem ao mal funcionamento de alguns canais do detector, ou simplesmente a diferenças de sensibilidade entre esses canais, ou ainda, artefatos induzidos pelo ruído presente nas projeções. Desde que se conheça sua causa, esses artefatos de caráter técnico quase sempre podem ser eliminados com a otimização da técnica utilizada. No entanto, restam artefatos que são causados pela natureza física da TC e que, embora não possam ser completamente eliminados, podem ser controlados se forem bem compreendidos.

Importantes causas de artefatos em imagens clínicas são: aliasing, efeitos de volume parcial, radiação espalhada, presença de ruído nas projeções, problemas técnicos no tubo de raios $\mathrm{X}$ ou no detector, movimento do paciente, endurecimento do feixe, implantes metálicos, e pacientes mal posicionados ou que excedem os limites do campo de medição. 


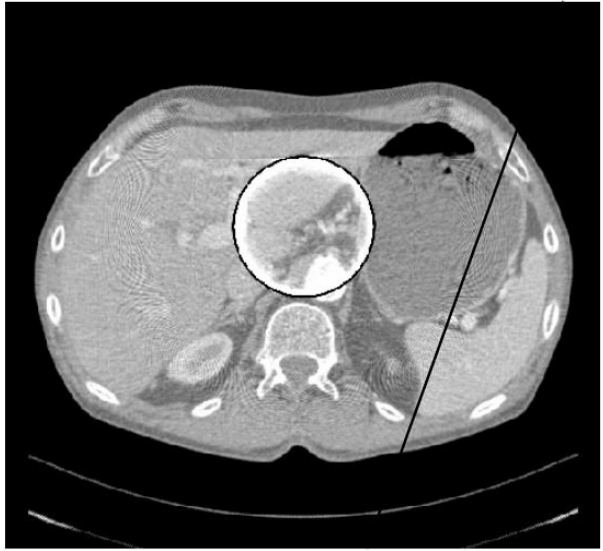

a)

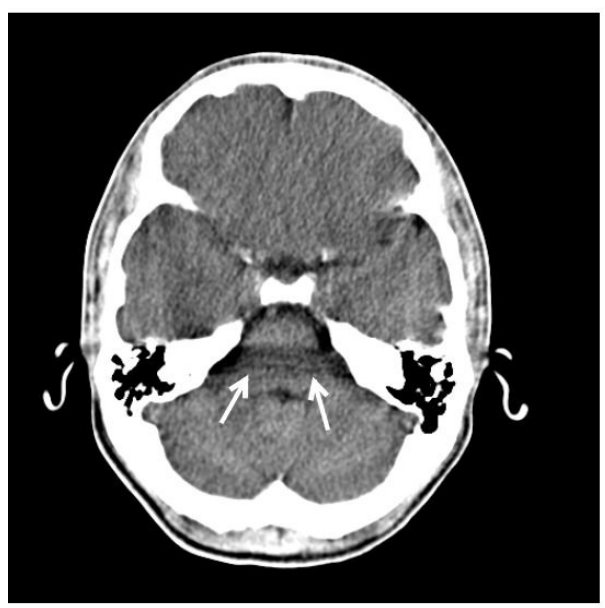

c)

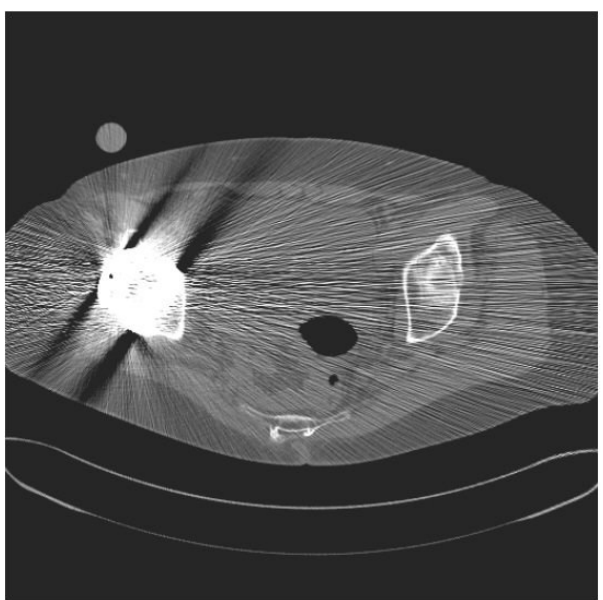

e)

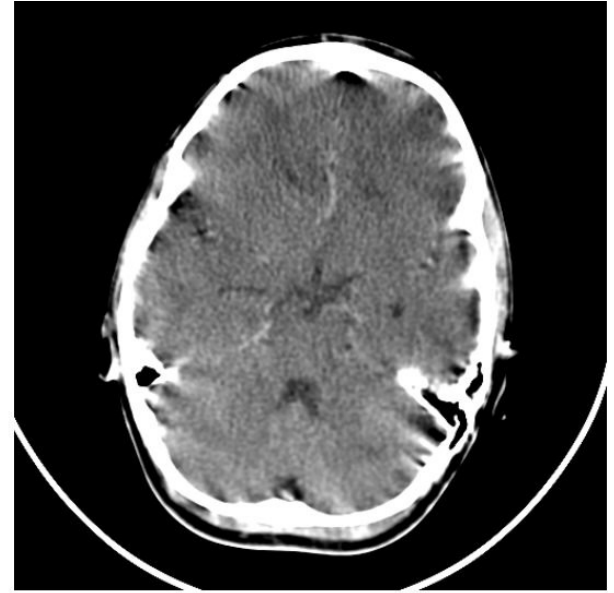

b)

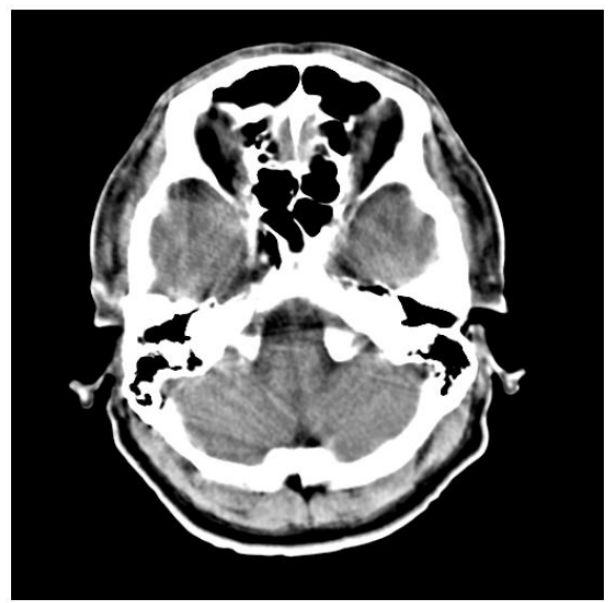

d)

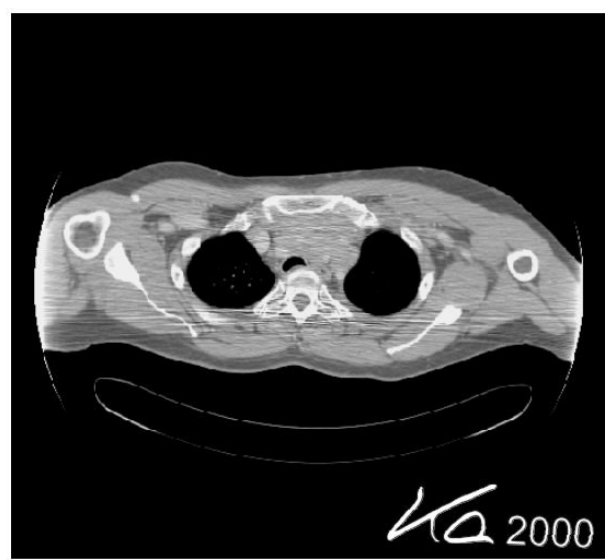

f)

Figura 18 - Exemplos típicos de artefatos em imagens de TC que podem resultar de falhas no detector (a), movimento do paciente (b), endurecimento de feixe (c), efeitos de volume parcial (d), implantes metálicos (e) ou pacientes que excedem o campo de medição (truncamento) (f). ${ }^{1}$ 


\subsection{Artefatos Induzidos pelo Paciente}

No caso de movimento do paciente, o conjunto de projeções coletadas se torna inconsistente, uma vez que as projeções vão caracterizar diferentes distribuições espaciais do coeficiente de atenuação linear para as diversas posições angulares do sistema fontedetector. Neste caso, a imagem fica localmente embaçada e com distorções em toda sua extensão (Figura 18 (b)).

Os artefatos devidos ao endurecimento do feixe podem ser vistos nas imagens como riscos ou zonas escuras entre as estruturas ósseas (Figura 18 (c)). O endurecimento do feixe é conseqüência da dependência do coeficiente de atenuação linear dos materiais com a energia do feixe de raios $\mathrm{X}$. Portanto, o feixe policromático de radiação $\mathrm{X}$ é atenuado de maneiras diferentes dependendo da direção e sentido em que atravessa o objeto a ser reconstruído, o que resulta em um conjunto de dados inconsistentes.

Artefatos de volume parcial ocorrem quando estruturas de atenuação relativamente alta se estendem apenas parcialmente no corte examinado. Como cada elemento do detector inevitavelmente indica a média das intensidades de radiação que o atinge, não há como detectar que a projeção de tal estrutura não esteja distribuída sobre toda espessura do corte (Figura 18 (d)).

Implantes metálicos intensificam os efeitos de endurecimento de feixe e volume parcial devido a sua alta atenuação relativa, e pode extinguir todo o conteúdo da imagem nas vizinhanças do objeto metálico, produzindo artefatos em toda a imagem (Figura 18 (e)). Artefatos devidos a implantes metálicos são amenizados com a utilização de valores mais altos de tensão no tubo de raios $\mathrm{X}$, e diminuindo a espessura dos cortes reconstruídos, mas nunca são completamente eliminados.

Se alguma parte do corpo do paciente ou objetos estão posicionados fora do campo de medição, surgem áreas "hiper-densas" próximas as regiões periféricas excedentes (Figura 18 (f)). 


\subsection{Artefatos Relacionados ao Design do Sistema}

$\mathrm{Na} \mathrm{TC}$, as imagens são reconstruídas a partir do conjunto de projeções coletadas, também chamado de Raw Data. Portanto, para garantir que as imagens reconstruídas apresentem o mínimo posível de artefatos, resolução espacial e contraste necessários, é de grande importância garantir a qualidade do Raw Data e a fidelidade com que representa as projeções reais do objeto. O problema mais típico encontrado nas projeções é o ruído inerente ao processo de medição. Ele é consequiência da radiação espalhada e da densidade não uniforme e variável de fótons do feixe, sem contar com o ruído eletrônico típico presente nos detectores. Essa flutuação nos valores de intensidade registrados em cada elemento do detector, por menor que seja, gera inconsistência no Raw Data, produzindo artefatos na imagem. Esses artefatos são visualizados como linhas retas claras e escuras, espalhadas por toda a imagem.

Outro problema, inerente ao processo de aquisição das projeções, é o de sobreposição espectral ou aliasing, que se deve a sub-amostragem do sinal original da distribuição de intensidades dos raios $\mathrm{X}$ que atravessam o paciente. $\mathrm{O}$ sinal original é discretizado no processo de detecção. Cada linha de elementos do detector envia um conjunto de sinais, que representam uma projeção do paciente. De acordo com a teoria de amostragem (Nyquist-Shannon) ${ }^{42,43}$, para evitar a sobreposição espectral, as projeções devem ser amostradas a uma taxa de, no mínimo, o dobro da frequiência espacial contida no sinal original. Em outras palavras, o intervalo entre as amostras do sinal discretizado deve ser de no máximo a metade da resolução máxima permitida pelo sistema de aquisição de imagens. Em equipamentos de TC da primeira à terceira geração, isso se torna um problema grave, uma vez que o intervalo mínimo de amostragem está limitado ao tamanho dos canais do detector, que definem um limite máximo para a resolução do sistema de aquisição de imagens. Assumindo que a freqüência máxima, $w_{\text {maxx }}$, contida no sinal amostrado seja $1 / d$, onde $d$ é o tamanho do canal do detector, a distância entre o centro de cada canal deve ser menor que $d / 2$ para evitar o aliasing. Esse problema não existe nos tomógrafos da quarta geração, que estão atualmente obsoletos por outras razões. 
Há duas técnicas para solucionar o problema de aliasing nos tomógrafos atuais (de terceira geração): uma conhecida como quarter-quarter offset, que é basicamente o deslocamento do centro do detector em 1/4 da largura, $d$, dos canais do detector (Figura 19), e outra conhecida como focal spot wobble (flutuação do ponto focal), onde o feixe de elétrons do tubo de raios $\mathrm{X}$ é constantemente desviado por um campo eletromagnético de modo a atingir, alternadamente, dois pontos focais do tubo e, dessa maneira, dobrar a amostragem reduzindo o problema de aliasing (Figura 20). A combinação dessas duas técnicas elimina quase que completamente os artefatos de aliasing das imagens de TC.

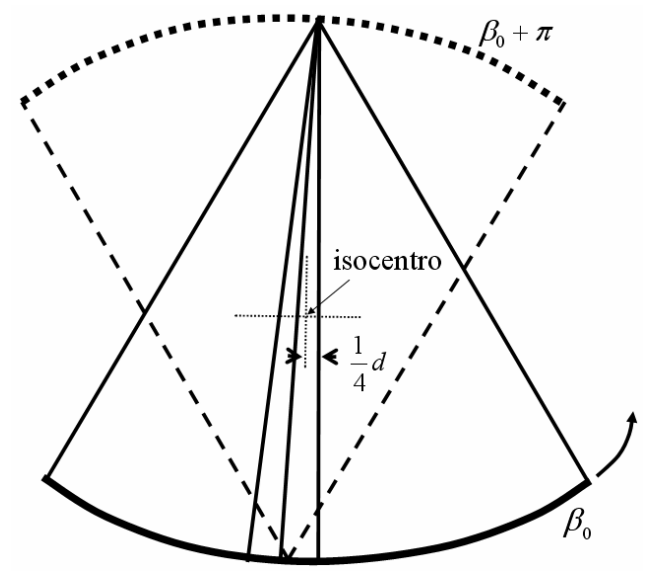

Figura 19 - llustração do quarter-quarter offset. Técnica utilizada para a redução de artefatos de aliasing, na qual se desloca o detector em 1/4 da largura dos canais do detector.
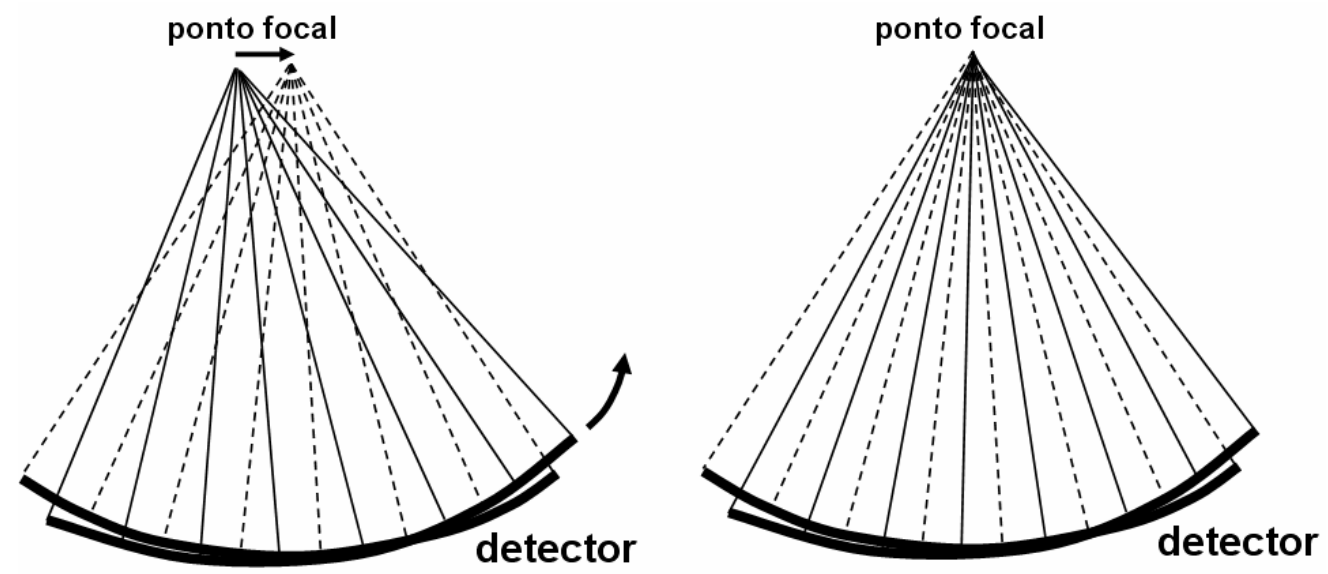

Figura 20 - Conceito de oscilação do ponto focal ${ }^{31}$. Técnica utilizada para reduzir o fenômeno de aliasing presente nos processos de reconstrução de imagens nos tomógrafos atuais (terceira geração), na qual o feixe de elétrons do tubo é constantemente desviado por um campo eletromagnético de modo a atingir, alternadamente, dois pontos focais do tubo e, dessa maneira, dobrar a amostragem reduzindo o problema de aliasing. 


\subsection{Artefatos Relacionados a Problemas com o Tubo de Raios X e com o Detector}

A precisão na determinação da posição do ponto focal do tubo de raios $\mathrm{X}$ é um fator fundamental no processo de reconstrução. Qualquer erro a respeito deste dado produz artefatos nas imagens reconstruídas. $\mathrm{O}$ uso prolongado de um tubo de raios $\mathrm{X}$ causa, eventualmente, o desgaste do seu rotor $^{31}$, e como conseqüência, ocorrem flutuações indesejadas no movimento de rotação do anodo, variando a posição do ponto focal. Outro problema decorrente do uso prolongado dos tubos é a ocorrência de arco voltaico, que se deve a presença de alguma impureza no interior do tubo de raios $\mathrm{X}$, o que causa um curto-circuito temporário. Como conseqüência, a corrente no tubo aumenta bruscamente, enquanto a tensão diminui. Essa variação durante o processo de varredura gera dados inconsistentes, produzindo artefatos nas imagens.

O ruído está sempre presente em qualquer dispositivo eletrônico, e com os detectores de TC não é diferente. Como já foi discutido anteriormente o ruído nas projeções produz artefatos nas imagens reconstruídas.

A eletrônica do sistema de aquisição de dados é inerentemente diferente de canal para canal, conseqüentemente, os ganhos individuais de cada célula do detector não são iguais, podendo variar com o tempo. Como discutido anteriormente, este problema poderá resultar em artefatos de anel.

\subsection{Reconstrução de Imagens Tomográficas a partir de Projeções com Ruído}

Em TC os níveis de restrição de dose ${ }^{44-46}$ limitam a densidade de fótons dos feixes de raios $\mathrm{X}$. Considerando o intervalo de tempo cada vez menor disponível para a aquisição de cada projeção, e os fenômenos de absorção e espalhamento de uma parte considerável dos fótons emitidos, pode-se dizer que o fluxo de fótons de raios $\mathrm{X}$ que atinge o detector é, em muitos casos, relativamente pequeno. Assumindo-se que a variação do fluxo de fótons detectados segue, aproximadamente, uma distribuição de Poisson, pode-se dizer que quanto menor o fluxo de fótons detectado, maior é a variação 
no sinal. Estes fatos caracterizam a densidade limitada de fótons nos feixes de raios $\mathrm{X}$ como uma das fontes predominantes de ruído nas imagens ${ }^{1}$.

A maior parte do ruído ocorre durante o processo de medição das projeções. O seguinte modelo descreve o processo de aquisição das projeções com ruído:

$$
P_{\Phi}(Y, Z)=A\{\mu(\vec{r})\}+n(Y, Z)
$$

onde, $\quad P_{\Phi}(Y, Z)$ é a projeção medida, A\{ \} é o operador de projeção, $\mu(\vec{r})$ é a distribuição espacial do coeficiente de atenuação linear do objeto, e $n(Y, Z)$ representa a contribuição do ruído em cada canal do detector.

O ruído em uma imagem radiográfica digital é bem determinado a partir da razão sinal ruído (SNR - Signal to noise ratio) do detector que, quando bem conhecida, possibilita uma grande redução dos efeitos do ruído nas imagens ${ }^{47}$.

Nos algoritmos de retro-projeção filtrada, a distribuição $\mu(\vec{r})$ é dada por:

$$
\square \mu(\vec{r})=B\left\{h\left(Y_{r}\right) * P_{\Phi}\left(Y_{r}, Z\right)\right\}
$$

onde, $\mathrm{B}\left\{\right.$ \} é o operador de retro-projeção e $\mathrm{h}\left(\mathrm{Y}_{\mathrm{r}}\right)$ é o filtro utilizado no processo de filtração da projeção. Reescrevendo o lado direito da equação (41) no espaço de freqüências, fica

$$
\mu(\vec{r})=B\left\{\mathfrak{I}^{-1}\left[H(w) \cdot Q_{\Phi}(w, Z)\right]\right\}=B\left\{\mathfrak{S}^{-1}|H(w) \cdot| \hat{Q}_{\Phi}(w, Z)+N(w, Z) \|\right\}
$$

onde, $\hat{Q}_{\Phi}(w, Z)$ é a transformada de Fourier da projeção sem ruído, $\hat{P}_{\Phi}(Y, Z)$. Aplicando os resultados da equação (16), pode-se reescrever a equação (31) na forma

$$
\oint d \Phi \frac{d^{2}}{\left(d+\vec{r} \cdot \hat{x}^{\prime}\right)} \int_{0}^{\infty} d w w \int_{-\infty}^{\infty} d Y \bar{P}_{\Phi}(Y, Z) e^{i 2 \pi w\left(Y_{r}-Y\right)}=\oint d \Phi \frac{d^{2}}{\left(d+\vec{r} \cdot \hat{x}^{\prime}\right)} \frac{1}{2} \int_{-\infty}^{\infty} d w|w| \bar{Q}_{\Phi}(Y, Z) e^{i 2 \pi w Y_{r}}
$$

onde, $\bar{P}_{\Phi}(Y, Z)=\frac{d}{\left(d^{2}+Y^{2}+Z^{2}\right)^{\frac{1}{2}}} P_{\Phi}(Y, Z)$ e $\bar{Q}_{\Phi}(w, Z)=\int_{-\infty}^{\infty} d Y \bar{P}_{\Phi}(Y, Z) e^{-i 2 \pi w Y}$. 
Portanto, para projeções sem ruído, o filtro $H(w)$ é facilmente identificado na equação (41) como $H(w)=|w|$, e é chamado de filtro rampa devido a sua forma (Figura $21(\mathrm{a}))$.

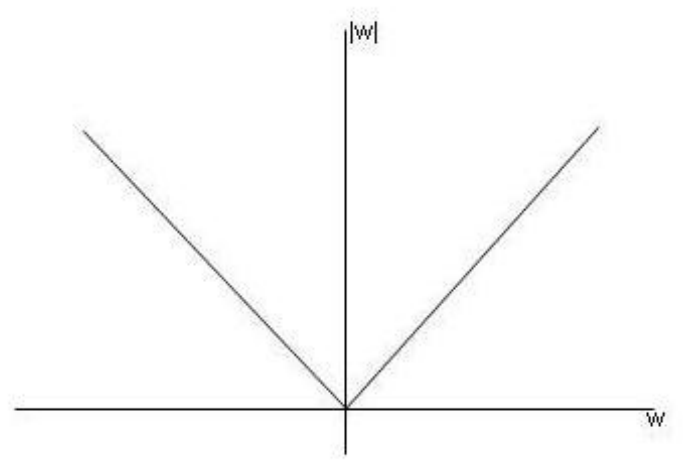

(a)

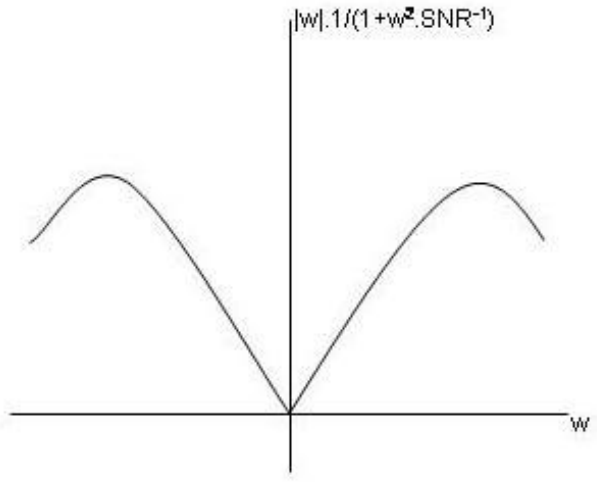

(b)

Figura 21 - Gráfico ilustrativo do filtro rampa (a) e do filtro rampa modificado (b), ambos em coordenadas espaciais.

A equação (43) define um algoritmo de reconstrução equivalente ao algoritmo FDK, porém o processo de filtração ocorre no espaço de frequiências. A Tabela 2 mostra as diferenças entre os algoritmos:

Tabela 2 - Os diferentes processos de filtração no algoritmo FDK; no primeiro, realiza-se a convolução da projeção com a transformada inversa de Fourier do filtro rampa, no segundo, multiplica-se a transformada de Fourier da projeção pelo filtro rampa e realiza-se a transformada inversa do produto.

\begin{tabular}{l|c}
\hline \multicolumn{1}{c|}{ Algoritmo FDK } & Algoritmo FDK modificado \\
\hline \hline Filtração: & Filtração: \\
$\tilde{P}_{\Phi}\left(Y_{r}, Z\right)=\bar{P}_{\Phi}\left(Y_{r}, Z\right) * h\left(Y_{r}\right)=$ & $\tilde{P}_{\Phi}\left(Y_{r}, Z\right)=\mathfrak{I}^{-1}\left[\tilde{Q}_{\Phi}(w, Z)\right]=\mathfrak{I}^{-1}\left[\bar{Q}_{\Phi}(w, Z) H(w, Z)\right]=$ \\
$=\int_{-\infty}^{\infty} \bar{P}_{\Phi}(Y, Z)\left\{\int_{-\infty}^{\infty} \mid \int_{-\infty}^{\infty} \int_{-\infty} \bar{P}_{\Phi}(Y, Z) e^{-i 2 \pi w Y} d Y\right\} e^{i 2 \pi w Y_{r}} d w$
\end{tabular}

No algoritmo FDK modificado, ao invés de se realizar a convolução nas coordenadas espaciais da projeção com a transformada inversa de Fourier do filtro rampa, é efetuada a multiplicação no espaço de freqüências do filtro rampa pela transformada de 
Fourier da projeção, seguida da transformada inversa do produto. Para projeções ideais, isto é, sem ruído, tem-se esquematicamente que:

$$
\square \mu=B\left\{\mathfrak{S}^{-1}\left[Q_{\Phi}(w) \cdot|w|\right]\right\}
$$

Para projeções ruidosas, a equação (44) é modificada e fica da seguinte forma:

$$
\square \tilde{\mu}=B\left\{\mathfrak{S}^{-1}\left[\left(\hat{Q}_{\Phi}(w)+N(w)\right) \cdot H\right]\right\}
$$

$H\left(\hat{Q}_{\Phi}(w)+N(w)\right)$ deve se aproximar o máximo possível de $|w| Q_{\Phi}(w)$, onde, $\hat{Q}_{\Phi}(w)$ é a transformada de Fourier da projeção ideal $\mathrm{P}_{\Phi}(Y)$.

O filtro, $H$, ideal para o modelo descrito pela equação (40) é dado por

$$
H(w)=|w| \frac{1}{1+w^{2} S N R^{-1}}
$$

que é uma modificação do filtro rampa (Figura 21 (b)), na qual para pequenos valores de freqüência, $H(w) \approx|w|$, e para valores mais altos de freqüência, $H(w) \approx \frac{S N R}{|w|}$, onde SNR é a razão sinal ruído média presente nas projeçõess ${ }^{47}$.

Num sistema ideal, com um Raw Data perfeito, o filtro rampa resulta na reconstrução exata do corte central. Num sistema real, com projeções ruidosas, a súbita transição na freqüência de corte $w_{y_{0}}$ gera um padrão oscilatório nas projeções filtradas, resultando em artefatos de anel na imagem reconstruída.

A utilização do algoritmo FDK modificado é muito vantajosa para a reconstrução a partir de projeções ruidosas, quando se deve utilizar o filtro rampa modificado, pois a representação de $\mathrm{H}$ nas coordenadas espaciais é muito complicada, enquanto que no espaço de freqüências é relativamente simples como se pode ver pela equação (46). 


\section{CAPÍTULO 6 - Metodologia}

Pode-se identificar quatro etapas distintas no presente trabalho. A primeira etapa consistiu no estudo e implementação computacional do algoritmo $\mathrm{FDK}^{25}$. A segunda trata da montagem de um sistema físico que simule o processo de aquisição de projeções em um equipamento de TCMC com varredura axial. A interação entre os resultados destas duas etapas constitui o sistema de TCMC implementado no presente trabalho. Na terceira etapa foram estudadas e implementadas correções matemáticas para a redução dos artefatos observados nas imagens reconstruídas. A quarta e última etapa do trabalho consistiu na análise das imagens reconstruídas, com as devidas correções de artefatos, a fim de validar o funcionamento do sistema de TCMC implementado.

\subsection{Implementação do Algoritmo FDK}

Esta etapa do trabalho tem como objetivo principal a implementação do algoritmo FDK para a reconstrução tridimensional com feixe cônico. Esse algoritmo admite uma órbita circular para a trajetória da fonte de raios $\mathrm{X}$ e pode ser estendido para órbitas helicoidais. Essas órbitas não respeitam as condições de Tuy ${ }^{39}$ e, portanto, impossibilitam a reconstrução exata. No entanto, devido à sua simplicidade e aos bons resultados obtidos, este algoritmo é a base de quase todos os algoritmos usados em equipamentos de tomografia computadorizada atualmente ${ }^{1}$.

Num algoritmo de retro-projeção filtrada, como o FDK, as etapas podem ser descritas, para cada posição angular do conjunto fonte-detector, da seguinte maneira:

1. Aquisição da projeção - Nesta etapa é coletada a projeção do objeto a ser reconstruído. Os raios $\mathrm{X}$ emitidos pela fonte são atenuados ao atravessarem o objeto e, em seguida, detectados por um detector digital.

2. Filtração - A projeção adquirida é filtrada, ou seja, é realizada a operação de convolução da projeção com uma "função filtro". 
3. Retro-projeção - Nesta última etapa a projeção já filttrada, resultante da etapa 2, é retro-projetada sobre a matriz da imagem, isto é, o valor da projeção convoluída em cada ponto do detector é superposto sobre todo o trajeto dos raios $\mathrm{X}$ que atingiram este ponto.

As etapas 1, 2 e 3 são repetidas para cada ângulo de projeção. A superposição de todas as retro-projeções filtradas tem como resultado a matriz da imagem final.

A partir da descrição das etapas acima, fica imediato o fato de que, utilizando um algoritmo de retro-projeção filtrada, após a etapa 1, as etapas 2 e 3 podem ser realizadas enquanto o sistema adquire a próxima projeção. Esta é uma grande vantagem desse tipo de algoritmo, pois economiza tempo no processo real da reconstrução tomográfica.

O algoritmo FDK foi implementado num computador com processador Dual Pentium ${ }^{\circledR} \mathrm{XEON}_{\mathrm{TM}}$ 3.0. Primeiramente o algoritmo foi implementado utilizando-se o software MATLAB® (The Mathworks, Inc., Natick, EUA), versão 6.5 DEMO. O algoritmo implementado nessa primeira etapa é descrito pelo Pseudocódigo 1.

Pseudocódigo 1 - Primeira implementação do algoritmo FDK.

LER $d, D, I, J, K, T, N, M$;

$\mu_{n, m, t} \leftarrow 0$

PARA $i \leftarrow 1$ ATÉ $I$, FAZ

LER $P_{\Phi_{i}}$;

PARA $j \leftarrow 1$ ATÉ $J$, FAZ

PARA $k \leftarrow 1$ ATÉ $K$, FAZ

$\bar{P}_{\Phi_{i}}\left(Y_{j}, Z_{k}\right) \leftarrow \frac{d}{\left(d^{2}+Y_{j}^{2}+Z_{k}^{2}\right)^{\frac{1}{2}}} P_{\Phi}\left(Y_{j}, Z_{k}\right) ;$

FIM PARA

FIM PARA

PARA $t \leftarrow 1$ ATÉ $T$, FAZ

PARA $n \leftarrow 1$ ATÉ $N$, FAZ

PARA $m \leftarrow 1$ ATÉ $M$, FAZ

$Y_{r} \leftarrow \frac{D\left(-x_{n} \operatorname{sen}\left(\Phi_{i}\right)+y_{m} \cos \left(\Phi_{i}\right)\right)}{d+x_{n} \cos \left(\Phi_{i}\right)+y_{m} \operatorname{sen}\left(\Phi_{i}\right)} ;$ 


$$
\begin{aligned}
& Z_{r} \leftarrow \frac{D \cdot z_{t}}{d+x_{n} \cos \left(\Phi_{i}\right)+y_{m} \operatorname{sen}\left(\Phi_{i}\right)} \\
& C_{\Phi_{i}}\left(Y_{r}, Z_{r}\right) \leftarrow \sum_{j=1}^{j=J} \bar{P}_{\Phi_{i}}\left(Y_{j}, Z_{r}\right) \int_{Y_{j}-\frac{\Delta Y}{2}}^{Y_{j}+\frac{\Delta Y}{2}}\left\{\int_{0}^{w_{y_{0}}} w \cos \left[2 \pi w\left(Y_{r}-Y\right)\right] d w\right\} d Y ; \\
& \mu_{n, m, t} \leftarrow \mu_{n, m, t}+\frac{D d}{\left(d+x_{n} \cos \left(\Phi_{i}\right)+y_{m} \operatorname{sen}\left(\Phi_{i}\right)\right)^{2}} C_{\Phi_{i}}\left(Y_{r}, Z_{r}\right) \cdot \Delta \Phi ;
\end{aligned}
$$

FIM PARA

FIM PARA

FIM PARA

FIM PARA

PARA $t \leftarrow 1$ ATÉ $T$, FAZ

PARA $n \leftarrow 1$ ATÉ $N$, FAZ

PARA $m \leftarrow 1$ ATÉ $M$, FAZ

$$
n C T_{n, m, t} \leftarrow \frac{\left(\mu_{n, m, t}-\mu_{\text {agua }}\right)}{\mu_{\text {agua }}} 1000 ;
$$

FIM PARA

FIM PARA

FIM PARA

Onde, $I$ é o número total de projeções, $P_{\Phi i}, J$ é o número de colunas do detector, $K$ é o número de linhas do detector, $T$ é o número de cortes a ser reconstruído, NxM determina a resolução de cada corte, $\mu_{n, m, t}$ é a matriz tridimensional que representa a distribuição do coeficiente de atenuação linear do objeto reconstruído, $C_{\Phi_{i}}\left(Y_{r}, Z_{r}\right)$ é a projeção filtrada, $\Delta \Phi$ é o intervalo angular entre cada projeção, $n C T_{n, m, t}$ são os valores de número $\mathrm{CT}$ correspondentes aos valores do coeficiente de atenuação linear $\mu_{n, m, t}$, d é a distância do ponto focal ao isocentro, $(0,0)$, e $D$ é a distância do ponto focal ao detector. Os valores de $P_{\Phi_{i}}\left(Y_{j}, Z_{r}\right)$ foram calculados por meio de interpolação linear entre as linhas, $Z_{k}$, da matriz de imagem da projeção. Para cada valor fixo de $t=\tau, \mu_{n, m, \tau}$ é a matriz com os valores do coeficiente de atenuação linear, calculados com o algoritmo, em todos os pontos $\left(x_{n}, y_{m}\right)$ do corte do objeto na altura $z_{\tau}$. Cada valor de número CT dado por $n C T_{n, m, t}$ determina um nível de cinza na imagem reconstruída, possibilitando identificar as diferentes estruturas que compõem o objeto. 
Para testar o funcionamento do algoritmo, projeções de objetos simples, compostos por estruturas com simetria cilíndrica, foram simuladas computacionalmente. Para tais simulações, foi admitido que a distância entre a fonte e o detector fosse grande o suficiente para assumir que os raios $\mathrm{X}$ chegassem aproximadamente perpendiculares ao detector, ou seja, paralelos entre si. Além disso, foi considerado um modelo físico ideal, onde não há espalhamento da radiação $\mathrm{X}$, a espessura dos feixes é infinitamente pequena, não há efeito de endurecimento do feixe, não há ruído eletrônico e, portanto, não existe ruído nas projeções. A Figura 22 mostra o esquema de simulação das projeções.

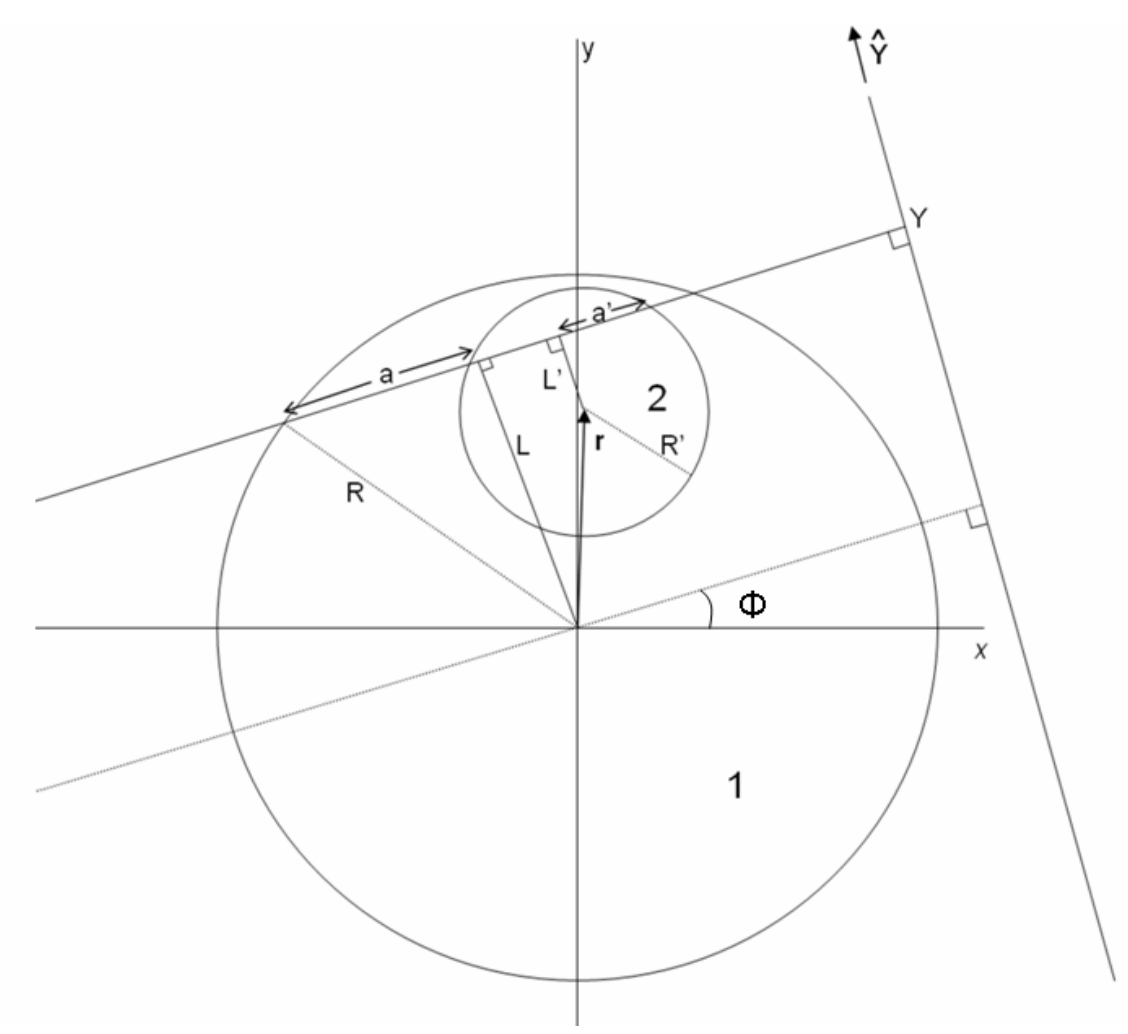

Figura 22 - Esquema geométrico da simulação das projeções com geometria de feixe paralelo.

Supondo os materiais 1 e 2, na Figura 22, com coeficientes de atenuação linear constantes, tem-se que $I=I_{0} e^{-\left[\mu_{1}\left(2 a-2 a^{\prime}\right)+\mu_{2}\left(2 a^{\prime}\right)\right]}$, e portanto basta conhecer os valores de $a$ e $a^{\prime}$ para quaisquer valores de $Y$ e $\Phi$, que é possível construir as projeções simuladas, $P_{\Phi}(Y)=\ln \left(\frac{I_{0}}{I}\right)$, para qualquer posição angular do conjunto fonte-detector. A partir da Figura 22 pode-se ver que 


$$
\begin{gathered}
L=Y \\
\square L^{\prime}=|Y-\mathbf{r} \cdot \hat{\mathbf{Y}}| \\
\square a=\sqrt{R^{2}-L^{2}} \\
\square a^{\prime}=\sqrt{R^{\prime 2}-L^{\prime 2}}
\end{gathered}
$$

O primeiro objeto simulado é composto por dois cilindros concêntricos. Um deles é sólido e fica no centro do objeto, enquanto o outro é oco com casca sólida de espessura finita que envolve o primeiro, de modo que haja um espaço entre o cilindro sólido e a casca cilíndrica. A Figura 23 esquematiza as projeções do primeiro objeto.

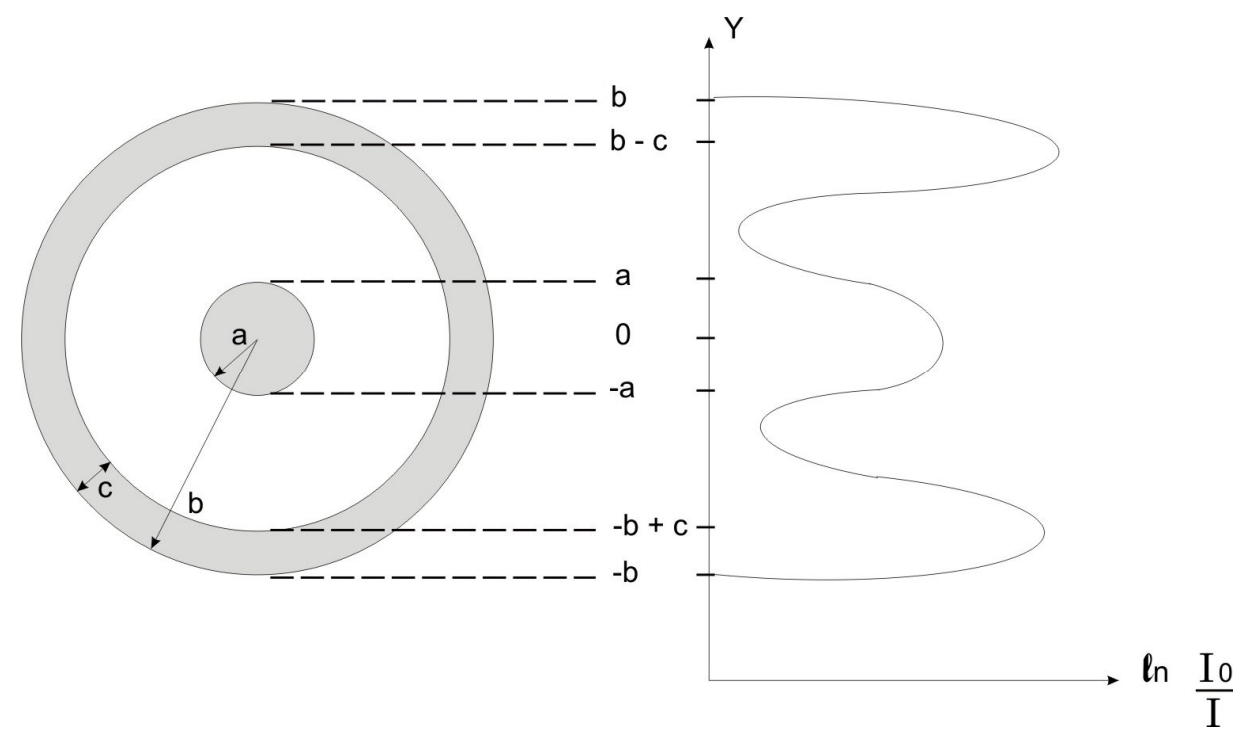

Figura 23 - Esquema da simulação computacional da projeção dos cilindros coaxiais centrados na origem, ambos com coeficiente de atenuação linear constante igual a $\mu$. 0 objeto possui simetria cilíndrica e o eixo principal coincidente com o eixo $z$.

O seguinte modelo matemático representa as projeções do objeto apresentado na Figura 23.

$$
\square(Y)=\left\{\begin{array}{l}
2 \mu\left(\sqrt{a^{2}-Y^{2}}+\sqrt{b^{2}-Y^{2}}-\sqrt{(b-c)^{2}-Y^{2}}\right), \quad|Y| \leq a, \forall \Phi \in[0, \pi] \\
2 \mu\left(\sqrt{b^{2}-Y^{2}}-\sqrt{(b-c)^{2}-Y^{2}}\right), \quad a<|Y|<b-c, \forall \Phi \in[0, \pi] \\
2 \mu\left(\sqrt{b^{2}-Y^{2}}\right), \quad b-c \leq|Y| \leq b, \forall \Phi \in[0, \pi] \\
0, \quad|Y|>b
\end{array}\right.
$$


O Pseudocódigo 2 descreve o algoritmo da simulação do primeiro objeto.

Pseudocódigo 2 - Algoritmo para a simulação das projeções com feixe paralelo do primeiro objeto idealizado.

LER $J, K, b, a, c$;

PARA $k \leftarrow 1$ ATÉ $K$

PARA $j \leftarrow 1$ ATÉ $J$

$\mathrm{SE}\left|Y_{j}\right| \leq a$ ENTÃO

$P\left(Y_{j}, Z_{k}\right)=2 \mu\left(\sqrt{a^{2}-Y_{j}^{2}}+\sqrt{b^{2}-Y_{j}^{2}}-\sqrt{(b-c)^{2}-Y_{j}^{2}}\right)$

SENÃO

$\mathrm{SE}\left|Y_{j}\right| \leq b-c$ ENTÃO

$P\left(Y_{j}, Z_{k}\right)=2 \mu\left(\sqrt{b^{2}-Y_{j}^{2}}-\sqrt{(b-c)^{2}-Y_{j}^{2}}\right) ;$

SENÃO

SE $\left|Y_{j}\right|<b$ ENTÃO

$P\left(Y_{j}, Z_{k}\right)=2 \mu\left(\sqrt{b^{2}-Y_{j}^{2}}\right) ;$

SENÃO

$P\left(Y_{j}, Z_{k}\right)=0$;

FIM SE

FIM SE

FIM SE

FIM PARA

FIM PARA

O segundo objeto simulado é composto por dois cilindros sólidos com eixos principais paralelos ao eixo z e deslocados da origem, como mostra a Figura 24. 


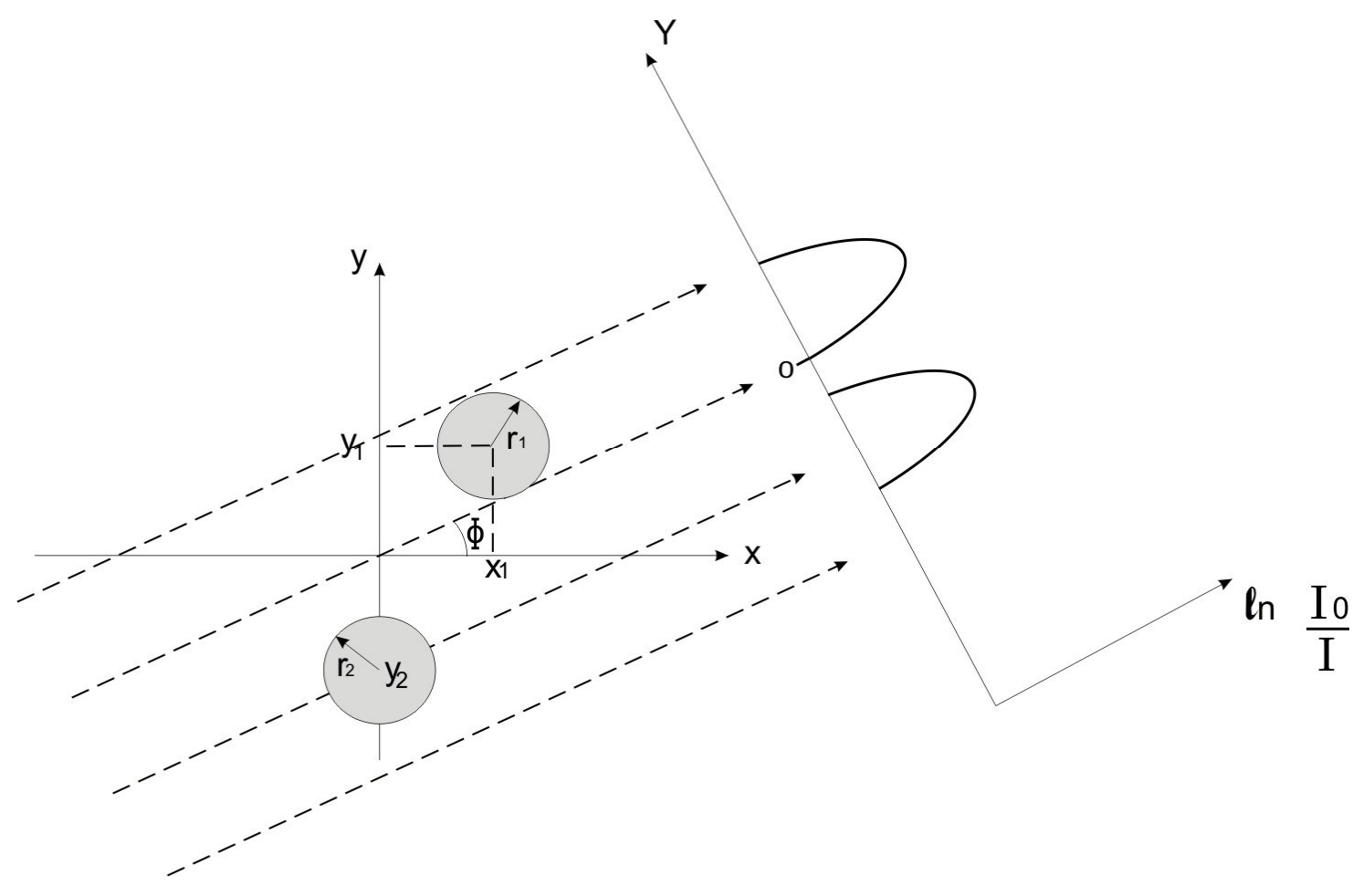

Figura 24 - Esquema da simulação computacional da projeção de dois cilindros com eixos principais paralelos ao eixo $z$ e deslocado da origem.

O modelo matemático utilizado para se obter as projeções do objeto representado na Figura 24 é determinado pela equação (52).

$$
P_{\Phi}(Y)= \begin{cases}2 \mu \sqrt{r_{1}^{2}-\left(Y-R_{1}\right)^{2}}, & \left|Y-R_{1}\right| \leq r_{1} \wedge\left|Y-R_{2}\right|>r_{2} \\ 2 \mu \sqrt{r_{2}^{2}-\left(Y-R_{2}\right)^{2}}, & \left|Y-R_{2}\right| \leq r_{2} \wedge\left|Y-R_{1}\right|>r_{1} \\ 2 \mu\left(\sqrt{r_{1}^{2}-\left(Y-R_{1}\right)^{2}}+\sqrt{r_{2}^{2}-\left(Y-R_{2}\right)^{2}}\right), & \left|Y-R_{1}\right| \leq r_{1} \wedge\left|Y-R_{2}\right| \leq r_{2} \\ 0, & \left|Y-R_{2}\right|>r_{2} \wedge\left|Y-R_{1}\right|>r_{1}\end{cases}
$$

Onde, $R_{1}=-x_{1} \operatorname{sen} \Phi+y_{1} \cos \Phi$ e $R_{2}=y_{2} \cos \Phi$ são as posições em $Y$ das projeções do eixo principal de cada cilindro sólido, em cada projeção $P_{\Phi}$.

O Pseudocódigo 3 descreve o algoritmo usado para simular as projeções do segundo objeto. Esse objeto não possui simetria cilíndrica, portanto as projeções dependem do ângulo $\Phi$. 


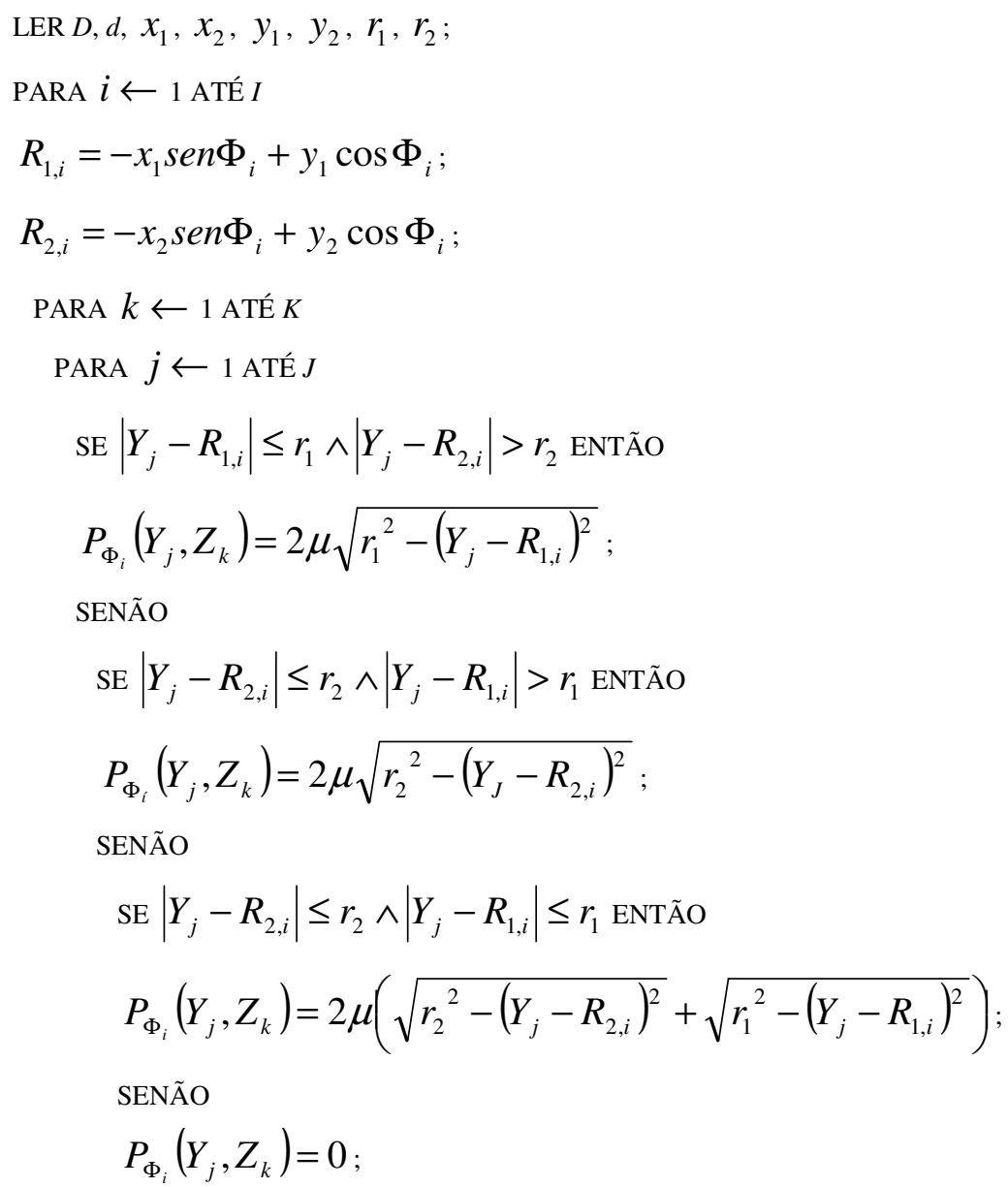

FIM SE

FIM SE

FIM SE

FIM PARA

FIM PARA

FIM PARA

A implementação no aplicativo MATLAB®, embora fosse simples devido às ferramentas matemáticas existentes no software, apresentava um problema com o tempo gasto no processamento (aproximadamente 1 hora para processar a reconstrução de uma imagem de $256 \mathrm{X} 256$ pixels a partir de 36 projeções). O longo tempo de processamento estava tornando inviável a reconstrução de imagens com uma resolução satisfatória, impossibilitando que fosse realizada qualquer análise das imagens reconstruídas. 
Imaginando que o problema pudesse ser a escolha do software MATLAB $®$, implementou-se o algoritmo na linguagem de programação C\#, utilizando-se a plataforma Microsoft ${ }^{\circledR}$ Visual Studio®.NET 2002 Professional (Microsoft Corp., EUA). A implementação do algoritmo tornou-se mais complicada devido à ausência do ferramental matemático disponível no MATLAB ${ }^{\circledR}$. No entanto o detalhamento exigido na implementação de cada passo do algoritmo permitiu observar que era possível reimplementá-lo com algumas modificações e reduzir muito o tempo de processamento. Ao analisar o Pseudocódigo 1, percebe-se que as etapas de filtração e retro-projeção estão ocorrendo simultaneamente, onde para cada voxel do objeto reconstruído é realizada a filtração da projeção na altura correspondente, o que atrasa muito o processo de reconstrução. Para reconstruir 100 cortes com uma resolução de 256x256 cada, seria preciso processar $100 \times 256^{2}$ filtrações, isto é, 6.553 .600 processos de filtração por projeção. Buscando uma maneira de acabar com esse problema, foi observado que o algoritmo poderia ser reimplementado de modo que os processos de filtração e retroprojeção ocorressem separadamente, e que cada projeção fosse filtrada uma única vez. Foi então implementado o algoritmo FDK, com os processos de filtração e retro-projeção sendo realizados separadamente. Essa alteração reduziu o tempo de processamento em mais de mil vezes, eliminando a hipótese de o problema ter sido a escolha do software MATLAB®. O Pseudocódigo 4 descreve a nova implementação do algoritmo.

Pseudocódigo 4 - Segunda implementação do algoritmo FDK. Os processos de filtração e retroprojeção ocorrem separadamente.

LER $I, J, K, d, D, T, N, M$;

$\mu_{n, m, t} \leftarrow 0$

PARA $i \leftarrow 1$ ATÉ $I$, FAZ

LER $P_{\Phi_{i}}$;

PARA $j \leftarrow 1$ ATÉ $J$, FAZ

PARA $k \leftarrow 1$ ATÉ $K$, FAZ

$\bar{P}_{\Phi_{i}}\left(Y_{j}, Z_{k}\right) \leftarrow \frac{d}{\left(d^{2}+Y_{j}^{2}+Z_{k}^{2}\right)^{\frac{1}{2}}} P_{\Phi}\left(Y_{j}, Z_{k}\right) ;$

FIM PARA

FIM PARA 
PARA $j \leftarrow 1$ ATÉ $J$, FAZ
PARA $k \leftarrow 1$ ATÉ $K$, FAZ
$C_{\Phi_{i}}\left(Y_{j}, Z_{k}\right) \leftarrow \sum_{j^{\prime}=1}^{j^{\prime}=J} \bar{P}_{\Phi_{i}}\left(Y_{j^{\prime}}, Z_{k}\right) \int_{Y_{j^{\prime}}-\frac{\Delta Y}{2}}^{Y_{j^{\prime}}+\frac{\Delta Y}{2}}\left\{\int_{0}^{w_{y_{0}}} w \cos \left[2 \pi w\left(Y_{j}-Y\right)\right] d w\right\} d Y ;$

FIM PARA

FIM PARA

PARA $t \leftarrow 1$ ATÉ $T$, FAZ

PARA $n \leftarrow 1$ ATÉ $N$, FAZ

PARA $m \leftarrow 1$ ATÉ $M$, FAZ

$Y_{r} \leftarrow \frac{D\left(-x_{n} \operatorname{sen}\left(\Phi_{i}\right)+y_{m} \cos \left(\Phi_{i}\right)\right)}{d+x_{n} \cos \left(\Phi_{i}\right)+y_{m} \operatorname{sen}\left(\Phi_{i}\right)} ;$

$Z_{r} \leftarrow \frac{D \cdot z_{t}}{d+x_{n} \cos \left(\Phi_{i}\right)+y_{m} \operatorname{sen}\left(\Phi_{i}\right)}$

$\mu_{n, m, t} \leftarrow \mu_{n, m, t}+\frac{D d}{\left(d+x_{n} \cos \left(\Phi_{i}\right)+y_{m} \operatorname{sen}\left(\Phi_{i}\right)\right)^{2}} C_{\Phi_{i}}\left(Y_{r}, Z_{r}\right) \cdot \Delta \Phi$

FIM PARA

FIM PARA

FIM PARA

FIM PARA

PARA $t \leftarrow 1$ ATÉ $T$, FAZ

PARA $n \leftarrow 1$ ATÉ $N$, FAZ

PARA $m \leftarrow 1$ ATÉ $M$, FAZ

$n C T_{n, m, t} \leftarrow \frac{\left(\mu_{n, m, t}-\mu_{\text {ăgua }}\right)}{\mu_{\text {aguа }}} 1000 ;$

FIM PARA

FIM PARA

FIM PARA

Onde, $C_{\Phi_{i}}\left(Y_{r}, Z_{r}\right)$, é calculado por interpolação linear entre as linhas e colunas do detector. São claras as diferenças entre as duas implementações do algoritmo. Nessa última, fica imediata a independência entre os processos de filtração e retro-projeção. A filtração é realizada uma única vez por projeção, e o valor de cada ponto $\left(Y_{r}, Z_{r}\right)$ da projeção filtrada $C_{\Phi_{i}}$ é retro-projetado sobre toda a linha que contém os voxels que foram atravessados pelos raios $\mathrm{X}$ que atingiram o ponto $\left(Y_{r}, Z_{r}\right)$ no detector, na projeção $i$. 
Foram realizadas várias reconstruções variando-se alguns parâmetros, como o número de projeções e o número de pixels das projeções. As imagens reconstruídas a partir das projeções simuladas foram importadas para o software ImageJ (National Institutes of Health, USA), onde puderam ser visualizadas e analisadas.

Em seguida, foi feita a simulação de projeções considerando a geometria cônica do feixe de raios X. Nesse caso, cada linha do detector é atingida por um feixe em leque, cada um varrendo um corte do objeto em uma inclinação diferente. Devido à inclinação dos cortes, cada linha do detector, com exceção da linha central, detecta um corte diferente do objeto em cada posição angular do sistema fonte-detector. No entanto, na altura do corte central, a geometria de feixe cônico se reduz, precisamente, à de feixe em leque, sem que haja inclinação relativa do objeto. Foram então simuladas projeções de feixe em leque para a reconstrução do corte central de um objeto idealizado. Novamente, foram consideradas situações físicas ideais na simulação das projeções. A Figura 25 ilustra o esquema de simulação das projeções com feixe em leque.

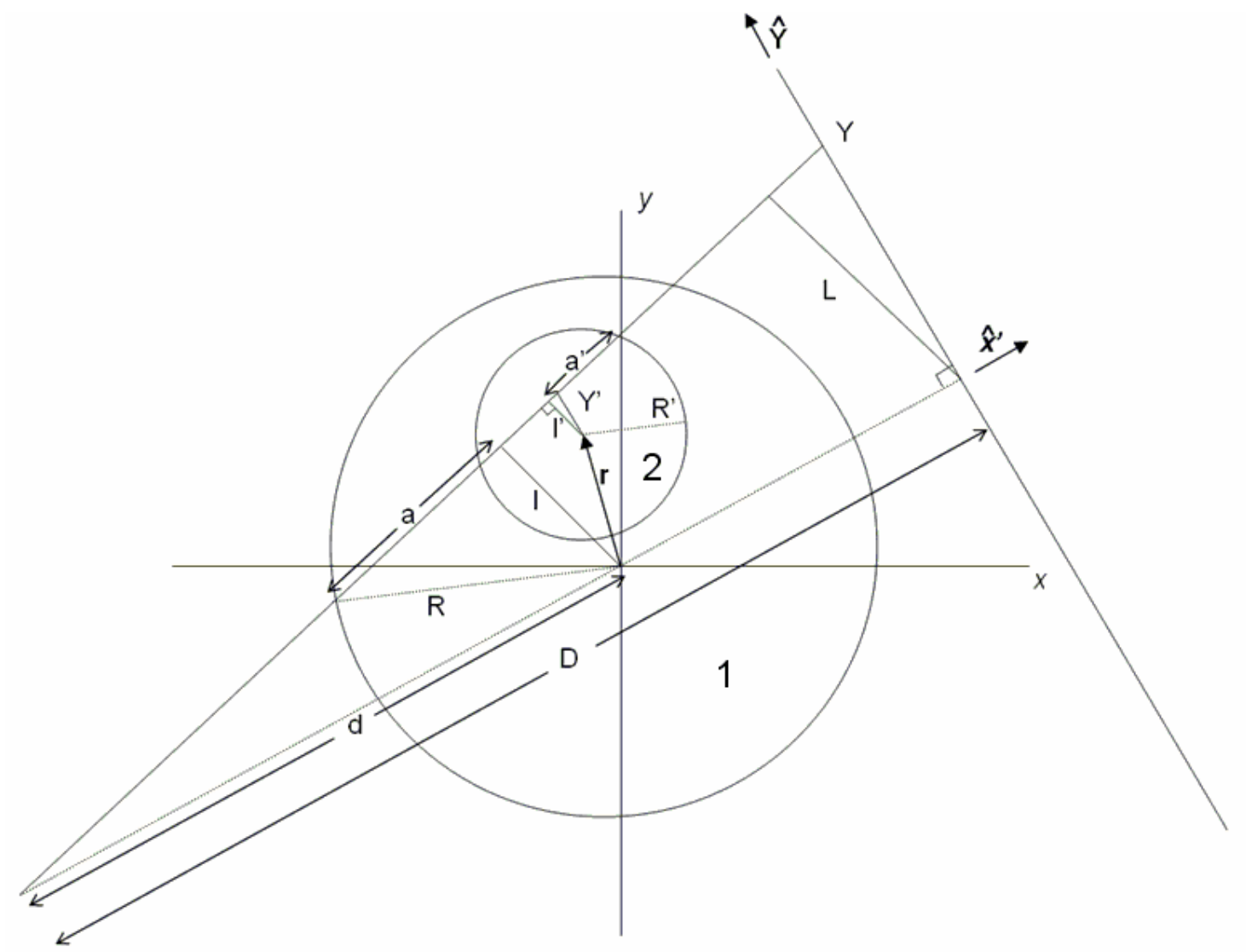

Figura 25 - Esquema geométrico da simulação das projeções com geometria de feixe em leque. 
Supondo os materiais 1 e 2 com coeficientes de atenuação constantes, tem-se que $I=I_{0} e^{-\left[\mu_{1}\left(2 a-2 a^{\prime}\right)+\mu_{2}\left(2 a^{\prime}\right)\right]}$ e, portanto, basta conhecer os valores de $a$ e $a^{\prime}$ para quaisquer valores de $Y$ e $\Phi$, que é possível construir as projeções simuladas, $P_{\Phi}(Y)=\ln \left(\frac{I_{0}}{I}\right)$, para qualquer posição angular do conjunto fonte-detector. A partir da Figura 25 pode-se ver que

$$
\begin{aligned}
& \square Y^{\prime}=\frac{\left(d+\mathbf{r} \cdot \hat{x}^{\prime}\right) Y}{D}-\mathbf{r} \cdot \hat{Y} \\
& \square=\frac{Y D}{\sqrt{Y^{2}+D^{2}}} \\
& \square=\frac{d}{D} L \\
& \square l^{\prime}=L \frac{Y^{\prime}}{Y}
\end{aligned}
$$

Os valores de $a$ e $a^{\prime}$ podem ser determinados a partir das equações (55) e (56), ficando:

$$
\begin{aligned}
& \square a=\sqrt{R^{2}-l^{2}} \\
& \square a^{\prime}=\sqrt{R^{\prime 2}-l^{\prime 2}}
\end{aligned}
$$

As simulações com geometria de feixe em leque só foram realizadas para o segundo objeto, o que foi suficiente para conduzir os testes desejados nas imagens reconstruídas. A Figura 26 mostra o esquema de simulação das projeções com geometria de feixe em leque. 


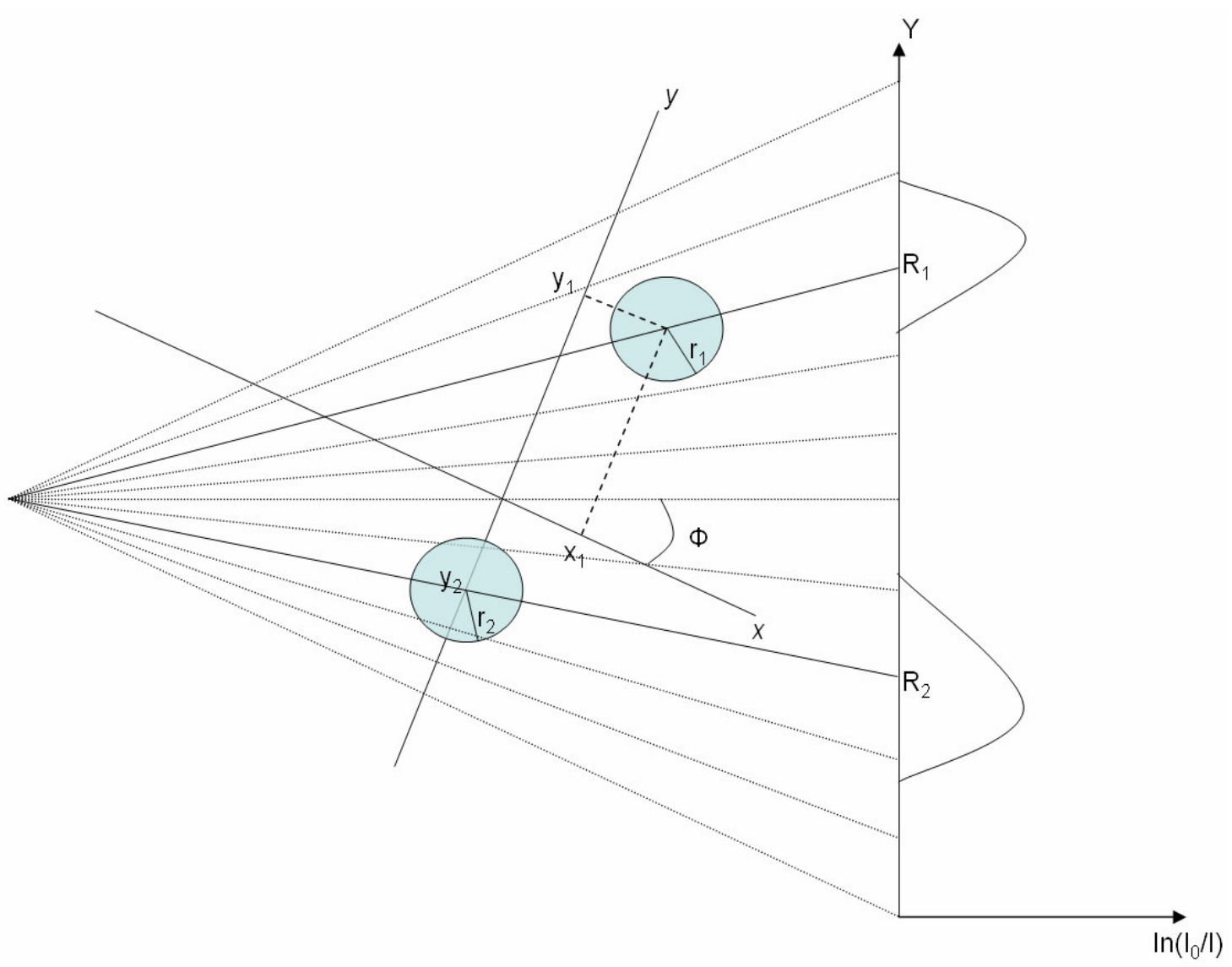

Figura 26 - Modelo físico idealizado para a simulação das projeções com feixe em leque do segundo objeto.

O modelo matemático utilizado para se obter as projeções do objeto representado na Figura 26 é determinado pela equação (59).

$$
P_{\Phi}(Y)= \begin{cases}2 \mu_{1} \sqrt{r_{1}^{2}-L_{1}^{2}}+2 \mu_{2} \sqrt{r_{2}^{2}-L_{2}^{2}}, \quad\left|L_{1}\right| \leq r_{1} \wedge\left|L_{2}\right| \leq r_{2} \\ 2 \mu_{1} \sqrt{r_{1}^{2}-L_{1}^{2}}, \quad\left|L_{1}\right| \leq r_{1} \wedge\left|L_{2}\right|>r_{2} \\ 2 \mu_{1} \sqrt{r_{1}^{2}-L_{1}^{2}}, \quad\left|L_{1}\right| \leq r_{1} \wedge\left|L_{2}\right|>r_{2} \\ 2 \mu_{2} \sqrt{r_{2}^{2}-L_{2}^{2}}, \quad\left|L_{2}\right| \leq r_{2} \wedge\left|L_{1}\right|>r_{1} \\ 0, \quad\left|L_{1}\right|>r_{1} \wedge\left|L_{2}\right|>r_{2}\end{cases}
$$

Sendo 


$$
\begin{aligned}
& L_{1}=\left(d+x_{1} \cos \Phi+y_{1} \operatorname{sen} \Phi\right) \frac{Y}{\sqrt{D^{2}+Y^{2}}}-\left(-x_{1} \operatorname{sen} \Phi+y_{1} \cos \Phi\right) \frac{D}{\sqrt{D^{2}+Y^{2}}} \\
& L_{2}=\left(d+x_{2} \cos \Phi+y_{2} \operatorname{sen} \Phi\right) \frac{Y}{\sqrt{D^{2}+Y^{2}}}-\left(-x_{2} \operatorname{sen} \Phi+y_{2} \cos \Phi\right) \frac{D}{\sqrt{D^{2}+Y^{2}}}
\end{aligned}
$$

O Pseudocódigo 5 descreve o algoritmo usado para simular as projeções.

Pseudocódigo 5 - Algoritmo para a simulação das projeções com feixe em leque

$$
\begin{aligned}
& \text { LER } D, d, x_{1}, x_{2}, y_{1}, y_{2} ; \\
& \text { PARA } i \leftarrow 1 \text { ATÉ } I \text {, FAZ } \\
& c_{1_{i}} \leftarrow d+x_{1} \cos \Phi_{i}+y_{1} \operatorname{sen} \Phi_{i} ; \\
& C_{1_{i}} \leftarrow-x_{1} \operatorname{sen} \Phi_{i}+y_{1} \cos \Phi_{i} ; \\
& c_{2_{i}} \leftarrow d+x_{2} \cos \Phi_{i}+y_{2} \operatorname{sen} \Phi_{i} ; \\
& C_{2_{i}} \leftarrow-x_{2} \operatorname{sen} \Phi_{i}+y_{2} \cos \Phi_{i} ; \\
& \text { PARA } j \leftarrow 1 \text { ATÉ } J, \text { FAZ } \\
& L_{1_{j, i}} \leftarrow c_{1_{i}} \frac{Y_{j}}{\sqrt{D^{2}+Y_{j}^{2}}}-C_{1_{i}} \frac{D}{\sqrt{D^{2}+Y_{j}^{2}}} ; \\
& L_{2_{j, i}} \leftarrow c_{2_{i}} \frac{Y_{j}}{\sqrt{D^{2}+Y_{j}^{2}}}-C_{2_{i}} \frac{D}{\sqrt{D^{2}+Y_{j}^{2}}} ;
\end{aligned}
$$

PARA $k \leftarrow 1$ ATÉ $K$, FAZ

$$
\begin{aligned}
& \mathrm{SE}\left|L_{1_{j, l}}\right| \leq r_{1} \text {, ENTÃO } \\
& \mathrm{SE}\left|L_{2_{j, I}}\right| \leq r_{2} \text {, ENTÃO } \\
& P_{\Phi_{i}}\left(Y_{j}, Z_{k}\right) \leftarrow 2 \mu_{1} \sqrt{r_{1}^{2}-L_{1_{j, i}}^{2}}+2 \mu_{2} \sqrt{r_{2}^{2}-L_{2_{j, i}}^{2}} ;
\end{aligned}
$$

SENÃO

$$
P_{\Phi_{i}}\left(Y_{j}, Z_{k}\right) \leftarrow 2 \mu_{1} \sqrt{r_{1}^{2}-L_{1_{j, i}}^{2}}
$$

FIM SE

SENÃO

$$
\mathrm{SE}\left|L_{2_{j, i}}\right| \leq r_{2}, \text { ENTÃO }
$$




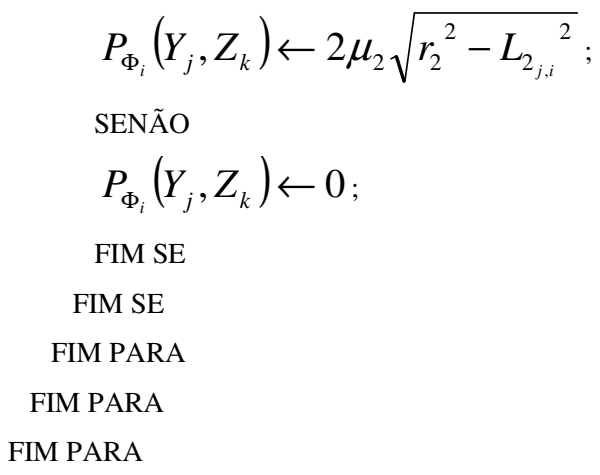

Mais uma vez foram feitas reconstruções para várias configurações diferentes, e as imagens foram igualmente analisadas. Essas imagens e os resultados das respectivas análises são apresentados no capítulo 7 .

\subsection{Implementação Experimental: Montagem dos Sistemas de Aquisição de Dados}

Esta etapa consiste na implementação de um sistema físico que simule o sistema de aquisição de dados de um equipamento de TCMC com varredura axial. Para isso, foi utilizado um detector digital, do tipo CCD, disponível comercialmente para aplicações em radiologia odontológica, e um equipamento de raios $\mathrm{X}$. Para simular o processo de aquisição de imagens dos equipamentos de TC convencionais, onde o conjunto fontedetector executa um movimento circular ao redor do corpo do paciente para irradiá-lo e obter projeções em todas as direções, na adaptação feita neste trabalho, o conjunto fontedetector fica imóvel, enquanto a amostra gira em torno do seu eixo de rotação, fixado no centro de uma plataforma giratória. Realiza-se a medição de uma projeção por cada posição angular da amostra. Cada projeção é arquivada com sua posição angular correspondente. As projeções coletadas são os dados de entrada do algoritmo de reconstrução de imagens implementado.

Para que o algoritmo funcionasse da maneira adequada e as reconstruções apresentassem uma qualidade mínima razoável, foi necessário garantir a melhor qualidade possível nas projeções coletadas, e ter um mínimo de precisão geométrica na 
montagem do sistema de aquisição de imagens, assim como foi apontado no capítulo 5, item 5.3.

Um dos fatores determinantes na qualidade das projeções é a técnica radiográfica utilizada, determinada pela tensão $(\mathrm{kV})$ aplicada ao tubo, pela corrente $(\mathrm{mA})$ que atinge o alvo do tubo e pela filtração na saída da cúpula do equipamento de raios $\mathrm{X}$. $\mathrm{O}$ ajuste da técnica deve se basear nos materiais que compõem o objeto a ser reconsruído, na filtração e detector utilizados. A tensão aplicada e a filtração determinam a energia dos fótons emitidos e, portanto, sua distância média de penetração na matéria. Para materiais mais atenuantes, a tensão deve ser alta o suficiente para que os fótons consigam atravessar todo o objeto. A corrente de elétrons que atinge o alvo do tubo determina a densidade de fótons produzidos, o que resulta numa razão sinal ruído maior nas imagens obtidas. A otimização da técnica radiográfica consiste em balancear corretamente a tensão, a filtração e a corrente do tubo, de modo que a imagem detectada apresente o melhor contraste e resolução espacial possíveis para o sistema fonte-detector disponível.

Para garantir a precisão geométrica do sistema de aquisição de imagens, é necessário alinhar o sistema fonte-detector, de modo que a reta que passa pelo ponto focal do tubo e o centro do detector seja perpendicular ao plano do detector e paralela ao plano de rotação do objeto a ser reconstruído. Para que as projeções constituam um conjunto de dados consistente, é necessário que haja precisão nas medidas angulares da rotação do objeto a ser reconstruído.

No processo de implementação experimental, foram testados, ao todo, três equipamentos de raios $\mathrm{X}$ e dois detectores digitais, todos de marcas diferentes. Foram realizados testes com esses equipamentos para determinar o conjunto fonte-detector que produzia as melhores projeções. A Tabela 3 apresenta os componentes utilizados na montagem de cada um dos três sistemas de aquisição de dados. 
Tabela 3 - Componentes utilizados em cada um dos sistemas de aquisição de projeções montados.

\begin{tabular}{|c|c|c|}
\hline $\begin{array}{c}\text { Sistema de aquisição de } \\
\text { dados }\end{array}$ & Equipamento de raios $X$ & Sistema de detecção \\
\hline Sistema № 1 & $\begin{array}{l}\text { MCN } 323 \text { (Philips, } \\
\text { Hamburgo, Alemanha) }\end{array}$ & $\begin{array}{c}\text { Dexis (mvg- } \\
\text { medizinrechner, } \\
\text { Dusseldórfia, Alemanha) }\end{array}$ \\
\hline Sistema № 2 & $\begin{array}{c}\text { Heliophos 4b (Siemens, } \\
\text { Alemanha) }\end{array}$ & $\begin{array}{l}\text { Sens-a-ray (Regam medical } \\
\text { systems, Sundsvall, Suécia) }\end{array}$ \\
\hline Sistema $\mathrm{N}^{\mathrm{o}} 3$ & $\begin{array}{l}\text { Spectro 70X (Dabi Atlante, } \\
\text { Ribeirão Preto, Brasil) }\end{array}$ & $\begin{array}{c}\text { Dexis (mvg- } \\
\text { medizinrechner, } \\
\text { Dusseldórfia, Alemanha) }\end{array}$ \\
\hline
\end{tabular}

\subsubsection{Sistema de Aquisição de Dados № 1: Equipamento de raios $X$ industrial MCN 323 e o sistema de detecção Dexis}

Primeiramente foi testado um equipamento de raios $\mathrm{X}$ industrial modelo $\mathrm{MCN}$ 323 (Philips, Hamburgo, Alemanha) (Figura 27 (a)), com unidade de controle modelo MGC 40 (Philips, Hamburgo, Alemanha) (Figura 27 (b)). O equipamento possui uma fonte emissora de alta estabilidade, de potencial constante, que permite a emissão de feixes de raios $\mathrm{X}$ entre 40 e $320 \mathrm{kV}$ com diversas combinações de tempo de exposição e corrente anódica.

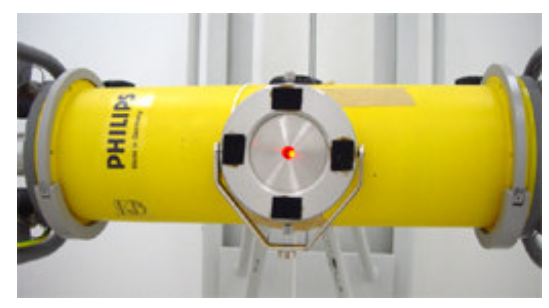

(a)

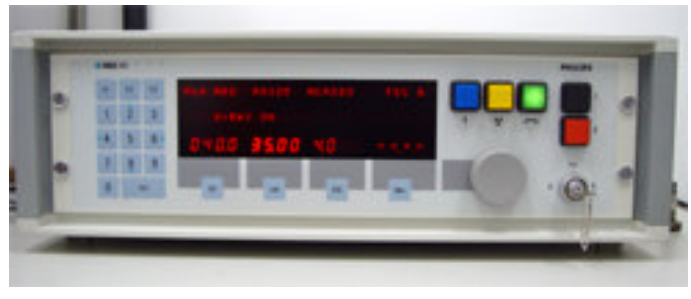

(b)

Figura 27 - Equipamento emissor de raios X MCN 323 (Philips, Hamburgo, Alemanha). (a) Cúpula do tubo de raios X; (b) Unidade de controle MGC 40 (Philips, Hamburgo, Alemanha).

Para coletar as primeiras imagens foi utilizado um detector do tipo CCD (Chargecoupled-device), modelo Dexis (mvg-medizinrechner, Dusseldórfia, Alemanha). Este dispositivo, originalmente projetado para aplicações em imagens odontológicas, é 
composto por um detector sensível aos raios X, uma placa de aquisição de dados e um software proprietário (Figura 28).

As características do sensor digital Dexis são:

Tamanho do sensor: $38,8 \mathrm{~mm} \times 29,8 \mathrm{~mm} \times 9,0 \mathrm{~mm}$;

Área sensível do sensor: 32,0 mm x 25,6 mm;

Matriz: 800 x 640 pixel

Tamanho do pixel: $40 \mu \mathrm{m} \times 40 \mu \mathrm{m}$

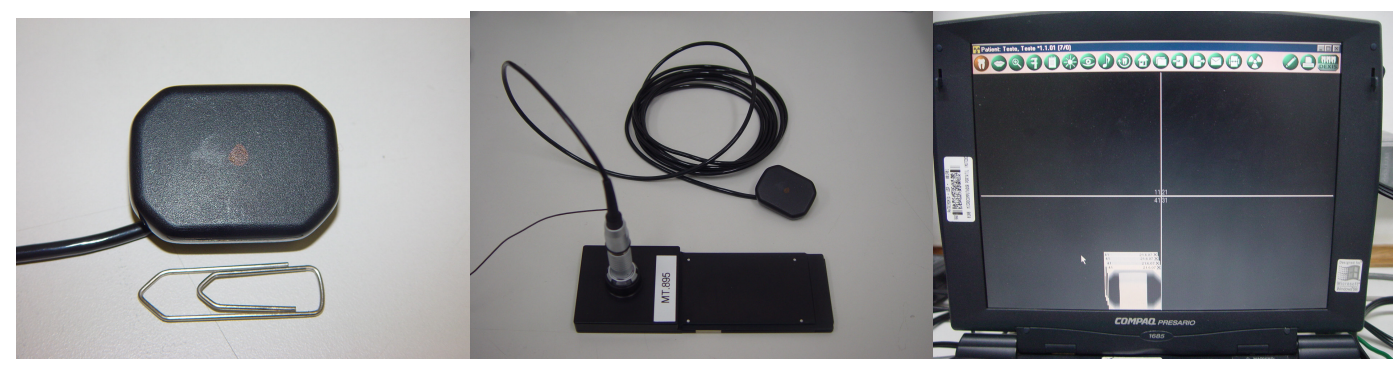

Figura 28 - Sistema de detecção Dexis: (a) sensor CCD; (b) drive (ISA Bus card); (c) software de aquisição das imagens.

As primeiras radiografias realizadas foram de um cilindro de acrílico (Figura 29 (a)). Esse conjunto fonte-detector não apresentou resultados satisfatórios. Foi impossível estabelecer uma técnica radiográfica que produzisse boas projeções. A ativação do sistema Dexis para detectar radiação X é feita pelo software do próprio sistema. Após ser ativado, o sistema aguarda um período de 600 segundos até que seja detectada a radiação. A partir do instante em que são detectados os primeiros fótons de raios $\mathrm{X}$, o sistema se mantém ativo por um período menor que 0,2 segundos, desativando-se automaticamente após esse período. Logo em seguida, é apresentada a imagem digital da radiografia no monitor do computador onde está ligado o sistema. Esse baixo tempo de exposição tornou-se um problema na otimização da técnica radiológica. O MCN 323 não apresentava um comportamento preciso para tempos de exposição tão pequenos. Esse problema, além de gerar inconsistência no conjunto de dados, produzia um artefato em algumas imagens, que era observado como uma faixa clara horizontal bem no centro da imagem (Figura 29 (b)). Outro problema era a mobilidade limitada do equipamento de raios $\mathrm{X}$, o que dificultou o alinhamento do mesmo com o detector. Devido a esses problemas, o sistema № 1 não foi utilizado para a aquisição das projeções. 


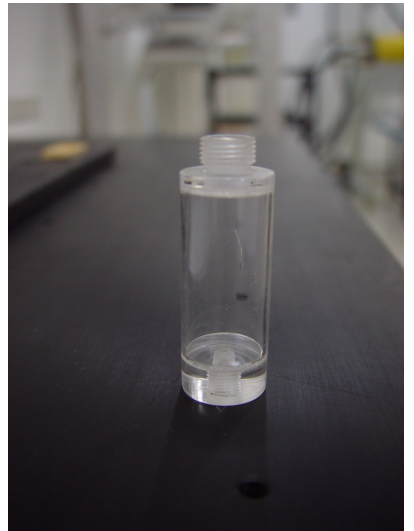

(a)

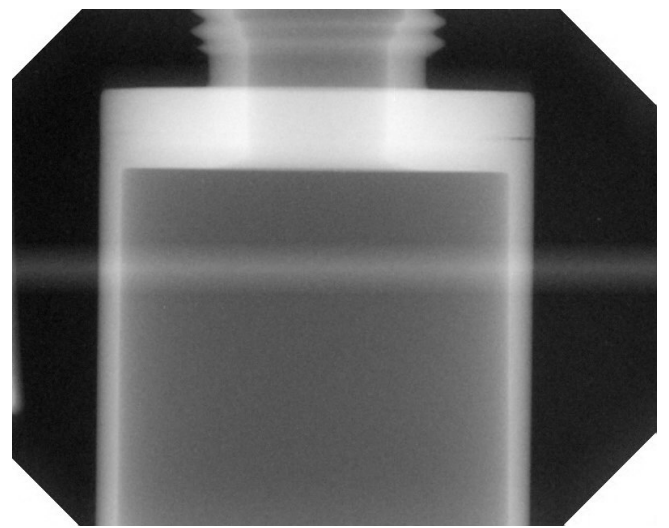

(b)

Figura 29 - Cilindro de acrílico utilizado nas primeiras imagens radiográficas realizadas no trabalho (a); Artefato produzido nas imagens radiográficas coletadas com o Dexis (b).

\subsubsection{Sistema de Aquisição de imagens № 2: Equipamento de raios $X$ clínico Heliophos 4 b e o sistema de detecção Sens-a-ray}

$\mathrm{Na}$ tentativa de resolver o problema, foram feitos testes com outro equipamento de raios X, modelo Heliophos 4b (Siemens, Alemanha) (Figura 30).

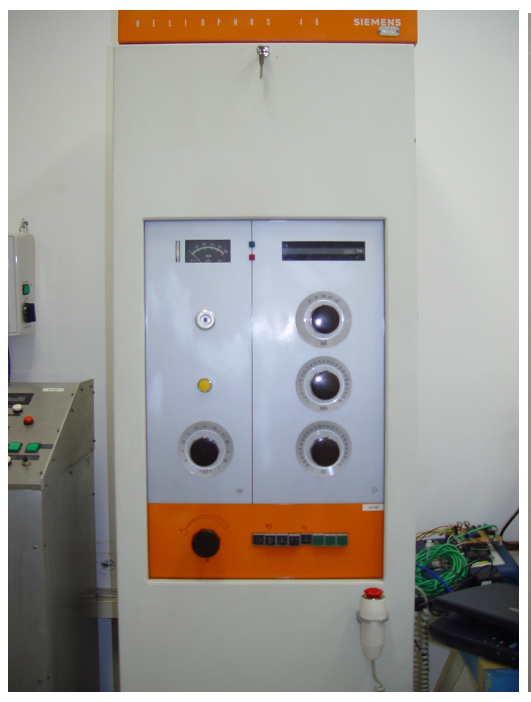

(a)

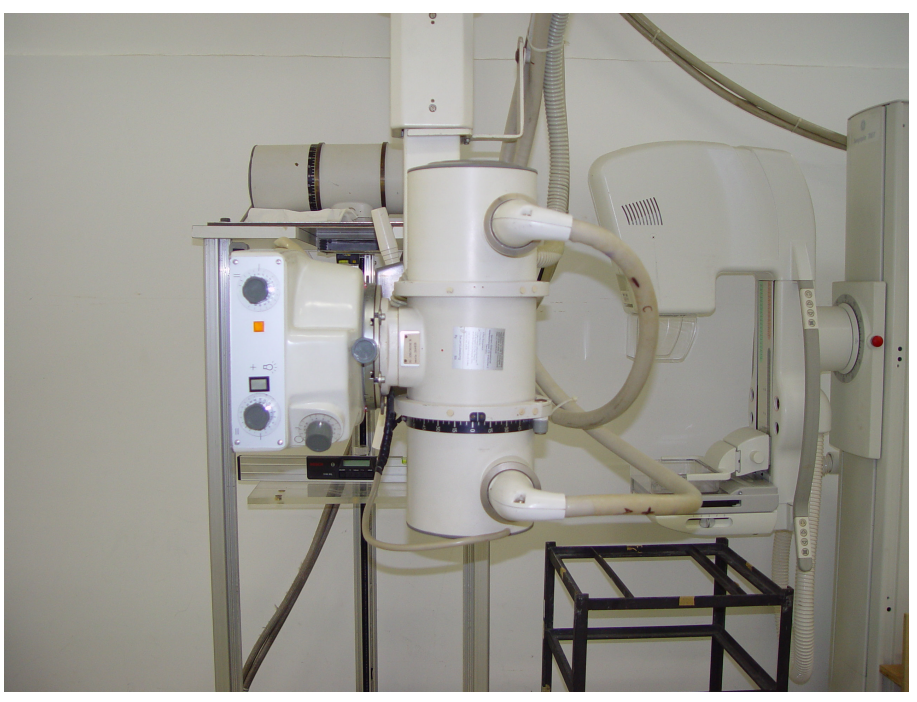

(b)

Figura 30 - Equipamento de raios X modelo Heliophos 4b (Siemens, Alemanha). (a) Unidade de Controle; (b) Cúpula do tubo de raios $\mathrm{X}$. 


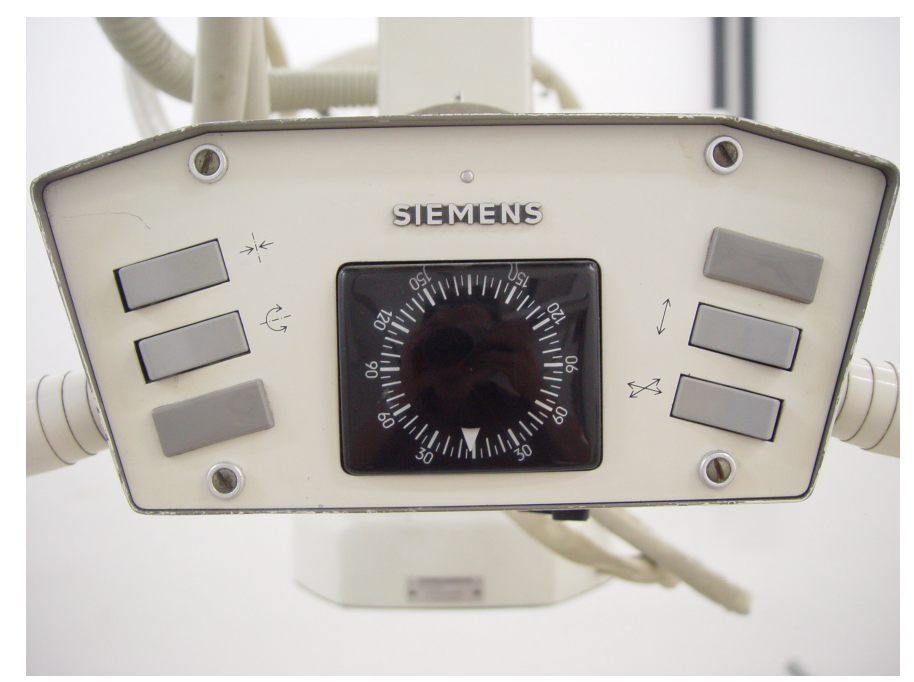

Figura 31 - Unidade de controle do suporte suspenso para o deslocamento tridimensional do Heliophos 4b.

Esse equipamento apresentou muitas vantagens com respeito à sua mobilidade $\mathrm{e}$ facilidade de posicionamento (Figura 31), o que facilitou muito o alinhamento do sistema fonte-detector. Visando evitar o mesmo problema com o tempo de exposição encontrado no primeiro sistema, foi utilizado outro sistema de detecção, que funcionasse com tempos de exposição maiores.

Foram então realizados testes com um detector digital, tipo CCD, modelo Sens-a-ray (Regam medical systems, Sundsvall, Suécia). Este dispositivo, assim como o Dexis, também foi originalmente projetado para aplicações em imagens odontológicas, e é composto por um detector sensível aos raios X, uma fonte de alimentação, uma placa de aquisição de dados e um software proprietário (Figura 32). As características do sensor digital são:

Tamanho do sensor: $41 \mathrm{~mm}$ x $22 \mathrm{~mm}$ x $8 \mathrm{~mm}$;

Área sensível do sensor: 26,0 mm x 17,3 mm;

Matriz 576 x 385 pixel

Resolução da imagem: melhor que 10 pares de linha por mm

Tamanho do pixel: $45 \mu \mathrm{m}$ x $45 \mu \mathrm{m}$ 


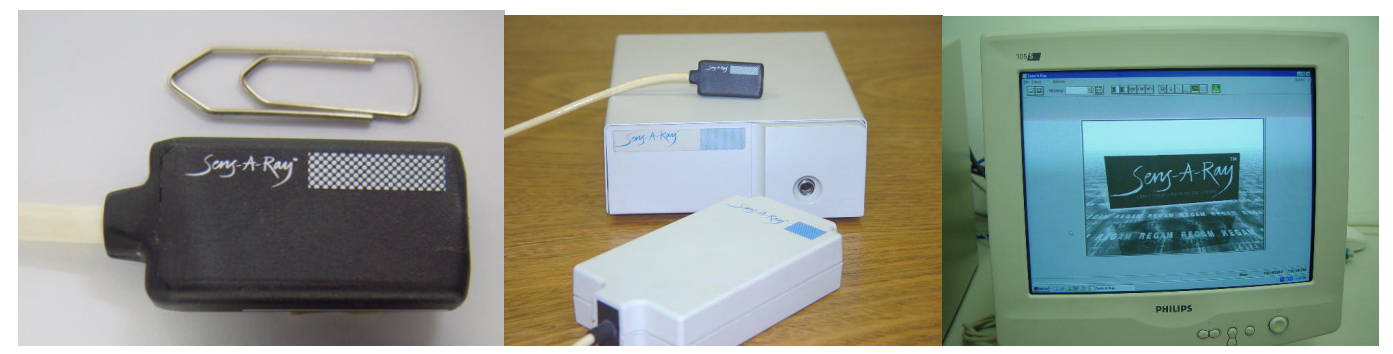

(a)

(b)

(c)

Figura 32 - Sistema de detecção Sens-a-ray: (a) sensor CCD; (b) fonte de alimentação; (c) software de aquisição das imagens.

O sistema Sens-a-ray funciona exatamente como o Dexis, porém realiza a detecção da radiação $\mathrm{X}$ num intervalo de tempo maior, cerca de meio segundo. Com esse tempo de exposição foi possível determinar uma técnica radiológica adequada, e as imagens produzidas não apresentavam mais o artefato presente nas imagens anteriores (Figura 29 (b)).

Para o alinhamento do sistema fonte-detector, primeiramente fixou-se o detector de maneira que seu plano fosse paralelo ao eixo de rotação do objeto a ser reconstruído e, em seguida, alinhou-se o equipamento de raios $\mathrm{X}$ de maneira que seu feixe fosse emitido perpendicularmente ao plano do detector. Para tal alinhamento, utilizou-se um emissor laser, fixado numa das paredes do laboratório, e um espelho plano. $\mathrm{O}$ espelho foi fixado nas superfícies do detector e na janela da cúpula de raios $\mathrm{X}$. O alinhamento era atingido quando o feixe de laser, emitido na direção horizontal e refletido pelo espelho, atingia o próprio emissor laser.

Para centralizar o detector no feixe, foi utilizado um mecanismo colimador luminoso disponível no equipamento de raios $\mathrm{X}$ que simula, com uma fonte luminosa, o formato do feixe irradiado. Esse formato pode ser alterado variando-se a abertura de duas janelas de chumbo, uma vertical e outra horizontal, que ficam na frente do ponto focal (Figura 33). O equipamento de raios $\mathrm{X}$ foi então posicionado e suas janelas ajustadas de forma que o detector ficasse no centro do feixe. 


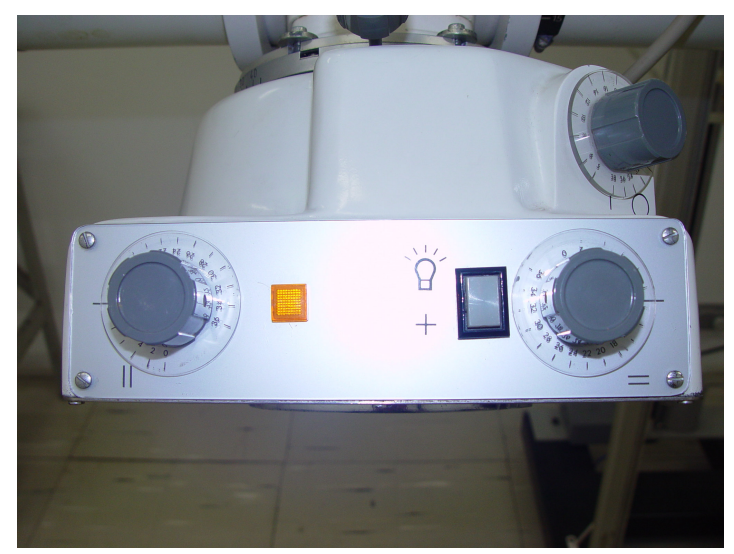

(a)

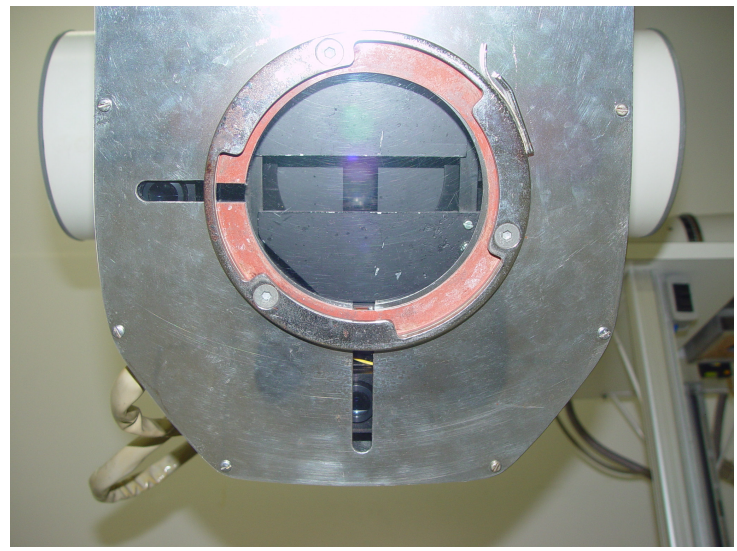

(b)

Figura 33 - Janelas de chumbo colimadoras do Heliophos 4b. (a) Reguladores de abertura das janelas de chumbo; (b) Janelas de chumbo colimadoras.

Para realizar a rotação do objeto a ser reconstruído, foi utilizada uma plataforma mecânica giratória (Optron, Campinas, Brasil) (Figura 34) com um goniômetro acoplado com precisão de até 2 centésimos de grau.

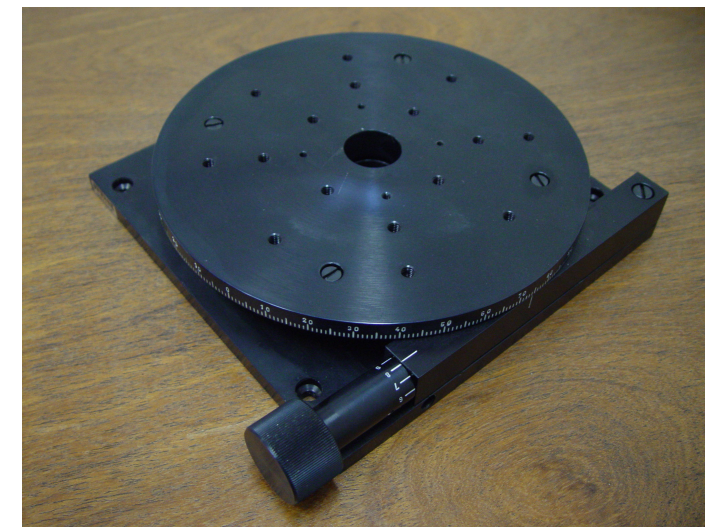

(a)

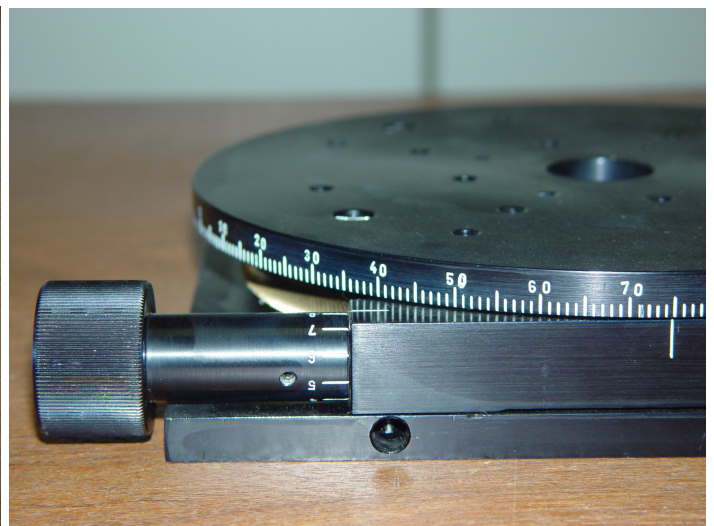

(b)

Figura 34- (a) Plataforma giratória com goniômetro acoplado. (b) Ajuste angular com precisão de 2 centésimos de grau.

Um objeto a ser reconstruído foi projetado especificamente para calibrar o sistema de TCMC implementado. Este objeto foi fabricado na oficina mecânica do Instituto de Eletrotécnica e Energia da Universidade de São Paulo. O objeto é composto por um cilindro sólido de acrílico com $20 \mathrm{~mm}$ de diâmetro e outros quatro cilindros sólidos com $4 \mathrm{~mm}$ de diâmetro, sendo: um de PVC, um de nylon e dois de polietileno com densidades diferentes. Todos os cilindros têm $25 \mathrm{~mm}$ de altura. $\mathrm{O}$ cilindro de acrílico contém 5 furos 
passantes paralelos de $4 \mathrm{~mm}$ de diâmetro cada (Figura 35 (a)), nos quais são inseridos os quatro outros cilindros (Figura 35 (b)). Cada cilindro preenche completamente 4 dos furos passantes do cilindro de acrílico, sobrando um deles com ar. A Figura 35 (c) mostra o objeto montado.

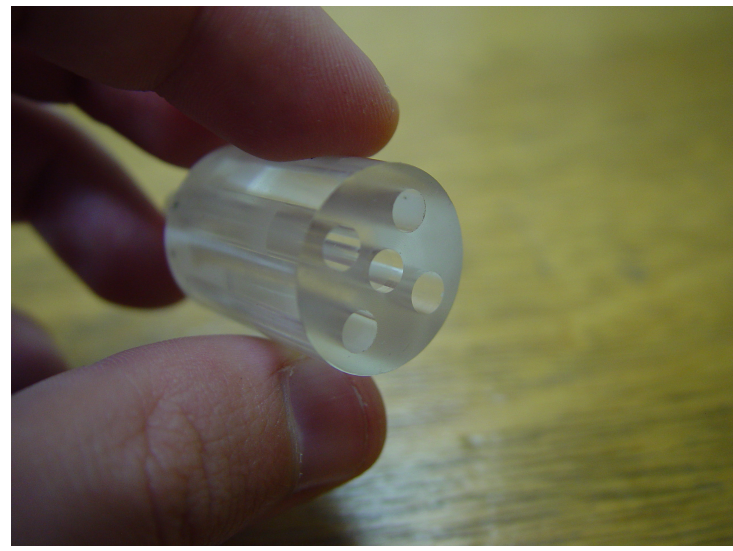

(a)

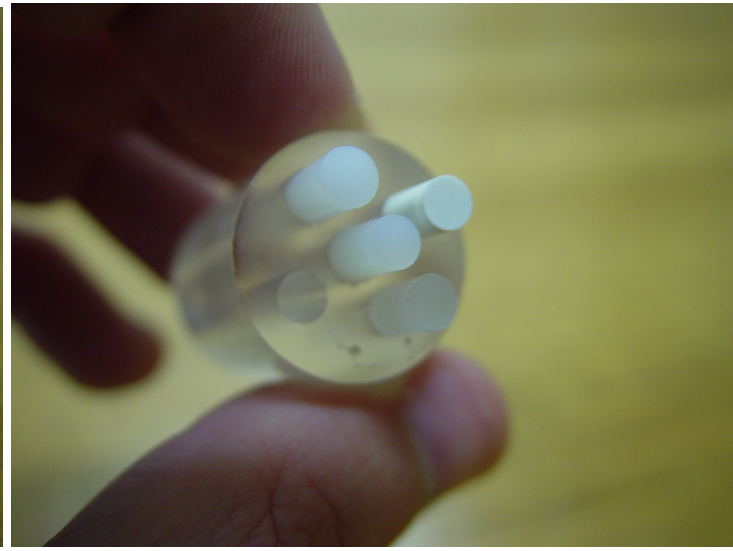

(b)

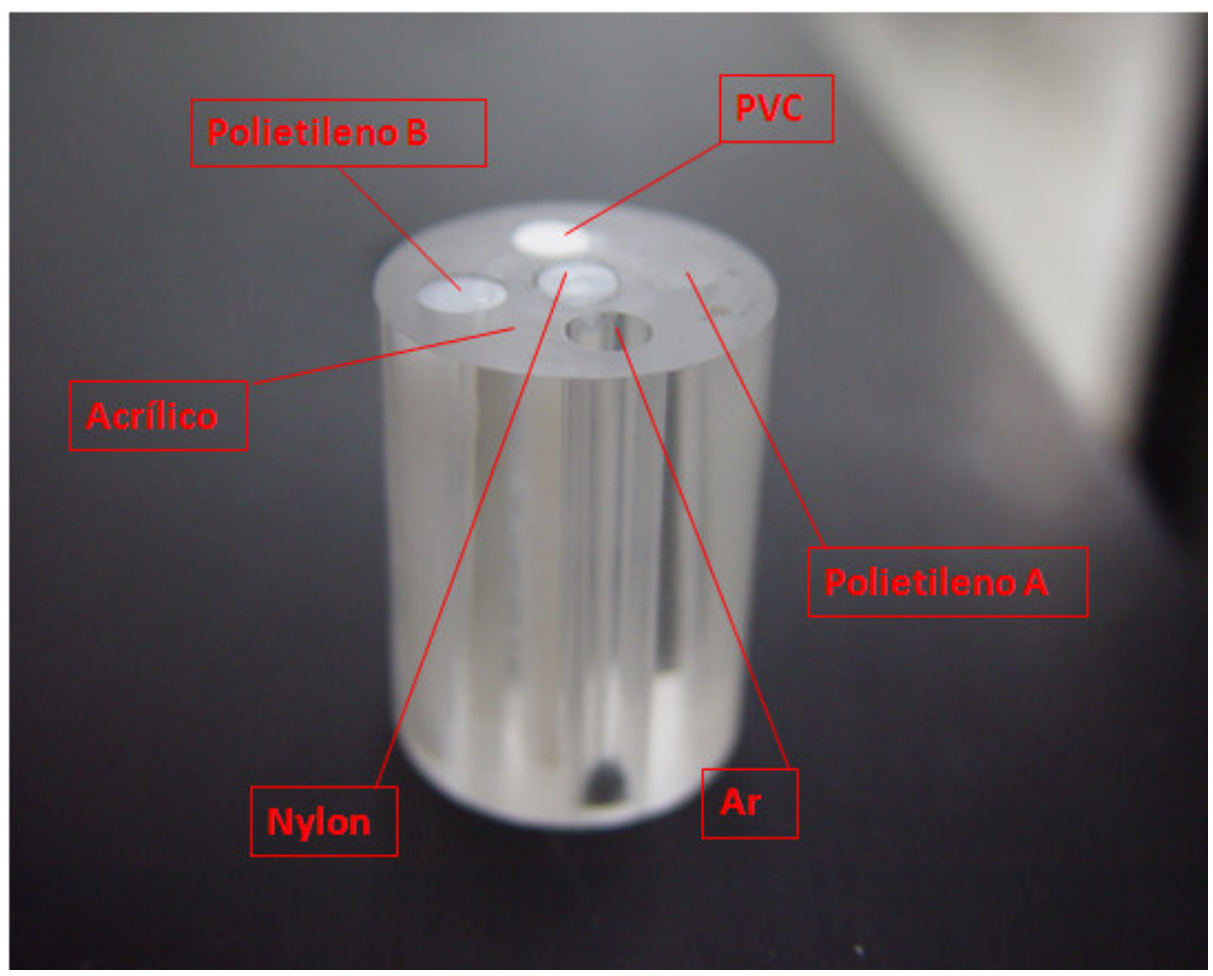

(c)

Figura 35 - (a) Cilindro de acrílico que compõe o objeto a ser reconstruído; (b) Cilindros plásticos parcialmente inseridos no cilindro de acrílico para formar o objeto; (c) Objeto montado, que foi usado na calibração do sistema de TC simplificado implementado. 
A Tabela 4 apresenta as fórmulas químicas de cada material que compõe o objeto.

Tabela 4 - Materiais que compõem o objeto fabricado e suas respectivas fórmulas químicas.

\begin{tabular}{cccccc}
\hline \hline \multirow{2}{*}{ Material } & $\begin{array}{c}\text { Polietileno } \\
\mathrm{A}\end{array}$ & $\begin{array}{c}\text { Polietileno } \\
\mathrm{B}\end{array}$ & \multirow{2}{*}{ Nylon } & \multirow{2}{*}{ Acrílico } & \multirow{2}{*}{ PVC } \\
\hline \hline Fórmula Química & $\mathrm{C}_{2} \mathrm{H}_{4}$ & $\mathrm{C}_{2} \mathrm{H}_{4}$ & $\mathrm{NO} \mathrm{C}_{6} \mathrm{H}_{11}$ & $\mathrm{C}_{5} \mathrm{O}_{2} \mathrm{H}_{8}$ & $\mathrm{C}_{2} \mathrm{H}_{3} \mathrm{Cl}$ \\
\hline Densidade $\left[\mathbf{g} \cdot \mathbf{~ c m}^{-3}\right]$ & $0,92 \pm 0,04$ & $0,97 \pm 0,04$ & $1,14 \pm 0,05$ & $1,18 \pm 0,06$ & $1,49 \pm 0,08$ \\
\hline $\boldsymbol{\mu}\left(\mathbf{E}_{\mathbf{E f}}\right)\left[\mathbf{c m}^{-1}\right]$ & $0,29 \pm 0,01$ & $0,30 \pm 0,01$ & $0,40 \pm 0,02$ & $0,44 \pm 0,02$ & $3,46 \pm 0,19$ \\
\hline \hline
\end{tabular}

O objeto foi posicionado e fixado no centro da plataforma giratória por um suporte de acrílico, especificamente fabricado para este fim (Figura 36).

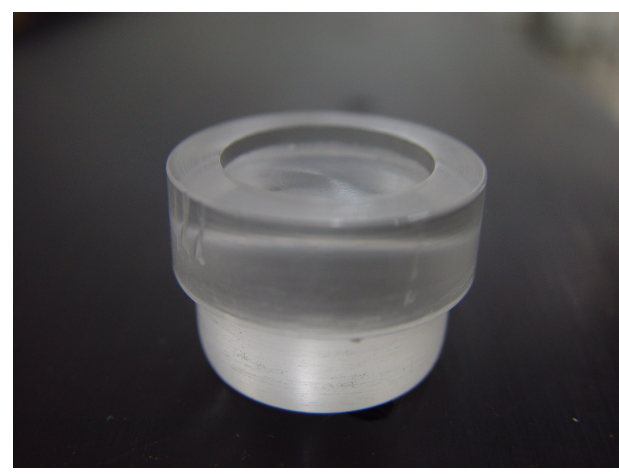

(a)

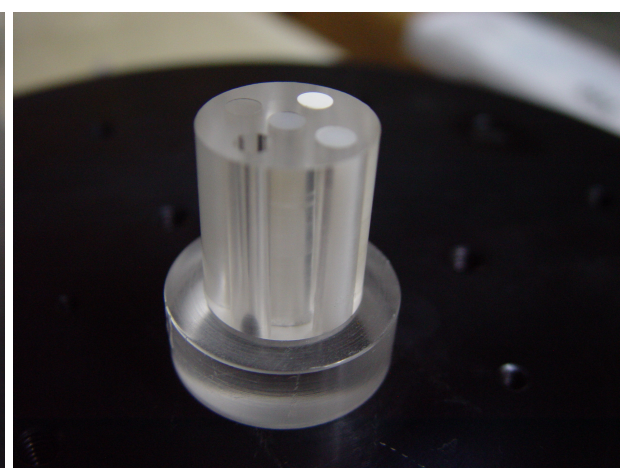

(b)

Figura 36 - (a) Suporte de acrílico fabricado para fixar o objeto a ser reconstruído à plataforma mecânica giratória. (b) Objeto fixo à plataforma giratória pelo suporte de acrílico.
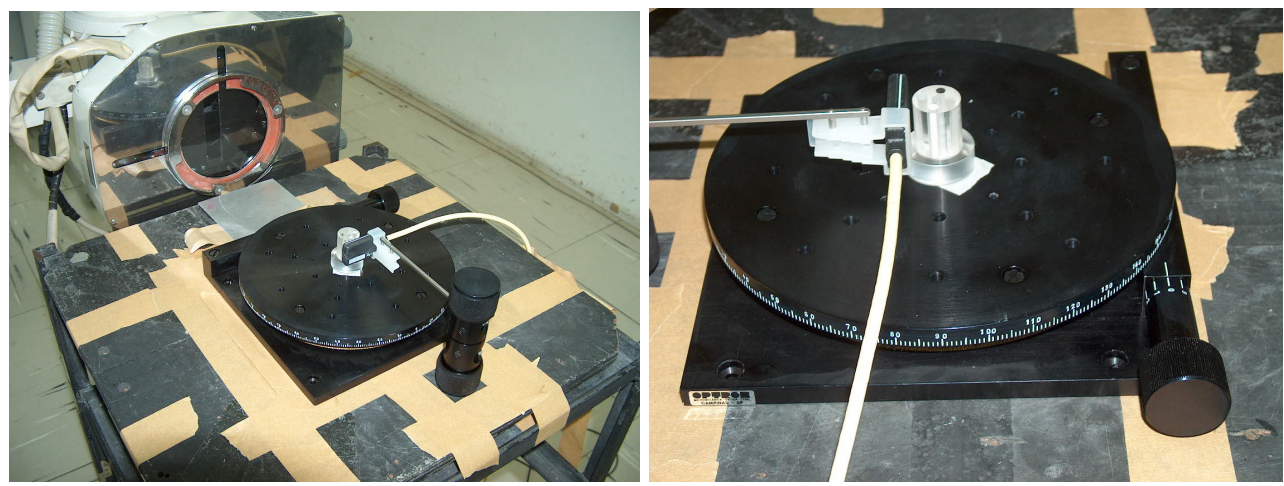

Figura 37 - Sistema de aquisição de imagens para a reconstrução tomográfica montado.

A Figura 37 mostra o sistema de aquisição das projeções montado. O sistema constituído pelo Heliophos $4 \mathrm{~b}$ e pelo Sens-a-ray, possibilitou a aquisição de um conjunto 
consistente de projeções. Foram coletadas 360 projeções com o intervalo angular de $1^{\circ}$ entre cada projeção. As projeções coletadas foram salvas e processadas no computador onde está implementado o algoritmo.

As matrizes numéricas das imagens reconstruídas foram salvas em arquivos de texto com extensão txt, e importadas pelo software ImageJ, onde podiam ser visualizadas. Essas imagens serão apresentadas no capítulo 7.

\subsubsection{Sistema de Aquisição de Imagens $N^{0}$ 3: Equipamento de raios $X$ odontológico, Spectro 70, e o sistema de detecção Dexis}

Um terceiro sistema de aquisição de projeções foi montado utilizando um equipamento de raios X de uso odontológico, Spectro 70X (Dabi Atlante, Ribeirão Preto, Brasil) (Figura 38), e o sistema de detecção Dexis (Figura 28).

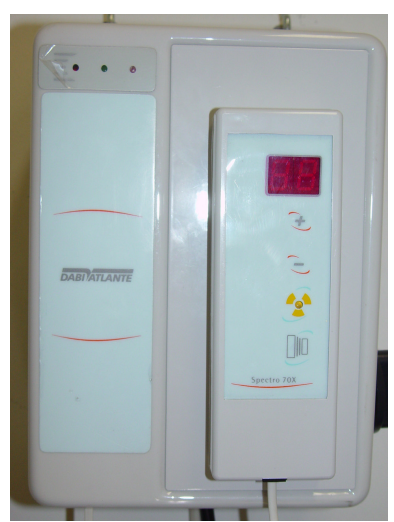

(a)

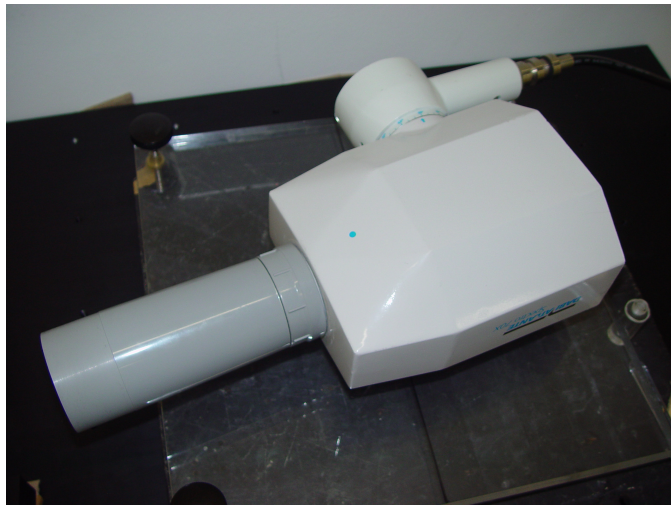

(b)

Figura 38 - Equipamento de raios X odontológico Spectro 70X (Dabi Atlante, Ribeirão Preto, Brasil). (a) Unidade de controle; (b) Cúpula do tubo de raios $\mathrm{X}$.

Nesse equipamento de raios $\mathrm{X}$, a técnica radiográfica já é pré-determinada, a menos do tempo de exposição que pode ser controlado. O tubo do equipamento funciona com uma tensão aplicada de $70 \mathrm{kV}$, e uma corrente de $7 \mathrm{~mA}$. As projeções apresentaram uma boa qualidade para o tempo mínimo de exposição do equipamento, que é de 0,2 segundos. Foi justamente o bom funcionamento do equipamento para baixos tempos de exposição que sugeriu que fossem realizados alguns testes com o sistema de detecção Dexis, que apresentou imagens muito menos ruidosas que o Sens-a-ray (Figura 39). 


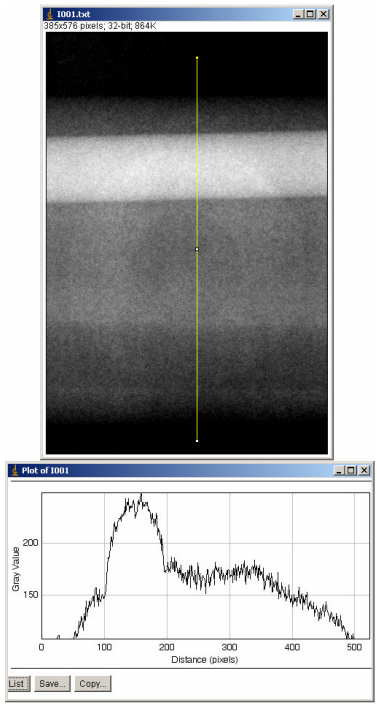

(a)

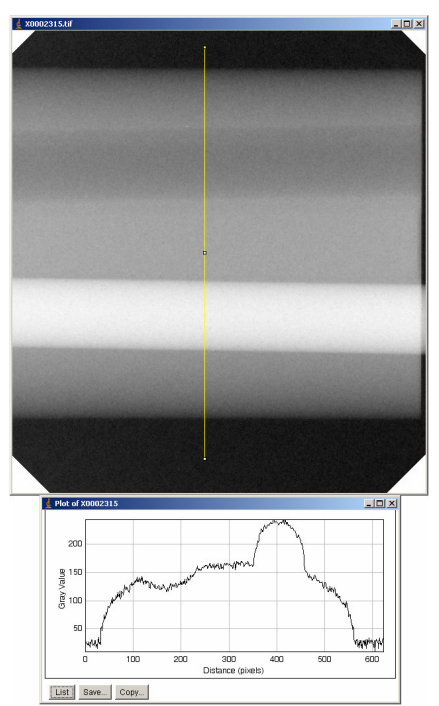

(b)

Figura 39 - Curvas de perfil de projeções coletadas com o Sens-a-ray (a) e com o Dexis (b).

$\mathrm{Na}$ montagem do novo sistema, procurou-se uma maneira de fixar o detector ao equipamento de raios $\mathrm{X}$ e, dessa forma, facilitar o alinhamento do conjunto fontedetector. Para isso, foi fabricada uma peça a partir de tubos de PVC (Figura 40 (a)), que encaixasse no colimador externo do equipamento de raios X (Figura 40 (b)). O detector era então preso a essa peça utilizando um suporte próprio do detector (Figura 40 (c)), que serve como uma espécie de guia de posição do equipamento nas radiografias odontológicas. O novo sistema de aquisição de imagens (Figura 41) foi montado de modo que respeitasse as mesmas exigências geométricas da montagem do sistema № 2 .

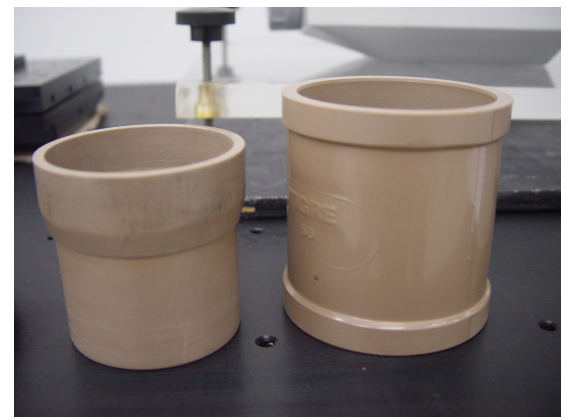

(a)

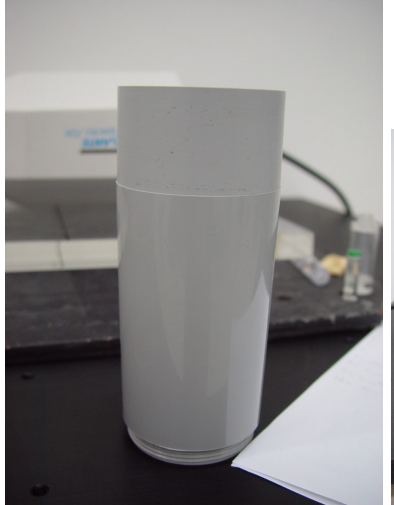

(b)

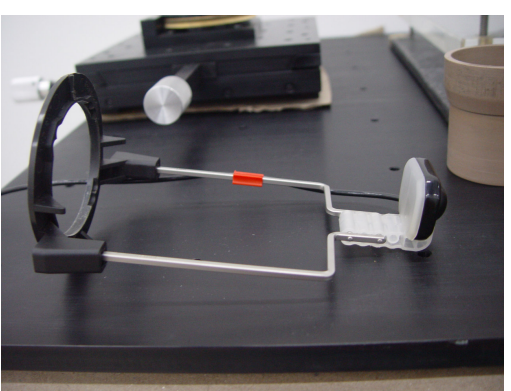

(c)

Figura 40 - (a) Peça fabricada para a fixação e centralização do detector no colimador; (b) colimador do equipamento odontológico; (c) suporte próprio do detector Dexis. 

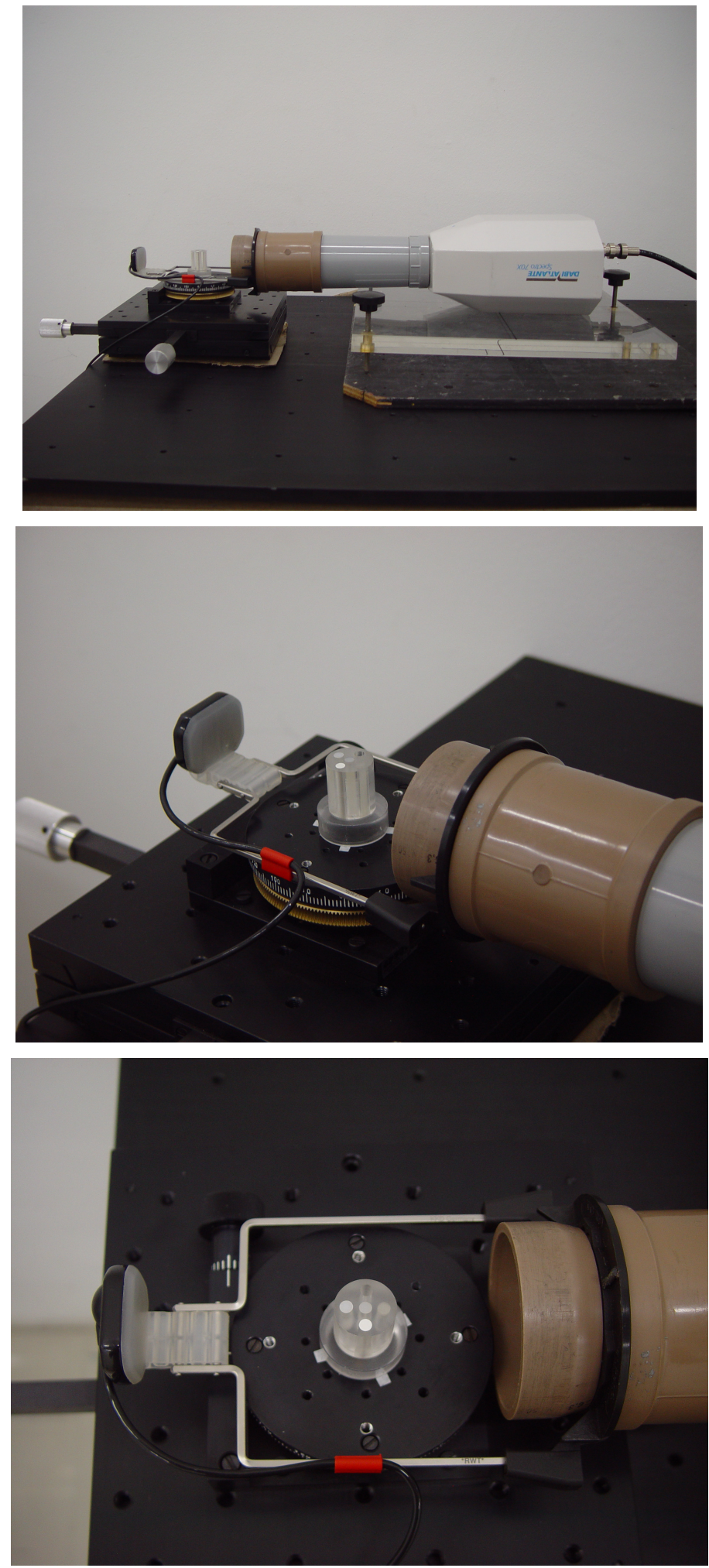

Figura 41 - Sistema de aquisição de imagens montado com o equipamento de raios $X$ odontológico e o sistema de detecção Dexis. 


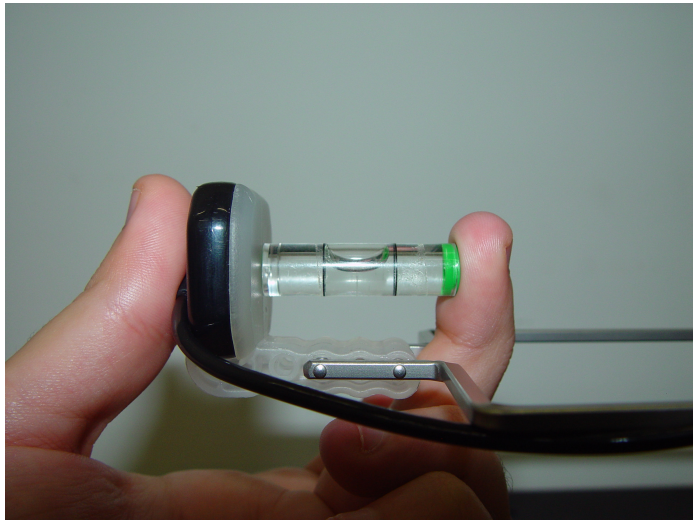

(a)

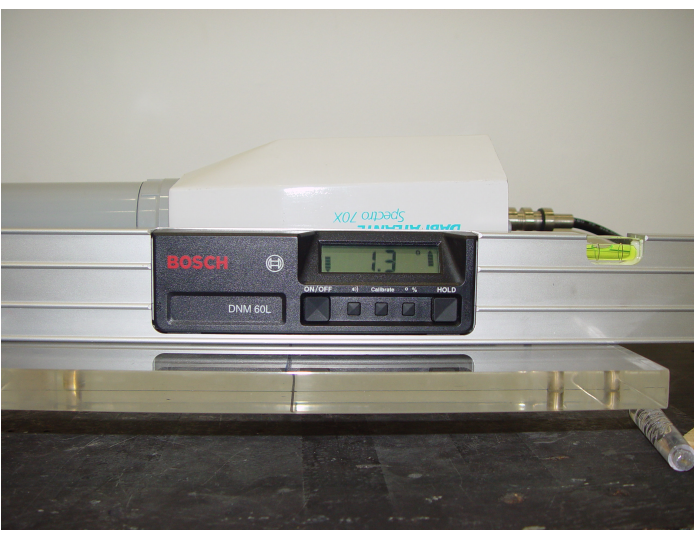

(c)

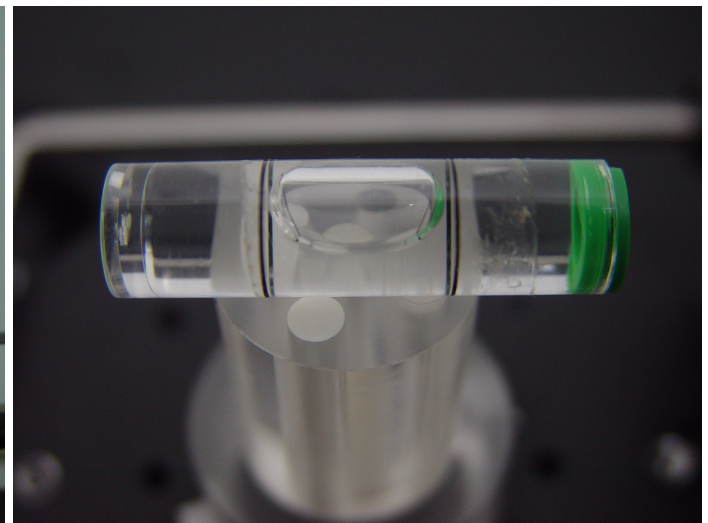

(b)

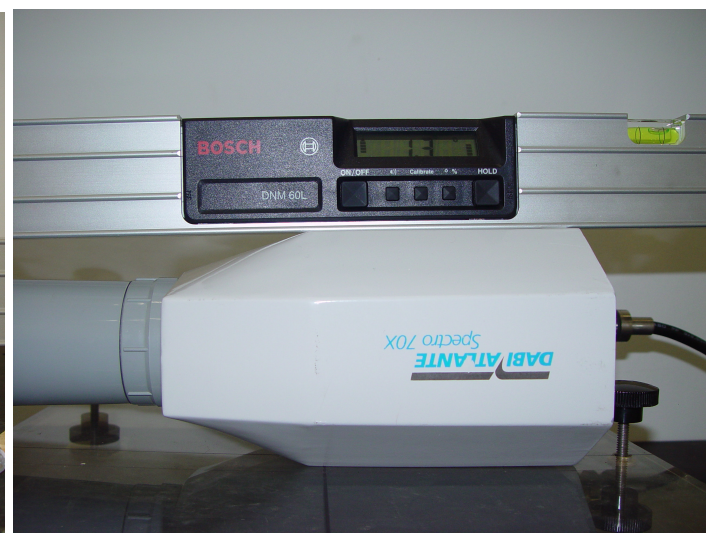

Figura 42 - Medição da inclinação do detector (a), inclinação do plano de rotação do objeto (b), inclinação da cúpula do equipamento de raios $X$ (c)

O sistema $\mathrm{N}^{\mathrm{o}} 3$ foi utilizado na reconstrução de dois objetos. Primeiramente, do objeto cilíndrico que foi fabricado, apresentado na Figura 35. Como será discutido no item 6.4.1, a reconstrução deste objeto possibilitou a calibração do sistema TCMC implementado. Em seguida, foi reconstruído um objeto não homogêneo $\mathrm{e}$ geometricamente assimétrico (Figura 43). Este objeto é construído em material plástico com bolhas de ar aleatoriamente distribuídas em seu interior. Neste caso, o principal objetivo era identificar as diferenças nas imagens reconstruídas dos diferentes cortes do objeto, a fim de avaliar o desempenho do sistema na reconstrução de vários cortes com uma única varredura, caracterizando uma reconstrução tomográfica multi-cortes. Cada objeto foi reconstruído a partir de 720 projeções com um intervalo angular de $0,5^{\circ}$ entre cada uma. 


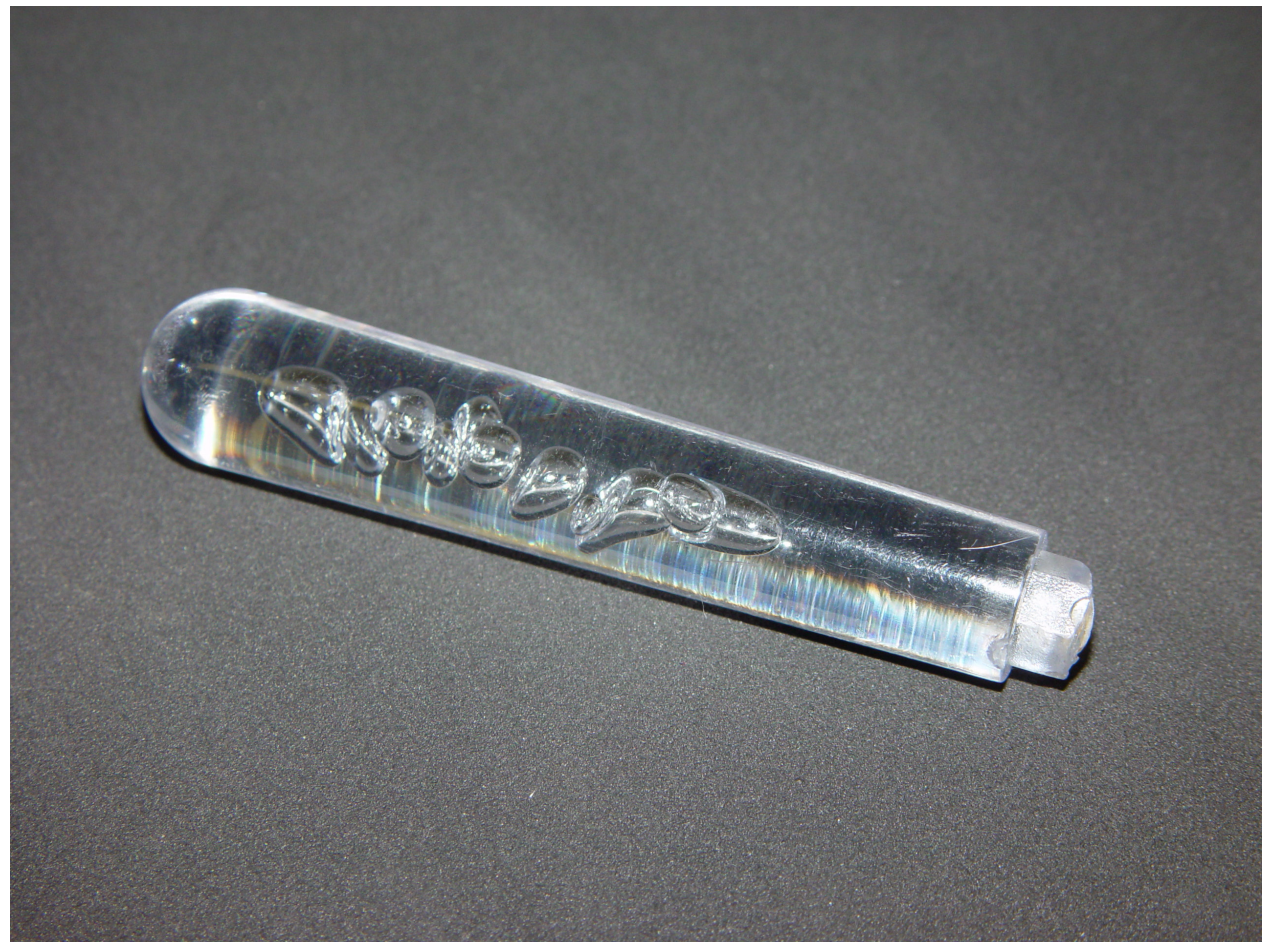

Figura 43 - Objeto não homogêneo e sem simetria cilíndrica que foi reconstruído a partir de 720 projeções coletadas com o sistema № 3 . O objeto é constituído por um material plástico com bolhas de ar distribuídas em seu interior.

As projeções coletadas com este último sistema de aquisição apresentaram uma qualidade superior àquelas coletadas com o sistema $\mathrm{N}^{\mathrm{o}} 2$, o que não eliminou a presença de artefatos nas imagens reconstruídas, mas facilitou a sua identificação e possível correção. O número maior de projeções teve como objetivo diminuir os artefatos de aliasing $^{31}$.

As imagens reconstruídas a partir do novo conjunto de projeções foram analisadas utilizando-se o programa ImageJ.

\subsection{Implementação das Correções Matemáticas dos Artefatos}

\subsubsection{Correção na Posição do Ponto Focal}

Como será observado nos resultados desse trabalho, apresentados no capítulo 7 , item 7.2.1 (Figura 57), as primeiras imagens reconstruídas apresentavam um artefato 
incomum. Estes artefatos aparecem como uma não uniformidade das estruturas cilíndricas que compõem o objeto reconstruído (Figura 35). Pode-se dizer que as imagens do corte de cada cilindro, que deveriam aparecer como discos homogêneos, aparecem como discos maiores e não homogêneos, com uma região central bem definida, com tom de cinza mais claro ou mais escuro que as bordas. Na tentativa de eliminar esse artefato das imagens, foi proposto um modelo para explicar a presença desses artefatos nas imagens reconstruídas e, em seguida, foi implementada uma formulação para solucionar o problema.

Como discutido no capítulo 5, no processo de reconstrução tomográfica, é fundamental determinar precisamente a posição do ponto focal do tubo com relação ao detector, pois no processo de retro-projeção, a determinação dos voxels, sobre os quais será retro-projetado cada ponto da projeção, depende diretamente da posição do feixe central com relação ao detector. A Figura 44 mostra o esquema da retro-projeção de um cilindro sólido homogêneo sobre seu corte central, a partir de 4 projeções, supondo que o feixe central incida perpendicularmente no centro do detector.

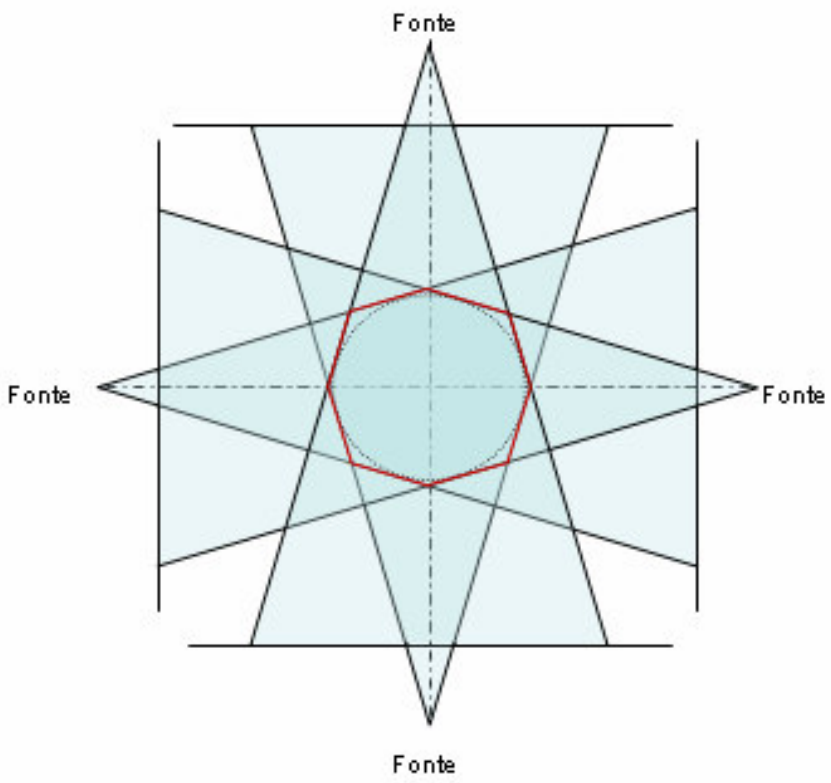

Figura 44 - Esquema da reconstrução do corte central de um cilindro sólido, a partir de 4 projeções, utilizando um algoritmo do tipo FBP.

Neste caso, a retro-projeção é consistente, e a reconstrução é perfeita. Pode-se ver que quanto maior o número de projeções, mais o polígono vermelho se aproximará da 
circunferência que delimita o cilindro reconstruído. Suponha agora que o feixe central esteja deslocado do centro do detector. Sendo assim, cada ponto (Y) da linha do detector, que deveria ser retro-projetado sobre o mesmo caminho dos fótons de raios $\mathrm{X}$ que o atingiram, será retro-projetado sobre uma trajetória com outra inclinação (Figura 45 (a)). A linha YO, suposta no algoritmo como o caminho dos fótons que atingem o ponto Y, estará incorreta.

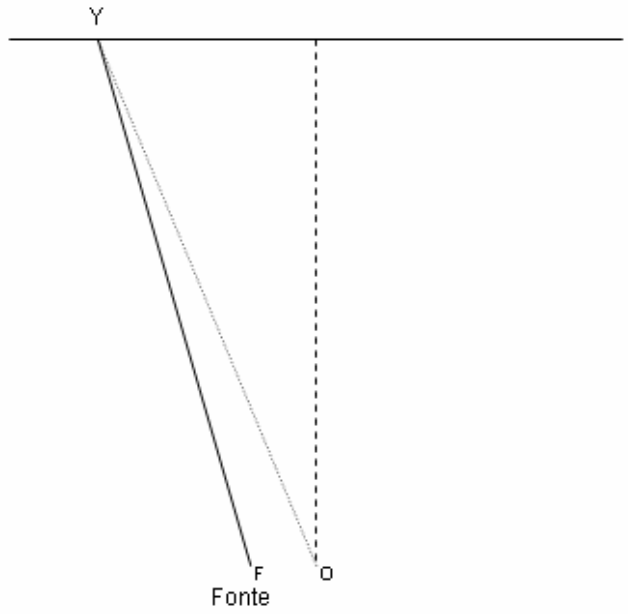

(a)

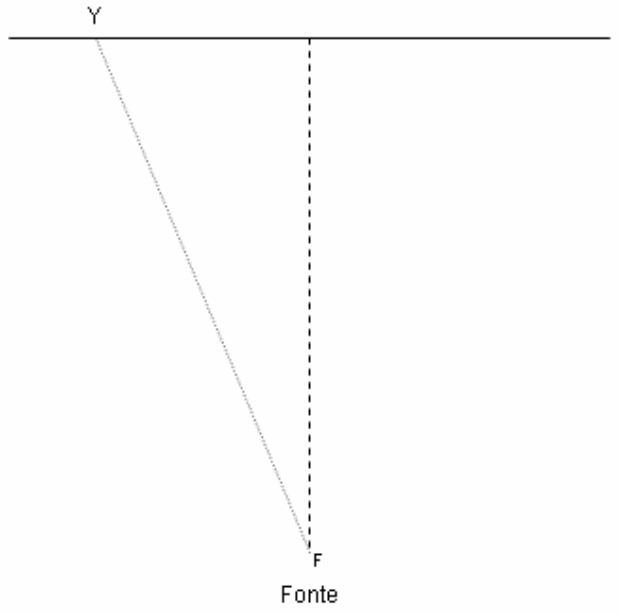

(b)

Figura 45 - Esquema da retro-projeção de um ponto $Y$ do detector no caso de feixe central deslocado (a). Esquema da retro-projeção de um ponto $Y$ do detector no caso de feixe central corretamente posicionado.

Quando se conhece a posição de incidência do feixe central, pode-se determinar a trajetória dos fótons que atingiram cada ponto do detector, e conseqüentemente o caminho inverso da retro-projeção (Figura 45 (b)). A Figura 46 mostra o mesmo esquema de retro-projeção da Figura 44, mas com o desvio da posição do feixe central. Pode-se ver que o efeito esperado de tal erro é semelhante ao observado nas imagens mostradas na Figura 57. 


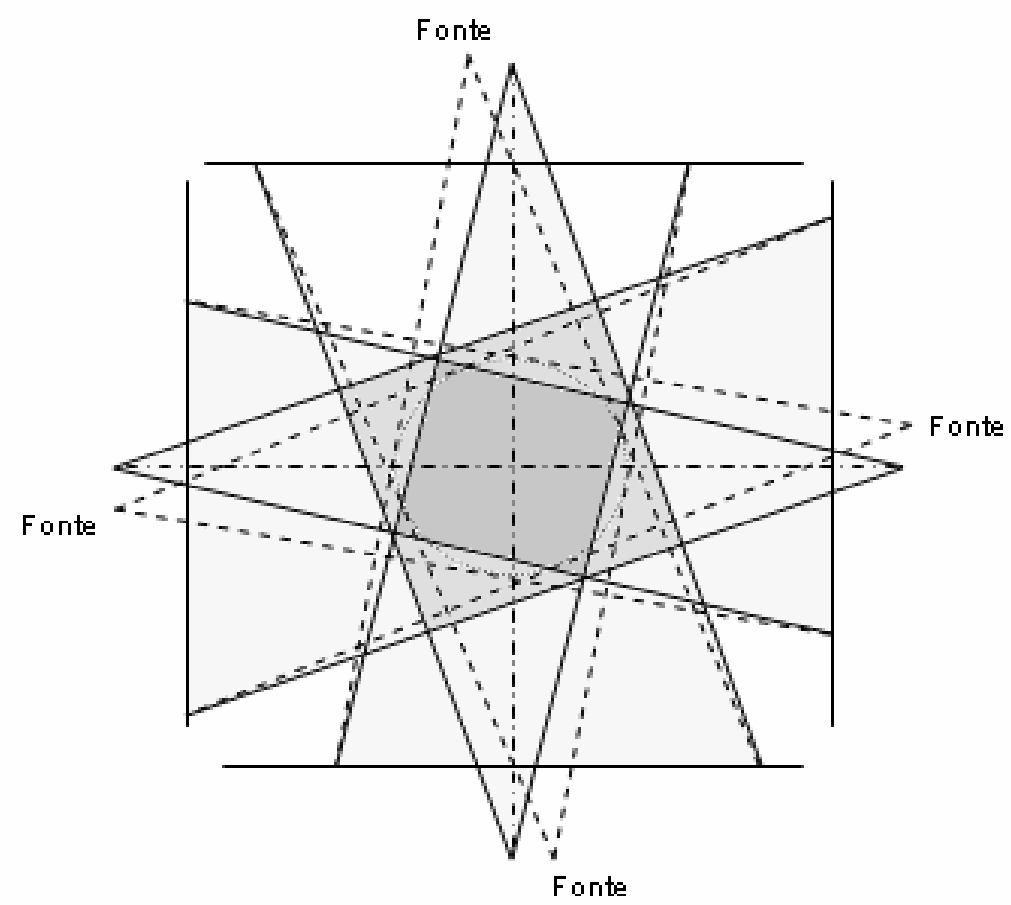

Figura 46 - Esquema da reconstrução do corte central de um cilindro sólido, a partir de 4 projeções com feixe central deslocado, utilizando um algoritmo do tipo FBP.

Supondo que esse era o problema que resultou nos artefatos nas imagens reconstruídas, inseriu-se uma variável $\Delta X$ de deslocamento na posição do ponto focal, e substituiu-se, no algoritmo implementado, $Y_{r}=\bar{Y}_{r}$, onde

$$
\bar{Y}_{r}=\frac{D(\vec{r} \cdot \hat{Y}-\Delta X)}{d+\vec{r} \cdot \hat{x}^{\prime}}
$$

$\mathrm{O}$ valor de $\Delta X$ foi, então, variado até que as imagens dos cortes dos cilindros apareçam como um disco o mais homogêneo e perfeito possível.

\subsubsection{Correção de Artefatos Devidos ao Ruído Presente nas Projeções: Implementação do Filtro Rampa Modificado}

Para diminuir os artefatos devidos ao ruído presente nas projeções, implementouse a versão modificada do algoritmo FDK, definida no capítulo 5. O Pseudocódigo 6 descreve a implementação do algoritmo FDK modificado. 


\section{Pseudocódigo 6 - Implementação do algoritmo FDK modificado.}

LER $I, J, K, d, D, T, N, M, S N R, \Delta X$;

$\mu_{n, m, t} \leftarrow 0$

PARA $i \leftarrow 1$ ATÉ $I$, FAZ

LER $P_{\Phi_{i}}$;

PARA $j \leftarrow 1$ ATÉ $J$, FAZ

PARA $k \leftarrow 1$ ATÉ $K$, FAZ

$\bar{P}_{\Phi_{i}}\left(Y_{j}, Z_{k}\right) \leftarrow \frac{d}{\left(d^{2}+Y_{j}^{2}+Z_{k}^{2}\right)^{\frac{1}{2}}} P_{\Phi_{i}}\left(Y_{j}, Z_{k}\right) ;$

FIM PARA

FIM PARA

PARA $j \leftarrow 1$ ATÉ $J$, FAZ

SE $j \leq \frac{J}{2}$, ENTÃO

$w_{j+\frac{J}{2}} \leftarrow 2 \pi\left(\frac{-J+1}{2 Y}+\frac{j-1}{Y}\right)$

SENÃO

$w_{j-\frac{J}{2}} \leftarrow 2 \pi\left(\frac{-J+1}{2 Y}+\frac{j-1}{Y}\right)$

FIM SE

FIM PARA

PARA $j \leftarrow 1$ ATÉ $J$, FAZ

$$
W R_{j} \leftarrow\left|w_{j}\right| \frac{S N R}{S N R+w_{j}^{2}} ;
$$

FIM PARA

PARA $k \leftarrow 1$ ATÉ $K$, FAZ

$F P_{\Phi_{i}}(k,:) \leftarrow F F T\left(P_{\Phi_{i}}(k,:)\right) W R ;$

$C_{\Phi_{i}}(k,:)=\mathfrak{R}\left(\operatorname{IFFT}\left(F P_{\Phi_{i}}(k,:)\right)\right) ;$

FIM PARA

PARA $t \leftarrow 1$ ATÉ $T$, FAZ

PARA $n \leftarrow 1$ ATÉ $N$, FAZ

PARA $m \leftarrow 1$ ATÉ $M$, FAZ

$$
Y_{r} \leftarrow \frac{D\left(-x_{n} \operatorname{sen}\left(\Phi_{i}\right)+y_{m} \cos \left(\Phi_{i}\right)-\Delta X\right)}{d+x_{n} \cos \left(\Phi_{i}\right)+y_{m} \operatorname{sen}\left(\Phi_{i}\right)} ;
$$




$$
\begin{aligned}
& Z_{r} \leftarrow \frac{D \cdot z_{t}}{d+x_{n} \cos \left(\Phi_{i}\right)+y_{m} \operatorname{sen}\left(\Phi_{i}\right)} \\
& \mu_{n, m, t} \leftarrow \mu_{n, m, t}+\frac{D d}{\left(d+x_{n} \cos \left(\Phi_{i}\right)+y_{m} \operatorname{sen}\left(\Phi_{i}\right)\right)^{2}} C_{\Phi_{i}}\left(Y_{r}, Z_{r}\right) \cdot \Delta \Phi ;
\end{aligned}
$$

FIM PARA

FIM PARA

FIM PARA

FIM PARA

PARA $t \leftarrow 1$ ATÉ $T$, FAZ

PARA $n \leftarrow 1$ ATÉ $N$, FAZ

PARA $m \leftarrow 1$ ATÉ $M$, FAZ

$$
n C T_{n, m, t} \leftarrow \frac{\left(\mu_{n, m, t}-\mu_{\text {agua }}\right)}{\mu_{\text {aguа }}} 1000 ;
$$

FIM PARA

FIM PARA

FIM PARA

Onde, $S N R$ é a razão sinal ruído média das projeções, $F P_{\Phi_{i}}(k,:), P_{\Phi_{i}}(k,:)$ e $C_{\Phi_{i}}(k,:)$ representam os vetores formados pelas linhas $k$ das matrizes $F P_{\Phi_{i}}, P_{\Phi_{i}}$ e $C_{\Phi i}$ e, $F F T$ e IFFT representam, respectivamente, a transformada finita de Fourier e sua inversa.

Esta correção foi, primeiramente, aplicada às imagens reconstruídas a partir das projeções coletadas com o sistema de aquisição № 2 . A fim de avaliar o resultado da aplicação desta correção, determinou-se o ruído presente nas imagens reconstruídas com e sem a correção. Como o ruído foi determinado somente para fins de comparação, sua medição foi simples. Apenas determinou-se o desvio padrão do valor médio dos números CT de uma determinada área sobre a imagem de um dos materiais componentes do objeto reconstruído, neste caso, o acrílico. Assumiu-se que o ruído presente nas imagens é diretamente proporcional ao desvio padrão.

\subsubsection{Correção Algorítmica de Artefatos de Aliasing}

Foi implementado um método para diminuir a produção de artefatos de aliasing, intrínseca ao processo de aquisição das projeções. Tal método consiste numa tentativa de 
respeitar as condições de amostragem de Nyquist-Shannon ${ }^{42,43}$, descritas resumidamente no capítulo 5 .

A re-amostragem das projeções coletadas foi feita de modo que cada pixel das projeções modificadas tenha uma largura múltipla da dos pixels das projeções originais. O intervalo entre cada pixel da nova matriz de imagem re-amostrada deve ser o mesmo da matriz original. Na Figura 47 mostra-se como é calculado o valor de cada pixel da nova projeção, e suas posições são indicadas pelas setas. Pode-se perceber que o intervalo espacial entre cada seta corresponde ao mesmo intervalo entre os pixels das projeções originais.

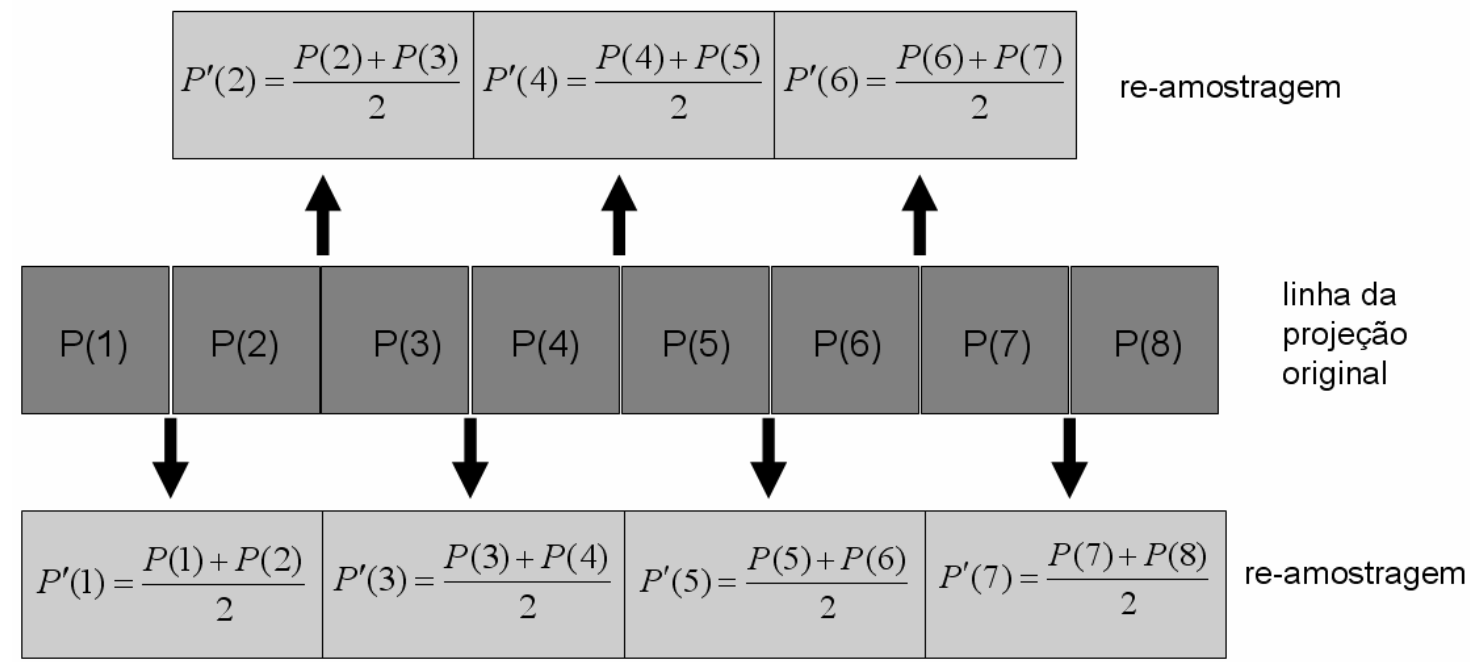

Figura 47 - Esquema de re-amostragem das projeções, assumindo pixels com duas vezes a largura dos elementos originais do detector. $P(\mathrm{i})$ e $P^{\prime}(\mathrm{i})$ correspondem ao i-ésimo elemento de cada linha das projeções, originais e re-amostradas, respectivamente.

\subsection{Análise das Imagens Reconstruídas}

A análise e a calibração do sistema de TCMC implementado no presente trabalho, foram realizadas com base nas imagens reconstruídas a partir das projeções coletadas, exclusivamente, com o sistema de aquisição de projeções $\mathrm{N}^{\mathrm{o}} 3$ (Tabela 3). Este fato é justificado pelo melhor desempenho apresentado por este sistema.

Para analisar as imagens reconstruídas foi utilizado o software ImageJ. Realizouse a medição dos valores de número $\mathrm{CT}$ de cada uma das estruturas identificadas nas 
imagens reconstruídas e o ruído correspondente, que foi assumido como o desvio padrão dos valores dos pixels nas regiões de interesse.

Para determinar o número CT de cada estrutura definida nas imagens, foi calculada a média aritmética dos valores de cerca de $80 \%$ dos pixels que compõem a imagem de cada uma dessas estruturas (Figura 48 (a)), juntamente com o respectivo desvio padrão, $\sigma$. Esses valores médios foram então comparados com os valores esperados para cada material que compõe os objetos reconstruídos.

Nas imagens reconstruídas a partir das projeções simuladas, além da medição dos valores de número $\mathrm{CT}$, verificou-se a concordância entre as dimensões esperadas e medidas para cada estrutura identificada nas imagens. Nesta verificação, procurou-se observar se as dimensões das diferentes estruturas presentes nas imagens reconstruídas eram iguais àquelas conhecidas e pré-determinadas nos objetos simulados. Pôde-se determinar as dimensões das imagens reconstruídas em número de pixels. Para tanto, foram plotadas as curvas de perfil de tons de cinza dos objetos reconstruídos (Figura 48 (b)) e determinou-se a dimensão de cada estrutura identificada nas imagens como sendo igual a largura à meia altura dos respectivos perfis. A incerteza associada à medida das dimensões foi determinada pela propagação do erro na determinação da altura média, $h$, do perfil de cada estrutura. Supondo um desvio padrão, $\sigma_{h}$, no valor da altura média, calculou-se o valor da incerteza, $\sigma_{D}$, associada à medida das dimensões, pela equação $\sigma_{D}=\frac{\sigma_{h}}{2} \frac{1}{\alpha_{1}}+\frac{\sigma_{h}}{2} \frac{1}{\alpha_{2}}$, onde $\alpha_{1}$ e $\alpha_{2}$ correspondem aos valores da derivada da curva de perfil em cada um dos dois pontos cujas imagens valem $h / 2$. 


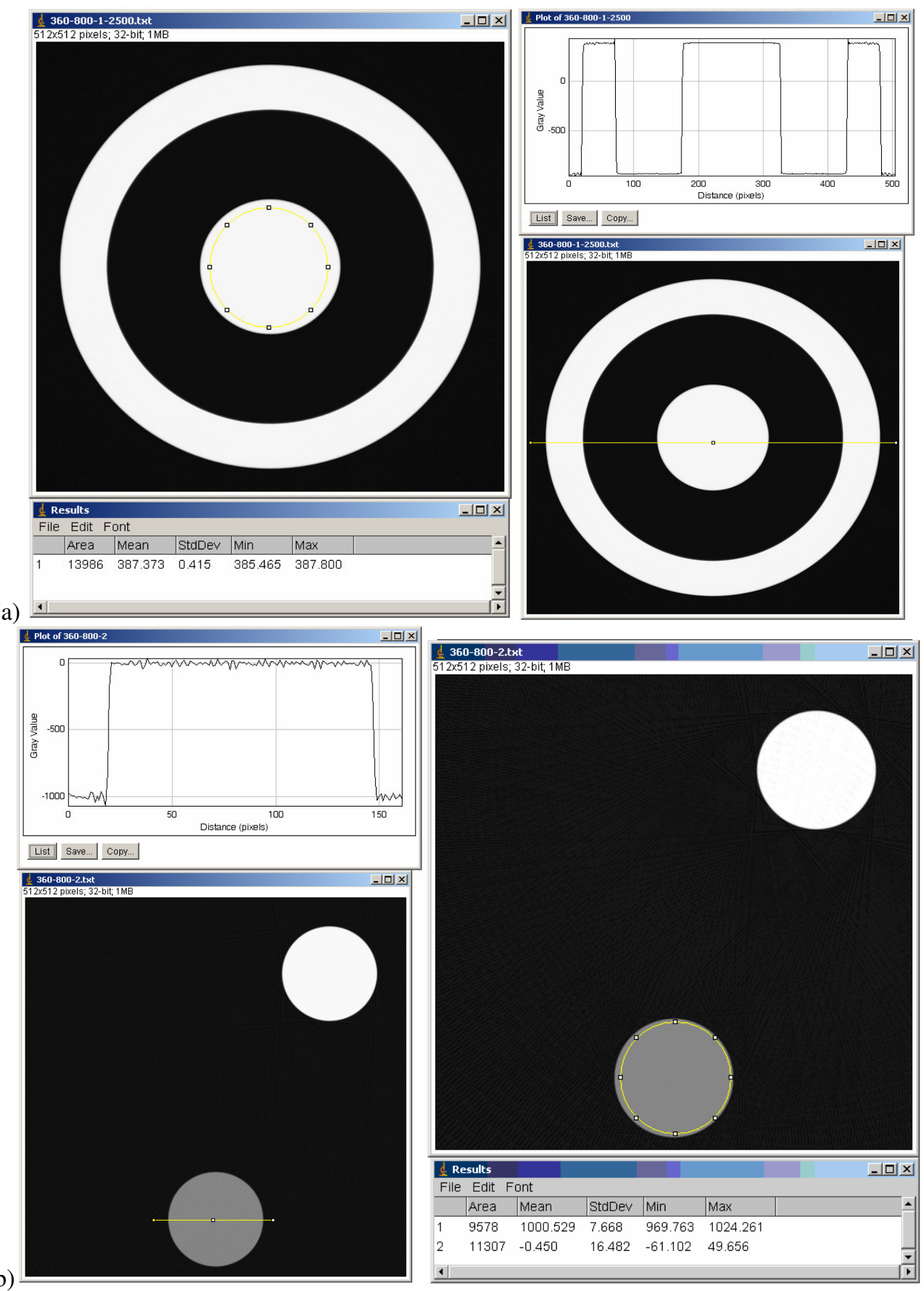

Figura 48 - Medição das dimensões relativas e número CT encontrados nas imagens reconstruídas, utilizando ferramentas do software ImageJ. (a) Medição das dimensões relativas de cada estrutura identificada na curva de nível; Medição dos valores médios de número CT de cada estrutura que compõe os objetos reconstruídos (b). 
Para poder determinar o número CT esperado para cada material que compõe o objeto fabricado (Figura 35), é necessário conhecer os valores dos coeficientes de atenuação linear, $\mu_{E f}$, de cada material que compõe o objeto, para a energia efetiva do feixe. Para isso, foram construídos gráficos de $\frac{\mu}{\rho} \times E$ para cada material que compõem o objeto. Os pontos dos gráficos foram obtidos através do programa $\mathrm{XCOM}^{48}$ a partir das composições químicas de cada material. Os valores de $\frac{\mu_{E f}}{\rho}$ dos materiais foram determinados diretamente nas equações das curvas, $y=y_{0}+A_{1} \exp \left(\frac{-x}{t_{1}}\right)+A_{2} \exp \left(\frac{-x_{0}}{t_{2}}\right)$, que foram obtidas por regressão exponencial de segunda ordem dos valores de $\frac{\mu}{\rho}$ sobre os valores de energia, $E$, realizada no software Origin ${ }^{\circledR}$ (Microcal Software, Inc., Northampton, EUA). A Tab Apresenta os coeficientes de cada curva exponencial obtida.

Tabela 5 - Coeficientes das curvas obtidas pela regreção exponencial de segunda ordem dos valores de $\frac{\mu}{\rho}$ sobre os valores de energia, E, para cada material.

\begin{tabular}{|c|cccc|}
\cline { 2 - 5 } & Polietileno & Nylon & Acrílico & PVC \\
\hline \hline \hline $\mathbf{y}_{\mathbf{0}}$ & $-2,13$ & $-2,13$ & $-2,15$ & $-2,24$ \\
\hline $\mathbf{A}_{\mathbf{1}}$ & 6,0 & 6,6 & 6,81 & 6,98 \\
\hline $\mathbf{t}_{\mathbf{1}}$ & 0,0086 & 0,0094 & 0,0098 & 0,0211 \\
\hline $\mathbf{A}_{\mathbf{2}}$ & 0,81 & 0,818 & 0,839 & 1,26 \\
\hline $\mathbf{t}_{\mathbf{2}}$ & 0,125 & 0,111 & 0,110 & 0,111 \\
\hline \hline
\end{tabular}

Da Figura 49 à Figura 52 são apresentados os gráficos citados acima. 


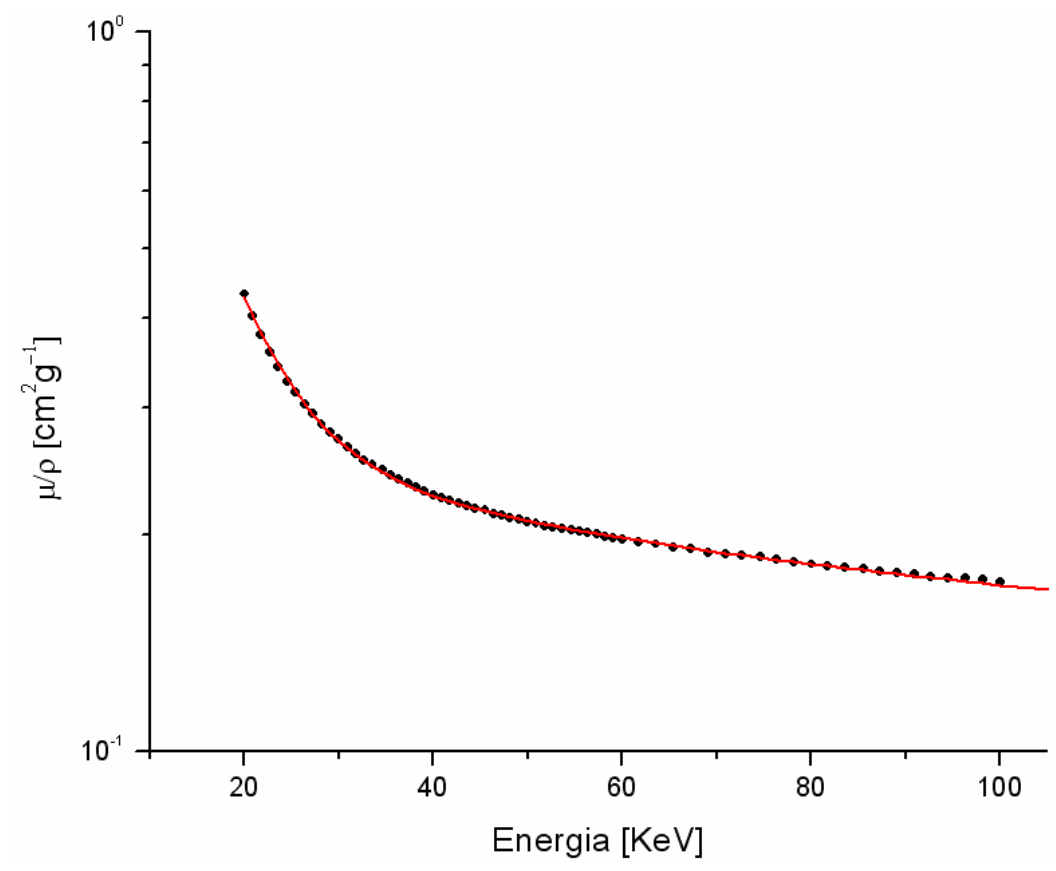

Figura 49 - Gráfico de $\frac{\mu}{\rho} \times E$ para o polietileno, com a regressão exponencial de segunda ordem dos valores de $\frac{\mu}{\rho}$ sobre os valores de E.

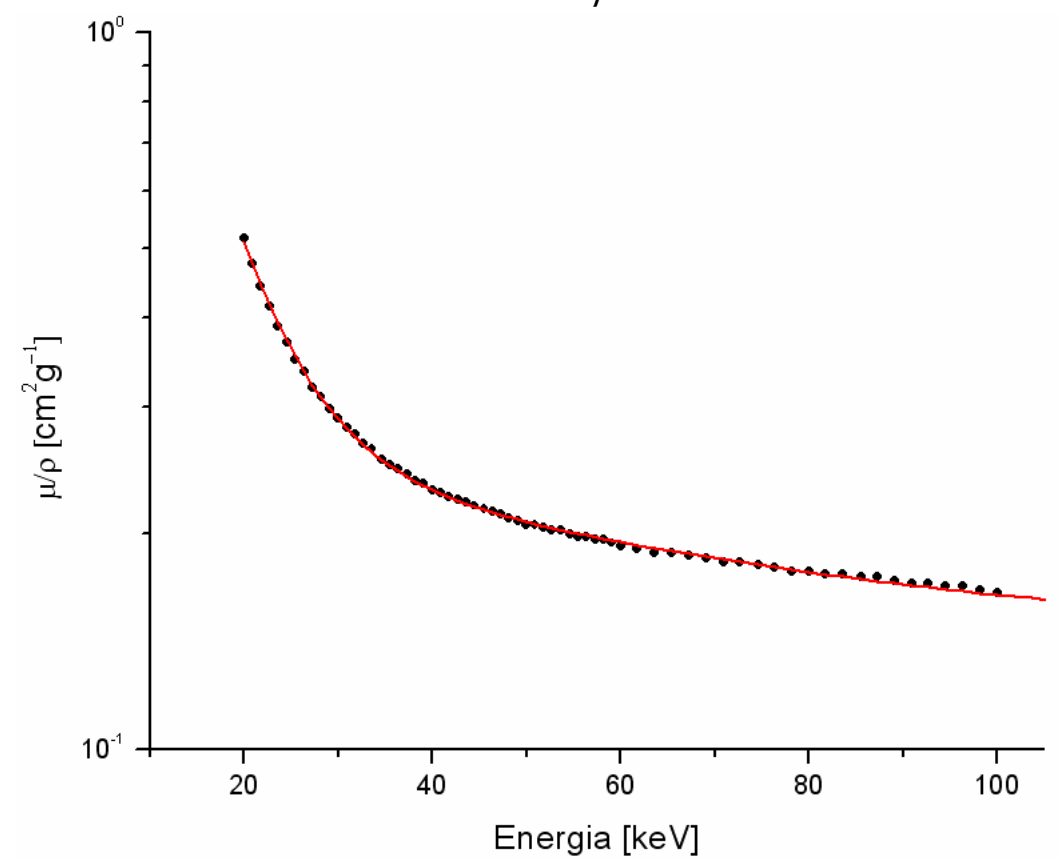

Figura 50 - Gráfico de $\frac{\mu}{\rho} \times E$ para o Nylon, com a regressão exponencial de segunda ordem dos valores de $\frac{\mu}{\rho}$ sobre os valores de $\mathrm{E}$. 


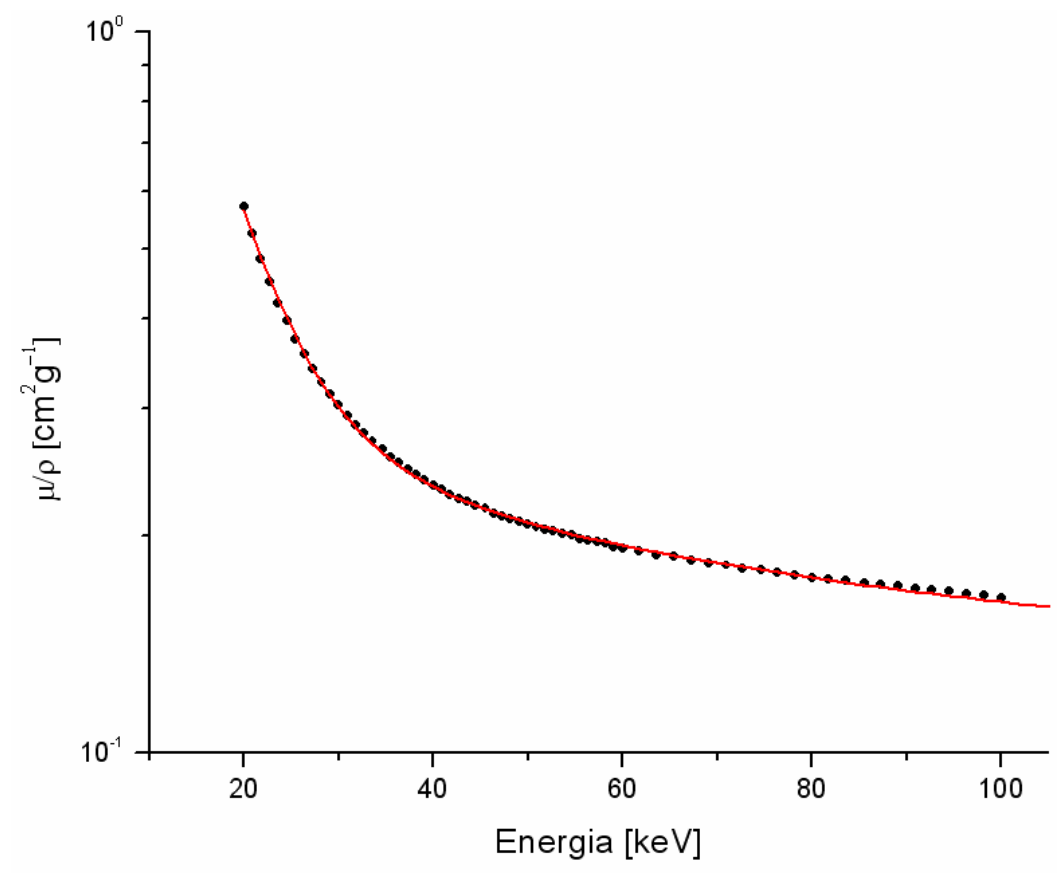

Figura 51 - Gráfico de $\frac{\mu}{\rho} \times E$ para o Acrílico, com a regressão exponencial de segunda ordem dos valores de $\frac{\mu}{\rho}$ sobre os valores de E.

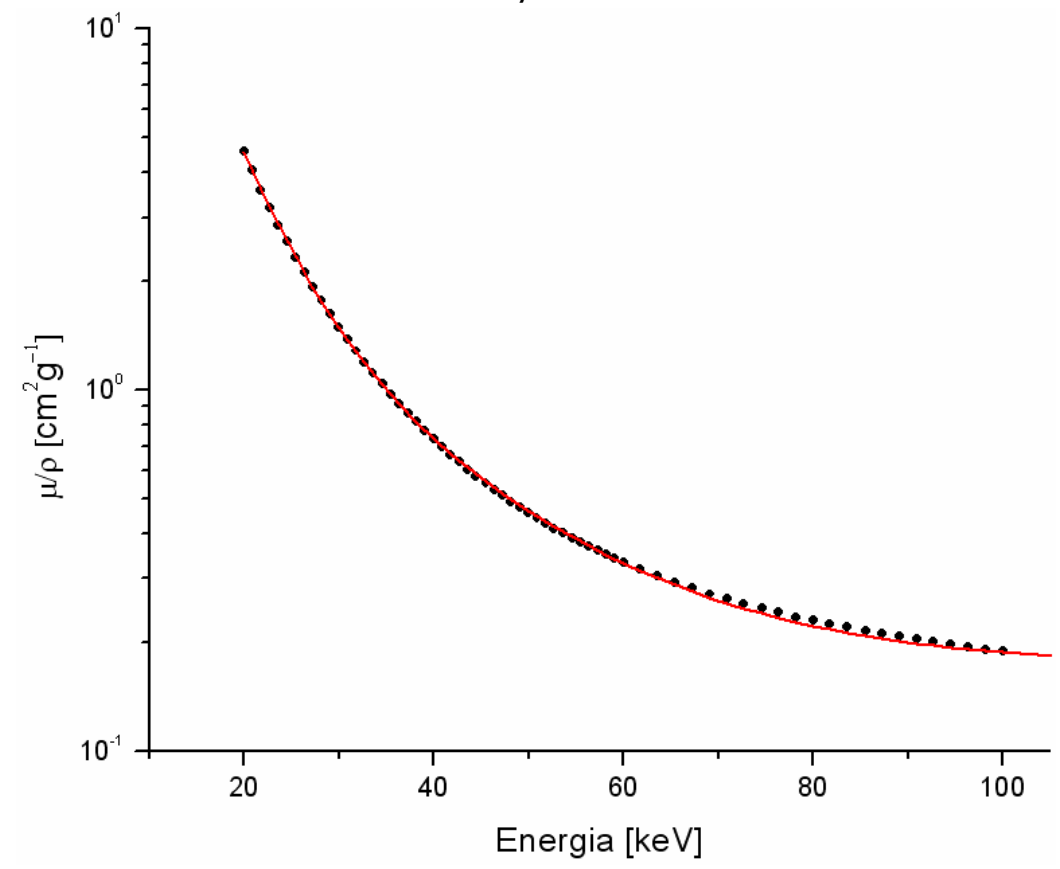

Figura 52 - Gráfico de $\frac{\mu}{\rho} \times E$ para o PVC, com a regressão exponencial de segunda ordem dos valores de $\frac{\mu}{\rho}$ sobre os valores de $\mathrm{E}$. 
A incertezas associadas às medidas de $\mu\left(E_{E f}\right)$ de cada material que compõe o objeto foram calculadas pela propagação das incertezas associadas à energia efetiva determinada para o feixe e às densidades medidas para cada cilindro que compõe o objeto.

Para determinar a energia efetiva do feixe, mediu-se a camada semi-redutora (CSR) em alumínio do equipamento de raios X e, a partir da equação (61), calculou-se o coeficiente de atenuação linear do alumínio para esse feixe.

$$
\mu\left(E_{E f}\right)=\frac{\ln 2}{C S R}
$$

A incerteza na determinação de $\mu\left(E_{E f}\right)$, foi calculada pela propagação da incerteza na determinação da $C S R$.

Utilizando-se o valor estimado para $\mu_{A l}\left(E_{E f}\right)$ e o valor conhecido da densidade do alumínio, $\rho_{\mathrm{Al}}=2,7 \mathrm{~g} / \mathrm{cm}^{3}$, pôde-se estimar o valor da energia efetiva do feixe diretamente na equação (62), da curva de $\frac{\mu_{A l}}{\rho_{A l}} \times E$ (Figura 53), obtida por regressão exponencial dos valores de $\frac{\mu_{A l}}{\rho_{A l}}$ sobre os valores de energia, $E$. Estes valores foram obtidos no programa XCOM, em um gráfico de $\frac{\mu_{A l}}{\rho_{A l}} \times E$. A regressão exponencial foi, novamente, realizada no software Origin ${ }^{\circledR}$. 


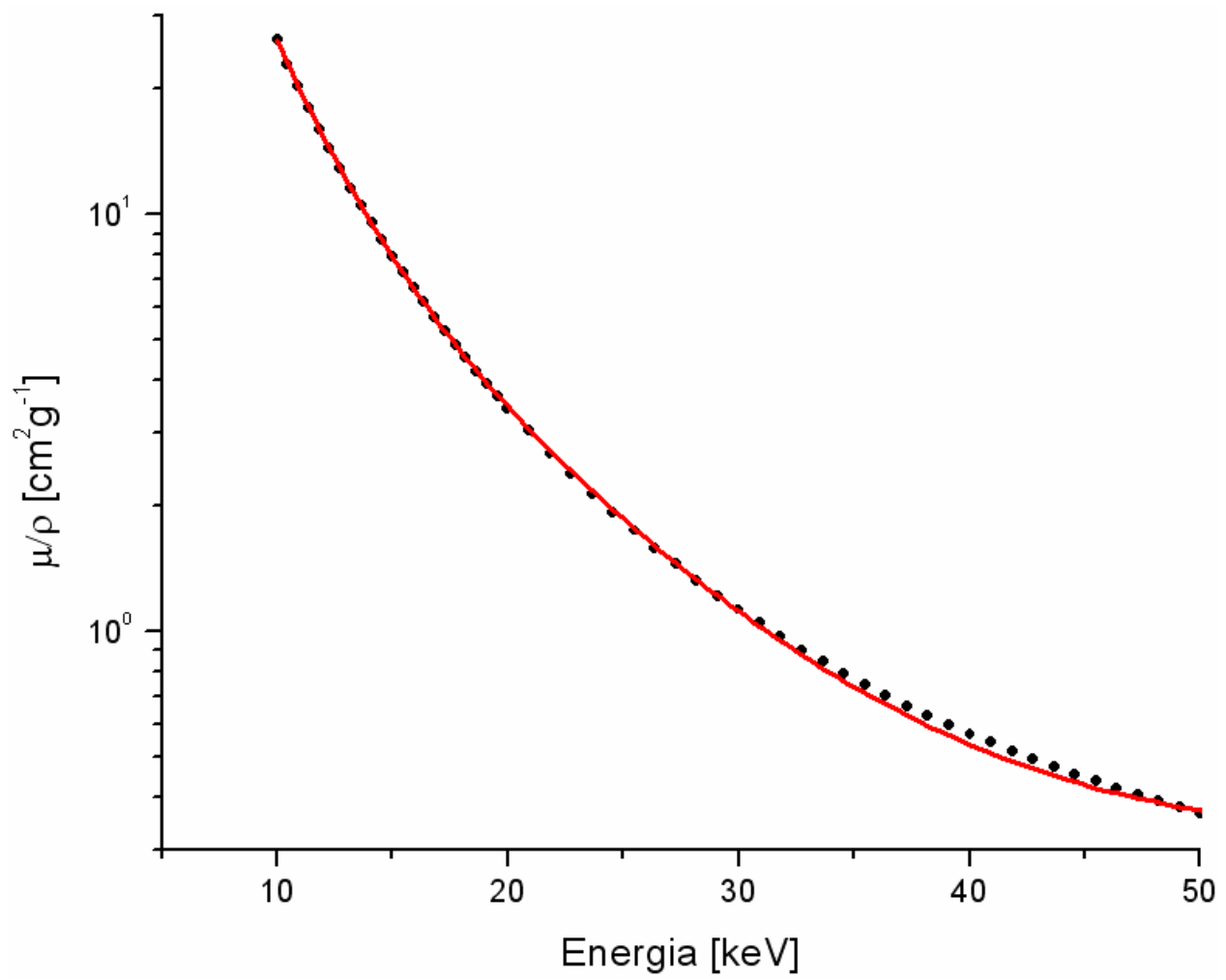

Figura 53 - - Gráfico de $\frac{\mu}{\rho} \times E$ para o Aluminio, com a regressão exponencial de primeira ordem dos valores de $\frac{\mu}{\rho}$ sobre os valores de $\mathrm{E}$.

$$
\ln \left(\frac{\mu_{A l}(E)}{\rho_{A l}}\right)=-1,62+8,03 \times \exp \left(\frac{-E}{0,0194}\right)
$$

A incerteza associada ao valor determinado para a energia efetiva do feixe foi calculada a partir da propagação do erro na determinação de $\mu_{A l}\left(E_{E f}\right)$, calculado utilizando-se a equação (61).

Na determinação da Camada Semi-Redutora de alumínio, utilizou-se a mesma geometria definida na norma internacional IEC 61267:2005 ${ }^{49}$ para a determinação das qualidades padronizadas de radiação (RQR2 a RQR10). Realizaram-se três medições de intensidade do feixe, para cada espessura de filtro de alumínio utilizada. As intensidades foram medidas com o medidor de radiação X, modelo 1515 (Radical Corp., EUA), acoplado a uma câmara de ionização 10x5, também da Radical Corp. Foi usado um 
conjunto de 6 filtros de alumínio (99,5\% de pureza), sendo quatro de 0,1 $\mathrm{mm}$, um de 0,5 $\mathrm{mm}$ e o último de $1 \mathrm{~mm}$. Combinando esses filtros é possível medir as intensidades para até 19 espessuras diferentes de filtro, variando de $0,1 \mathrm{~mm}$ até $1,9 \mathrm{~mm}$. A partir dos valores de intensidade obtidos, foi obtida uma curva de atenuação para o feixe de raios $\mathrm{X}$ do equipamento odontológico, obtida por regressão linear dos valores de $\frac{I_{0}}{I}$ sobre os valores das espessuras, $x$, dos filtros, utilizando o software Origin®. Os resultados referentes a estas medidas são apresentados no ítem 7.2.2.1, na Figura 75. O valor da camada semi-redutora foi obtido diretamente na equação, $y=A+B x$, que descreve a curva de atenuação ajustada.

A incerteza, $\sigma_{C S R}$, na determinação da $C S R$ em alumínio é composta pela propagação das incertezas, $\sigma_{A} e \sigma_{B}$, associadas aos coeficientes, $A$ e $B$, da reta e pela incerteza, $\bar{\sigma}$, associada à espessura de cada filtro de Al utilizado. A incerteza, $\sigma_{C S R}$, foi calculada pela equação (63).

$$
\sigma_{C S R}=\sqrt{\bar{\sigma}^{2}+\left(\frac{\partial x}{\partial A} \sigma_{A}\right)^{2}+\left.\left(\frac{\partial x}{\partial B} \sigma_{B}\right)^{2}\right|_{y=\ln (2)}}
$$

Onde, $x(y)=\frac{y-A}{B}$ e $\bar{\sigma}$ é a soma das incertezas, $\sigma$, conhecidas na espessura de cada placa de alumínio utilizada para compor o filtro com a menor espessura que fosse maior que a $C S R$ determinada.

A incerteza associada a cada medida de $I / I_{0}$, foi calculada pela propagação das incertezas nas intensidades médias determinadas que, por sua vez, são compostas pelo desvio padrão e o erro do equipamento de medição. A equação (64) apresenta o método utilizado no cálculo das incertezas nas medidas de $I / I_{0}$.

$$
\sigma_{I / I_{0}}=\sqrt{\left(\frac{1}{I_{0}} \sigma_{I}\right)^{2}+\left(\frac{I}{I_{0}^{2}} \sigma_{I_{0}}\right)^{2}}
$$


Onde, a incerteza associada a cada medida de intensidade, inclusive $I_{0}$, vem dada por $\sigma_{I}=\sqrt{\sigma_{e}^{2}+\sigma_{s}^{2}}$, sendo $\sigma_{e}$ e $\sigma_{s}$, respectivamente, o desvio padrão da média das intensidades medidas e a resolução do equipamento utilizado nas medições.

A densidade de cada material foi determinada a partir da medição de suas massas e volumes. Para medir o volume de cada cilindro que compõe o objeto fabricado, utilizou-se um micrômetro (Mitutoyo, Brasil). Para determinar a massa dos cilindros, utilizou-se uma balança digital, modelo AS 2000 (Marte, Brasil). A incerteza em cada medição foi assumida como sendo igual à resolução de cada equipamento utilizado. A incerteza na determinação das densidades foi calculada por propagação das incertezas nas medidas de massa, diâmetro e altura de cada cilindro.

\subsubsection{Verificação da Linearidade do Sistema}

A definição de número CT (equação (3)) apresentada no capítulo 2, determina uma relação linear entre o número CT e o coeficiente de atenuação linear dos materiais. Portanto, todo equipamento de tomografia computadorizada deve apresentar esta relação de linearidade.

Nos processos de calibração dos equipamentos de TC, realiza-se a reconstrução tomográfica de um phantom constituído de materiais homogêneos conhecidos. As imagens reconstruídas foram analisadas, a fim de comparar os valores de número CT medidos com aqueles esperados para cada material e verificar a relação de linearidade entre esses dados. No presente trabalho, a reconstrução tomográfica do objeto descrito no item 6.2.3 (Figura 35) foi utilizada para a calibração do sistema de TCMC implementado.

A verificação da linearidade do sistema não implica, a princípio, na equivalência entre os valores de número CT medidos e esperados. Mesmo para um sistema linear, o número CT medido depende da resposta do detector utilizado no equipamento. Sendo assim, é necessário incorporar uma correção linear para o ajuste dos valores de número CT ao algoritmo de reconstrução. 
Para verificar a linearidade do sistema, foram construídos gráficos da relação entre os valores de número CT medidos e esperados para cada material do objeto reconstruído. Pela regressão linear dos valores esperados sobre os valores medidos, obteve-se a equação da reta que melhor se ajusta aos dados. Com isso foi possível analisar e quantificar a linearidade do sistema, assim como determinar o ajuste linear que deve ser incorporado ao algoritmo de reconstrução.

O algoritmo corrigido foi então aplicado na reconstrução das mesmas imagens, que foram novamente analisadas para a verificação da concordância entre os valores de número CT esperados e medidos.

\subsubsection{Reconstrução Tomográfica Multi-cortes de um Objeto Não Homogêneo e Sem Simetria Geométrica}

$\mathrm{O}$ algoritmo $\mathrm{FDK}^{25}$ é um algoritmo para a reconstrução tomográfica multi-cortes, isto é, um algoritmo capaz de reconstruir vários cortes de um objeto a partir de suas projeções bi-dimensionais, coletadas com uma única varredura.

Para verificar o desempenho do sistema na reconstrução tomográfica multi-cortes, realizou-se a reconstrução de um objeto assimétrico e não homogêneo (Figura 43). O objeto foi reconstruído a partir de 720 projeções coletadas com o sistema de aquisição de projeções $\mathrm{N}^{\mathrm{o}} 3$, com intervalo angular de $0,5^{\circ}$ entre cada uma.

Foram reconstruídos 16 cortes de $1 \mathrm{~mm}$ de espessura. As imagens reconstruídas deveriam apresentar um padrão de variação consistente com a forma do objeto real. Todas as imagens reconstruídas são apresentadas no capítulo 7, item 7.2.2.2. 


\section{CAPÍTULO 7 - Resultados}

Os resultados obtidos podem ser divididos em dois grupos: Resultados das simulações computacionais, necessários para verificar se o algoritmo FDK foi implementado corretamente; e resultados das reconstruções feitas a partir das projeções reais medidas com os sistemas de aquisição de imagens montados.

\subsection{Resultados das Simulações}

O objetivo das simulações computacionais foi testar o funcionamento do algoritmo implementado na reconstrução de imagens a partir das projeções ideais, que não apresentam ruído ou qualquer outro fator que cause a produção de artefatos nas imagens reconstruídas. Desse modo, qualquer artefato encontrado nas imagens reconstruídas a partir de projeções reais, obtidas com o sitema de aquisição de projeções implementado, seria devido às propriedades do processo físico de aquisição das projeções, ou ainda devido a falhas na metodologia utilizada na etapa de implementação do sistema de aquisição de projeções.

A Figura 54 e a Figura 55 mostram as imagens reconstruídas, a partir das projeções simuladas com geometria de feixe paralelo, dos cortes centrais do primeiro e segundo objetos idealizados, respectivamente, para diferentes configurações.

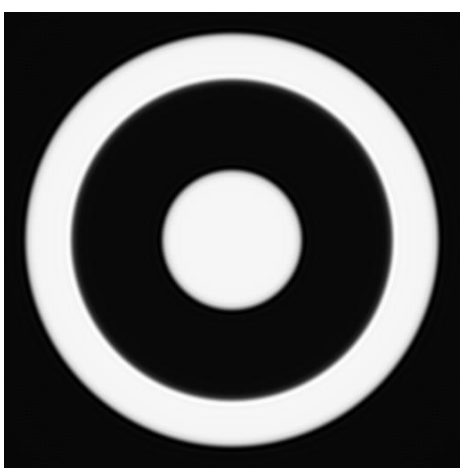

(a)

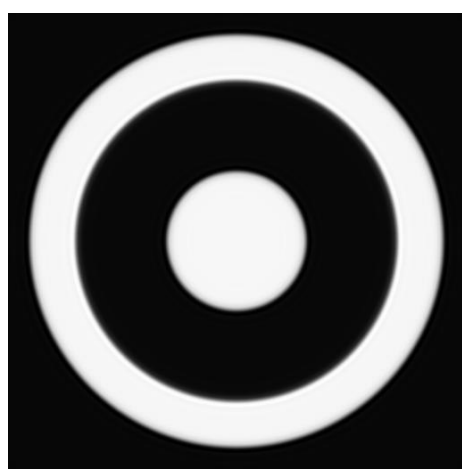

(b)

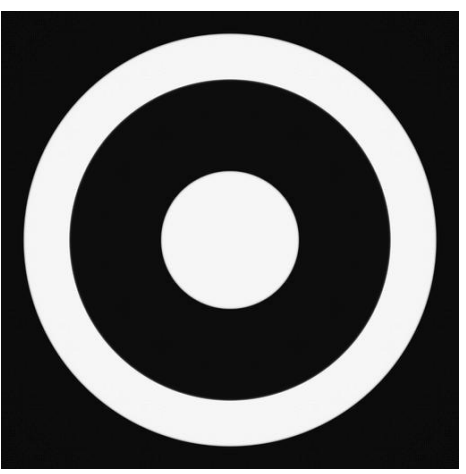

(c)

Figura 54 - Imagens reconstruídas do corte central do primeiro objeto, a partir de projeções simuladas com feixe paralelo, para 3 configurações diferentes. (a) 180 projeções de 200 pixels, com um intervalo angular de $1^{\circ}$ entre cada uma; (b) 360 projeções de 200 pixels, com um intervalo angular de 0,5e entre cada uma; (c) 360 projeções de 800 pixels, com intervalo angular de 0,5 ${ }^{\circ}$ entre cada uma. Todas as imagens reconstruídas possuem resolução de $512 \times 512$ pixels. 


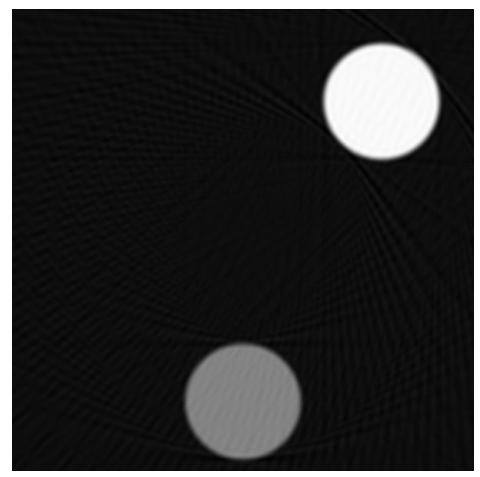

(a)

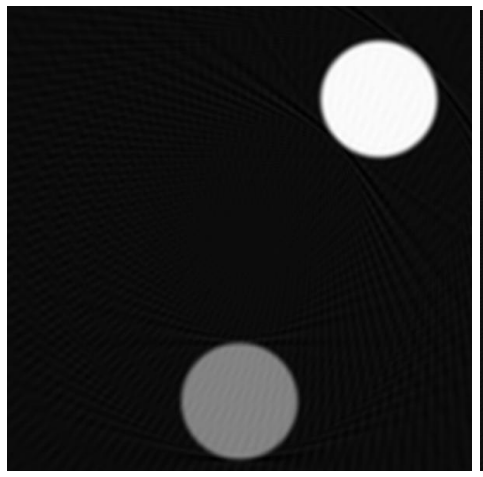

(b)

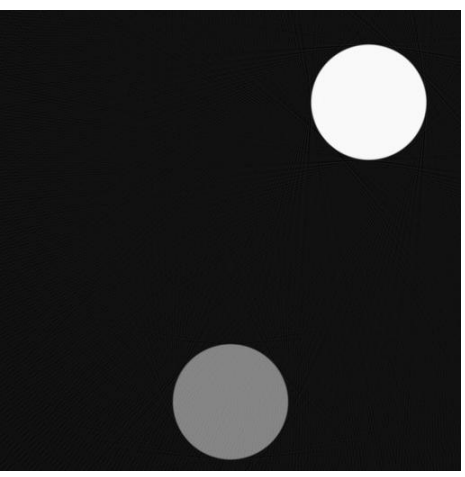

(c)

Figura 55- Imagens reconstruídas do corte central do segundo objeto, a partir de projeções simuladas com feixe paralelo, para 3 configurações diferentes. (a) 180 projeções de 200 pixels, com

um intervalo angular de $1^{\circ}$ entre cada uma; (b) 360 projeções de 200 pixels, com um intervalo angular de 0,5e entre cada uma; (c) 360 projeções de 800 pixels, com intervalo angular de 0,5 0 entre cada uma. Todas as imagens reconstruídas possuem resolução de $512 \times 512$ pixels.

As imagens apresentadas nas Figura 54 e Figura 55 indicam um bom funcionamento do algoritmo, pois as imagens reconstruídas apresentam os cortes esperados para os objetos simulados.

Uma análise mais detalhada das imagens foi feita com o auxílio do software ImageJ, assim como descrito no capítulo 6, item 6.4. A Tabela 6 apresenta as medidas das dimensões das estruturas que compõem os objetos reconstruídos.

Tabela 6 - Medidas das dimensões das estruturas que compõem os objetos reconstruídos, a partir das projeções simuladas com geometria de feixe paralelo.

\begin{tabular}{cccc}
\hline \hline Objeto simulado & \multicolumn{2}{c}{$\begin{array}{c}\text { Dimensões esperadas para cada } \\
\text { estrutura [pixels] }\end{array}$} & $\begin{array}{c}\text { Dimensão determinada } \\
\text { [pixels] }\end{array}$ \\
\hline \hline \multirow{2}{*}{ Primeiro } & $\begin{array}{c}\text { diâmetro do } \\
\text { cilindro interno }\end{array}$ & 150 & $150 \pm 0,5$ \\
\cline { 2 - 4 } & $\begin{array}{c}\text { espessura da } \\
\text { casca cilíndrica }\end{array}$ & 50 & $50 \pm 0,5$ \\
\hline \multirow{2}{*}{ Segundo } & $\begin{array}{c}\text { diâmetro do } \\
\text { cilindro No } 1\end{array}$ & 102 & $102 \pm 0,5$ \\
\cline { 2 - 4 } & $\begin{array}{c}\text { diâmetro do } \\
\text { cilindro No } 2\end{array}$ & 102 & $102 \pm 0,5$ \\
\hline \hline
\end{tabular}

Pode-se ver que as dimensões das estruturas presentes nas imagens apresentam excelente concordância com as dos objetos idealizados.

A Tabela 7 mostra os resultados obtidos nas medições dos valores de número CT. 
Tabela 7 - Comparação entre os valores de número CT esperados e medidos, para os dois objetos idealizados.

\begin{tabular}{cccccc}
\hline \hline $\begin{array}{c}\text { Objeto } \\
\text { simulado }\end{array}$ & Número CT esperado & $\begin{array}{c}\text { Número de } \\
\text { pixels }\end{array}$ & $\begin{array}{c}\text { Número } \\
\text { CT médio }\end{array}$ & $\begin{array}{c}\text { Desvio } \\
\text { Padrão }\end{array}$ \\
\hline \hline Primeiro & 386 & & 13960 & 387 & 1 \\
\hline \multirow{2}{*}{ Segundo } & cilindro $\mathrm{N}^{\mathrm{o}} 1$ & 1000 & 11287 & 1000 & 8 \\
\cline { 2 - 6 } & cilindro $\mathrm{N}^{\mathrm{o}} 2$ & 0 & 10456 & 0 & 16 \\
\hline \hline
\end{tabular}

Os resultados da análise das imagens confirmam o funcionamento do algoritmo. Tanto as dimensões como os valores de numero CT medidos nas imagens reconstruídas estavam de acordo com os valores esperados.

A Figura 56 mostra as imagens reconstruídas do segundo objeto a partir das projeções simuladas com geometria de feixe em leque.

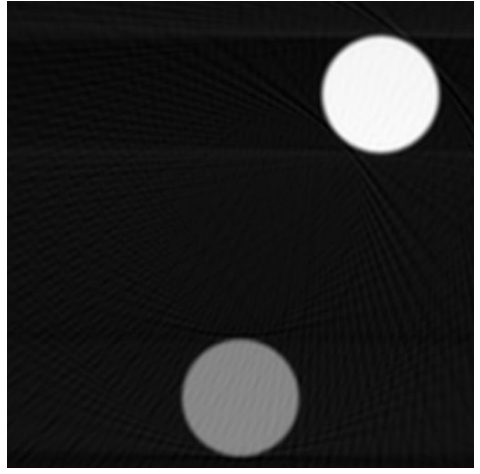

(a)

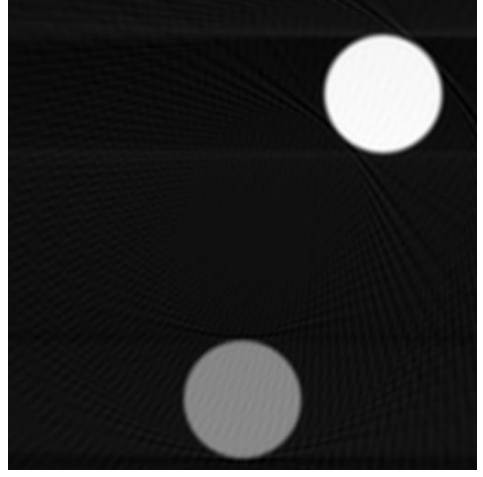

(b)

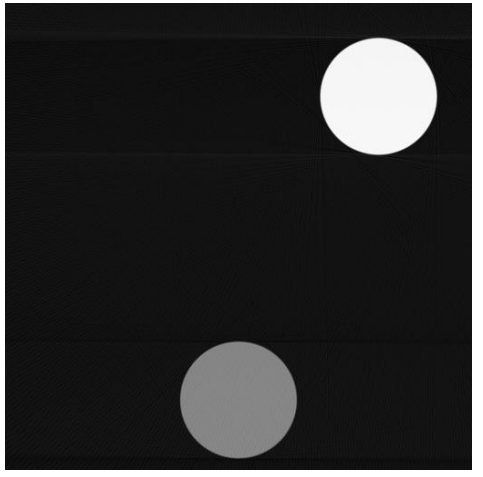

(c)

Figura 56 - Imagens reconstruídas do corte central do segundo objeto, a partir de projeções simuladas com geometria de feixe em leque, para 3 configurações diferentes. (a) 180 projeções de 200 pixels, com um intervalo angular de $1^{\circ}$ entre cada uma; (b) 360 projeções de 200 pixels, com um intervalo angular de 0,50 entre cada uma; (c) 360 projeções de 800 pixels, com intervalo angular de $0,5^{\circ}$ entre cada uma. Todas as imagens reconstruídas possuem resolução de $512 \times 512$ pixels.

As imagens apresentadas na Figura 56 foram igualmente analisadas no ImageJ. A Tabela 8 apresenta os resultados da medição das dimensões das estruturas que compõem o objeto reconstruído a partir das projeções simuladas com geometria de feixe em leque. 
Tabela 8 - Medidas das dimensões das estruturas que compõem o objeto reconstruído a partir das projeções simuladas com geometria de feixe em leque.

\begin{tabular}{ccc}
\hline \hline Objeto de medida & Dimensão esperada & Dimensão medida \\
\hline \hline diâmetro do cilindro $\mathrm{N}^{\mathrm{o}} 1$ & 102 & $102 \pm 0,6$ \\
\hline diâmetro do cilindro $\mathrm{N}^{\mathrm{o}} 2$ & 102 & $102 \pm 0,6$ \\
\hline \hline
\end{tabular}

Mais uma vez as dimensões das estruturas contidas nas imagens concordam com as dos objetos idealizados. A Tabela 9 mostra os resultados da medição dos valores de número CT de cada estrutura que compõe o objeto simulado.

Tabela 9 - Valores de número CT esperados e medidos, para cada estrutura cilíndrica que compõe o segundo objeto.

\begin{tabular}{ccccc}
\hline \hline $\begin{array}{c}\text { Estrutura do } \\
\text { objeto }\end{array}$ & $\begin{array}{c}\text { Número CT } \\
\text { esperado }\end{array}$ & $\begin{array}{c}\text { Número de } \\
\text { pixels }\end{array}$ & $\begin{array}{c}\text { Número CT } \\
\text { médio }\end{array}$ & $\begin{array}{c}\text { Desvio } \\
\text { padrão }\end{array}$ \\
\hline \hline Cilindro $\mathrm{N}^{0} 1$ & 1000 & 10798 & 997 & 6 \\
\hline Cilindro $\mathrm{N}^{0} 2$ & 0 & 11205 & 0 & 14 \\
\hline \hline
\end{tabular}

Novamente há concordância entre os valores de número CT esperados e medidos. $\mathrm{O}$ resultado positivo nas reconstruções, a partir das projeções simuladas com geometria de feixe em leque, confirmou novamente o funcionamento do algoritmo.

\subsection{Resultados das Reconstruções Reais}

Como descrito no capítulo 6, item 6.2, foram implementados três sistemas distintos de aquisição de projeções, que simulam o funcionamento de um equipamento de TC. Como o sistema № 1 era incapaz de produzir um conjunto de dados consistente, apenas os sistemas № 2 e № 3 foram utilizados para a aquisição das projeções do objeto a ser reconstruído. É importante frisar que em todas as reconstruções, a área de retroprojeção foi limitada à circunferência com diâmetro igual ao tamanho do FOV (Fild Of View). 


\subsubsection{Imagens Reconstruídas a partir das Projeções Coletadas com o Sistema de Aquisição № 2}

A Figura 57 mostra as imagens reconstruídas do objeto fabricado (Figura 35) a partir das projeções coletadas com o sistema de aquisição № 2 .

(a)
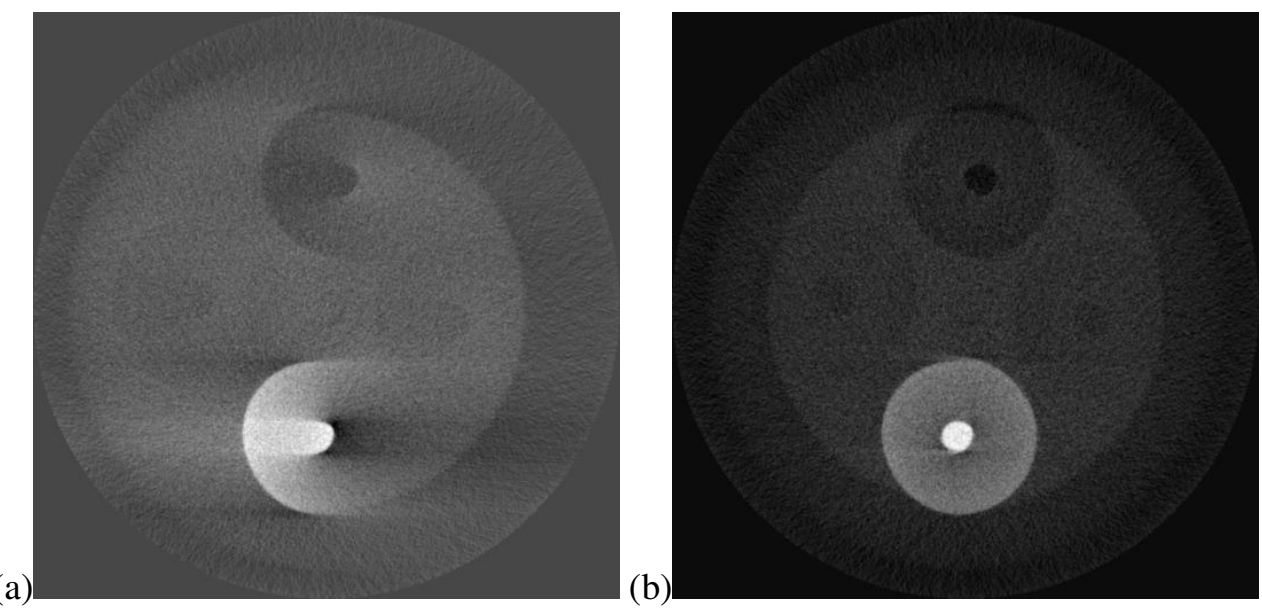

Figura 57 - Imagens reconstruídas a partir das projeções medidas com o sistema de aquisição de imagens № 2. (a) 180 projeções e (b) 360 projeções, com um intervalo angular de $1^{\circ}$ entre cada projeção.

Como discutido no capítulo 6, item 6.3, observa-se a presença de um artefato bastante pronunciado nas imagens apresentadas na Figura 57. Foi, então, implementada a correção matemática da posição do ponto focal, descrita no capítulo 6, item 6.3.1. A Figura 58 apresenta as imagens com um fator de correção, $\Delta X=-1,3 \mathrm{~mm}$.

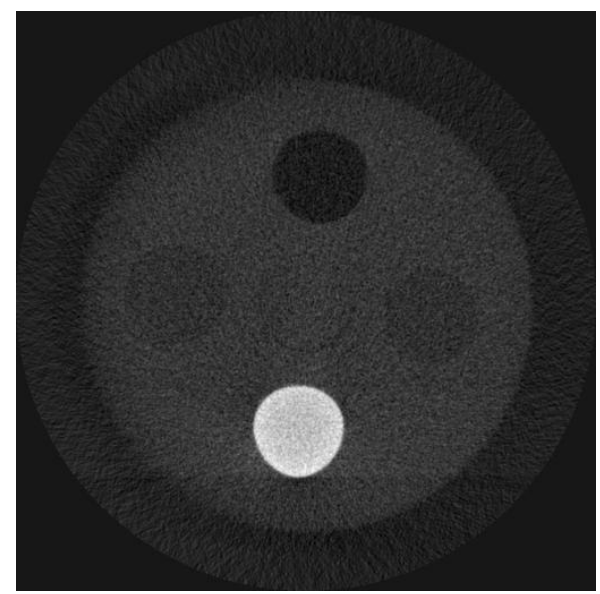

(a)

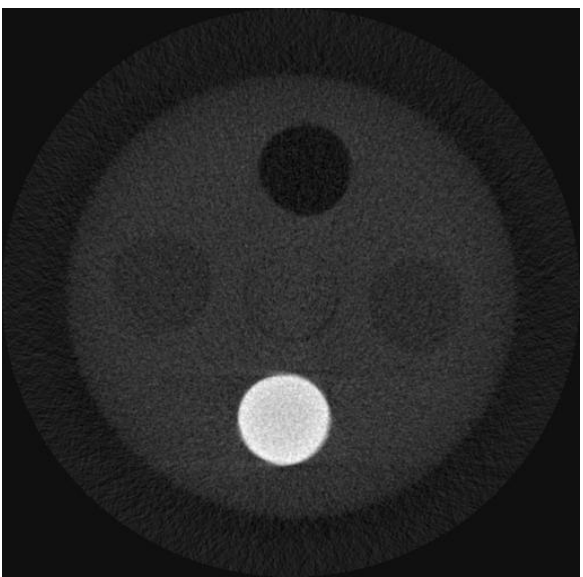

(b)

Figura 58 - Imagens reconstruídas com correção de posicionamento do feixe central, a partir de 180 (a) e 360 (b) projeções simuladas. 
Para reduzir o ruído presente nas imagens, aplicou-se a versão modificada do algoritmo FDK, descrita no capítulo 6, item 6.3.2. Não foi encontrada referência a respeito da razão sinal ruído $(S N R)$ do sistema de detecção sens-a-Ray.

A Figura 59 mostra as imagens reconstruídas a partir do algoritmo descrito pelo Pseudocódigo 6, utilizando o valor da razão sinal ruído, $S N R=10$.

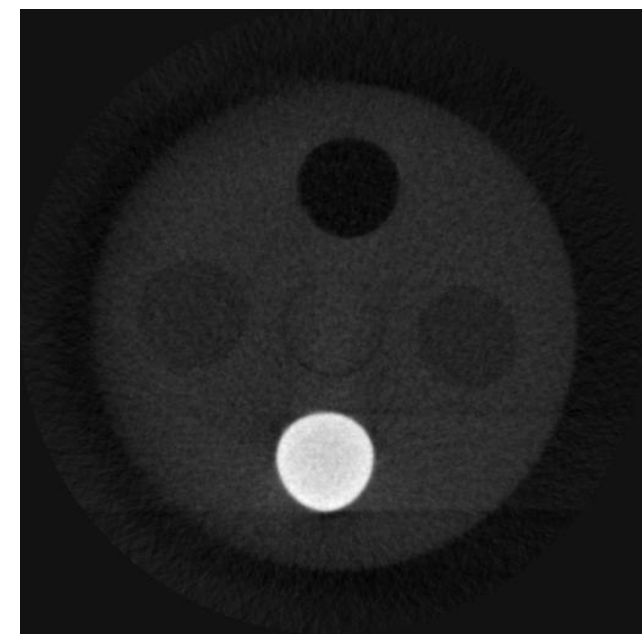

(a)

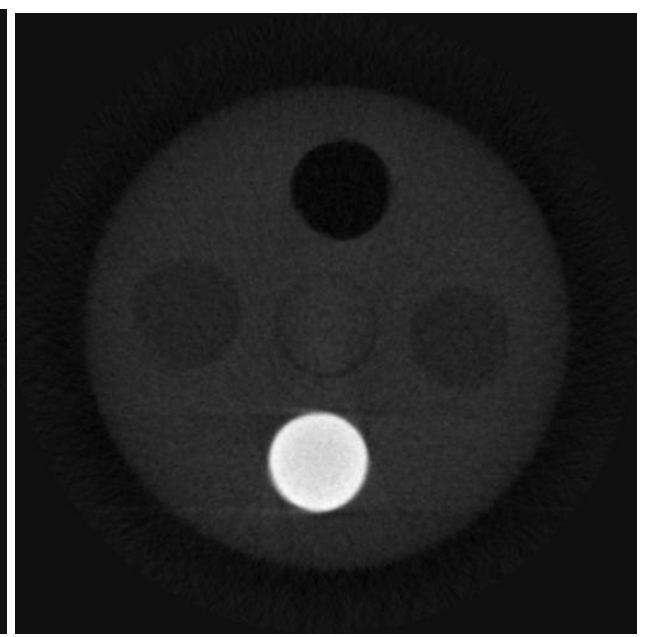

(b)

Figura 59 - Imagens reconstruídas do corte central do objeto com o algoritmo FDK modificado, a partir de 180 (a) e 360 projeções simuladas (b), ambas com intervalos angulares de 1‥

A comparação entre o ruído presente nas imagens antes (Figura 58) e depois da correção (Figura 59) é apresentada na Tabela 10.

Tabela 10 - Comparação entre o ruído presente nas imagens reconstruídas a partir das projeções coletadas com o sistema de aquisição № 2 , com e sem a aplicação do filtro rampa modificado.

\begin{tabular}{|c|c|c|c|}
\hline \hline $\begin{array}{c}\text { Número de } \\
\text { projeções }\end{array}$ & $\begin{array}{c}\text { Filtro aplicado no processo } \\
\text { de filtração }\end{array}$ & Número de pixels & $\begin{array}{c}\text { Desvio Padrão } \\
\text { (Ruído) }\end{array}$ \\
\hline \hline \multirow{2}{*}{$\begin{array}{c}180 \\
\text { (entre } 0 \text { e } \pi)\end{array}$} & Filtro rampa & 5681 & 70 \\
\cline { 2 - 4 } & Filtro rampa modificado & 5642 & 25 \\
\hline 360 & Filtro rampa & 5633 & 97 \\
\cline { 2 - 4 }$($ entre 0 e $2 \pi)$ & Filtro rampa modificado & 5670 & 36 \\
\hline \hline
\end{tabular}


A aplicação do filtro rampa modificado mostrou-se eficaz na redução de ruídos nas imagens reconstruídas. Após obter este resultado, passou-se a aplicar somente o algoritmo FDK modificado (Pseudocódigo 6) para a reconstrução das imagens.

\subsubsection{Imagens Reconstruídas a partir das Projeções Coletadas com o Sistema de Aquisição № 3}

Como descrito no capítulo 6, item 6.2.3, o sistema de aquisição № 3 foi utilizado na reconstrução de dois objetos. Os resultados da reconstrução primeiro objeto (Figura 35) possibilitaram verificar a linearidade do sistema e, conseqüentemente, calibrá-lo. Na reconstrução do segundo objeto, apresentado na Figura 43, foi testada a capacidade de reconstrução tomográfica multi-cortes do sistema.

\subsubsection{Calibração do sistema: Verificação da Linearidade e Correção dos Valores de Número CT}

O objeto reconstruído na etapa de calibração do sistema é apresentado na Figura 35. Foram reconstruídas, ao todo, sete imagens do corte central do objeto. Em cada reconstrução variou-se um parâmetro importante como: número de projeções, espessura do corte, e o tamanho dos elementos da re-amostragem (correção de aliasing, capítulo 6, item 6.3.3). A Tabela 11 mostra os parâmetros usados em cada reconstrução.

Todas as imagens foram reconstruídas com o algoritmo FDK modificado. Utilizou-se o valor, $S N R=25$, para a razão sinal ruído, conforme especificado pelo fabricante do detector ${ }^{50}$. 
Tabela 11 - Parâmetros usados em cada reconstrução realizada, a partir das projeções coletadas com o sistema de aquisição № 3 .

\begin{tabular}{|c|c|c|c|}
\hline $\begin{array}{l}\text { Número da } \\
\text { Reconstrução }\end{array}$ & $\begin{array}{l}\text { Número de } \\
\text { Projeções }\end{array}$ & $\begin{array}{l}\text { Espessura do } \\
\text { corte }(\mathrm{mm})\end{array}$ & $\begin{array}{c}\text { Aplicação da } \\
\text { correção de } \\
\text { aliasing } \\
\end{array}$ \\
\hline Reconstrução No 1 & $180(0,2 \pi)$ & 1,00 & Sem correção \\
\hline Reconstrução $\mathrm{N}^{\mathrm{o}} 2$ & $360(0,2 \pi)$ & 1,00 & Sem correção \\
\hline Reconstrução No 3 & $720(0,2 \pi)$ & 1,00 & Sem correção \\
\hline Reconstrução № 4 & $720(0,2 \pi)$ & 0,50 & Sem correção \\
\hline Reconstrução № 5 & $720(0,2 \pi)$ & 0,25 & Sem correção \\
\hline Reconstrução № 6 & $720(0,2 \pi)$ & 1,00 & Com correção \\
\hline Reconstrução Nº 7 & $720(0,2 \pi)$ & 3,00 & Com correção \\
\hline
\end{tabular}

Da Figura 60 à Figura 66, são apresentadas as sete reconstruções indicadas na Tabela 11. Em cada figura são apresentadas as imagens sem e com ajuste de janela e nível. 


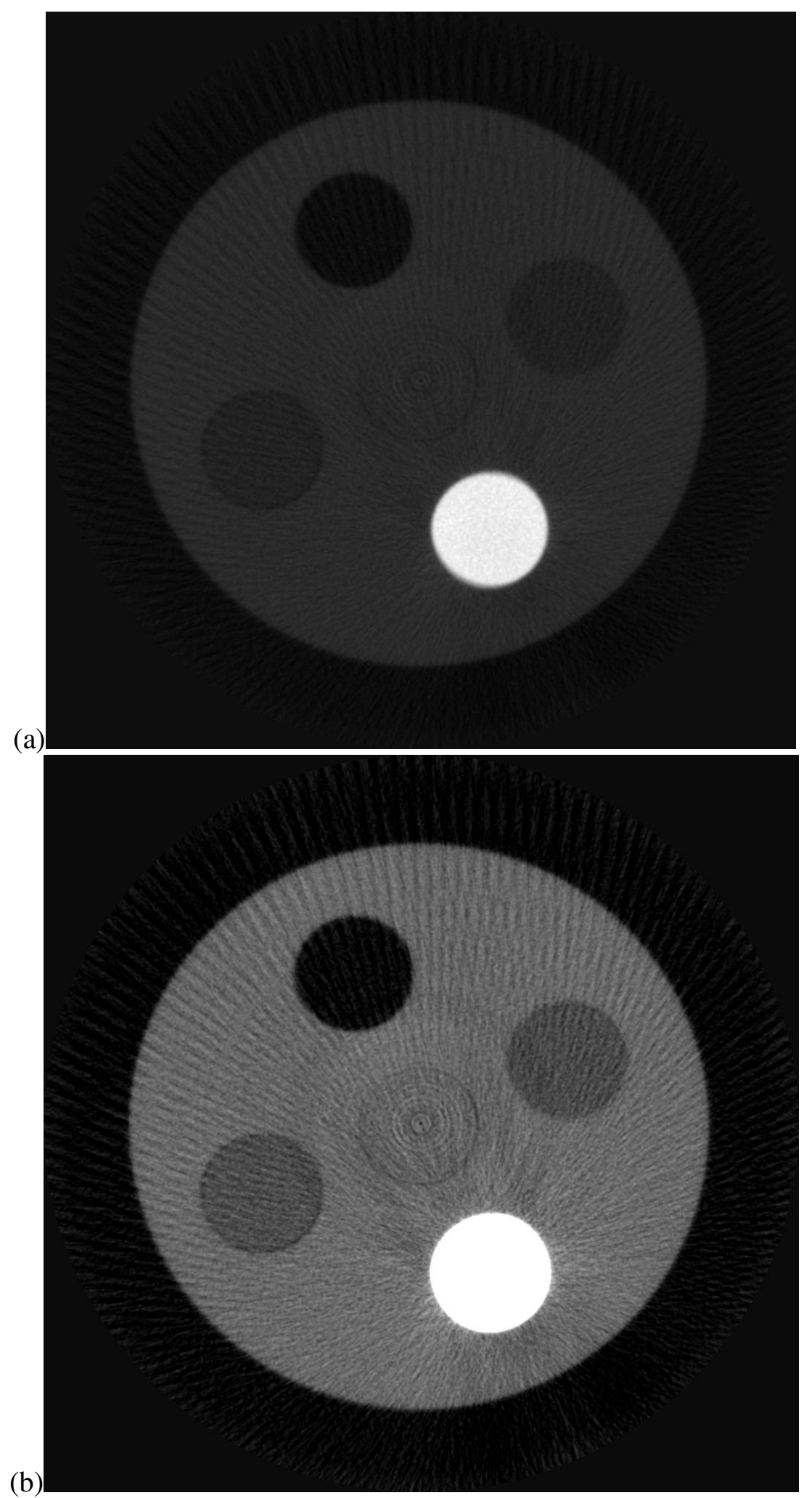

Figura 60 - Imagem reconstruída, sem correção de aliasing, a partir de 180 projeções coletadas com o sistema de aquisição № 3 , com $2^{\circ}$ de intervalo angular entre cada projeção. Espessura do corte: $1 \mathrm{~mm}$. (a) imagem normal; (b) imagem com ajuste de janela, $J$, e nível, $N$. (J=922 e $N=-579$ ). 
(a)
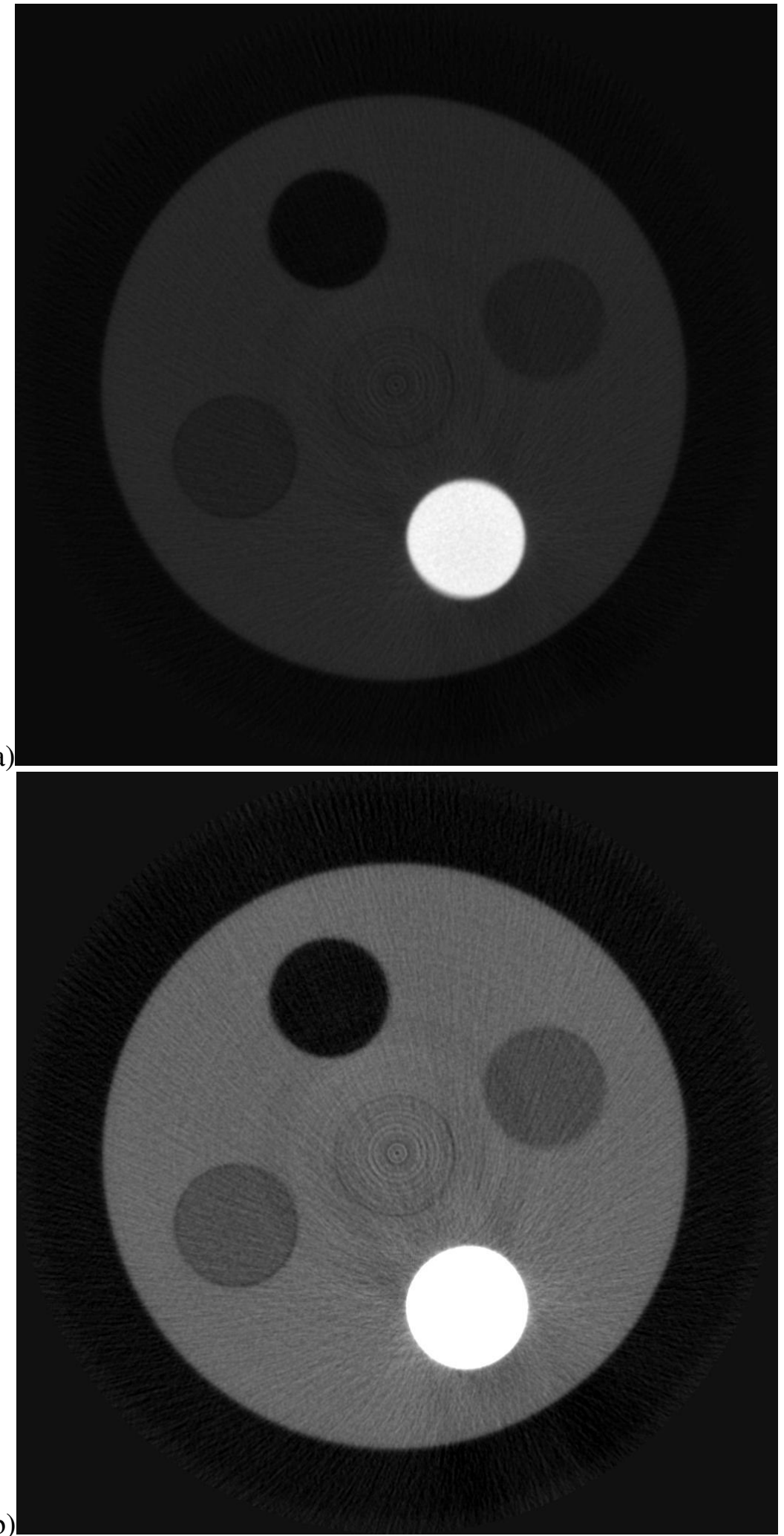

Figura 61 - Imagem reconstruída, sem correção de aliasing, a partir de 360 projeções coletadas com o sistema de aquisição $N^{\circ} 3, \operatorname{com} 1^{\circ}$ de intervalo angular entre cada projeção. Espessura do corte: $1 \mathrm{~mm}$. (a) imagem normal; (b) imagem com ajuste de janela e nível. ( $\mathrm{J=2034}$ e $\mathrm{N=-124}$ ). 
(a)
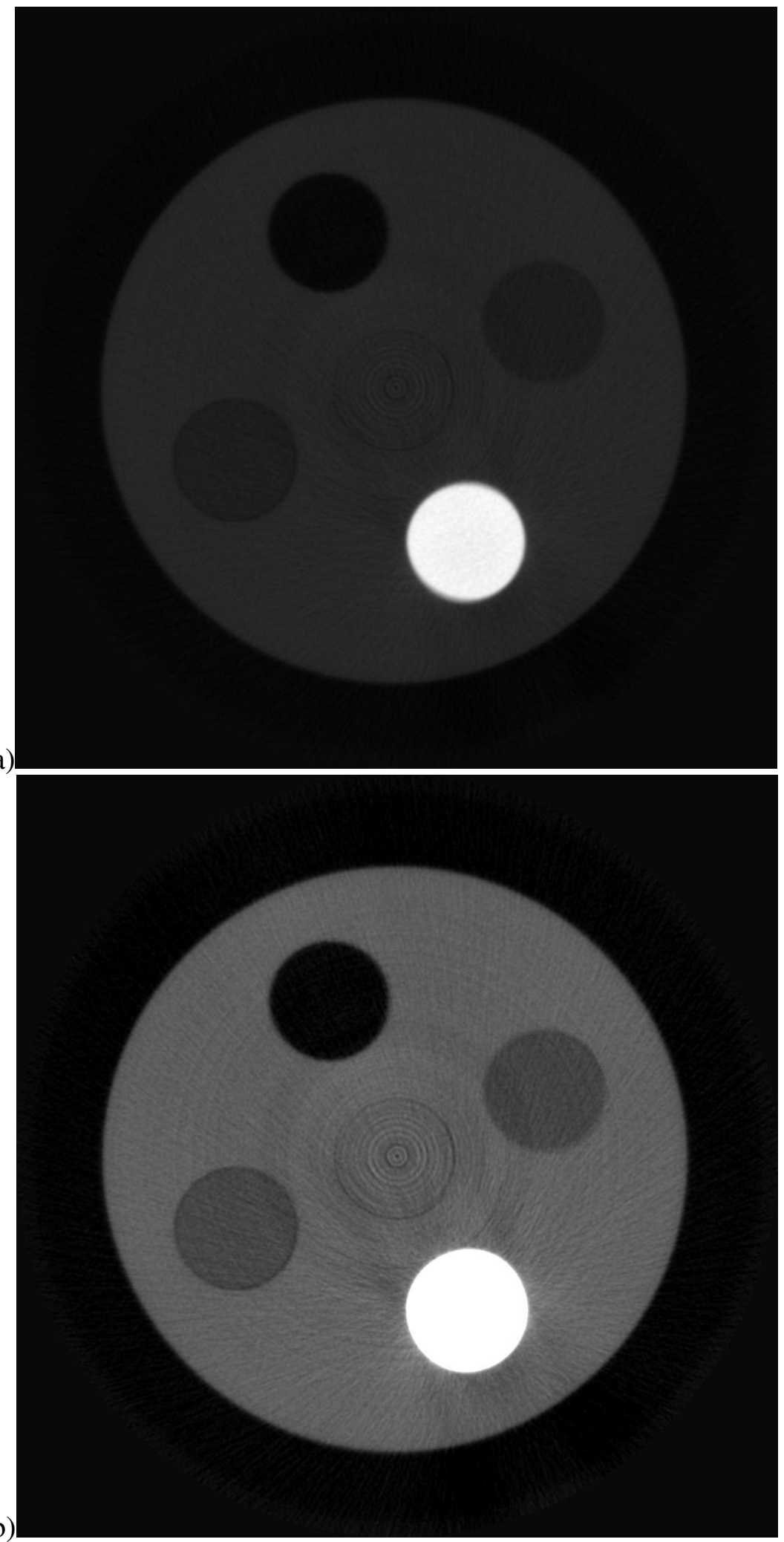

Figura 62 - Imagem reconstruída, sem correção de aliasing, a partir de 720 projeções coletadas com o sistema de aquisição $\mathrm{N}^{\circ} 3$, com $0,5^{\circ}$ de intervalo angular entre cada projeção. Espessura do corte: $1 \mathrm{~mm}$. (a) imagem normal; (b) imagem com ajuste de janela e nível. ( $J=3974$ e $N=835$ ). 
(a)
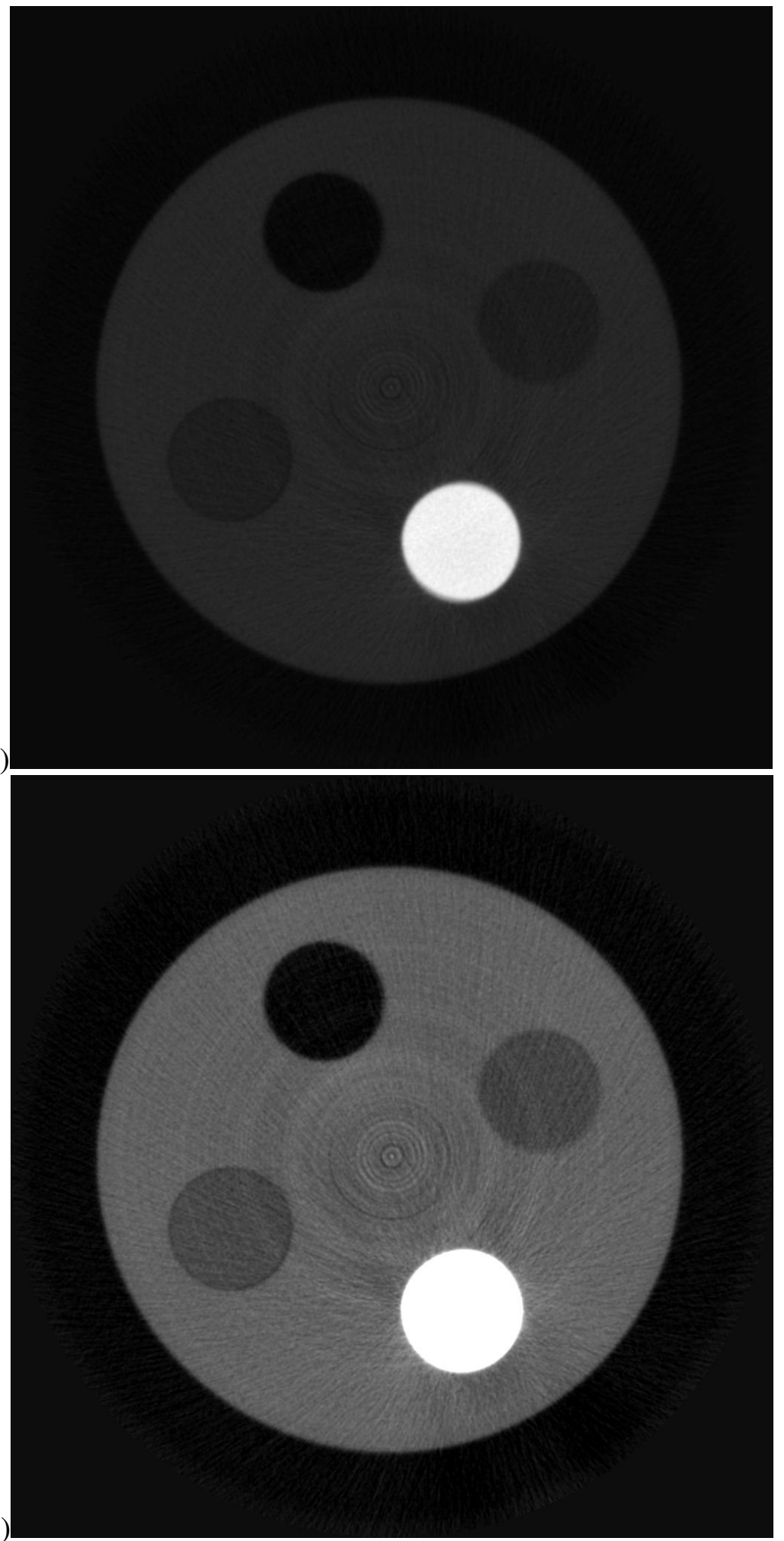

Figura 63 - Imagem reconstruída, sem correção de aliasing, a partir de 720 projeções coletadas com o sistema de aquisição № 3, com $0,5^{\circ}$ de intervalo angular entre cada projeção. Espessura do corte: $0,5 \mathrm{~mm}$. (a) imagem normal; (b) imagem com ajuste de janela e nível. ( $J=4062$ e $N=823$ ). 
(a)
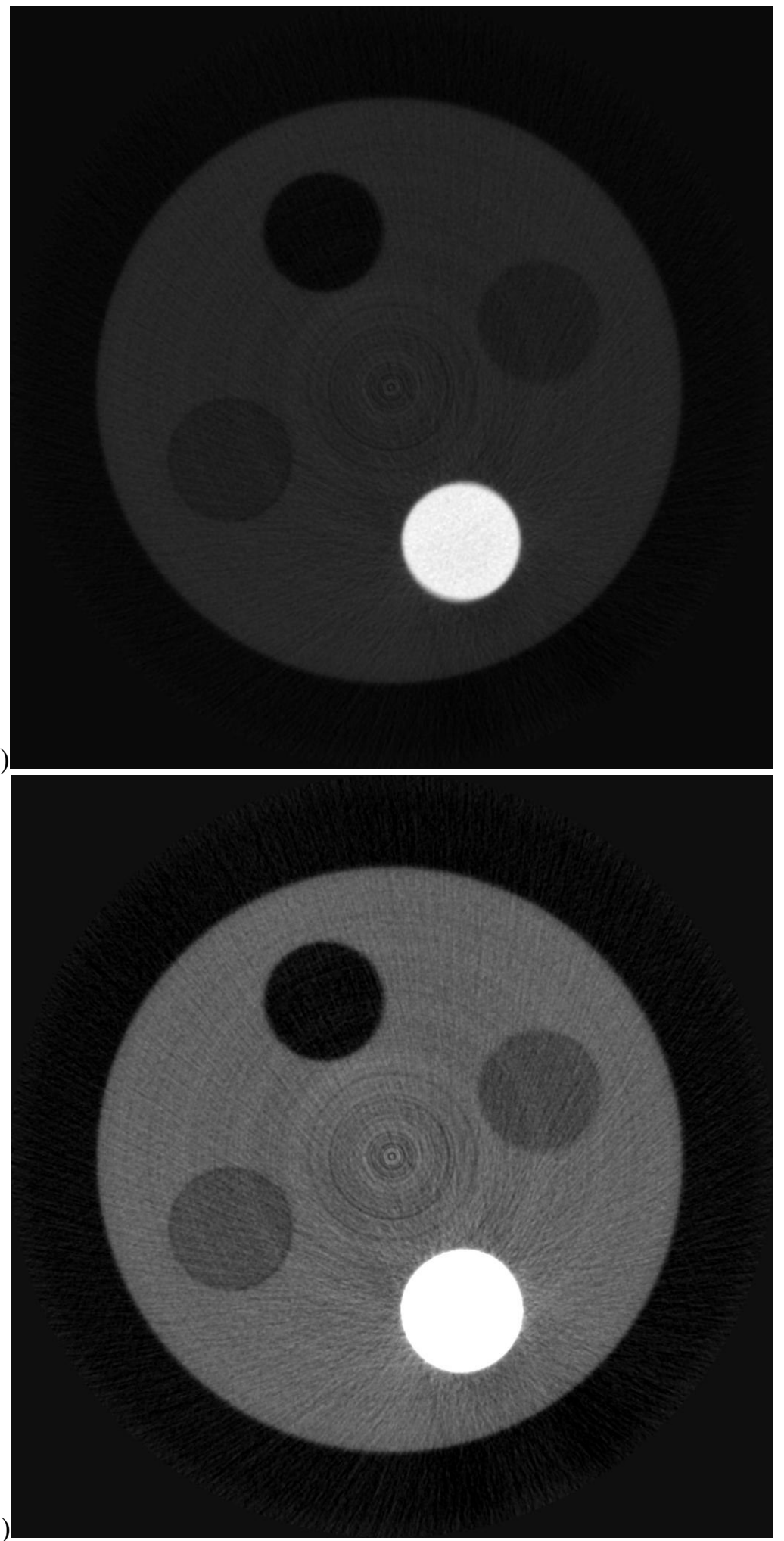

Figura 64 - Imagem reconstruída, sem correção de aliasing, a partir de 720 projeções coletadas com o sistema de aquisição № 3, com $0,5^{\circ}$ de intervalo angular entre cada projeção. Espessura do corte: $0,25 \mathrm{~mm}$. (a) imagem normal; (b) imagem com ajuste de janela e nível. ( $J=4109$ e $N=807$ ). 


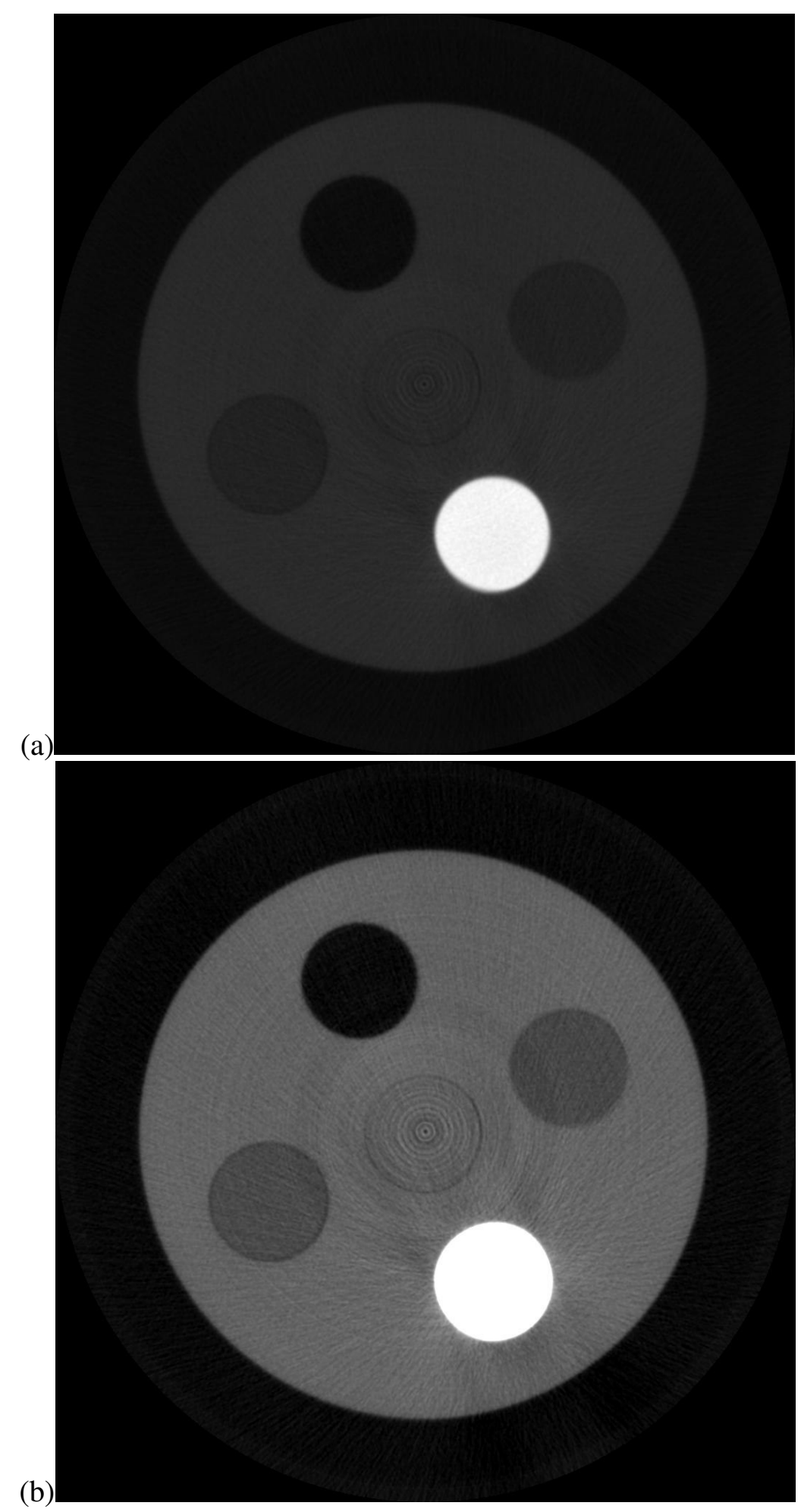

Figura 65 - Imagem reconstruída, com correção de aliasing (re-amostragem para duas vezes o tamanho original dos elementos do detector), a partir de 720 projeções coletadas com o sistema de aquisição № 3, com $0,5^{\circ}$ de intervalo angular entre cada projeção. Espessura do corte: $1 \mathrm{~mm}$. (a) imagem normal; (b) imagem com ajuste de janela e nível. ( $J=2026$ e $N=218$ ). 


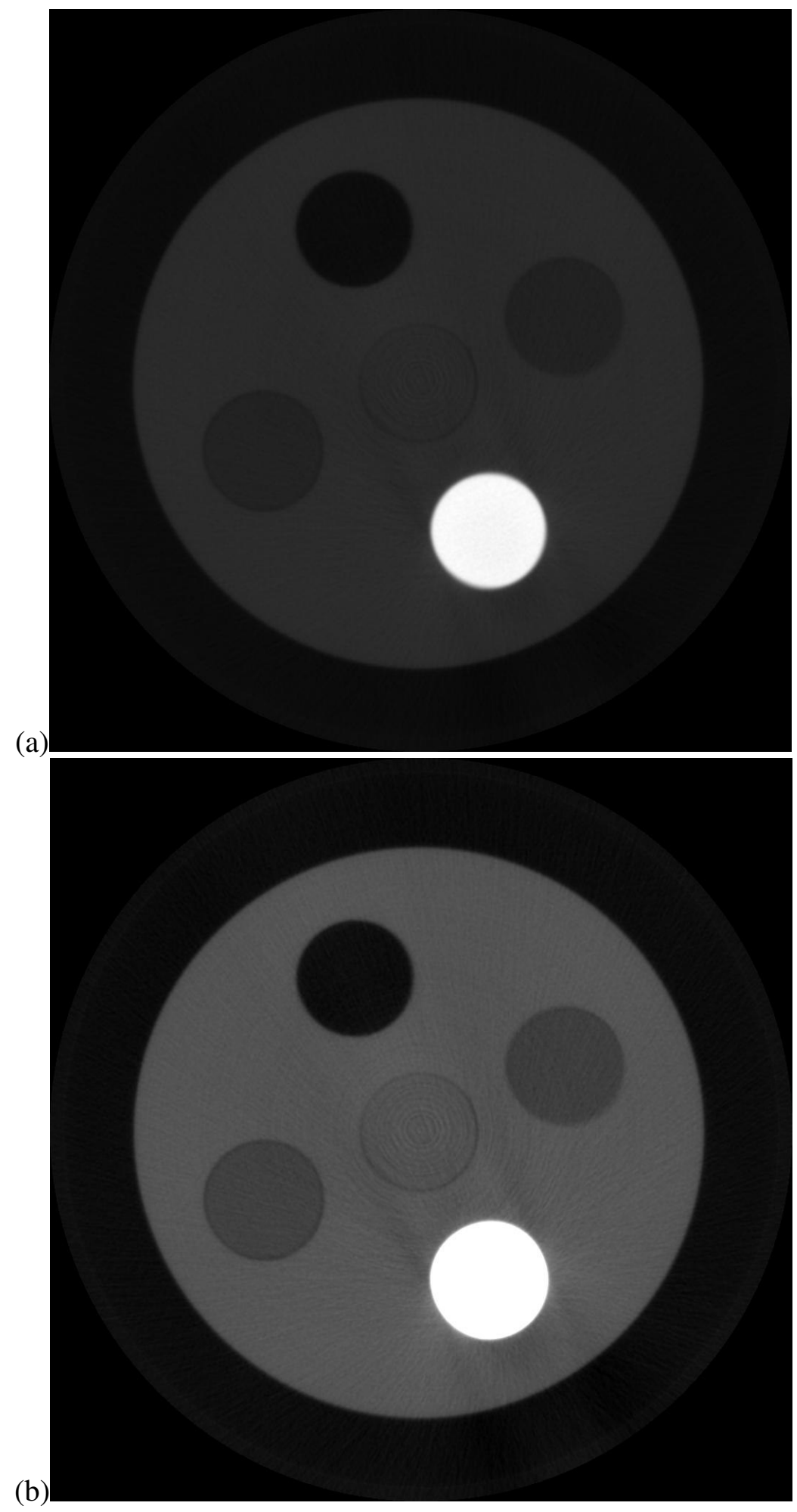

Figura 66 - Imagem reconstruída, com correção de aliasing (re-amostragem para duas vezes o tamanho original dos elementos do detector), a partir de 720 projeções coletadas com o sistema de aquisição $\mathrm{N}^{\circ} 3, \operatorname{com} 0,5^{\circ}$ de intervalo angular entre cada projeção. Espessura do corte: $3 \mathrm{~mm}$. (a) imagem normal; (b) imagem com ajuste de janela e nível. ( $J=2499$ e $N=405)$. 
O tempo gasto na reconstrução de imagens, utilizando algoritmos do tipo FBP, depende basicamente do número de pixels das imagens reconstruídas, uma vez que $90 \%$ do tempo de processamento é gasto na etapa de retro-projeção. Foram marcados os tempos gastos no processamento de cada uma das reconstruções descritas na Tabela 11.

Todas as imagens foram reconstruídas com uma resolução de 1024×1024 pixels em aproximadamente 17 minutos. As imagens reconstruídas foram analisadas com o auxílio do software ImageJ. Conforme especificado no capítulo 6, item 6.4, foram obtidas as curvas de perfil de cada imagem reconstruída e foram determinados os valores de número CT de cada material que compõe o objeto reconstruído. Além disso, foi realizada a comparação do ruído presente em cada imagem. A Figura 67 apresenta uma legenda para a identificação de cada uma das estruturas, que foram denominadas por letras, de A a F. Ainda na Figura 67 são apontadas as linhas sobre as quais foram plotadas as curvas de perfil.

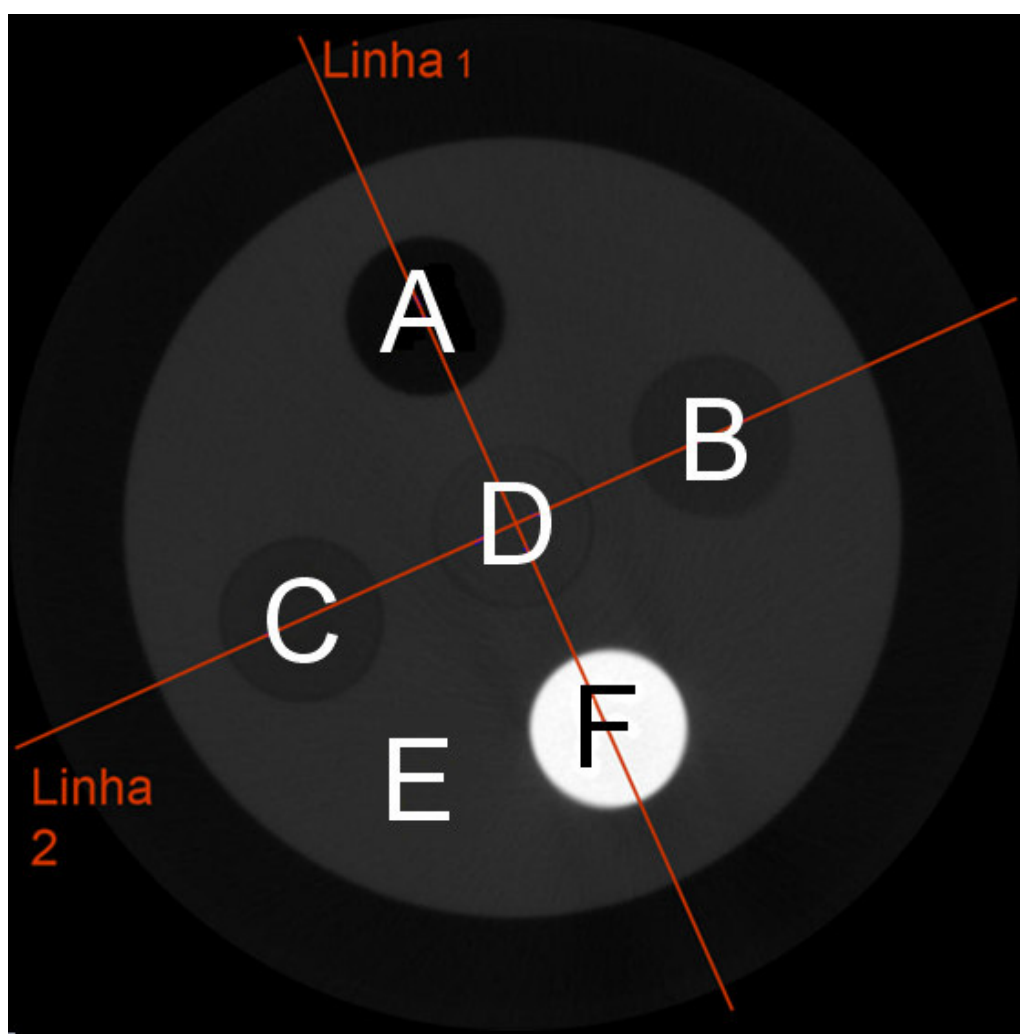

Figura 67 - Legenda com a denominação de cada estrutura identificada nas imagens reconstruídas e com a indicação das linhas sobre as quais foram plotadas as curvas de perfil.

Da Figura 68 à Figura 74 são apresentadas as curvas de perfil de tons de cinza de cada imagem, sobre as linhas indicadas na Figura 67. 

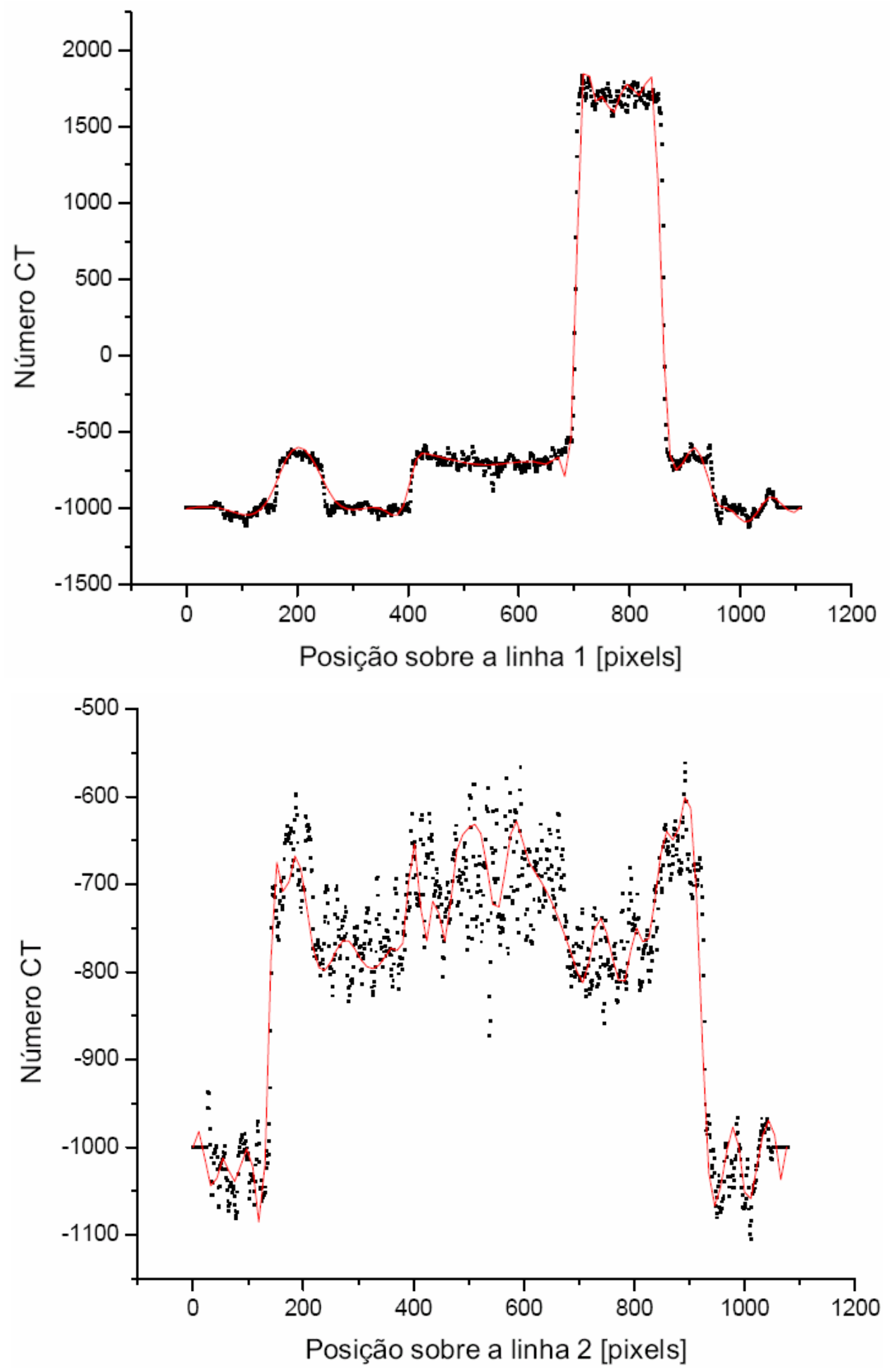

Figura 68 - Curvas de perfil de tons de cinza das estruturas identificadas na reconstrução № ${ }^{0}$, obtidas com o software ImageJ. As curvas são plotadas sobre as duas linhas perpendiculares apresentadas na Figura 67 que se interceptam no centro do objeto reconstruído. A linha sólia foi obtida por interpolação cubic spline dos pontos do gráfico. 

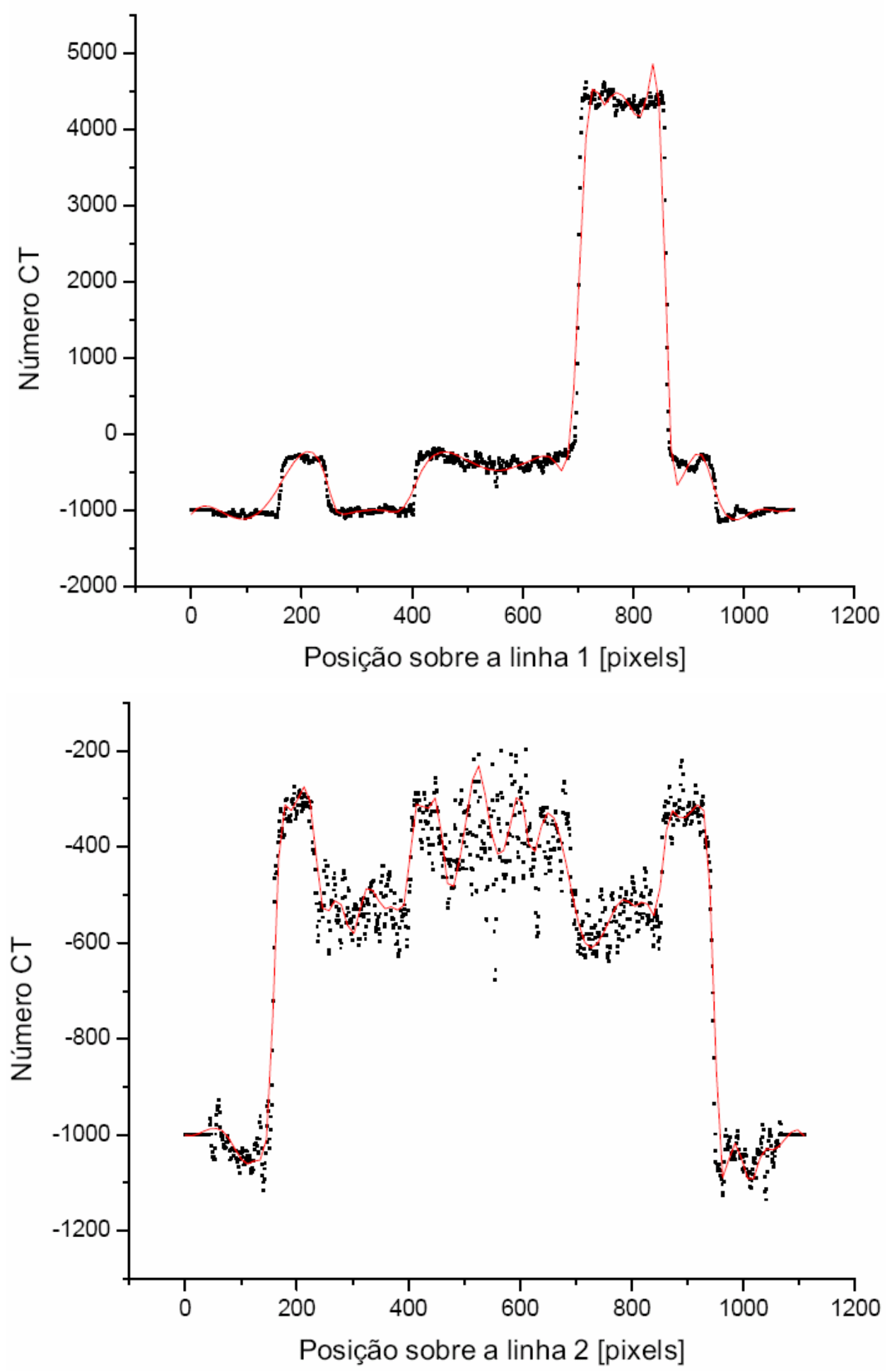

Figura 69 - Curvas de perfil de tons de cinza das estruturas identificadas na reconstrução № 2 , obtidas com o software ImageJ. As curvas são plotadas sobre as duas linhas perpendiculares apresentadas na Figura 67 que se interceptam no centro do objeto reconstruído. A linha sólia foi obtida por interpolação cubic spline dos pontos do gráfico. 

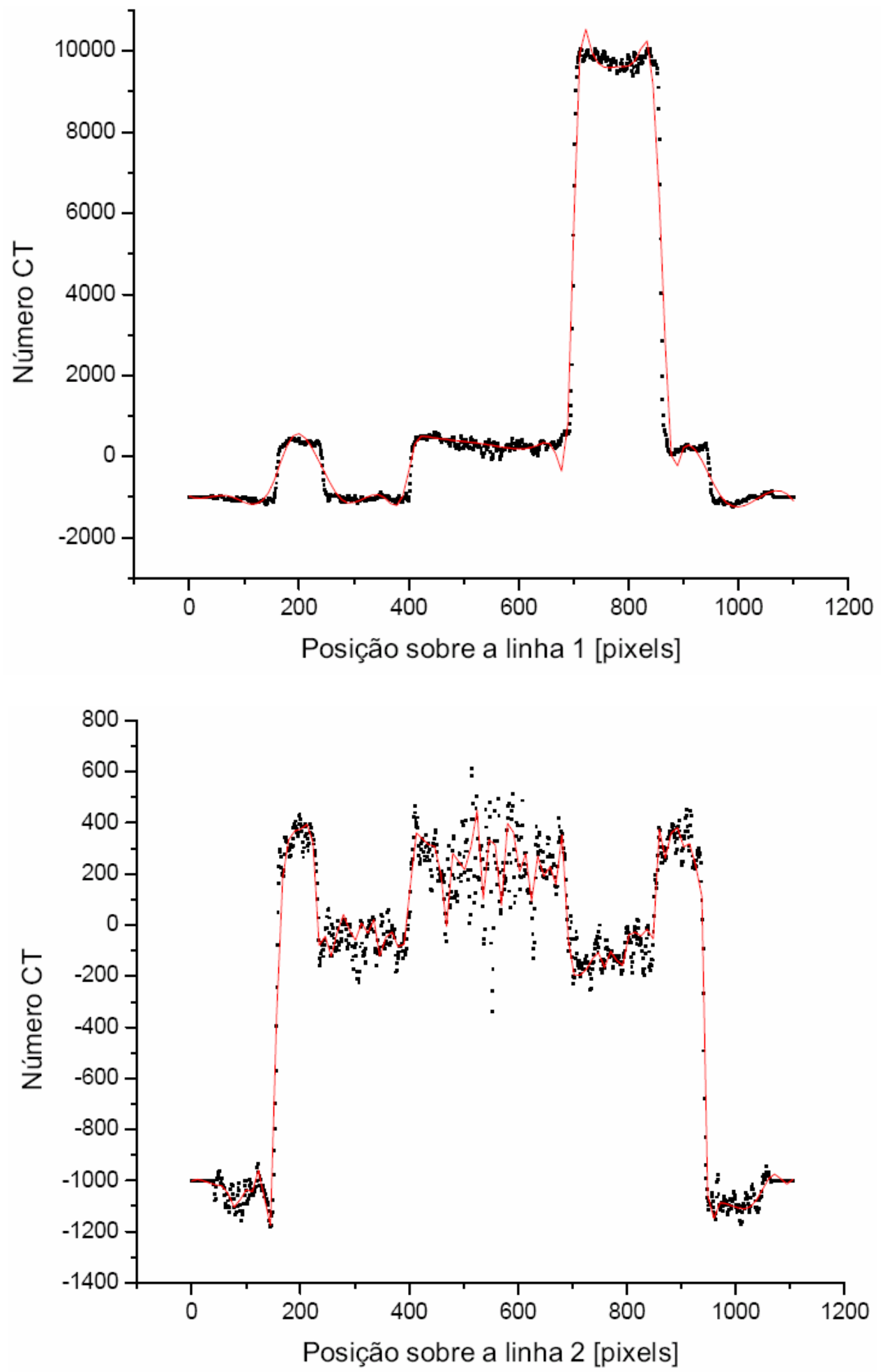

Figura 70 - Curvas de perfil de tons de cinza das estruturas identificadas na reconstrução № 3 , obtidas com o software ImageJ. As curvas são plotadas sobre as duas linhas perpendiculares apresentadas na Figura 67 que se interceptam no centro do objeto reconstruído. A linha sólia foi obtida por interpolação cubic spline dos pontos do gráfico. 

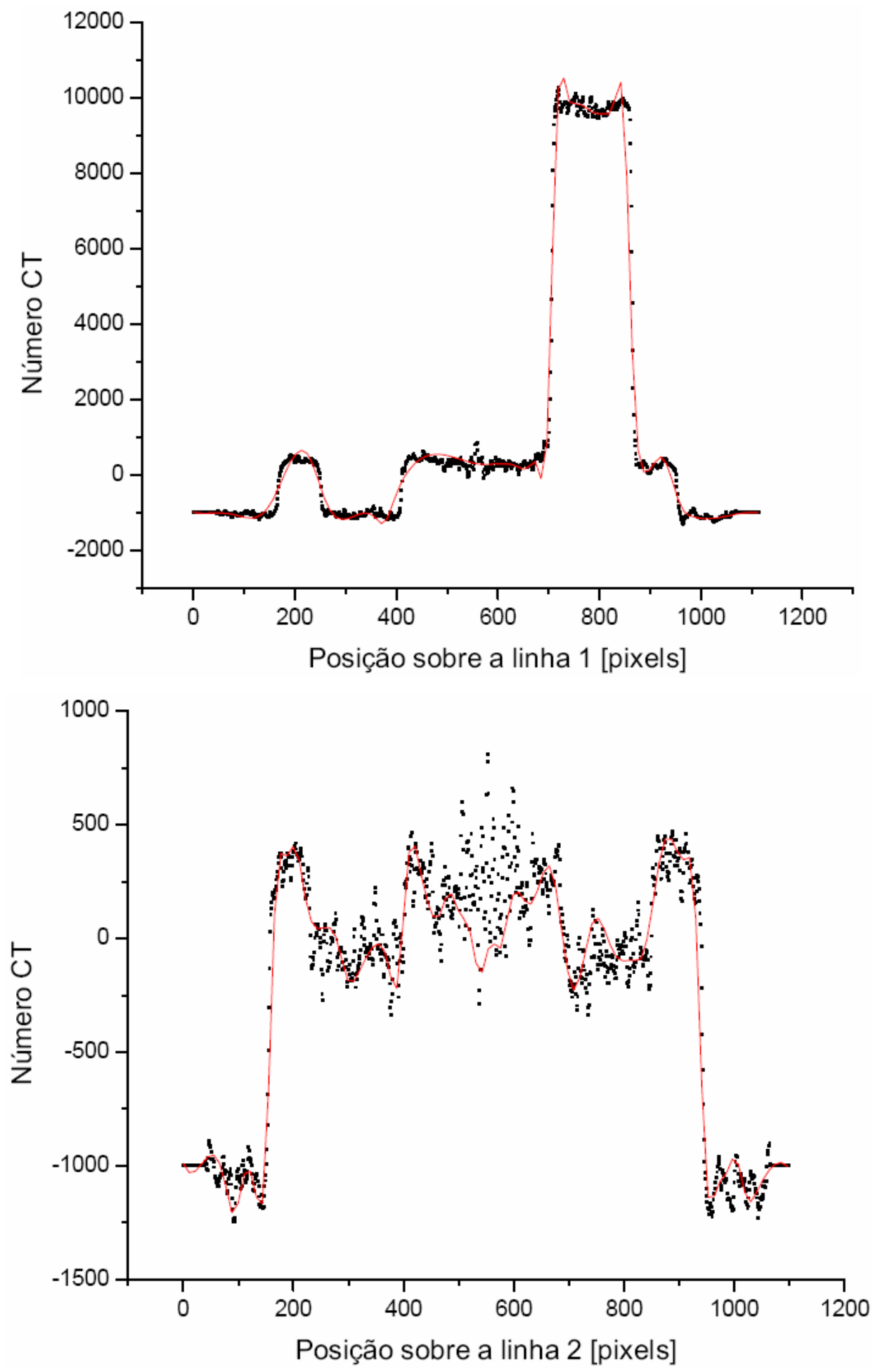

Figura 71 - Curvas de perfil de tons de cinza das estruturas identificadas na reconstrução № 4 , obtidas com o software ImageJ. As curvas são plotadas sobre as duas linhas perpendiculares apresentadas na Figura 67 que se interceptam no centro do objeto reconstruído. A linha sólia foi obtida por interpolação cubic spline dos pontos do gráfico. 

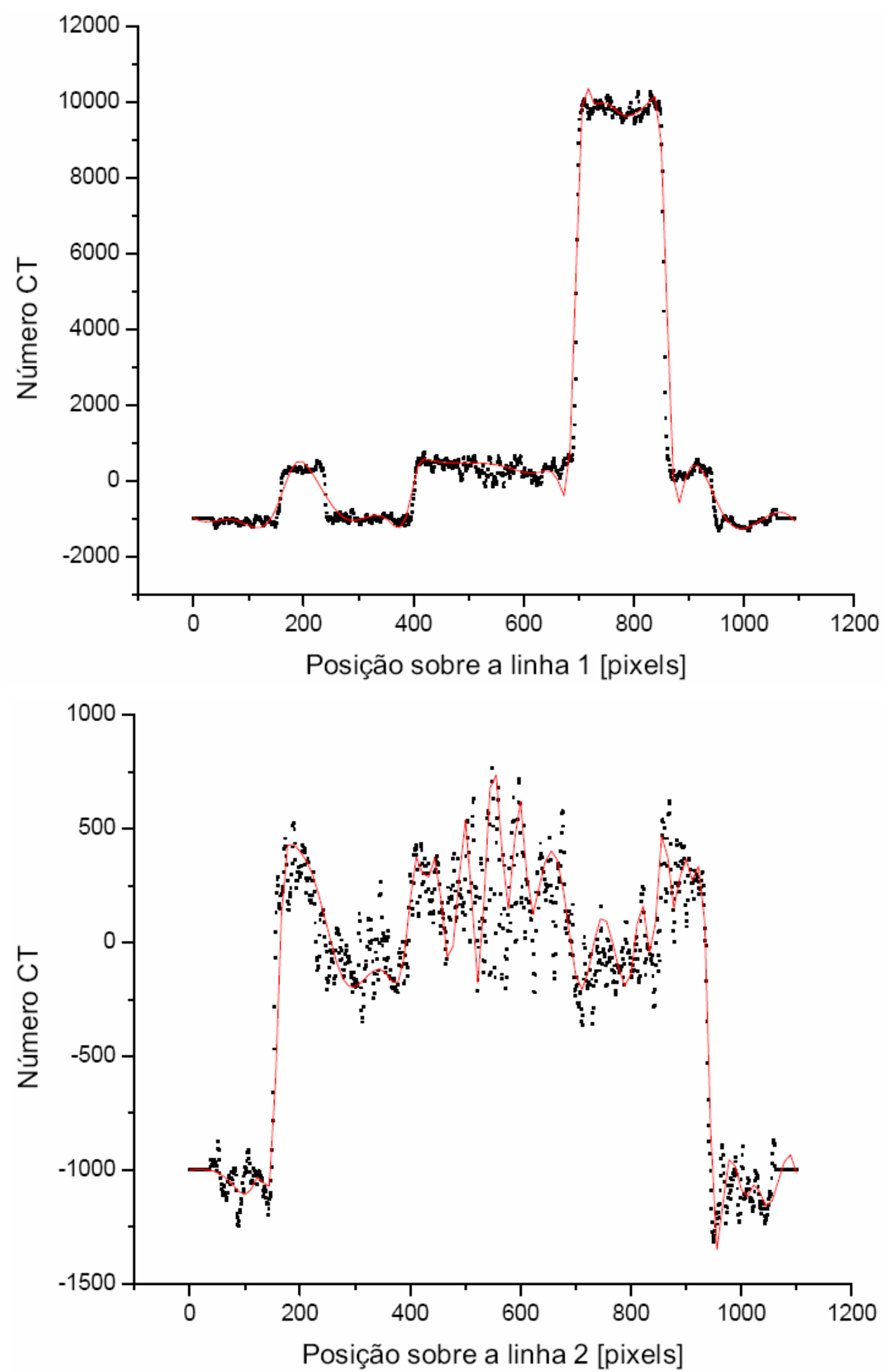

Figura 72 - Curvas de perfil de tons de cinza das estruturas identificadas na reconstrução № 5 , obtidas com o software ImageJ. As curvas são plotadas sobre as duas linhas perpendiculares apresentadas na Figura 67 que se interceptam no centro do objeto reconstruído. A linha sólia foi obtida por interpolação cubic spline dos pontos do gráfico. 

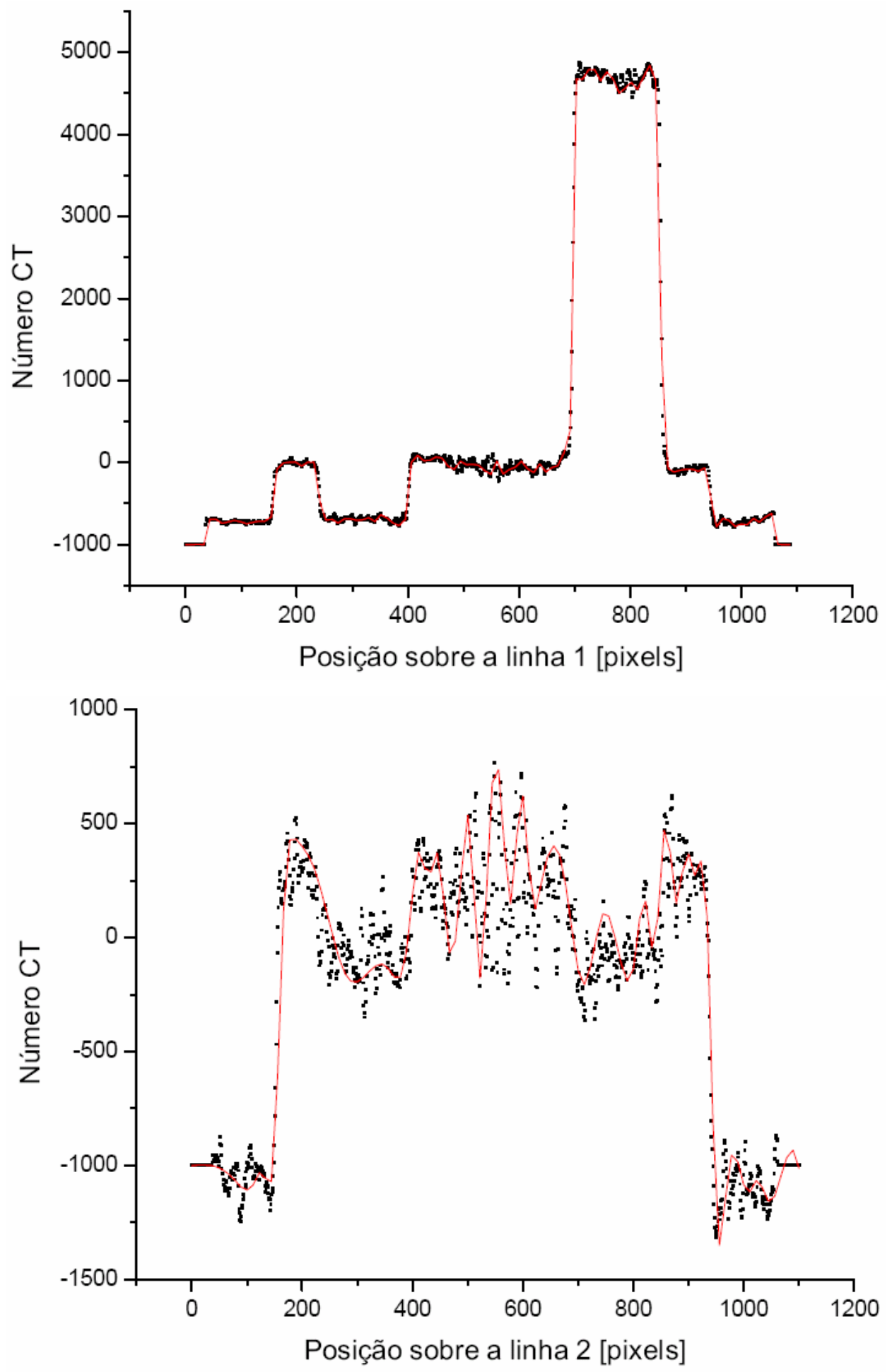

Figura 73 - Curvas de perfil de tons de cinza das estruturas identificadas na reconstrução № 6 , obtidas com o software ImageJ. As curvas são plotadas sobre as duas linhas perpendiculares apresentadas na Figura 67 que se interceptam no centro do objeto reconstruído. A linha sólia foi obtida por interpolação cubic spline dos pontos do gráfico. 

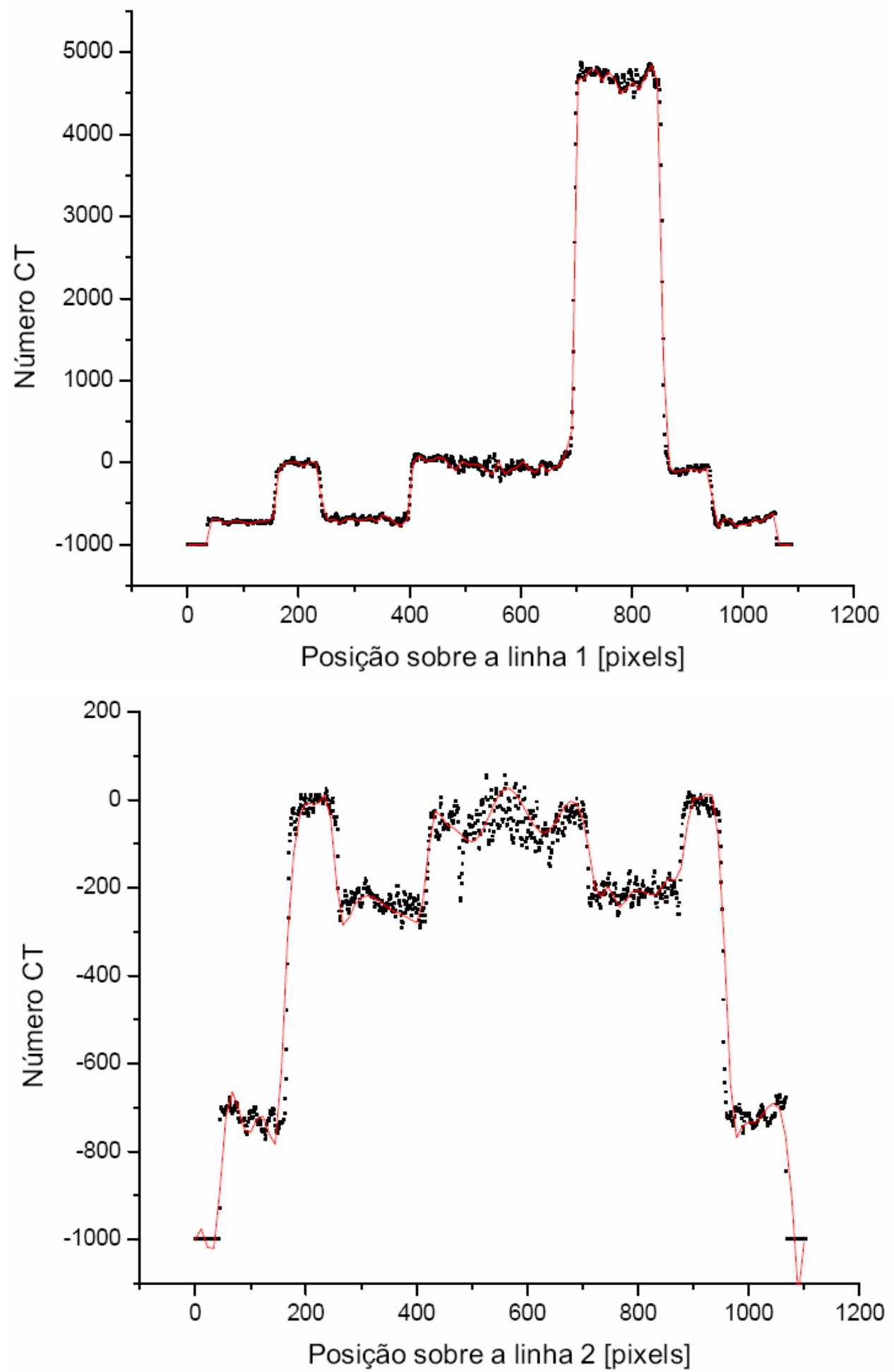

Figura 74 - Curvas de perfil de tons de cinza das estruturas identificadas na reconstrução № 7 , obtidas com o software ImageJ. As curvas são plotadas sobre as duas linhas perpendiculares apresentadas na Figura 67 que se interceptam no centro do objeto reconstruído. A linha sólia foi obtida por interpolação cubic spline dos pontos do gráfico. 
Como descrito no capítulo 6 , item 6.4 , o primeiro passo para se calcular os valores de número CT esperados para cada material, é determinar a energia efetiva do feixe de raios X. Para isso mediu-se a camada semi-redutora em alumínio do feixe. A Tabela 12 apresenta os resultados obtidos na medição das intensidades do feixe para as diferentes espessuras de filtro de alumínio utilizadas.

Tabela 12 - Valores de intensidade relativa obtidos na medição da CSR de alumínio para o feixe do equipamento de raios $\mathrm{X}$ odontológico.

\begin{tabular}{|c|c|c|c|}
\hline $\begin{array}{c}\text { Espessura do } \\
\text { filtro de Al } \\
\text { [mm] }\end{array}$ & $\sigma$ & I/lo & $\sigma_{I / I_{0}}$ \\
\hline 0,000 & 0 & 1,000 & 0,018 \\
\hline 0,104 & 0,003 & 0,947 & 0,017 \\
\hline 0,214 & 0,005 & 0,888 & 0,017 \\
\hline 0,321 & 0,008 & 0,852 & 0,019 \\
\hline 0,430 & 0,01 & 0,811 & 0,016 \\
\hline 0,532 & 0,005 & 0,776 & 0,016 \\
\hline 0,636 & 0,008 & 0,732 & 0,015 \\
\hline 0,746 & 0,01 & 0,693 & 0,016 \\
\hline 0,853 & 0,013 & 0,654 & 0,015 \\
\hline 0,962 & 0,015 & 0,619 & 0,016 \\
\hline 1,004 & 0,003 & 0,605 & 0,015 \\
\hline 1,108 & 0,006 & 0,586 & 0,015 \\
\hline 1,218 & 0,008 & 0,557 & 0,013 \\
\hline 1,325 & 0,011 & 0,536 & 0,013 \\
\hline 1,434 & 0,013 & 0,514 & 0,014 \\
\hline 1,536 & 0,008 & 0,490 & 0,014 \\
\hline 1,640 & 0,011 & 0,468 & 0,015 \\
\hline
\end{tabular}

A partir dos resultados apresentados na Tabela 12, foi obtida uma curva de atenuação do feixe de raios X (Figura 75). 


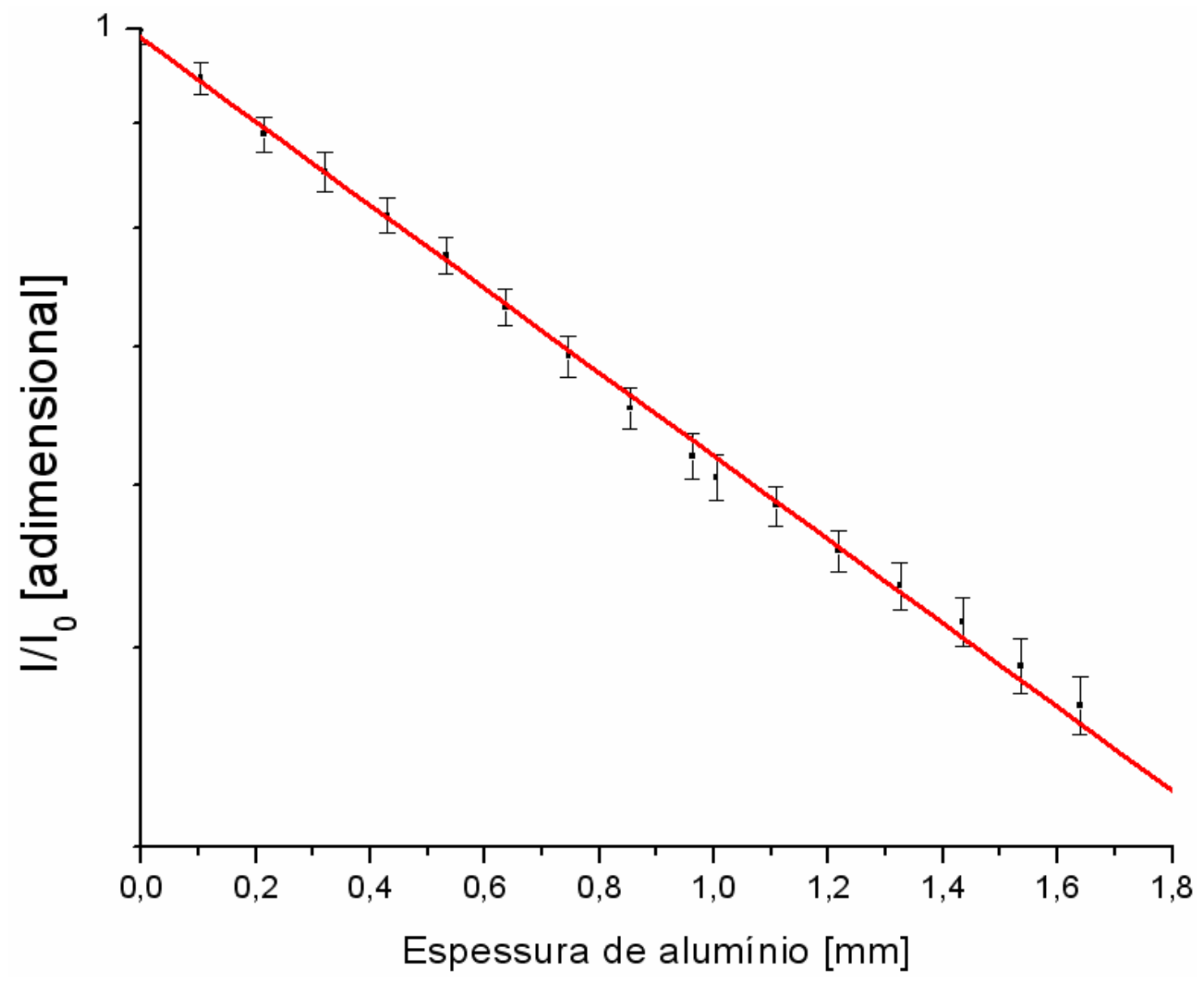

Figura 75 - Curva de atenuação do feixe de raios $X$ do equipamento odontológico. Intensidade relativa por espessura de alumínio, $\mathrm{l} / \mathrm{I}_{0} \times \mathrm{mmAl}$.

O valor estimado da CSR de alumínio para o equipamento de raios X, Spectro 70X, por interpolação linear foi de 1,48 $\pm 0,03 \mathrm{~mm}$. Substituindo o valor da CSR na Equação 61, obtém-se $\mu\left(E_{E f}\right)=4,68 \mathrm{~cm}^{-1}$ e, a partir da equação (62) pôde-se obter o valor aproximado da energia efetiva do feixe, $\mathrm{EEf}=25 \pm 1 \mathrm{keV}$.

A partir da fórmula química dos materiais que compõem o objeto cujas imagens foram reconstruídas, calculou-se os valores dos seus respectivos coeficientes de atenuação linear a partir do programa XCOM. Na Tabela 13 são apresentadas as fórmulas químicas de cada material que compõe o objeto e seus respectivos coeficientes de atenuação linear na energia efetiva, $\mu\left(E_{E f}\right)$, exceto o ar, cujo $\mu\left(E_{E f}\right) \cong 0$. 
Tabela 13 - Materiais que compõem o objeto, e suas respectivas fórmulas químicas e coeficientes de atenuação linear na energia efetiva, $\mu\left(\mathrm{E}_{\mathrm{Ef}}\right)$.

\begin{tabular}{cccccc}
\hline \hline \multirow{2}{*}{ Material } & $\begin{array}{c}\text { Polietileno } \\
\mathrm{A}\end{array}$ & $\begin{array}{c}\text { Polietileno } \\
\mathrm{B}\end{array}$ & Nylon & Acrílico & \multirow{2}{*}{ PVC } \\
\hline \hline Fórmula Química & $\mathrm{C}_{2} \mathrm{H}_{4}$ & $\mathrm{C}_{2} \mathrm{H}_{4}$ & $\mathrm{NO} \mathrm{C}_{6} \mathrm{H}_{11}$ & $\mathrm{C}_{5} \mathrm{O}_{2} \mathrm{H}_{8}$ & $\mathrm{C}_{2} \mathrm{H}_{3} \mathrm{Cl}$ \\
\hline Densidade $\left[\mathbf{g} \cdot \mathbf{~ c m}^{-3}\right]$ & $0,92 \pm 0,04$ & $0,97 \pm 0,04$ & $1,14 \pm 0,05$ & $1,18 \pm 0,06$ & $1,49 \pm 0,08$ \\
\hline $\boldsymbol{\mu}\left(\mathbf{E}_{\mathbf{E f}}\right)\left[\mathbf{c m}^{-1}\right]$ & $0,29 \pm 0,01$ & $0,30 \pm 0,01$ & $0,40 \pm 0,02$ & $0,44 \pm 0,02$ & $3,46 \pm 0,19$ \\
\hline \hline
\end{tabular}

A Tabela 14 apresenta os valores de número CT esperados de cada material, juntamente com os respectivos valores medidos nas imagens reconstruídas. Cada região de interesse possui uma área de 16000 pixels. Para o cálculo do número CT, utilizou-se a equação (3), onde $\mu_{\text {água }}\left(\mathrm{E}_{\mathrm{Ef}}\right)=0,49 \mathrm{~cm}^{-1}$.

\begin{tabular}{|c|c|c|c|c|c|c|}
\hline Material & $\mathrm{Ar}$ & $\begin{array}{l}\text { Polietileno } \\
\text { A }\end{array}$ & $\begin{array}{l}\text { Polietileno } \\
\text { B }\end{array}$ & Nylon & Acrílico & PVC \\
\hline $\begin{array}{l}\text { Número CT } \\
\text { esperado }\end{array}$ & -1000 & $-413 \pm 20$ & $-380 \pm 20$ & $-187 \pm 41$ & $-102 \pm 41$ & $6037 \pm 387$ \\
\hline $\begin{array}{l}\text { Número da } \\
\text { Reconstrução }\end{array}$ & \multicolumn{6}{|c|}{$\begin{array}{c}\text { Valores médios de Número CT medidos para cada material, sobre uma área } \\
\text { de } 16000 \text { pixels. (média } \pm \text { desvio padrão) }\end{array}$} \\
\hline 1 & $-1014 \pm 37$ & $-776 \pm 37$ & $-763 \pm 37$ & $-683 \pm 43$ & $-654 \pm 35$ & $1709 \pm 60$ \\
\hline 2 & $-1028 \pm 41$ & $-553 \pm 46$ & $-526 \pm 47$ & $-365 \pm 66$ & $-307 \pm 48$ & $4416 \pm 89$ \\
\hline 3 & $-1054 \pm 62$ & $-103 \pm 67$ & $-52 \pm 69$ & $272 \pm 116$ & $388 \pm 72$ & $9827 \pm 147$ \\
\hline 4 & $-1059 \pm 83$ & $-106 \pm 94$ & $-51 \pm 93$ & $271 \pm 141$ & $385 \pm 90$ & $9847 \pm 173$ \\
\hline 5 & $-1062 \pm 105$ & $-103 \pm 116$ & $-49 \pm 117$ & $282 \pm 172$ & $391 \pm 124$ & $9868 \pm 213$ \\
\hline 6 & $-709 \pm 31$ & $-233 \pm 36$ & $-207 \pm 38$ & $-46 \pm 61$ & $11 \pm 38$ & $4734 \pm 74$ \\
\hline 7 & $-707 \pm 22$ & $-232 \pm 22$ & $-207 \pm 21$ & $-47 \pm 32$ & $11 \pm 23$ & $4730 \pm 56$ \\
\hline
\end{tabular}

A partir dos dados apresentados na Tabela 14, foi possível verificar a linearidade do sistema. Da Figura 76 à Figura 82, são apresentados os gráficos com a regressão linear dos valores de número CT esperados sobre os valores medidos em cada reconstrução. 


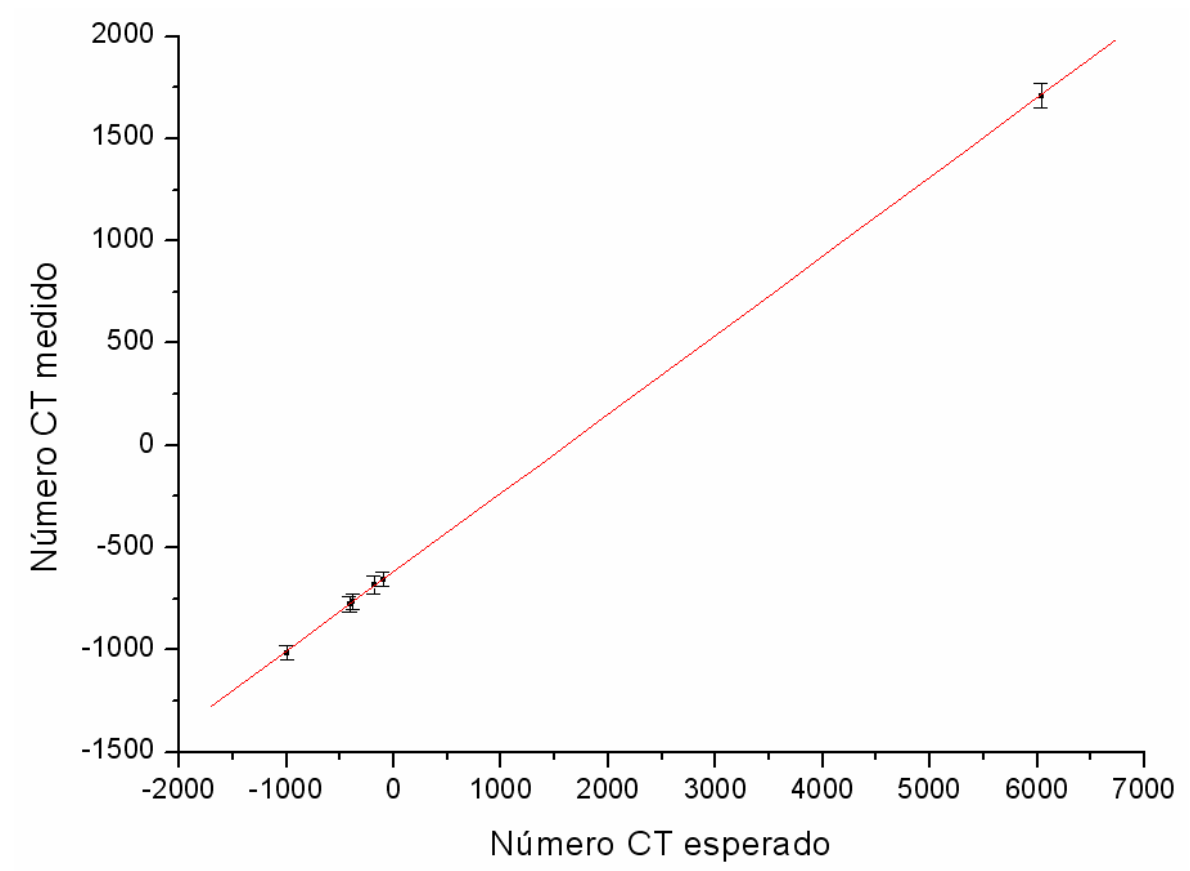

Figura 76 - Gráfico com a regressão linear dos valores de número CT esperados sobre os valores medidos na reconstrução 1 .

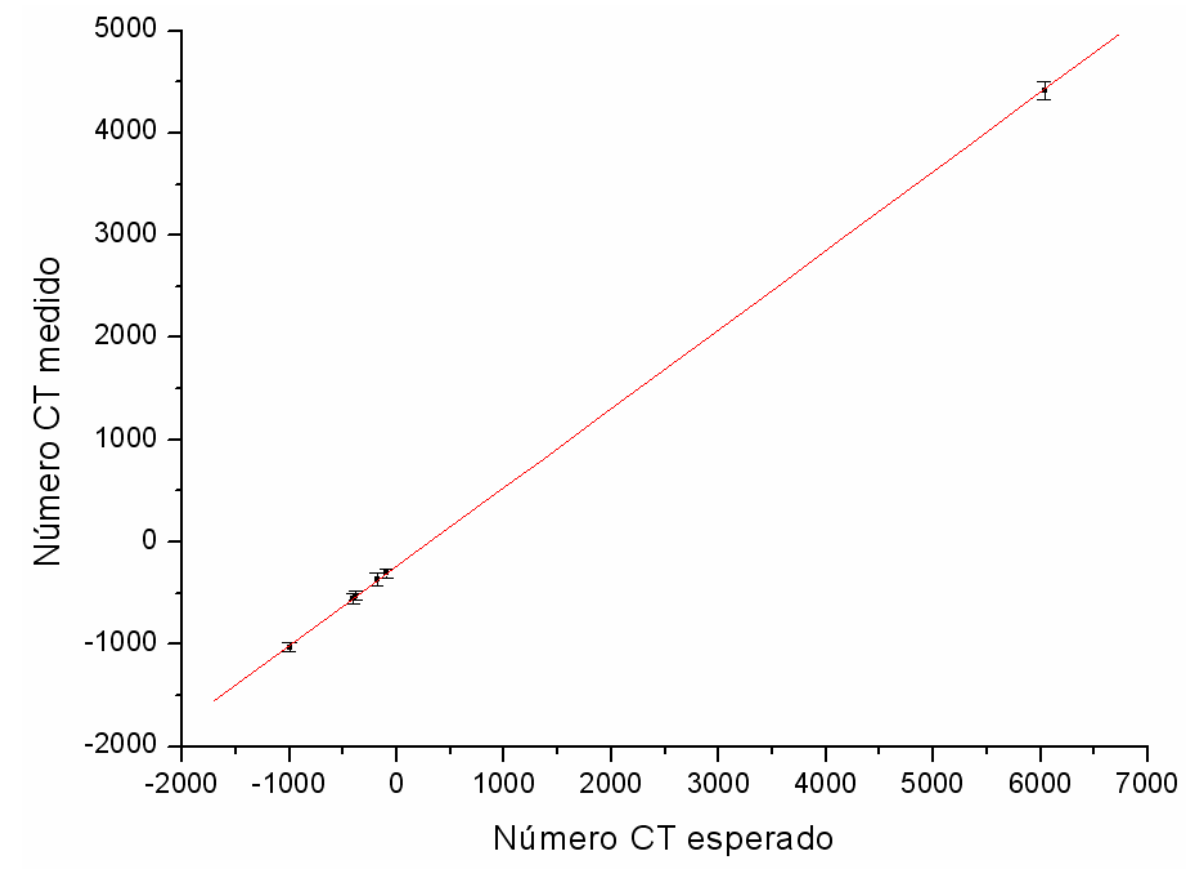

Figura 77 - Gráfico com a regressão linear dos valores de número CT esperados sobre os valores medidos na reconstrução 2. 


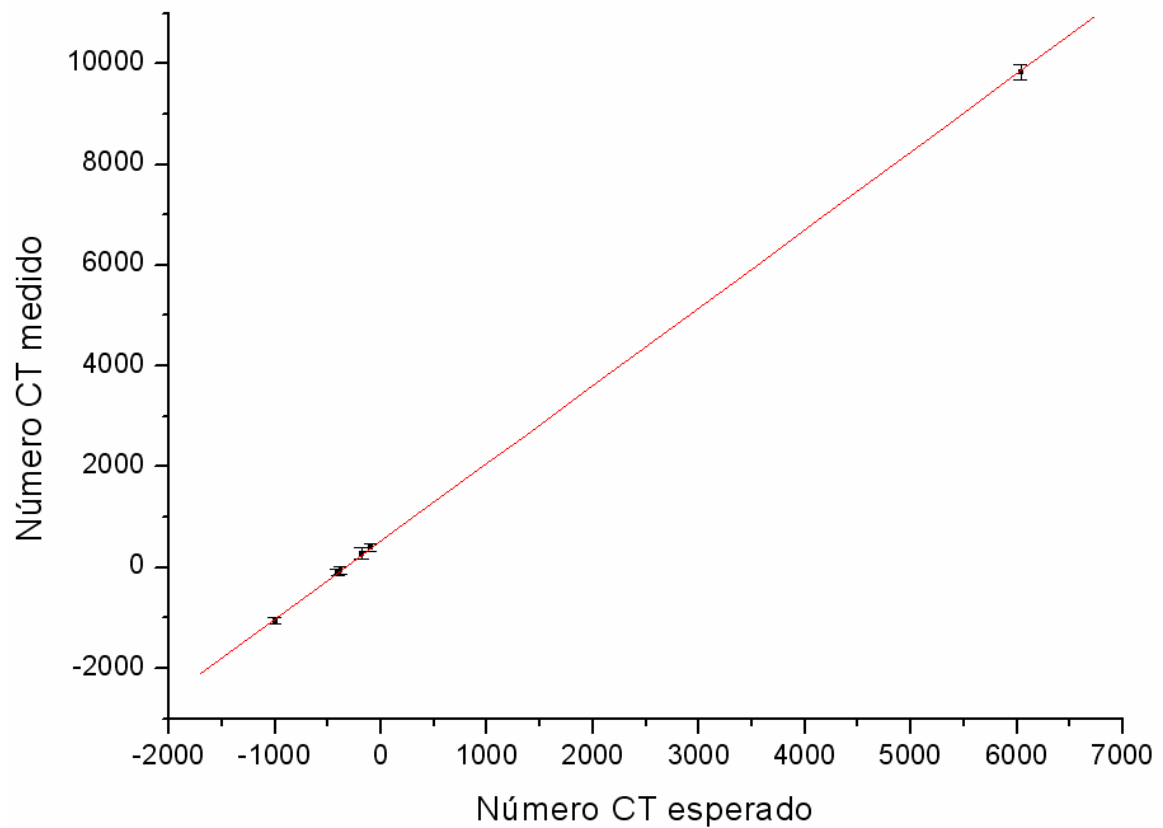

Figura 78 - Gráfico com a regressão linear dos valores de número CT esperados sobre os valores medidos na reconstrução 3 .

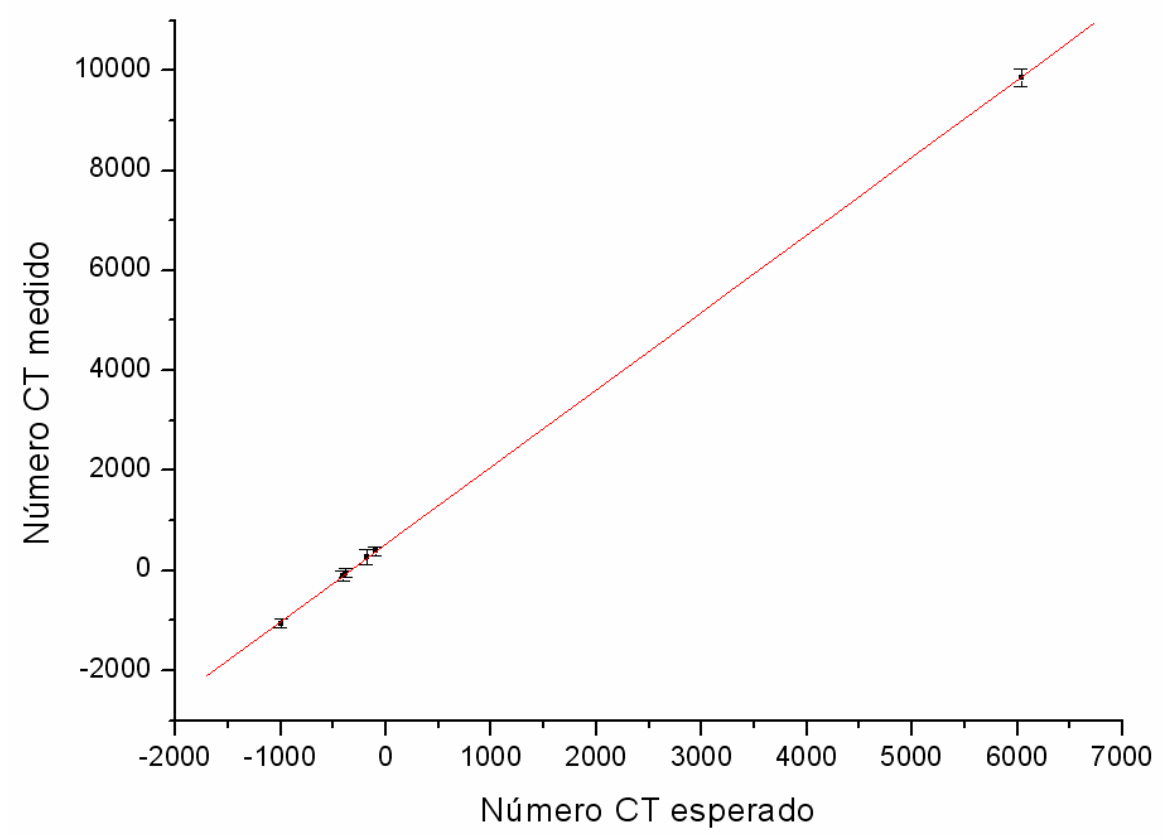

Figura 79 - Gráfico com a regressão linear dos valores de número CT esperados sobre os valores medidos na reconstrução 4. 


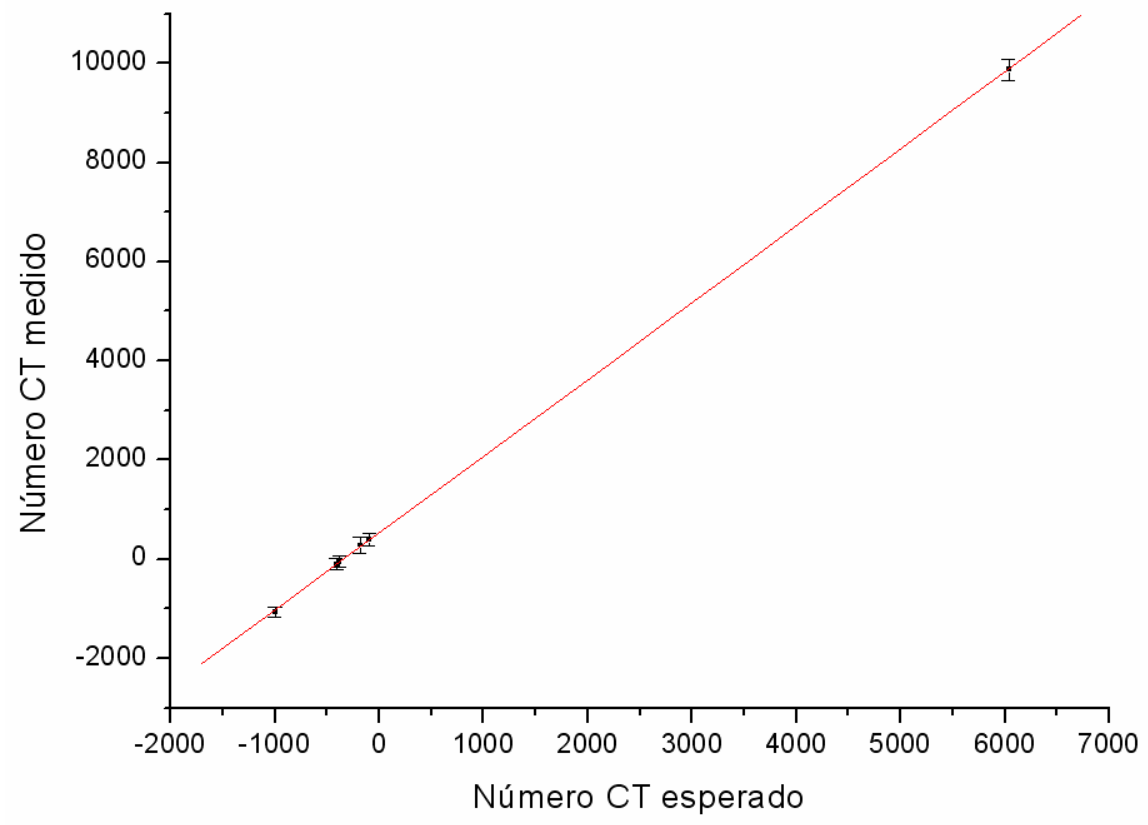

Figura 80 - Gráfico com a regressão linear dos valores de número CT esperados sobre os valores medidos na reconstrução 5 .

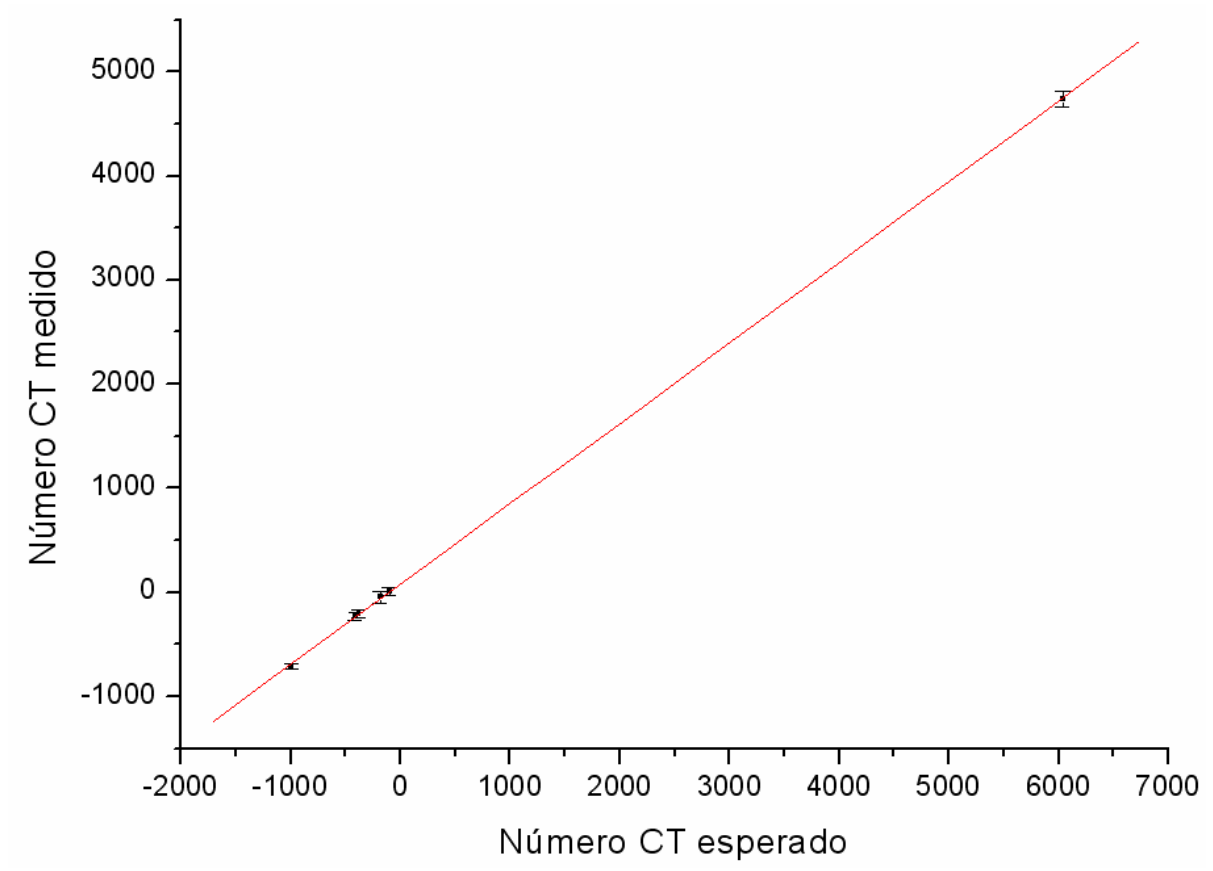

Figura 81 - Gráfico com a regressão linear dos valores de número CT esperados sobre os valores medidos na reconstrução 6 . 


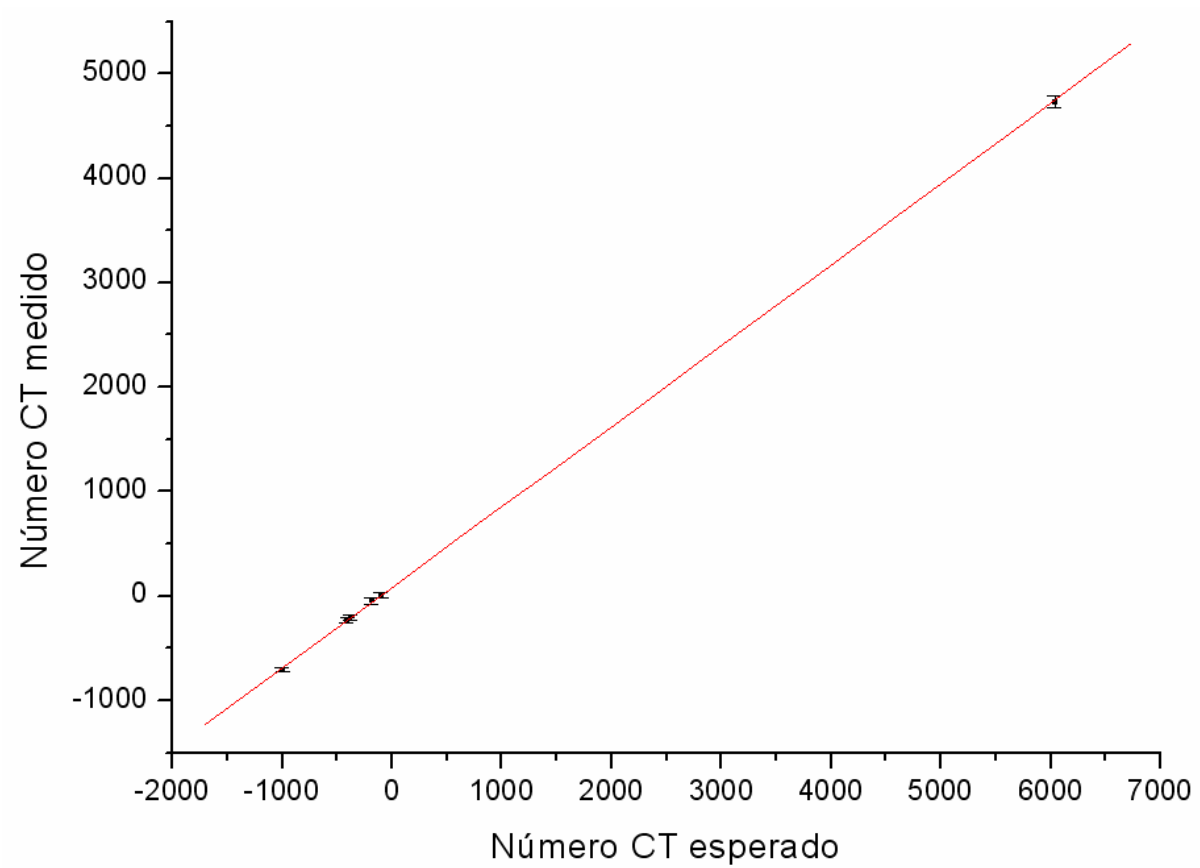

Figura 82 - Gráfico com a regressão linear dos valores de número CT esperados sobre os valores medidos na reconstrução 7 .

Estes resultados confirmam a linearidade do sistema. As equações das retas obtidas com as regressões lineares determinam as correções que devem ser aplicadas ao algoritmo de reconstrução para cada configuração utilizada. A Tabela 15 apresenta os parâmetros, $A$ e $B$, das retas, $y=A+B x$, obtidas.

Tabela 15 - Coeficientes angular e linear das retas, $y=A+B x$, obtidas pela regressão linear dos valores de número $\mathrm{CT}$ medidos sobre os valores de número $\mathrm{CT}$ esperados nas imagens reconstruídas.

\section{Número da Reconstrução}

\section{Coeficiente linear}

Coeficiente linear

A B

\begin{tabular}{|c|c|c|}
\hline Reconstrução N ${ }^{0} 1$ & $-618 \pm 3$ & $0,386 \pm 0,002$ \\
\hline Reconstrução № 2 & $-238 \pm 6$ & $0,773 \pm 0,004$ \\
\hline Reconstrução N으 3 & $526 \pm 12$ & $1,545 \pm 0,008$ \\
\hline Reconstrução N No 4 & $526 \pm 12$ & $1,547 \pm 0,008$ \\
\hline Reconstrução № 5 & $529 \pm 14$ & $1,550 \pm 0,008$ \\
\hline Reconstrução № 6 & $81 \pm 6$ & $0,773 \pm 0,004$ \\
\hline Reconstrução № 7 & $83 \pm 5$ & $0,772 \pm 0,004$ \\
\hline
\end{tabular}


As correções para cada configuração utilizada em cada uma das sete reconstruções foram incorporadas ao algoritmo e, em seguida, sete novas imagens foram reconstruídas com as mesmas configurações definidas na Tabela 11. Como o ajuste é linear, a apresentação visual das imagens se mantém idêntica e a alteração só é perceptível quando se mede o número CT de cada estrutura identificada nas imagens. A Tabela 16 apresenta os valores de número CT esperados de cada material, juntamente com os respectivos valores medidos nas novas imagens reconstruídas. Novamente, os valores medidos correspondem à média aritmética dos valores dos pixels das regiões de interesse, relativas a cada material.

Tabela 16 - Valores de número CT esperados para cada material que compõe o objeto, juntamente com seus respectivos valores medidos nas imagens reconstruídas com o algoritmo corrigido.

\begin{tabular}{ccccccc}
\hline \hline Material & Ar & $\begin{array}{c}\text { Polietileno } \\
\text { A }\end{array}$ & $\begin{array}{c}\text { Polietileno } \\
\text { B }\end{array}$ & Nylon & Acrílico & PVC \\
\hline $\begin{array}{c}\text { Número CT } \\
\text { esperado }\end{array}$ & -1000 & $-413 \pm 20$ & $-380 \pm 20$ & $-187 \pm 41$ & $-102 \pm 41$ & $6037 \pm 387$ \\
\hline \hline
\end{tabular}

\begin{tabular}{ccccccc}
\hline \hline $\begin{array}{c}\text { Número da } \\
\text { Reconstrução }\end{array}$ & \multicolumn{7}{c}{ Valores médios de Número CT medidos para cada material, sobre uma área } \\
de 16000 pixels. (média \pm desvio padrão) \\
\hline 1 & $-1028 \pm 96$ & $-412 \pm 96$ & $-377 \pm 94$ & $-169 \pm 110$ & $-92 \pm 92$ & $6032 \pm 156$ \\
\hline 2 & $-1027 \pm 54$ & $-411 \pm 60$ & $-376 \pm 61$ & $-168 \pm 86$ & $-84 \pm 67$ & $6033 \pm 114$ \\
\hline 3 & $-1028 \pm 40$ & $-412 \pm 44$ & $-378 \pm 45$ & $-168 \pm 75$ & $-83 \pm 53$ & $6035 \pm 93$ \\
\hline 4 & $-1032 \pm 54$ & $-413 \pm 61$ & $-377 \pm 61$ & $-169 \pm 92$ & $-83 \pm 67$ & $6048 \pm 113$ \\
\hline 5 & $-1032 \pm 68$ & $-412 \pm 76$ & $-377 \pm 76$ & $-161 \pm 111$ & $-85 \pm 87$ & $6057 \pm 141$ \\
\hline 6 & $-1025 \pm 43$ & $-410 \pm 47$ & $-377 \pm 49$ & $-168 \pm 78$ & $-83 \pm 55$ & $6025 \pm 102$ \\
\hline 7 & $-1023 \pm 32$ & $-410 \pm 28$ & $-377 \pm 27$ & $-170 \pm 42$ & $-83 \pm 36$ & $6032 \pm 70$ \\
\hline \hline
\end{tabular}

Após a aplicação das correções lineares, observou-se uma concordância, dentro dos limites de incerteza, dos valores de número CT medidos e esperados em quase todas as reconstruções. 


\subsubsection{Reconstrução Multi-cortes de um Objeto Não Homogêneo e Geometricamente Assimétrico}

A Figura 83 apresenta as imagens reconstruídas de 16 cortes do objeto apresentado na Figura 43. É possível observar as diferenças nas bolhas de ar internas do objeto nos diferentes cortes reconstruídos.
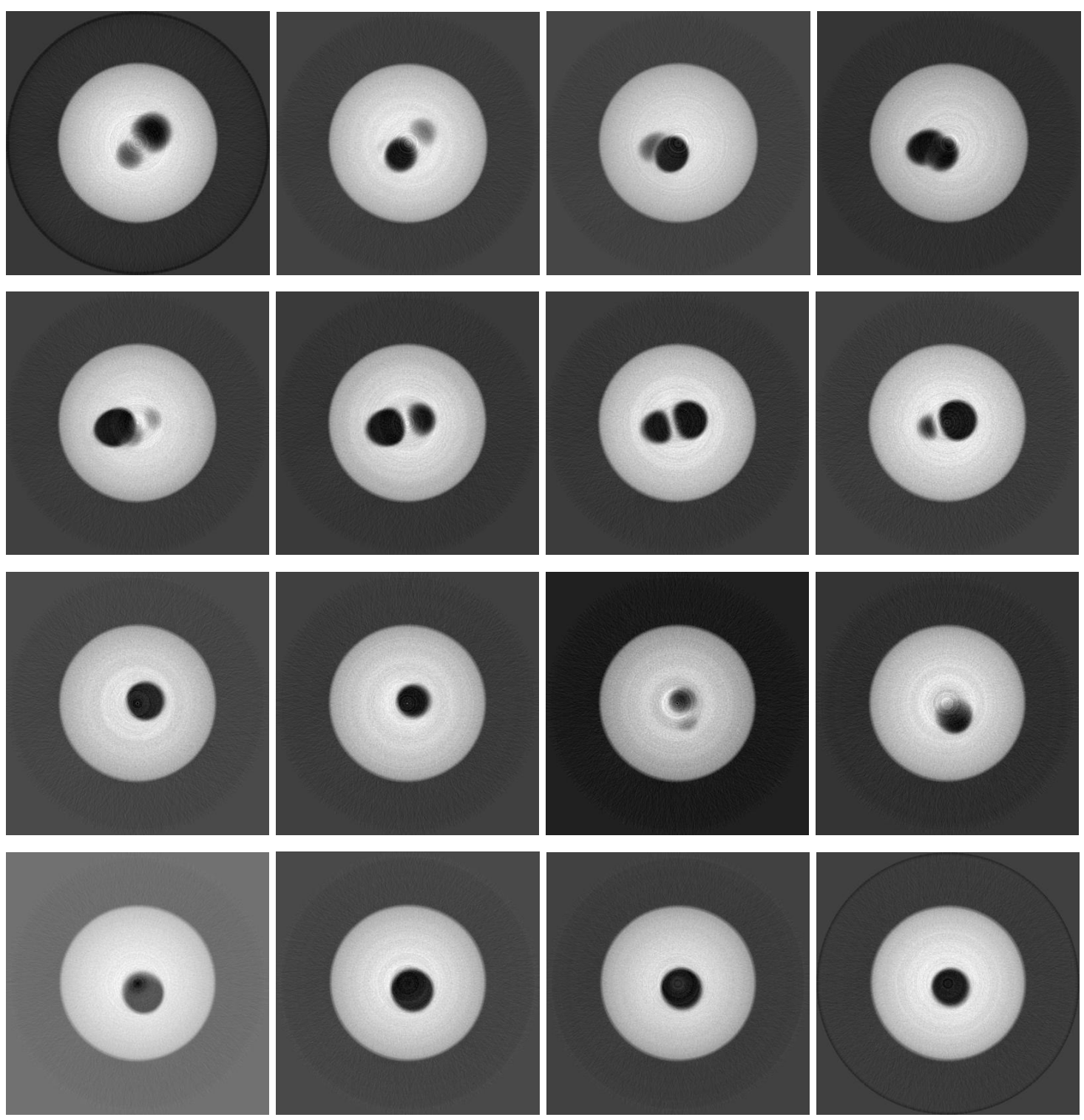

Figura 83 - Imagens reconstruídas a partir de 720 projeções de um objeto não homogêneo e assimétrico. Cada imagem representa um corte de $1 \mathrm{~mm}$ de espessura. Foram reconstruídos 16 cortes com uma única varredura. Há um espaçamento de $1 \mathrm{~mm}$ entre o centro de cada corte adjacente. 


\section{CAPÍTULO 8 - Discussão dos Resultados}

\subsection{Resultados das Simulações Computacionais}

A utilização de simulações computacionais no desenvolvimento da tomografia computadorizada (TC) vem aumentando a cada dia ${ }^{31}$. Simulações computacionais são cruciais no desenvolvimento de algoritmos de processamento e reconstrução de imagens, e na otimização dos componentes que compõem um equipamento.

As simulações podem ser divididas em duas categorias: analíticas e estatísticas. Simulações analíticas são aplicadas a modelos de sistemas com equações analíticas bem conhecidas, como por exemplo, a geração de phantoms matemáticos. Já as simulações estatísticas usam geradores numéricos randômicos e as propriedades físicas do processo de interação da radiação X com a matéria, para prever o desempenho de um sistema. Um bom exemplo é a utilização do método de Monte Carlo para prever a distribuição de radiação espalhada durante o processo de aquisição de uma projeção.

Há duas grandes áreas onde é aplicada a simulação computacional: na óptica e na física do sistema. Simulações da física relacionada ao sistema auxiliam na compreensão do impacto das características dos componentes no seu desempenho. Por outro lado, simulações computacionais da óptica do sistema são direcionadas, principalmente, ao impacto de fatores geométricos na resolução espacial, como: dimensão do ponto focal, dimensão do detector, abertura do feixe de raios $\mathrm{X}$, espessura dos cortes, número de detectores, etc.

No presente trabalho, foram utilizadas simulações analíticas, aplicadas à geometria do sistema, para a geração de objetos matemáticos, desconsiderando alguns fatores, como a dimensão do ponto focal e dos elementos do detector, uma vez que o objetivo era, simplesmente, testar o funcionamento do algoritmo. Portanto, na simulação das projeções, foram consideradas hipóteses físicas ideais para o processo de TC. Sendo assim, as imagens reconstruídas deveriam representar, de maneira fiel (sem artefatos), os cortes dos objetos simulados. Esse fato pode ser observado na Figura 54, na Figura 55 e na Figura 56. 


\subsection{Resultados das Reconstruções Reais}

\subsubsection{Resultados das Correções de Artefatos}

No caso das imagens reconstruídas a partir das projeções reais coletadas com os sistemas de aquisição montados, observou-se a presença de artefatos. Estes artefatos foram produzidos por inúmeros motivos, todos associados à natureza imprecisa e inexata do sistema físico real. Neste caso, fez-se necessária a aplicação de correções de artefatos.

\subsubsection{Correção da Posição do Ponto Focal}

A aplicação desta correção foi fundamental para o progresso do presente trabalho. Houve uma dificuldade muito grande, durante a montagem dos sistemas de aquisição de projeções, em se determinar com precisão a posição do ponto focal do tubo de raios X, o que é fundamental no processo de retro-projeção, assim como foi discutido no capítulo 5, item 5.3.

O resultado dessa correção fica evidente ao comparar as imagens apresentadas na Figura 57 e na Figura 58, que mostram o efeito nas imagens reconstruídas para uma variação de 1,3 mm na posição do ponto focal. Para as imagens reconstruídas a partir das projeções coletadas com o sistema de aquisição № 3 , também foi necessário aplicar esta correção. Neste caso, a correção na posição do ponto focal foi de $0,5 \mathrm{~mm}$.

\subsubsection{Aplicação do Filtro Rampa Modificado}

Esta correção teve a função básica de diminuir o ruído presente nas imagens reconstruídas. A Tabela 10 apresenta o efeito desta correção no valor do ruído. Observase uma redução de mais de $60 \%$ do ruído presente nas imagens reconstruídas. Na Figura 58 e na Figura 59, pode-se observar o resultado da aplicação do filtro rampa modificado. Pode-se observar que há uma suavização nas imagens reconstruídas com o filtro rampa modificado. Portanto, esta correção proporciona uma diminuição no ruído presente nas imagens, em troca de uma pequena perda de resolução espacial. 


\subsubsection{Aplicação da Correção de Aliasing}

Foi observado um resultado positivo da aplicação desta correção nas imagens reconstruídas. Ao se comparar as imagens apresentadas na Figura 62 e na Figura 65, pode-se observar diferenças sutis, principalmente na região periférica das imagens, onde nota-se uma diminuição das linhas (ou estrias) de aliasing. Observando-se a Tabela 14, pode-se perceber uma diferença na quantidade de ruído presente nas imagens, que é maior na reconstrução 3, na qual não foi aplicada a correção, e menor na reconstrução 6, na qual a correção foi aplicada. No entanto, pode-se ver na Tabela 16 que, após o ajuste linear dos valores de número CT, o ruído torna-se levemente maior na reconstrução 6.

As diferentes variações do ruído presente nas imagens, antes e depois dos ajustes lineares dos valores de número $\mathrm{CT}$, podem ser explicadas pela diferença dos coeficientes, $B$ (Tabela 15), utilizados nestes ajustes, que são inversamente proporcionais às variações observadas no ruído.

\subsubsection{Resultados da Calibração do Sistema}

$\mathrm{Na}$ determinação dos números $\mathrm{CT}$ de cada material que compõe o objeto reconstruído (Figura 35), encontrou-se um resultado inesperado para o PVC. Não se esperava que o PVC fosse um material tão atenuante para o feixe de raios $\mathrm{X}$ produzido com o equipamento Spectro 70X, utilizado no sistema de aquisição de projeções № 3 . Esta alta atenuação do PVC resultou em um valor de número CT relativamente alto. Na Tabela 14 pode-se observar que o número CT determinado para o PVC é muito maior que os números CT determinados para os outros materiais que compõem o objeto reconstruído. Somado a este fato, há o indesejável efeito de endurecimento de feixe, que é intensificado por materiais muito atenuantes. Este efeito resultou em artefatos nas imagens reconstruídas, que podem ser observados como linhas mais claras que se originam no centro do cilindro de PVC e se espalham por toda a imagem. $\mathrm{O}$ alto valor de número CT determinado para o PVC também resultou numa maior imprecisão na 
medição dos números CT dos demais materiais. Este problema é equivalente àquele produzido por implantes metálicos em pacientes, como foi comentado no capítulo 5 , item 5.1 .

A partir das imagens reconstruídas para as diferentes configurações apresentadas na Tabela 11, pôde-se verificar a qualidade das imagens em função do número de projeções e da espessura dos cortes. Nas reconstruções de $\mathrm{N}^{\mathrm{o}} 1$, № 2 e $\mathrm{N}^{\mathrm{o}}$ 3, variou-se de maneira crescente o número de projeções. Na reconstrução № 1 (Figura 60), observa-se linhas que oscilam entre claras e escuras em toda a imagem mais evidentes na região periférica, causando a perda de resolução na imagem, principalmente na direção azimutal. Esse artefato se deve à sub-amostragem angular, caracterizando-se como artefato de aliasing. Com o aumento do número de projeções houve a diminuição desses artefatos e conseqüentemente uma melhora na qualidade das imagens (Figura 61 e Figura 62).

Nas reconstruções $\mathrm{N}^{\mathrm{o}} 3, \mathrm{~N}^{\mathrm{o}} 4, \mathrm{~N}^{\mathrm{o}} 5$ e $\mathrm{N}^{\mathrm{o}} 7$ variou-se, basicamente, a espessura do corte. Observando as imagens reconstruídas (Figura 63, Figura 64, Figura 65 e Figura 66), percebe-se uma melhoria na qualidade das imagens devido ao aumento na espessura dos cortes. Esta melhoria é consequiência da suavização das projeções na direção $\mathrm{z}$ em decorrência do aumento da espessura do corte. Na Tabela 14 pode se ver que o ruído nas imagens aumenta significativamente com a diminuição da espessura dos cortes.

Nos tomógrafos com varredura helicoidal, o tempo de exposição pode ser muito reduzido com a utilização de cortes mais espessos. No entanto, quanto mais espessos forem os cortes, maior a probabilidade de se produzir artefatos de volume parcial nas imagens reconstruídas. O objeto reconstruído nesta etapa do trabalho possui uma distribuição de coeficiente de atenuação linear independente da altura $z \mathrm{e}$, portanto, as imagens reconstruídas não devem apresentar artefatos de volume parcial.

A Tabela 16 apresenta os resultados da medição dos valores de número CT nas imagens reconstruídas após a calibração do sistema. Todos os valores medidos encontram-se dentro dos intervalos de número CT esperados para cada material, o que confirma a concordância dos valores de número CT medidos e esperados para cada material.

Dentre todas as imagens reconstruídas nesta etapa do trabalho, a reconstrução № 7 foi a que apresentou a melhor qualidade. Ela não só é a imagem menos ruidosa, como 
também é na qual se identifica as diferentes estruturas com maior facilidade, o que pode ser observado ao comparar os gráficos apresentados nas Figuras 68 à 74. Nas curvas de perfil apresentadas na Figura 74, é mais fácil identificar as estruturas observadas na imagem.

\subsubsection{Resultados da Reconstrução Multi-cortes de um Objeto Não Homogêneo e Geometricamente Assimétrico}

Os últimos resultados do presente trabalho são apresentados na Figura 83, que mostra a capacidade de reconstrução multi-cortes do sistema de TCMC implementado. As imagens mostram as diferenças entre os cortes reconstruídos a diferentes alturas do objeto.

Atualmente, existem softwares específicos de renderização 3D. Esses programas têm a função de agrupar todos os cortes reconstruídos de um objeto, de modo a apresentar uma representação visual tridimensional do objeto.

Com o constante aumento da qualidade das imagens produzidas pelos tomógrafos clínicos atuais, é possível reconstruir cortes de espessuras suficientemente pequenas, de modo que, a partir da renderização das imagens, seja possível obter cortes em planos de qualquer inclinação. 


\section{CAPÍTULO 9 - Conclusões e Sugestões para Trabalhos Futuros}

Os equipamentos de tomografia computadorizada comercializados atualmente, englobam um know how de décadas de investimento em pesquisa e desenvolvimento tecnológico por parte dos grandes fabricantes de equipamentos de radiodiagnóstico. Durante esse período, cada componente dos equipamentos de TC foi desenvolvido e aprimorado para uma função específica. Foram desenvolvidos chips dedicados para o processamento dos dados, incluindo o pré-processamento das projeções, a reconstrução, as correções de artefatos e etc. Esse avanço é evidenciado na redução do tempo de reconstrução, de duas horas e meia para produzir a primeira imagem de TC, em 1967, para menos de meio segundo nos tomógrafos atuais ${ }^{31}$. Tubos de raios $\mathrm{X}$, detectores $\mathrm{e}$ sistemas mecânicos de alta precisão, permitem a aquisição de projeções com altíssima qualidade, o que é fundamental para atender as exigências mínimas de qualidade nas imagens reconstruídas.

No capítulo 4, foram apresentados os principais aspectos técnicos que são exigidos dos componentes de um equipamento de TC. Certamente, os componentes utilizados na montagem do sistema de TCMC adaptado nesse trabalho não atendem a essas exigências e, portanto, nunca houve a pretensão de se implementar um sistema que produzisse imagens comparáveis com as de equipamentos clínicos comerciais, mas sim, um sistema funcional, onde fossem estudados e aplicados os principais aspectos físicos e matemáticos da técnica da tomografia computadorizada. Como se vê nos resultados apresentados, este objetivo foi alcançado. O sistema implementado não só é capaz de reconstruir imagens de vários cortes dos objetos, como fornece informação quantitativa e qualitativa a respeito dos materiais constituintes dos objetos reconstruídos.

Considerando os equipamentos disponíveis para a realização desse trabalho, podese dizer que os resultados obtidos foram animadores. A implementação de um sistema funcional de TCMC, utilizando um equipamento de raios $\mathrm{X}$ nacional e um detector do tipo CCD, ambos de uso odontológico, evidencia a possibilidade de se desenvolver essa tecnologia no país. 
Como sequiência a este trabalho, pretende-se avaliar parâmetros importantes do sistema, tais como: resolução espacial e contraste. Além disso, seria interessante estudar o comportamento do sistema com a utilização de diferentes técnicas radiográficas, equipamentos de raios $\mathrm{X}$ e detectores. Seria anida interessante, realizar a automação do sistema de aquisição de projeções e extendê-lo para um sistema com varredura helicoidal, de modo que facilite sua aplicação, seja em microtomografia, tomografia de pequenos animais, etc. Por último, pretende-se utilizar o sistema implementado como uma ferramenta didática em futuros cursos sobre Tomografia computadorizada.

A produção de equipamentos clínicos de TC no Brasil seria muito enriquecedora, não só do ponto de vista científico e tecnológico, mas também do ponto de vista econômico. Sem mencionar a contribuição para a saúde pública, dado o fato de que a importação desses equipamentos requer investimentos altos, inviabilizando sua compra pela maioria dos hospitais da rede pública, que acabam sendo privados desse recurso tão importante para o diagnóstico de diversas doenças.

Baseando-se nos resultados obtidos no presente trabalho, acredita-se que, com um plano de trabalho bem estruturado e o financiamento adequado, uma equipe especializada e competente, formada por físicos, biomédicos, engenheiros e cientistas da computação, possui totais condições de desenvolver essa tecnologia, que abriria grandes portas para pesquisa e desenvolvimento tecnológico no país. 


\section{Bibliografia}

1 Kalender, W.A. Computed Tomography - Fundamentals, System Technology, Image Quality, Applications. 2nd Ed; Publicis Corporate Publishing, Erlangen, Alemanha, 2005. (Cap. 1,4 and 9)

2 ASSOCIAÇÃO BRASILEIDA DA INDÍSTRIA DE EQUIPAMENTOS ODONTO-MÉDICO-HOSPITALARES E DE LABORATÓRIO. Informativo 11, 2006, disponível em http://www.abimo.org.br/default_interno.asp. Consultado em 24/04/2006.

3 Barroso, R. C.; Lopes, R. T.; Gonçalves, O. D.; Assis, J. T. Image Reconstruction Algorithm to X-ray Diffraction Tomography. Nuclear Instruments \& Methods In Physics Research, Section A, n. 422, p. $718-723,1999$

4 Oliveira, L. F.; Lopes, R. T.; Jesus E. F. O.; Braz, D. 3D X-ray Tomography to evaluate volumetric objects. Nuclear Instruments \& Methods In Physics Research, Section A, n. 505 , p. 573-576, 2003

5 Souza, M. I. S.; Almeida, G. L.; Furieri, R. C. A. A. Comparison of Tomographic Systems for Xray and Thermal Nêutrons. Brazilian Journal of Physics, v. 33, n. 2, Junho, 2003

6 Cesareo R.; Brunetti, A.; Golosio, B.; Lopes, R. T.; Barroso, R. C.; Castellano, A.; Quarta, S. Material Analisys with a Multiple X-ray Tomography Scanner Using Ttransmitted and Scattered Radiation. Nuclear Instruments \& Methods In Physics Research, section A, n. 525, p. 336-341, 2004

7 Almeida, G. L.; Silvani, M. I.; Furieri, R. C. A. A.; Gonçalves, M. J.; Lopes, R. T. Development of a Simulator for Tomographic Images Generated by Radiation Transmission. Brazilian Journal of Physics, v. 34, n. 3A, Setembro, 2004

8 Lopes, R. T.; Rocha, H. S.; Jesus, E. F. O.; Barroso, R. C.; Oliveira, L. F.; Anjos, M. J.; Braz, D.; Moreira, S. X-ray Transmition Microtomography Using Synchrotron Radiation. Nuclear Instruments \& Methods In Physics Research, Section A, n. 505, p. 604-607, 2006

9 Lima, I. C. B.; Oliveira, L. F.; Lopes, R. T. Bone Architecture Analyses of Rat Fêmur With 3D Microtomographics Images. Journal of Radioanalytical and Nuclear Chemistry, v. 269, $\mathrm{n}$. 3, p. 639-642, 2006

10 Pereira, G. R.; Conceição, S. C.; Lopes, R. T.; Anjos, M. J.; Oliveira L. F.; Rocha, H. S.; Perez, C. A. Elemental Distribution in Breast Tissue Samples Using X-ray Fluorenscence Microtomography. Journal of Radioanalytical and Nuclear Chemistry, v. 269, n. 2, p. 469473, 2006

11 Pereira, G. R.; Rocha, H. S.; Anjos, M. J.; Faria P.; Pérez, C. A.; Lopes, R. T. X-ray Fluorescence and X-ray Transmission Microtomography imaging systems. Nuclear Instruments \& Methods In Physics Research, Section A, n. 581, p. 128-132, 2007

12 Xiap, S.; Bresler, Y.; Munson, D.C.Jr. Fast Feldkamp Algorithm For Cone-beam Computer Tomography. International Conference on Image Processing, v. 3, p. II - 819-22, Sept. 2003

13 Shih, A.; Wang, G.; Cheng, P. Fast Algorithm for X-ray Cone-beam Microtomography. Microsc. Microanal., v. 7, p. 13-23, 2001

14 Tang, X.; Hsieh, J.; Nilsen, R.A.; Dutta, S.; Samsonov, D.; Hagiwara, A. A three-dimensional-weighted cone beam filtered backprojection (CB-FBP) algorithm for image reconstruction in volumetric CT-helical scanning. Phys. Med. Biol., v. 51, p. 855-874, 2006

15 Nielsen, Manzke T. R., Proksa R, Grass M. Cardiac cone-beam CT volume reconstruction using ART. Med. Phys. 32(4), April 2005. 
16 Ay, MR, Zaidi - H Development and validation of MCNP4C-based Monte Carlo simulator for fan- and cone-beam x-ray CT. Phys Med Biol., v.50, p.4863-4885,2005.

17 Youngbin Choa, Y.; Moseley, D. J.; Siewerdsen, J. H.; Jaffray, D. A. Accurate technique for complete geometric calibration of cone-beam computed tomography systems. Med. Phys., v.32, n.4, 2005.

18 Fang-Fang Yin,a_Huaiqun Guan, Wenkai Lu. A technique for on-board CT reconstruction using both kilovoltage and megavoltage beam projections for 3D treatment verification

Med. Phys., v.32, n.9, 2005

19 Herzog C, Arning-Erb M, Zangos S, Eichler K, Hammerstingl R, Dogan S, Ackermann H, and Vogl T J. Multi-Detector Row CT Coronary Angiography: Influence of Reconstruction Technique and Heart Rate on Image Quality. Radiology, v.238, p.75-86, 2006

20 Wolbarst A B and Hendee W R. Evolving and Experimental Technologies in Medical Imaging. Radiology, v.238, p.6-39, 2006

21 FLOHR, T.G.; SCHALLER, S.; STIERSTORFER, K. BRUDER, H. OHNESORGE, B.M.; SCHOEPF, U.J. Multi-detector row CT systems and image reconstruction techniques. Radiology, v.235, n.3, p.756 773,2005

22 SCHIMIDT, T.G.; FAHRIG, R.; PELC, N.J. A Three-dimensional reconstruction algorithm for an inversegeometry volumetric CT system. Medical Physics, v.32, n.11, p.3234-3245, 2005

23 NING, R.; TANG, X.; CONOVER, D.; YU, R. Flat-panel detector-based cone beam computed tomography with circle-plus-two-arcs data acquisition orbit: Preliminary phantom study. Medical Physics, v.30, n.7, p.1694-1705, 2003.

24 LEE, S.W.; WANG, G. A Grengeat-type half-scan algorithm for cone-beam CT. Medical Physics, v.30, n.4, p.689-700, 2003.

25 Feldkamp, L. A.; Davis, L. C.; Kress, J. W. Practical cone-beam algorithm. J. Opt. Soc. Am, v. 1, n. 6, Jun. 1984.

26 Radon, J. H. Über die Bestmmung von Funktionen durch ihre Integralwerte längs gewisser Mannigfaltigkeiten. Ber. Vor Sächs. Akad. Wiss., 1917; 69: 262-277 (English translation available: J Radon: On determination of functions from their integral values along certain manifolds. IEEE Transactions on Medical Imaging, v.MI-5, n. 4, p.170-176, 1986

27 Cormack A.M. Representation of a function by its line integrals, with some radiological applications. J. Appl. Physics, v. 1063, n. 34, p. 2722-2727, 1963

28 Cormack A.M. 75 years of Radon transform. J. Comput. Assist. Tomogr., v.16, n. 5, 1992

29 SEERAM, E. Compuded Tomography - Physical Principles, Clinical Applications , and Quality Control. 2nd Ed., W.B. Saunders Company, London, UK, 2001. (Cap. 4, 5, 6 and 11).

30 Bushberg, J. T.; Seibert J. A.; Leidholdt, E. M. Jr.; Boone, J. M. The Essential Physics of Medical Imaging. 2nd Lippincott Williams \& Wilkins, Philadelphia, USA, 2002. (Cap. 13)

31 Hsieh J. Computed Tomography - Principles, Design, Artifacts, and Recent Advances. SPIE, Washington, USA, 2003

32 Kalender, W.A.; Seissler W.; Vock P. Single-breath-hold spiral volumetric CT by continuous patient translation and scanner rotation. Radiology, v. 173(P), p. 414, 1989

33 Kalender, W. A.; Seissler W.; Klotz E.; Vock P. Spiral volumetric CT with single-breath-hold technique, continuous transport, and continuous scanner rotation. Radiology, V. 176, n. 1, p. 181-183, 1990b

34http://www.medical.toshiba.com/products/ct/Multidetector/Clinical Image Gallery.aspx. Acessado pela última vez em primeiro de junho de 2008. 
35 Imagens Disponíveis em:

http://www.medical.toshiba.com/products/ct/Multidetector/Clinical Image Gallery.aspx.

Acessado em: primeiro de junho de 2008.

36 Michette, A. G.; Buckley, C. J. X-Ray Science and Technology. Bristol, UK and Philadelphia, USA: Institute of Phsics Publishing, 1993. (Cap. 1, 2 and 5).

37 Hasegawa, B. H. The Physics of Medical X-ray Imaging. 2nd Ed. Medical Physics Publishing Company, Wisconsin, USA, 1991. (Cap 4, 6 and 8).

38 Knoll, G. F. Radiation Detection and Measurement. 3rd Ed. John Wiley \& Sons, Michigan, USA, 1999. (Cap. 2, 4, 5 and 8).

39 Tuy, H. K. An Inversion Formula For Cone-Beam Reconstruction. SIAM J. APPL. MATH, v. 43, n. 3 , Jun. 1983.

40 Imagens disponíveis em: http://www.e-radiography.net/radtech/x/xray tubes.pdf. Acessado em: primeiro de junho de 2008.

41 NERSISSIAN, D.Y. Determinação das Dimensões do Ponto Focal de Tubos de Raios $\mathbf{X}$ utilizando um sensor CCD e o Método das Funções de Transferência. Tese (Doutorado) - Instituto de Pesquisas Energéticas e Nucleares, IPEN, São Paulo, 2004.

42 Nyquist, H. Certain topics in telegraph transmission theory. Trans. AIEE, v. 47, pp. 617-644, Apr. 1928. Reprint as classic paper in: Proc. IEEE, v. 90, No. 2, Feb. 2002

43 Shannon, C. E. Comunication in the presence of noise. Proc. Institute of Radio Engineers, v. 37, No. 1, pp 10-21, Jan 1949. Reprint as classic paper in: Proc. IEEE, v. 86, No. 2, Feb. 1998

44 Dixon, R. L. A new look at CT dose measurement: Beyond CTDI. Medical Physics, v. 30, n. 6, Jun. 2003

45 Dixon, R. L.; Munley, M. T.; Bayram, E. An Improved Analytical Model for CT Dose Simulation With a New Look at the Theory of CT Dose. Medical Physics, v. 32, n. 12, Dec. 2005

46 Secretaria de Vigilância Sanitária. Portaria n 453 de 01 de junho de 1998.

47 Parker J. A. Image Reconstruction in Radiology. CRC Press, Boston, USA, 1990. (Cap. 22, 23, 24, 26, 31 and 32).

48 Berger, M. J.; Hubbell, J. H.; Seltzer, S. M.; Chang, J.; Coursey, J. S.; Sukumar, R.; Zucker, D. S. XCOM: Photon Cross Sections Database. NIST Standard Reference Database 8. Disponível em: http://physics.nist.gov/PhysRefData/Xcom/Text/XCOM.html. Acessado em: 13 mar 2008.

49 Medical diagnostic X-ray equipment - Radiation conditions for use in the determination of characteristics. 2nd Ed., IEC, Geneva, Switzerland, 2005

50 Vandre, R. H. Comparative Evaluation of the MVG-MEDIZINRECHNER, Dexis, and Schick, CDR, Sensors. Central Research Detachment of the Walter Reed Army Institute of Research. EUA, 1996. 